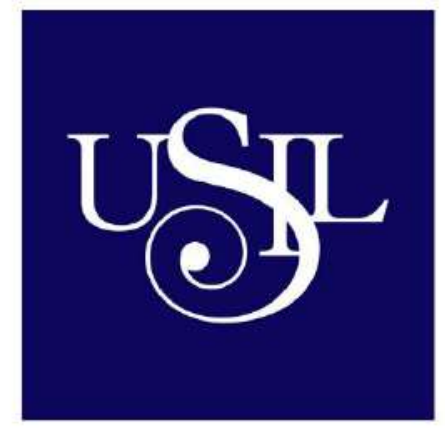

\title{
ESCUELA DE
} POSTGRADO

UNIVERSIDAD

SAN IGNACIO DE LOYOLA

MBA EXECUTIVE

\section{PLAN DE NEGOCIOS PARA IMPLEMENTAR MEJORAS TECNOLÓGICAS EN UNA COOPERATIVA DE BANANO ORGÁNICO}

\section{ERWIN HERNAN LOZADA GOMEZ JOSE ANTONIO HIPOLITO PEREZ MORON}

Proyecto de Investigación Gerencial Aplicado

\section{Asesor}

Ana Fidela Hospina Schaefer

\author{
Lima - Perú
}

06 de Noviembre de 2017 



\title{
PLAN DE NEGOCIOS PARA IMPLEMENTAR MEJORAS
}

TECNOLÓGICAS EN UNA COOPERATIVA

\author{
DE BANANO ORGÁNICO
}




\section{Dedicatorias}

A Dios por bendecirnos, protegernos, darnos fuerzas para superar los obstáculos que se presentaron y por permitirnos hacer realidad este sueño anhelado.

Erwin y José

A Hernán, Rosa y Damna, por estar siempre a mi lado, por sus enseñanzas, por apoyarme y guiarme, por ser las bases que me ayudaron a llegar hasta aquí.

A Nathalie, quien ha estado a mi lado, apoyándome y motivándome durante todo este tiempo para la culminación de este trabajo de investigación.

Erwin Lozada

A mi esposa Lía, a mis hijos José Mariano y Leonardo, por ser mi ilusión y la motivación para haber culminado con éxito mis estudios.

José Pérez 


\section{AGRADECIMIENTOS}

En primer lugar, a todos los directivos de la Cooperativa Agraria Alto Grande Santa Sofía quienes confiaron en nosotros para apoyarlos en la implementación de un plan de negocios que pudiese ayudarlos a crecer como organización.

De modo particular a Luis Felipe Grados Morante por sus valiosos comentarios y sugerencias para mejorar tanto el contenido como la forma del presente trabajo.

A Ana Fidela Hospina Schaefer, quien tuvo a cargo la valiosa tarea de asesorar en todo momento la correcta realización de este plan de negocios.

Erwin y José 


\section{ÍNDICE}

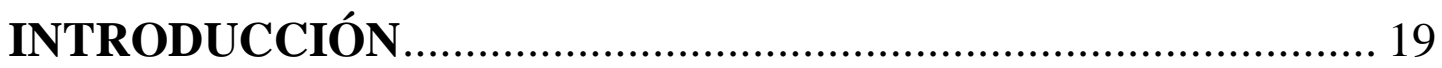

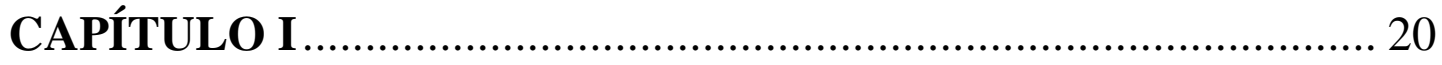

1. FORMULACIÓN DE LA IDEA DEL NEGOCIO................... 20

1.1. Descripción general de la idea y modelo de negocio............ 20

1.1.1. Datos generales de la organización. .......................... 22

1.1.2. Cultura organizacional. .................................. 24

1.1.2.1. Visión. ........................................................... 24

1.1.2.2. Misión................................................................ 25

1.1.2.3. Principios.................................................. 27

1.1.2.4. Objetivos estratégicos. ................................ 27

\section{CAPÍtULUO II}

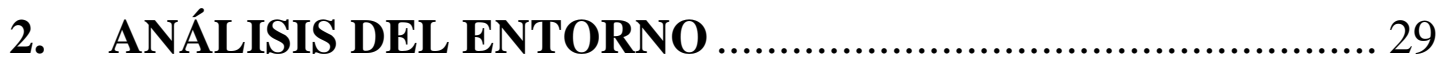

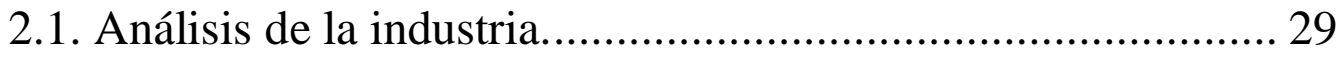

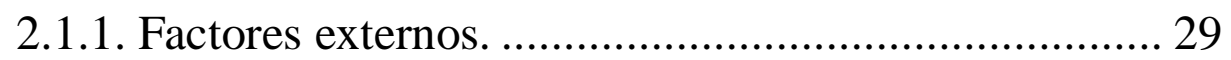

2.1.1.1. Fuerzas económicas. .................................... 30

2.1.1.2. Fuerzas sociales, culturales, demográficas. .. 37

2.1.1.3. Fuerzas políticas, gubernamentales $\mathrm{y}$ legales.................................................... 39

2.1.1.4. Fuerzas tecnológicas. .................................... 40

2.1.1.5. Fuerzas ecológicas. ...................................... 41

2.1.2. Cinco fuerzas competitivas. ..................................... 45

2.1.2.1. La rivalidad entre competidores existentes... 46

2.1.2.2. Entrada potencial de nuevos competidores... 48

2.1.2.3. Desarrollo potencial de productos sustitutos.................................................... 53

2.1.2.4. Poder de negociación de los proveedores. .... 53 
2.1.2.5. Poder de negociación de los clientes. 54

2.1.3. Nuevas fuerzas del análisis externo........................... 55

2.1.3.1. Digitalización................................................ 56

2.1.3.2. Globalización.............................................. 56

2.1.3.3. Desregulación .............................................. 57

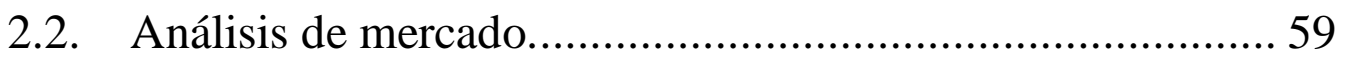

2.2.1. Mercado potencial..................................................... 60

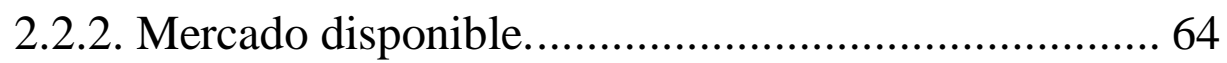

2.2.2.1. Análisis de la oferta de banano orgánico. ..... 64

2.2.2.2. Análisis de la Demanda de Banano

Orgánico ........................................................ 69

2.2.3. Mercado efectivo. .................................................... 72

2.2.4. Mercado objetivo....................................................... 77

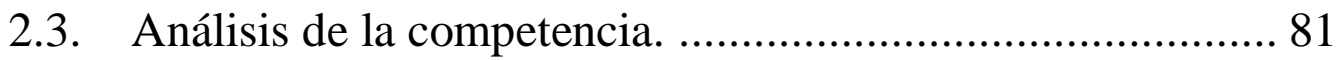

2.4. Análisis de la cadena de valor............................................ 85

\section{CAPÍTULO III}

3. PLAN DE MARKETING Y DE VENTAS ............................. 91

3.1. Estrategia del producto........................................................ 91

3.1.1. Clasificación del producto.......................................... 92

3.1.2. Diferencias entre banano y plátano. ......................... 92

3.1.3. Variedad y Envasado ................................................... 95

3.2. Estrategia de distribución..................................................... 96

3.3. Estrategia de promoción. ................................................ 100

3.4. Estrategia de precio ............................................................ 101

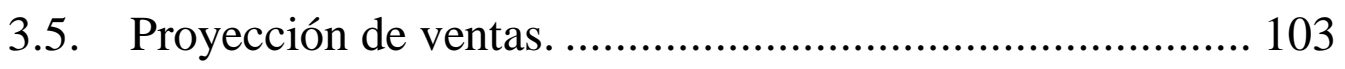

3.5.1. Situación actual - proyección de ventas.................... 103

3.5.2. Situación futura - proyección de ventas.................... 107

\section{CAPÍtULO IV}

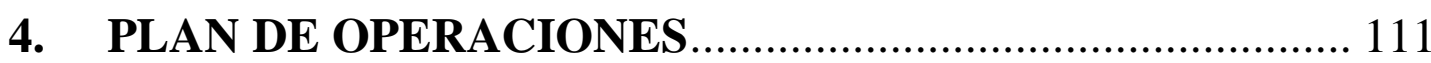


4.1. Ubicación geográfica...................................................... 111

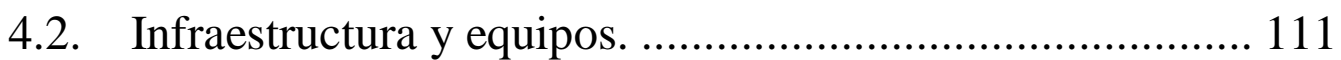

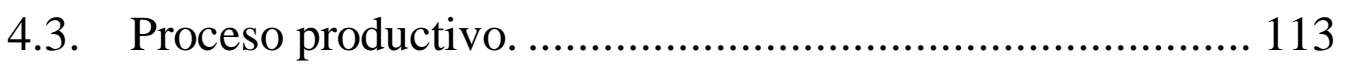

4.3.1. Manejo del cultivo. ................................................. 114

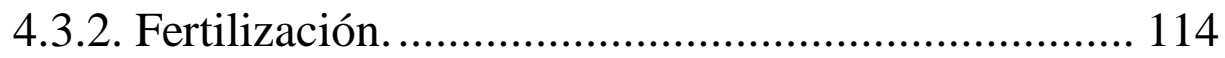

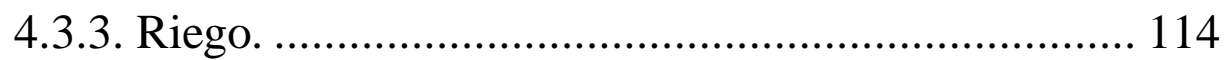

4.3.4. Manejo del racimo. ............................................... 115

4.3.5. Control de plagas y enfermedades.......................... 115

4.3.5.1. Virus del mosaico...................................... 115

4.3.5.2. Trips de la mancha roja. ........................... 115

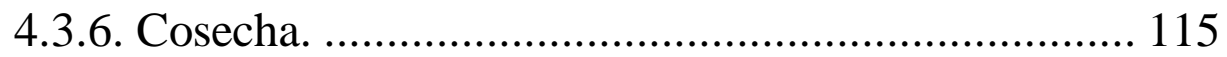

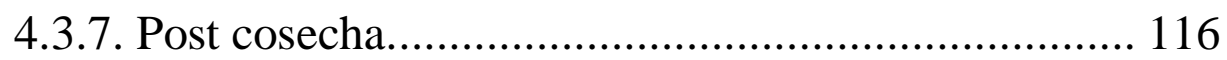

4.3.7.1. Traslado hacia la empacadora. .................... 116

4.3.7.2. Lavado y tratamiento................................. 116

4.3.7.3. Selección, pesado y empaque. ..................... 116

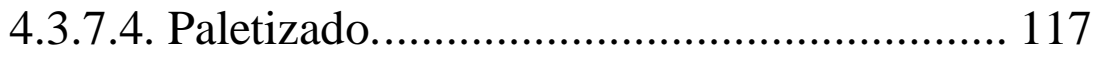

4.4. Regulación de licencias y políticas. ............................................ 117

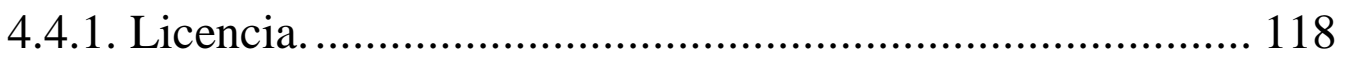

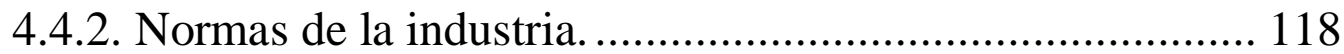

4.4.2.1. Certificación de análisis HACCP ......................... 118

4.4.2.2. Certificación fitosanitario internacional. .............. 119

4.4.2.3. Certificado de origen........................................ 120

4.4.2.4. Certificación orgánica........................................ 121

4.4.2.5. Certificación global g.a.p.................................... 122

4.4.2.6. Certificación comercio justo (fair trade). ............. 123

4.4.3. Aspectos tributarios y laborales. ...................................... 125

4.4.3.1. Impuesto a la renta. ............................................ 125

4.4.3.2. Impuesto general a las ventas. ............................. 125 
4.4.3.3. Promoción de la inclusión de los productores agrarios en cooperativas.

4.5. Proyección de costos de producción.

4.5.1. Situación actual - proyección del costo de compra de fruta en planta al socio productor.

4.5.2. Situación actual - proyección del costo del proceso de lavado y empaque.

4.5.2.1. Transporte de la fruta al centro de empaque rústico

4.5.2.2. Proceso de lavado ................................................. 128

4.5.2.3. Proceso de empaque............................................... 131

4.5.3. Implementación de mejoras tecnológicas.......................... 137

4.5.3.1. Certificar los campos. ......................................... 139

4.5.3.2. Mejorar las condiciones de empacado.................. 140

4.5.3.3. Reducir los costos de distribución ......................... 141

4.5.3.4. Comprar tres tinas móviles................................... 142

4.5.4. Situación futura - proyección del costo de compra de fruta en planta al socio productor.

4.5.5. Situación futura - proyección del costo del proceso de lavado y empaque. 144

4.5.5.1. Transporte de la fruta a los centros de empaque... 144

4.5.5.2. Proceso de lavado. 144

4.5.5.3. Proceso de empaque 146

\section{CAPÍtulO V}

5. PLAN DE RECURSOS HUMANOS ..................................... 151

5.1. Organización funcional..................................................... 151

5.1.1. La organización formal.......................................... 151

5.1.2. La organización informal..................................... 152 


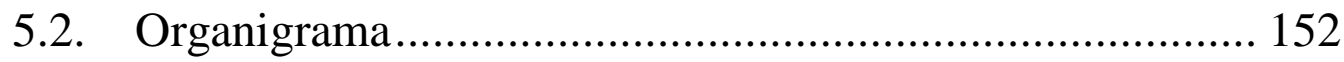

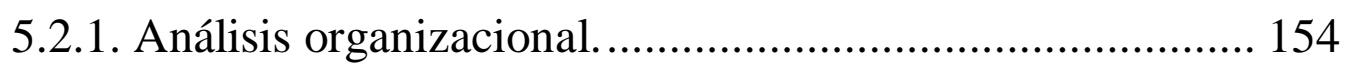

5.2.1.1. Asamblea general de socios................................ 154

5.2.1.2. Consejo de administración................................. 154

5.2.1.3. Consejo de vigilancia......................................... 154

5.2.1.4. Comité de educación.......................................... 155

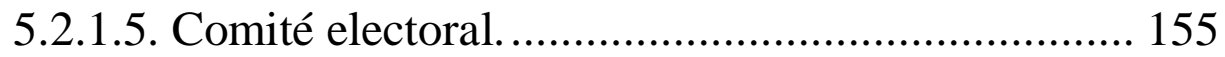

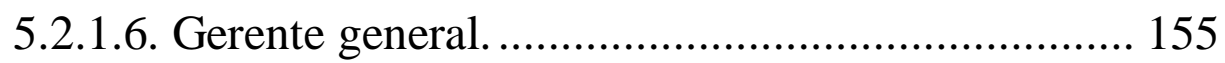

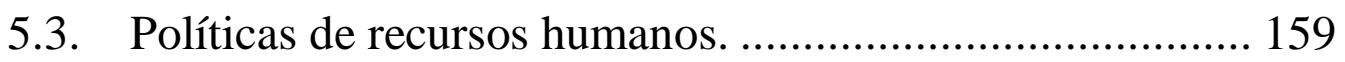

\section{CAPÍtULO VI}

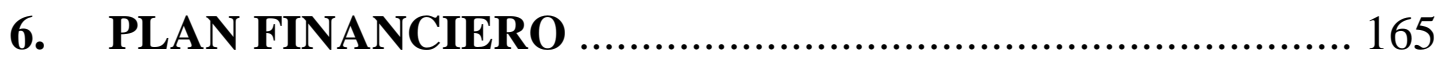

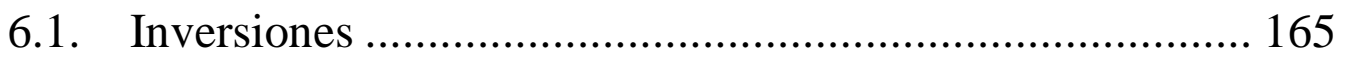

6.1.1. Inversiones en activo fijo...................................... 165

6.1.2. Inversiones en capital de trabajo. ............................ 167

6.1.3. Inversiones en activos intangibles........................... 169

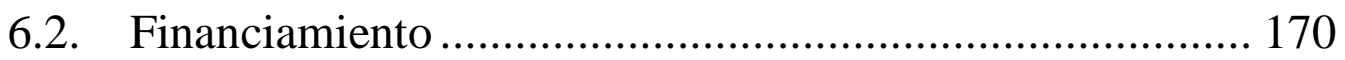

6.2.1. Costo de oportunidad............................................ 170

6.2.1.1. La tasa libre de riesgo (Rf) ........................ 172

6.2.1.2. Riesgo de mercado $(\mathrm{Rm})$.......................... 172

6.2.1.3. Beta des apalancado $(\beta)$............................ 173

6.2.1.4. Costo capital usa ( Ke (usa) ) ...................... 173

6.2.1.5. Riesgo país................................................ 174

6.2.1.6. Inflación Perú / inflación usa....................... 174

6.2.1.7. Factor de corrección................................... 175

6.2.1.8. Costo capital Perú ( ke (Perú) ) .................. 175

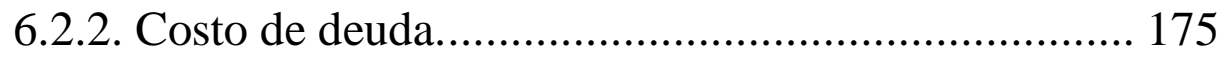

6.2.3. Costo promedio ponderado de capital ..................... 176

6.3. Presupuesto base.............................................................. 176

6.3.1. Presupuesto de ventas. ............................................ 176 
6.3.1.1. Situación actual - presupuesto de ingresos . 177

6.3.1.2. Situación futura - presupuesto de ingresos . 177

6.3.2. Presupuesto de costos. ............................................ 178

6.3.2.1. Situación actual - presupuesto de costos..... 178

6.3.2.2. Situación futura - presupuesto de costos..... 180

6.3.3. Presupuesto de gastos administrativos. ................... 181

6.3.3.1. Situación actual - presupuesto de gastos administrativos......................................... 182

6.3.3.2. Situación futura - presupuesto de gastos administrativos........................................ 182

6.4. Estados financieros proyectados............................................... 183

6.4.1. Estado de situación financiera........................................... 183

6.4.1.1. Situación actual - estado de situación financiera.. 183

6.4.1.2. Situación futura - estado de situación financiera.. 184

6.4.1. Estado de resultados. ...................................................... 185

6.4.1.1. Situación actual - estado de resultados ................. 186

6.4.1.2. Situación futura - estado de resultados ................ 186

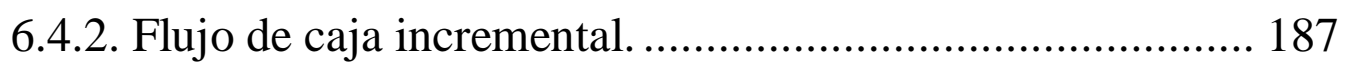

6.4.2.1. Situación actual - flujo de caja económico y

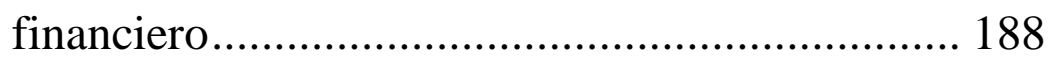

6.4.2.2. Situación futura - flujo de caja económico y financiero......................................................... 189

6.5. Evaluación de la rentabilidad................................................. 190

6.5.1. La tasa interna de retorno (TIR) ...................................... 191

6.5.2. El valor actual neto (VAN) ............................................. 192

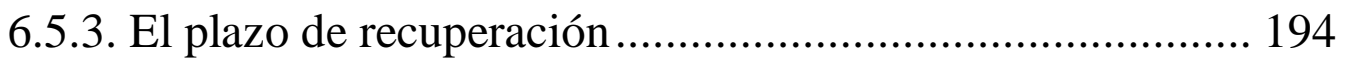

6.6. Análisis de la sensibilidad ........................................................ 195

6.6.1. Variaciones en el dólar recibido por concepto de comercio justo. 
6.6.2. Variaciones en el porcentaje de merma del lavado fruta ... 198

6.6.3. Variaciones en la productividad de la plantación 199

\section{CAPÍTULO VII}

7. CONCLUSIONES Y RECOMENDACIONES ...................... 202

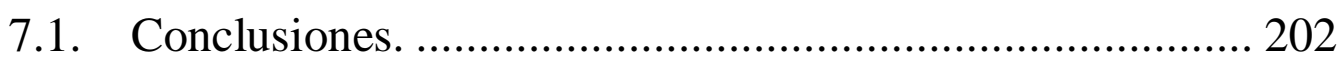

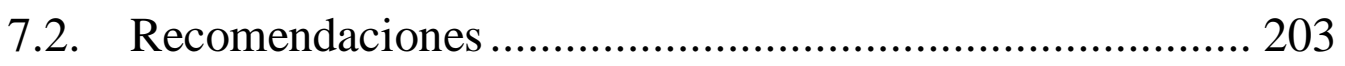

\section{ÍNDICE DE TABLAS}

Tabla 1: Datos Generales de la Organización ......................................... 22

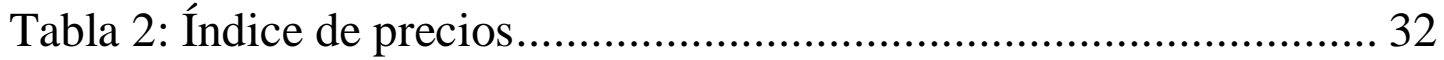

Tabla 3: Tipo de cambio proyectado ……………………................... 33

Tabla 4: Resumen del análisis de las fuerzas externas .......................... 43

Tabla 5: Matriz de evaluación de factores externos - EFE .................... 44

Tabla 6: Atractivo de la rivalidad entre competidores............................ 48

Tabla 7: Atractivo para la entrada de nuevos competidores .................. 52

Tabla 8: Atractivo para el poder de negociación de los clientes ............. 55

Tabla 9: Importaciones mundiales de plátano y banano.......................... 61

Tabla 10: Importaciones mundiales de plátano y banano........................ 61

Tabla 11: Exportaciones mundiales de plátano y banano........................ 63

Tabla 12: Exportaciones mundiales de plátano y banano........................ 63

Tabla 13: Exportaciones peruanas de banano orgánico.......................... 74

Tabla 14: Exportaciones peruanas en miles US\$ de banano orgánico

2012-2016

Tabla 15: Exportaciones peruanas en Kg. de banano orgánico 2012-

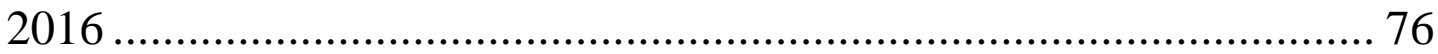

Tabla 16: Evolución de las exportaciones en US\$ de APBOSMAM .... 79

Tabla 17: Principales competidores ...................................................... 82

Tabla 18: Matriz del perfil competitivo ................................................ 84

Tabla 19: Diferencias entre plátano y banano ....................................... 93 
Tabla 20: Características del banano orgánico de exportación 94

Tabla 21: Dinámica comercial de la Cooperativa Agraria Alto Grande Santa Sofía 99

Tabla 22: Evolución del precio internacional del banano orgánico ..... 102

Tabla 23: Situación actual - Supuestos de la producción de fruta ........ 103

Tabla 24: Situación actual - Proyección de la producción de fruta...... 105

Tabla 25: Situación actual - Supuestos de proyección de ventas......... 106

Tabla 26: Situación actual - Proyección de ventas ............................... 106

Tabla 27: Situación futura - Supuestos de la producción de fruta ....... 107

Tabla 28: Situación futura - Proyección de la producción de fruta...... 108

Tabla 29: Situación futura - Supuestos de proyección de ventas......... 109

Tabla 30: Situación futura - Proyección de ingresos ............................. 110

Tabla 31: Relación de activos ............................................................ 112

Tabla 32: Situación actual - Proyección del costo de compra de fruta 127

Tabla 33: Costo de los operarios....................................................... 133

Tabla 34: Indumentaria de los operarios ............................................ 134

Tabla 35: Situación actual - Proyección de costos de producción ...... 136

Tabla 36: Agroideas - Montos para adopción de tecnología ................ 139

Tabla 37: Proyección de inversiones tecnológicas ................................ 142

Tabla 38: Situación futura - Proyección del costo de compra de fruta 143

Tabla 39: Situación futura - Proyección del costo de operarios............ 144

Tabla 40: Situación actual - Costo por alquiler de camión furgón....... 147

Tabla 41: Costo proyectado por compra de camión furgón.................. 149

Tabla 42: Cuadro comparativo de alquilar o comprar camión.............. 149

Tabla 43: Situación futura - Proyección de costos de producción ........ 150

Tabla 44: Perfil del gerente general ................................................. 156

Tabla 45: Perfil del jefe de control y calidad ..................................... 157

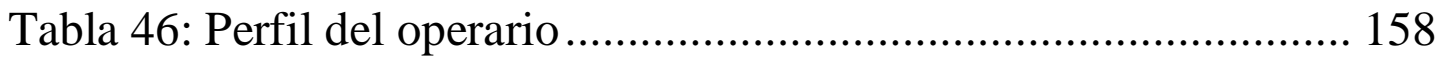

Tabla 47: Perfil del jefe de contabilidad y finanzas ........................... 159 
Tabla 48: Situación actual - Gasto de personal

Tabla 49: Perfil del técnico agrario..................................................... 163

Tabla 50: Situación futura - Gastos de personal................................... 164

Tabla 51: Situación actual - Proyección de la composición del activo

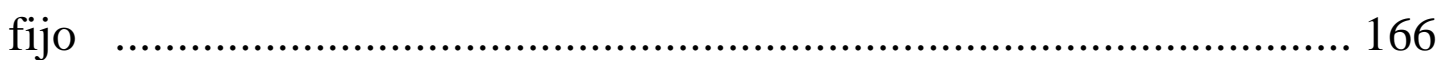

Tabla 52: Situación futura - Proyección del activo fijo ......................... 167

Tabla 53: Situación actual - Proyección del capital de trabajo ............. 168

Tabla 54: Situación futura - Proyección del capital de trabajo ............. 169

Tabla 55: Situación futura - Inversión en activos intangibles............... 170

Tabla 56: Tasa libre de riesgo......................................................... 172

Tabla 57: Tasa riesgo de mercado ................................................... 173

Tabla 58: Inflación histórica del Perú y Estados Unidos ...................... 174

Tabla 59: Situación actual - Presupuesto de ingresos........................... 177

Tabla 60: Situación futura - Presupuesto de ingresos........................... 178

Tabla 61: Situación actual - Presupuesto de costos .............................. 179

Tabla 62: Situación futura - Presupuesto de costos ............................... 181

Tabla 63: Situación actual - Presupuesto de gastos administrativos .... 182

Tabla 64: Situación futura - Presupuesto de gastos administrativos .... 183

Tabla 65: Situación actual - Estados de situación financiera proyectados

Tabla 66: Situación futura - Estados de situación financiera proyectados

Tabla 67: Situación actual - Estados de resultados proyectados.......... 186

Tabla 68: Situación futura - Estados de resultados proyectados .......... 187

Tabla 69: Situación actual - Flujo de caja económico ........................... 189

Tabla 70: Situación futura: Flujo de caja económico .......................... 190

Tabla 71: Cálculo de la tasa interna de retorno económica .................. 191

Tabla 72: Cálculo de la tasa interna de retorno financiera.................... 192

Tabla 73: Cálculo del valor actual neto económico ............................ 193 
Tabla 74: Cálculo del valor actual neto financiero

Tabla 75: Plazo de recuperación descontado ..................................... 195

Tabla 76: Análisis de sensibilidad - Dólar adicional por caja............. 197

Tabla 77: Análisis de sensibilidad - \% de merma del lavado de fruta. 198

Tabla 78: Análisis de sensibilidad - Productividad de la plantación.... 200

Tabla 79: Probabilidad que la TIR sea mayor que el costo de

oportunidad

\section{ÍNDICE DE ILUSTRACIONES}

Ilustración 1: El modelo de las cinco fuerzas......................................... 45

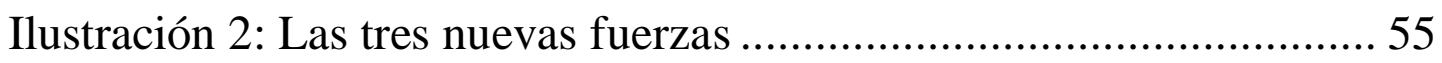

Ilustración 3: Acuerdos comerciales del Perú ........................................ 58

Ilustración 4: Partida arancelaria del banano orgánico............................ 59

Ilustración 5: Principales países exportadores de banano orgánico ........ 66

Ilustración 6: Evolución de exportaciones de banano orgánico 1999-

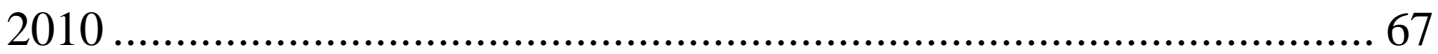

Ilustración 7: Comportamiento del consumidor europeo ....................... 71

Ilustración 8: Principales empresas exportadoras de banano orgánico .. 74

Ilustración 9: Principales exportadoras de banano orgánico peruano .... 75

Ilustración 10: Esquema de valor del banano orgánico .......................... 87

Ilustración 11: Especies de plátanos y bananos....................................... 92

Ilustración 12: Tipos de empacado del banano orgánico......................... 95

Ilustración 13: Cadena de suministro para banano orgánico .................. 97

Ilustración 14: Banano orgánico embolsado y/o con adhesivos ............. 98

Ilustración 15: Proceso productivo del banano orgánico....................... 113

Ilustración 16: Corte y transporte de la fruta al centro de empaque .... 128

Ilustración 17: Corte de clústeres........................................................ 129

Ilustración 18: Proceso de lavado ........................................................ 130

Ilustración 19: Proceso de empaque .................................................... 131 
Ilustración 20: Ruta recorrida por el camión furgón alquilado

Ilustración 21: Organigrama de la Cooperativa Agraria Alto Grande

Santa Sofía

\section{ANEXOS}

Anexo 1: Carta de Intención de Compra............................................ 206

Anexo 2: Cotizaciones de Certificaciones .......................................... 208

Anexo 3: Ficha Registral de Compra de Derechos y Acciones ........... 231

Anexo 4: Cotización del Centro de Empaque ..................................... 232

Anexo 5: Cotización del Camión......................................................... 237

Anexo 6: Cotización de la Carrocería Tipo Furgón ............................ 240

Anexo 7: Betas Publicados por Damodaran a Febrero 2017 ................ 241

Anexo 8: Riesgo País Perú ................................................................ 242

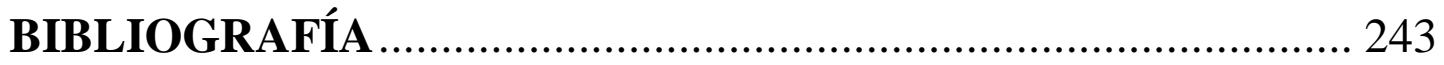




\section{RESUMEN EJECUTIVO}

El presente plan de negocios busca ayudar a la Cooperativa Agraria Alto Grande Santa Sofía en la obtención de fondos no reembolsables que otorga AGROIDEAS (unidad ejecutora del ministerio de agricultura y riego); fondos que serán utilizados para implementar mejoras en los flujos de los procesos para reducir los costos del proceso de producción, los costos de distribución y el alto porcentaje de merma durante el proceso de la fruta. Adicionalmente, se busca obtener fondos para pagar a las empresas certificadoras para que realicen la evaluación de los procesos operativos con la finalidad de obtener las certificaciones: Orgánica, Global GAP y Comercio Justo. La obtención de las certificaciones permitirá a la organización no depender de un único comprador de su fruta y beneficiarse con el pago adicional que realiza el importador - europeo o norteamericano - por concepto de comercio justo.

Es requisito de AGROIDEAS, la presentación de un plan de negocios que demuestre los beneficios económicos que obtendrá la empresa luego de obtener los fondos solicitados para la implementación de las inversiones señaladas. El plan de negocios debe ser elaborado y firmado por profesionales competentes que demuestren la rentabilidad de la inversión solicitada.

Para ello hemos analizado los factores externos, las cinco fuerzas competitivas de Michael Porter y las nuevas fuerzas del análisis externo. También se analizó el mercado y las estrategias de producto, precio, promoción, distribución y ventas. El análisis se completó con el análisis del proceso operativo y organizacional de la cooperativa. Como resultado del análisis realizado se concluye que es necesario invertir 315710 soles para implementar el plan de negocios; fondos que permitirán: (1) Pagar la supervisión de los procesos para obtener las certificaciones orgánica, global gap y comercio justo, (2) Adquirir un camión furgón para mejorar el acopio y distribución de la fruta y, (3) Construir un centro de empaque que ayudará a reducir el porcentaje de merma de la fruta y a reducir los costos del proceso productivo. 
La evaluación económica - financiera nos indica que, la inversión se recuperará en un plazo de 06 años y 102 días; genera una tasa interna de retorno del $28.88 \%$. Considerando una tasa de descuento del $19.6973 \%$, el proyecto genera un valor actual neto de 134,764 soles y la probabilidad que la tasa interna de retorno sea mayor que costo de oportunidad es del $71.53 \%$.

Considerando el análisis cualitativo y cuantitativo realizado en el presente plan de negocios y, que los indicadores económicos se muestran razonablemente aceptables se sugiere la implementación del plan de negocios. 


\section{INTRODUCCIÓN}

El presente plan de negocios plasma nuestras ideas, análisis, conclusiones y recomendaciones para la implementación de mejoras tecnológicas en una cooperativa agraria procesadora de banano orgánico. Toda nuestra investigación se asienta en los conocimientos recibidos de nuestros profesores y de la revisión de los textos de los mejores investigadores y autores que han escrito sobre la formulación y evaluación de proyectos. A muchos de ellos los hemos citado, pero otros están implícitos.

El presente plan de negocios se ha realizado sobre la base de la experiencia de una cooperativa procesadora de banano orgánico, con cuyos directivos se realizaron interminables reuniones y entrevistas en profundidad. Se ha basado sobre la revisión de abundante bibliografía a fin de ofrecer una investigación objetiva que ayude a la organización a determinar la viabilidad de realizar inversiones como la construcción de un centro de empaque, la adquisición de un camión furgón y la certificación de la fruta procesada; que le ayuden a mejorar sus ingresos y reducir sus costos. 


\section{CAPÍTULO I}

\section{Formulación de la idea del negocio}

\subsection{Descripción general de la idea y modelo de negocio.}

Choquehuanca. (2008) nos dice que "La cooperativa es una organización que agrupa a varias personas (socios) con la finalidad que todos cooperen para beneficiarse de forma directa, obteniendo un bien o un servicio. El concepto de socio debe ser el de una persona con espíritu de hacer empresa con responsabilidad social y con moral cooperativista" (p.10).

La Alianza Cooperativa Internacional. (2015). Define a las cooperativas como "asociaciones autónomas de personas unidas voluntariamente para satisfacer sus necesidades y aspiraciones económicas, sociales y culturales comunes a través de una empresa de propiedad conjunta y democráticamente controlada."

La Organización de las Naciones Unidas. (2017). Reconoce que "Las cooperativas son un modelo de negocios que debe ser promovido en todo el mundo. No sólo por el reconocimiento de los valores que conlleva este modelo solidario que utilizan las personas para producir, consumir o proveerse de bienes y servicios para su vida o su actividad sino porque permite a los individuos que las integran controlar la organización de la que son parte, de modo democrático." 
Es necesario resaltar algunas diferencias del modelo de negocio cooperativista respecto a los modelos de negocios tradicionales:

- En las cooperativas todos los socios tienen participación equitativa en la Asamblea General, donde cada uno de los socios participa con un voto en la toma de decisiones de la cooperativa. Las decisiones se toman de manera democrática. A diferencia de los negocios tradicionales donde cada uno de los socios participa en la toma de decisiones de acuerdo al capital social aportado.

- Las cooperativas buscan que la comunidad se involucre y desarrolle; para lo cual los beneficios obtenidos por las cooperativas son repartidos entre todos los socios o son reinvertidos para la compra de nuevos activos que favorezcan económica, social o públicamente a la comunidad. En los negocios tradicionales los beneficios son repartidos entre los accionistas de acuerdo al capital social aportado.

Choquehuanca. (2008), dice que "la cooperativa se rige por los 7 principios cooperativos: (1) libre adhesión y retiro voluntario, (2) control democrático, (3) interés limitado al capital, (4) retorno de excedentes, (5) educación cooperativa, (6) integración cooperativa, (7) irrepartibilidad de la reserva de la cooperativa. El cumplimiento de estos principios garantiza la continuidad de la cooperativa en el tiempo."

En resumen, las cooperativas deben buscar crecer y desarrollarse porque de esta manera se garantiza un crecimiento sostenido de los socios productores y de las comunidades a las que pertenecen. 


\subsubsection{Datos generales de la organización.}

Tabla 1: Datos Generales de la Organización

\begin{tabular}{|c|c|c|c|}
\hline Razón Social & \multicolumn{3}{|c|}{ Cooperativa Agraria Alto Grande Santa Sofía - COOPAG } \\
\hline RUC & \multicolumn{3}{|l|}{20600061691} \\
\hline Domicilio Legal & \multicolumn{3}{|c|}{ Villa Santa Sofía, Av. Miguel Grau No 21} \\
\hline \multirow{2}{*}{ Representante Legal } & Juarez Correa, Jhon Carlos & Cargo: & Gerente \\
\hline & Período de Vigencia : & Abril 2016 & Diciembre 2016 \\
\hline \multirow{2}{*}{ Sede Productiva } & Distrito & Provincia & Departamento \\
\hline & Ignacio Escudero & Sullana & Piura \\
\hline Producto & Banano Orgánico & & \\
\hline \multirow{3}{*}{ Número Socios } & \multicolumn{3}{|c|}{ Hombres $\quad 56$} \\
\hline & \multicolumn{3}{|l|}{ Mujeres } \\
\hline & \multicolumn{3}{|l|}{ Total } \\
\hline Área en Producción & \multicolumn{3}{|l|}{55.65 Hectáreas } \\
\hline
\end{tabular}

Fuente: Área contable de la organización y Elaboración propia

La cooperativa está ubicada en el distrito de Ignacio Escudero, provincia Sullana, región Piura y, se dedica a la comercialización de banano orgánico. Inscrita el 09 de enero del 2015 , en la partida registral $\mathrm{N}^{\circ} 11071682$ de los registros públicos de Sullana. A la fecha, cuenta con 59 socios con un área de 55.65 hectáreas en producción, dejando abierta la posibilidad de anexar a más productores y áreas en producción por libre adhesión.

El valle de Santa Sofía concentra pequeños agricultores productores de banano orgánico que cultivan la fruta en pequeñas áreas productivas. La gran mayoría de los agricultores son dueños de 0.5 a 1.5 hectáreas; quienes venden la producción individual a las empresas agro exportadoras. Debido a que la producción individual de fruta es muy pequeña, su poder de negociación de la fruta es bajo. 
Así, se forma la Cooperativa Agraria Alto Grande Santa Sofía que desarrolla un modelo de negocio Business to business (B2B) bajo la normativa y sistema cooperativista. El modelo de negocio se basa en la compra de toda la producción de banano orgánico de los socios productores para procesarla y envasarla; generando como propuesta de valor la comercialización en volumen de fruta de alta calidad que se entrega a las empresas agroexportadoras en los plazos convenidos; buscando obtener el mejor precio de venta garantizándole al socio productor un precio justo por la misma. El precio permite cubrir el costo de compra de la fruta, los costos de los procesos de lavado, empaque, distribución y, los gastos operativos generando una ganancia que será distribuida entre los socios productores.

El presente plan de negocios busca ayudar a la Cooperativa Agraria Alto Grande Santa Sofía en la obtención de fondos no reembolsables que otorga AGROIDEAS (unidad ejecutora del ministerio de agricultura y riego); fondos que serán utilizados para implementar mejoras en los flujos de los procesos que ayuden a reducir los costos del proceso de producción, los costos de distribución y el alto porcentaje de merma durante el proceso de la fruta. Adicionalmente, se busca obtener fondos para pagar a las empresas certificadoras para que realicen la evaluación de los procesos operativos con la finalidad de obtener las certificaciones: Orgánica, Global GAP y Comercio Justo. Las certificaciones permitirán a la organización no depender de un único comprador de su fruta y beneficiarse con el pago adicional que realiza el importador - europeo o norteamericano - por concepto de comercio justo. 


\subsubsection{Cultura organizacional.}

La Cooperativa Agraria Alto Grande Santa Sofía no ha realizado nunca un plan estratégico, razón por la cual es necesario definirle una cultura organizacional.

Davis (2013) define que “...la visión debe responder a la pregunta “¿En qué nos queremos convertir?” (p.45). Respecto a la misión, Davis (2013) afirma que es “...una afirmación perdurable acerca del propósito que distingue a una empresa de otras similares...Responde a la pregunta: ¿Cuál es nuestro negocio?" (p.47)

\subsubsection{1.visión.}

Para poder formular la visión de la empresa se realizó una reunión con la asamblea general de socios, a quienes se les realizaron las siguientes preguntas:

\section{a. ¿Hasta dónde quieren que la cooperativa llegue a ser en el futuro?}

La gran mayoría de respuestas se orientaron a: "ser la cooperativa líder en exportación de banano orgánico de la provincia de Sullana”.

\section{b. ¿Qué resultados quieren alcanzar en el futuro?}

Ser reconocidos por la cooperativa que utiliza tecnología de punta en los diversos procesos productivos que garantiza un banano de excelente calidad. 
c. ¿Cómo desean que la cooperativa sea vista en el futuro?

Como la cooperativa que provee de banano orgánico a todos los países del mercado europeo y asiático.

En conclusión, la visión de la cooperativa se define de la siguiente manera:

"Ser una cooperativa líder en la exportación de banano orgánico de calidad reconocida por el uso de tecnología de punta y presencia en todos los países de Europa y Estados Unidos".

\subsubsection{Misión.}

Para formular la misión de la empresa se realizaron las siguientes preguntas al mismo grupo de socios:

\section{a. ¿Cuál es el producto de la organización?}

Comercialización de banano orgánico.

b. ¿Quién es el cliente de la organización?

Los clientes directos son todas las agroexportadoras. Sin embargo, el cliente final es el consumidor del banano orgánico exportado.

c. ¿Qué necesidad satisface la cooperativa?

Proveer a los mercados de banano orgánico de excelente calidad, producido mediante técnicas no contaminantes; es decir, sin el uso de productos químicos en el proceso vegetativo de la planta. 


\section{d. ¿Qué beneficios brinda la cooperativa?}

Exportar banano orgánico sano, garantizándole al pequeño productor un precio justo por su producción.

e. ¿La tecnología es importante en los procesos operativos?

Definitivamente "Si". El utilizar tecnología de punta, ayuda a reducir las mermas y los costos de producción, permitiendo mejorar la rentabilidad del negocio.

f. ¿Qué valores consideran que son importantes en una cooperativa?

Respeto y honestidad para con todos los stakeholders de la organización, responsabilidad de cumplir con los plazos de entrega establecidos por los clientes, lealtad para con todos los socios de la organización.

g. ¿Por qué comercializar banano orgánico?

Porque buscan consolidar a la cooperativa como líder en exportación de banano orgánico de la provincia de Sullana.

En conclusión, podemos definir la Misión de la siguiente manera:

"Ser una cooperativa proveedora de alimentos sanos comprometida con los pequeños productores garantizándoles un precio justo. Es por ello que procesan y exportan banano de calidad usando tecnología de punta". 


\subsubsection{Principios.}

La cultura organizacional es fundamental para el éxito de todo emprendimiento. Por este motivo se han determinado los siguientes principios básicos de su filosofía empresarial:

\section{a. Cultura de Mejora Continua,}

Este principio permite a la organización realizar inversiones en tecnología que permita garantizar la sostenibilidad de la producción de banano orgánico de alta calidad y a bajo costo.

\section{b. Cumplimiento de Entrega}

Es muy importante cumplir con la entrega a tiempo del producto procesado. El no fallarle en las entregas a los clientes genera confianza y buenas relaciones con ellos.

\section{c. Respeto por el Medio Ambiente,}

El apoyar a los pequeños productores a mantener y promover la siembra de banano orgánico ayuda a mantener las tierras agrícolas limpias, libres de químicos y otros agentes que la contaminan.

\subsubsection{Objetivos Estratégicos.}

Los objetivos estratégicos son importantes para tener una orientación precisa de la dirección que se desea implementar para la cooperativa. 
De acuerdo a las conversaciones realizadas con los directivos de la cooperativa se pudieron establecer los siguientes objetivos estratégicos:

a. Ser la única cooperativa agraria comercializadora de banano orgánico en el valle de Santa Sofía.

b. Ser una cooperativa reconocida por su sostenibilidad económica, social y medioambiental.

c. Ser una cooperativa capaz de exportar su producción de banano orgánico directamente a los mercados internacionales. 


\section{CAPÍTULO II}

\section{Análisis del entorno}

\subsection{Análisis de la industria.}

El análisis de la industria de la organización se realizará en 03 etapas: en la primera etapa se realizará un análisis de los factores externos, en una segunda etapa aplicaremos el modelo de las cinco fuerzas competitivas para complementar el análisis de la industria y, por último, aplicaremos el análisis de las tres nuevas fuerzas externas.

\subsubsection{Factores externos.}

Para ello, el análisis estará basado en las afirmaciones realizadas por los siguientes autores:

Thompson y Strickland (2004) definen este análisis como: “...las fuerzas relevantes que están fuera de la compañía pero que son lo suficientemente importantes como para tener un peso en las decisiones que una empresa toma respecto a su modelo de negocio y a su estrategia” (p.60)

David (2013) afirma que “...el análisis de las fuerzas externas y de las variables de la industria son la base para alcanzar y mantener la ventaja competitiva de la compañía" (p.63) 
David (2013), afirma: "las fuerzas externas pueden clasificarse en cinco amplias categorías: (1) fuerzas económicas (2) fuerzas sociales, culturales, demográficas y ambientales (3) fuerzas políticas, gubernamentales y legales (4) fuerzas tecnológicas (5) fuerzas competitivas” (p.63)

Para poder realizar el análisis de la industria en la que se encuentra la Cooperativa Agraria Alto Grande Santa Sofía procederemos a analizar cada una de las cinco fuerzas externas claves descritas por Davis:

\subsubsection{Fuerzas económicas.}

Los factores económicos son de gran importancia pues inciden de manera directa en el atractivo de las diversas estrategias a implementar. Es fundamental analizar las variables económicas claves relacionadas con la industria del negocio en el que opera la organización.

De todas las variables económicas descritas por Davis, se identificaron las siguientes variables económicas que influyen en la industria del banano orgánico:

a. Condiciones económicas del país.

El área de soporte económico del banco Scotiabank (2016), afirmó que la economía peruana se ha desacelerado en los últimos años producto de la falta de inversiones. Sin embargo, el país se recupera a partir de mediados del 2015 y continúa creciendo desde entonces; proyectando un crecimiento 
económico del $3.0 \%$ para el 2016 y hasta $4.8 \%$ para el 2017.

Micklethwaite, K. (2017). Afirma: “...una serie de desafortunados sucesos como las inundaciones en el norte y centro del país y los casos de corrupción han afectado las perspectivas de crecimiento del Perú y es probable que el crecimiento del PBI este cerca del 2.5 a 3.0\%. La economía es una de las menos volátiles de la región, caracterizada por sólidos fundamentos macro económicos y una gestión responsable que la hacen resistir cualquier disminución de precios de materias primas."

El Banco Mundial (2017), dice: "se mantiene la proyección de crecimiento de la economía peruana de hasta $4.2 \%$ para el 2017, pero se estima que el PBI solo crecería 3.8\% el 2018 y 3.6\% el 2019." Estas proyecciones contrastan con las previsiones del ministerio de economía y finanzas (2016), contenidas en el Marco Macroeconómico Multianual, donde se indicó que la economía peruana crecerá en $4.8 \%$, mientras que el 2018 lo hará en $4.3 \%$ y el 2019 en 4.1\%. Podemos observar un panorama optimista para el país para los siguientes años que permitiría el ingreso de nuevos agroexportadores de banano orgánico aumentando el precio de la fruta pagada. 
b. Tasa de inflación.

En el Perú la inflación está controlada desde hace más de quince años. Sin embargo, el cierre del 2016 (entre $3.2 \%$ y $3.4 \%$ ) fue superior al rango objetivo del Banco Central de Reserva de entre $1 \%$ y $3 \%$.

Lo destacable es que la inflación del 2016 fue menor al 4.4\% registrado en el 2015 (año en que alcanzó el pico inflacionario más alto de los últimos 05 años, como consecuencia de un aumento de la divisa norteamericana). Se estima que para el 2017 sea menor al $3 \%$.

Tabla 2: Índice de Precios

\begin{tabular}{|l|c|c|c|c|}
\hline & $\mathbf{2 0 1 5}$ & $\mathbf{2 0 1 6}$ & $\mathbf{2 0 1 7}$ & $\mathbf{2 0 1 8}$ \\
\hline Índice de Precios & 4.4 & 3.5 & 3.0 & 2.9 \\
\hline
\end{tabular}

Fuente: Marco Macroeconómico Multianual 2017 - 2019. Ministerio de Economía y Finanzas (MEF). Elaboración Propia

El hecho que la inflación proyectada sea baja y estable es un indicador de estabilidad macroeconómica que contribuye a que los proyectos nuevos se desarrollen en un entorno de confianza.

c. Tipo de cambio.

Por ser una empresa exportadora, el tipo de cambio es una variable muy importante para el cálculo de la proyección de ingresos de la cooperativa. Una tendencia alcista del tipo de cambio sería beneficiosa para la organización, porque al vender su cosecha en 
dólares, recibiría más soles de los que anteriormente recibía. Esto le permite incrementar sus ingresos de corto plazo, mejorando su utilidad. Si bien el dólar cerró en 3.357 soles (una caída de $1.7 \%$ respecto al cierre 2015), se proyecta un tipo de cambio creciente para los siguientes años:

Tabla 3: Tipo de Cambio Proyectado

\begin{tabular}{|l|c|c|c|c|}
\hline & $\mathbf{2 0 1 5}$ & $\mathbf{2 0 1 6}$ & $\mathbf{2 0 1 7}$ & $\mathbf{2 0 1 8}$ \\
\hline $\begin{array}{l}\text { Tipo de Cambio Promedio } \\
\text { (Soles por US dólar) }\end{array}$ & 3.19 & 3.30 & 3.37 & 3.38 \\
\hline
\end{tabular}

Fuente: Marco Macroeconómico Multianual 2017 - 2019. Ministerio de Economía y Finanzas (MEF). Elaboración Propia

d. Niveles de producción.

Teniendo en consideración los datos históricos de los últimos cinco años, el valor de las exportaciones de banano orgánico peruano tiende al crecimiento.

El volumen exportado casi se ha duplicado en los últimos cinco años. Ante este crecimiento sostenido, se puede afirmar que la demanda del mercado internacional se encuentra garantizada.

En la actualidad, toda la producción de banano orgánico que cumpla con los requisitos de ser exportada es inmediatamente vendida. Las empresas agro exportadoras se encuentran constantemente a la búsqueda de volúmenes de banano exportable. 
Se debe considerar que para el 2017 la producción de banano orgánico se verá mermada debido a la sequía que afectó el norte del país a finales del 2016 y por las lluvias anormales de inicios del 2017. Esto ha originado que la producción de banano orgánico se vea mermada. Sin embargo, con la declaratoria de emergencia dada por el gobierno, se espera poder revertir los efectos negativos y recuperar los niveles de producción para fines de año.

e. Tasas de impuestos.

Minagri (2015) dice que el sistema tributario para el sector agrario es diverso y complejo por la existencia de regímenes especiales de exoneración cruzada por lista de productos, por niveles de ingreso, por región del Perú y por nivel de valor agregado.

Sin embargo, los incentivos más relevantes para el sector agrícola se contemplan en:

- La Ley $\mathrm{N}^{\circ} 27360$ que aprueba las normas de promoción del sector agrario. En esta ley se permite una reducción de la tasa del Impuesto a la Renta del $30 \%$ al $15 \%$. El plazo de vigencia de este beneficio es hasta el 31 de diciembre del 2021.

- La Ley $\mathrm{N}^{\circ} 27614$ que prorroga el plazo de exoneración a algunas partidas arancelarias del texto único ordenado de la Ley del IGV e Impuesto Selectivo al Consumo. 
- La Ley $\mathrm{N}^{\circ} 27037$ que aplica una tasa reducida del impuesto a la renta de $15 \%$ y exoneraciones del IGV en zonas priorizadas de la amazonia.

- La Ley $\mathrm{N}^{\circ} 27445$ que exonera el pago de IGV, IPM e IR a los productores agrarios cuyas ventas anuales no superen las 50 UIT.

- La implementación del Programa de Regulación Tributaria que ha permitido la condonación y reprogramación de deudas tributarias para empresas agrarias y agroindustriales.

- Sunat (2016), las personas jurídicas podrán depreciar a razón del $20 \%$ anual, el monto de las inversiones en obras de infraestructura hidráulica y obras de riego. El plazo de vigencia de este beneficio es hasta el 31 de diciembre del 2021.

Los incentivos tributarios del régimen agrícola, permiten a los proyectos agrícolas gozar de un marco beneficioso para su desarrollo.

f. Régimen laboral y de seguridad social.

Sunat (2016), los empleadores de la actividad agraria podrán contratar a su personal por período indeterminado o determinado. En este último caso, la duración de los contratos dependerá de la actividad agraria por desarrollar, pudiendo establecerse jornadas de trabajo acumulativas en razón de la naturaleza especial de las labores, siempre que el número de horas trabajadas durante el plazo del contrato no exceda en 
promedio los límites máximos previstos por la Ley. Los pagos por sobretiempo procederán sólo cuando se supere el referido promedio.

Para el sector agrícola se ha establecido un régimen laboral y de seguridad social especial basado en la siguiente normativa vigente:

- D.L. $\mathrm{N}^{\circ}$ 885. Ley de promoción del sector agrario

- D.S. N ${ }^{\circ}$ 003-97-TR; texto Único Ordenado del Decreto Legislativo 728, Ley de Productividad y competitividad Laboral.

- Ley $\mathrm{N}^{\mathrm{a}}$ 26970, Ley de la modernidad en la seguridad social en salud

- D.S. No 002-98-AG, aprueban el Reglamento de la Ley de Promoción en el Sector Agrario.

- Ley 27360, que aprueba las normas de Promoción del Sector Agrario.

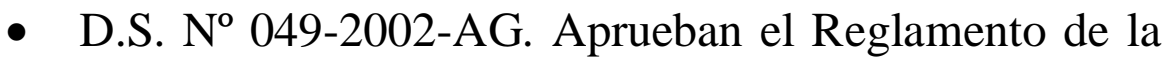
Ley $N^{o} 27360$ - Ley que aprueba las Normas de Promoción del Sector Agrario.

- Resolución de Gerencia Central de Seguros N ${ }^{\circ}$ 008GCSEG-GDA-ESSALUD-2005; establecen requisitos de afiliación al seguro de salud agrario para trabajadores independientes

De acuerdo a la revisión de este marco legal podemos resumir que para la empresa aplican las siguientes condiciones: 
- Jornada laboral de 8 horas diarias, descanso vacacional de 15 días calendarios e indemnización equivalente a 15 remuneraciones diarias por cada año completo de servicios, con un máximo de 180 remuneraciones.

- El aporte mensual al Seguro de Salud a cargo del empleador, será del 4\%.

- Establecen que la remuneración mínima con un pago diario no podrá ser menor a 29.27 soles.

- La CTS está incluida en la remuneración diaria.

- Asignación familiar del 10\% del sueldo mínimo vital: 85 soles mensuales.

- Las gratificaciones se hallan incluidas en la remuneración diaria.

Los incentivos en beneficios sociales del régimen agrícola, permiten a los proyectos agrícolas gozar de un marco beneficioso para su desarrollo.

2.1.1.2.Fuerzas sociales, culturales, demográficas.

David (2013) afirma que: "todas las organizaciones se ven sacudidas por las oportunidades y amenazas que surgen a partir de los cambios en las variables sociales, culturales, demográficas y ambientales" (p.67)

A continuación, se realiza el análisis de las variables indicadas anteriormente: 
a. Demográficas.

El Instituto Nacional de Estadística e Informática (2016) señala que el Perú tiene una población aproximada de 33 millones de habitantes. De acuerdo a la FAO (2012), la población mundial superó los 7,000 millones de personas. Por lo tanto, hay miles de millones de personas que podrían estar interesadas en adquirir los bienes y servicios producidos por las empresas peruanas. Bajo esta perspectiva, limitarse a ofrecer productos y servicios en el mercado nacional constituye una estrategia inadecuada; sobre todo, si consideramos que la población mundial seguirá creciendo hasta alcanzar un estimado de 8,000 millones de personas para el 2028 y 9,000 para el 2054.

Teniendo en cuenta las afirmaciones descritas, podemos concluir que el crecimiento poblacional garantiza una demanda creciente de alimentos a nivel mundial.

b. Culturales.

La FAO (2012) nos dice que en la actualidad existe una preferencia por consumir productos orgánicos, el consumidor final busca frutas frescas con certificación orgánica, pues de esta manera tiene la seguridad de consumir productos libres de insumos químicos. Esta tendencia viene creciendo año a año, razón por la cual la demanda por productos orgánicos cada día es mayor. 
En este mismo contexto, muchos consumidores con la finalidad de poder contar con productos orgánicos están dispuestos a pagar un mayor precio por el producto. El consumidor final en Estados Unidos y Europa está dispuesto a pagar un precio mayor por los productos orgánicos que tengan la certificación Orgánica y Comercio Justo, garantizando que los productores reciban una ganancia mayor por la comercialización de sus productos.

c. Sociales.

El crecimiento de las exportaciones de banano orgánico originó un impacto social positivo para los pequeños productores de banano orgánico, quienes al ser socios de las cooperativas y asociaciones comercializadoras de banano orgánico podrán asegurar la venta de su producción mejorando la calidad de vida de sus familias.

\subsubsection{Fuerzas políticas, gubernamentales y legales.}

David (2013) nos dice que: "los gobiernos estatales, locales y extranjeros son importantes reguladores, desreguladores, empleadores y clientes de las organizaciones. Por lo tanto, las fuerzas políticas, gubernamentales y legales pueden representar oportunidades y amenazas para las organizaciones de todo tamaño" (p.68) 
El gobierno peruano ha propiciado políticas y mejoras para fomentar el aumento de cultivos rentables. Una de estas políticas es otorgar exoneraciones tributarias e impositivas para la venta y comercialización de banano orgánico. Otra política de desarrollo propiciada por el estado peruano es la firma de nuevos acuerdos comerciales para ampliar las opciones de destino para las exportaciones de productos peruanos.

Uno de los objetivos del ministerio de agricultura es incrementar el área productiva de banano orgánico para poder abastecer nuevos mercados y no centralizarnos en los tres países que actualmente concentran el $85 \%$ de las exportaciones peruanas de banano orgánico.

\subsubsection{Fuerzas tecnológicas.}

David (2013) afirma que: "en casi todas las industrias, las organizaciones más preparadas, desde la perspectiva tecnológica, obtienen una ventaja competitiva abrumadora sobre los rivales menos competentes" (p.71)

Toda organización requiere de la tecnología para incrementar la productividad. Para ello, es necesario no sólo adquirir maquinaria adecuada sino también capacitar al productor en cuanto al uso de nuevas técnicas de siembra, riego y cosecha con la finalidad de aumentar la productividad por área sembrada y garantizar mayores utilidades por campaña. 
Un riesgo latente para los pequeños productores, es la presencia de grandes inversionistas que entren a competir al mercado ya que por factores de economías de escala tienen mayor ventaja competitiva y comparativa. Las organizaciones de productores deben incluir el costo social dentro de su flujo de costos; concepto que no aplica para las grandes empresas cuyo objetivo final es generar valor para las empresas a lo largo del tiempo.

\subsubsection{Fuerzas ecológicas.}

El negocio del banano orgánico se sustenta en no usar suministros químicos durante los procesos de siembra, mantenimiento y cosecha. Esto ayuda a tener campos de cultivo sanos y crear un ambiente amigable con los ecosistemas regionales, cumpliendo con la responsabilidad ambiental que todo negocio debe asumir.

Los valles de Piura ofrecen buena calidad de suelos y condiciones climatológicas favorables que garantizan un abastecimiento constante de banano orgánico a los diferentes mercados. Sin embargo, la sequía del año 2016 y las fuertes lluvias de inicios del 2017 han demostrado que el cultivo es vulnerable frente a los cambios climáticos porque impactan en la productividad de los cultivos pudiendo llegar en caso extremo a la pérdida de la plantación.

Finalmente, la preocupación de la comunidad internacional por el consumo de productos orgánicos los ha 
llevado a preocuparse por fomentar la siembra de cultivos orgánicos. Para ello, están dispuestos a pagar un precio adicional por los productos certificados como "orgánicos" y "comercio justo", importe adicional que es entregado directamente a las asociaciones de productores para motivarlos a continuar con la producción orgánica. En este contexto, toda asociación productora debe contar con las certificaciones necesarias a fin de poder gozar de este beneficio. 
Tabla 4: Resumen del Análisis de las Fuerzas Externas

Categoría

\section{Descripción}

Condiciones Económicas del País: La proyección económica permite mirar con optimismo la recuperación del capital de la inversión que se está analizando.

Inflación. La inflación proyectada en el Perú es baja y estable contribuyendo a un entorno de confianza para el desarrollo de cualquier proyecto de inversión.

FUERZAS ECONOMICAS Tipo de Cambio. Se proyecta un tipo de cambio creciente que llegaría a 3.38 en el año 2018; proyección favorable para la empresa en análisis por comercializar un producto de exportación.

Niveles de Producción. La demanda de banano orgánico viene creciendo, lo que permite afirmar que la producción de banano orgánico es demandada al $100 \%$.

Tasas de Impuestos - Régimen Laboral y Seguridad Social. Los incentivos del régimen agrícola, permiten a los proyectos agrícolas gozar de un marco beneficioso para su desarrollo.

FUERZAS SOCIALES

CULTURALES $Y$

Demográficas. El crecimiento poblacional garantiza una demanda creciente de las exportaciones peruanas de alimentos.

Culturales. Existe una tendencia creciente hacia el consumo de productos orgánicos y a fomentar la siembra de cultivos orgánicos.

DEMOGRAFICAS

Sociales. El desarrollo y crecimiento económico de las asociaciones y cooperativas productoras de banano orgánico asegura un mejor calidad de vida a los pequeños productores.

FUERZAS POLITICAS, GUBERNAMENTALES $y$ LEGALES

Beneficios Tributarios. El estado ha dado leyes en favor de promover la siembra de cultivos de banano orgánico.

Nuevos Tratados de Libre Comercio. Con la finalidad de asegurar nuevos mercados para la exportación de banano orgánico.

Promoción del Banano Orgánico. El Ministerio de Comercio Exterior y Turismo tiene dentro de sus funciones el promocionar banano orgánico y buscar nuevos mercados para este producto.

\section{FUERZAS}

TECNOLOGICAS

FUERZAS ECOLOGICAS
Tecnología de Punta. Se hace necesario invertir en tecnología para mejorar los procesos de siembra, lavado y distribución para poder reducir los costos operativos de la cooperativa.

Capacitación en Uso de Tecnología. Es urgente capacitar a los productores en el uso de tecnologías de mejora de siembra, mantenimiento y cosecha; a fin de garantizar una mayor producción con menores costos.

Ecosistema Amigable. La siembra de cultivos de banano orgánico garantiza mantener los campos de cultivo con un ecosistema regional amigable.

Cambios Climáticos. La sequía de fines del 2016 mostró la vulnerabilidad del cultivo a los cambios climatológicos y a la productividad de los cultivos.

Fuente y elaboración propia 
Para culminar el análisis de los factores externas de la industria, hemos procedido a la elaboración de la Matriz EFE:

Tabla 5: Matriz de Evaluación de Factores Externos - EFE

\begin{tabular}{|c|c|c|c|}
\hline OPORTUNIDADES & PONDERACION & CALIFICACION & $\begin{array}{l}\text { PUNTUACION } \\
\text { PONDERADA }\end{array}$ \\
\hline 1 Estabilidad de la Economía Peruana & 0.07 & 3 & 0.21 \\
\hline 2 Crecimiento del Mercado del Banano Orgánico & 0.20 & 4 & 0.80 \\
\hline 3 Tendencia creciente a consumir frutas orgánicas & 0.20 & 4 & 0.80 \\
\hline 4 Firma de Tratados de Libre Comercio & 0.10 & 3 & 0.30 \\
\hline 5 Crecimiento de la población a nivel mundial & 0.07 & 2 & 0.14 \\
\hline 6 Beneficios Tributarios & 0.10 & 3 & 0.30 \\
\hline AMENAZAS & PONDERACION & CALIFICACION & $\begin{array}{l}\text { PUNTUACION } \\
\text { PONDERADA }\end{array}$ \\
\hline 7 Cambios en el Tipo de cambio & 0.07 & 2 & 0.14 \\
\hline 8 Cambios climatológicos & 0.10 & 1 & 0.10 \\
\hline 9 Aumento inesperado de inflación & 0.09 & 1 & 0.09 \\
\hline TOTAL & 1.00 & & 2.88 \\
\hline $\begin{array}{l}\text { CALIFICACION: } \\
1 \text { Respuesta deficiente } \\
2 \text { Respuesta promedio } \\
3 \text { Respuesta por encima del promedio } \\
4 \text { Respuesta óptima }\end{array}$ & & & \\
\hline
\end{tabular}

Fuente propia. Elaboración siguiendo el formato de la matriz EFE de la tesis: "Implementación del servicio de vending de zumo de naranja”. Autores: Barrios, Becerra, Dejo, Pazos, Rojas. 2015.

Basados en la información proporcionada por la matriz EFE podemos afirmar que el entorno es favorable para la industria de la producción y comercialización de banano orgánico porque el Perú es un país que goza de una estabilidad económica favorable con una demanda de banano orgánico en crecimiento que abre una oportunidad de negocio a los productores peruanos, para realizar ventas competitivas, sustentadas en la buena calidad de suelos y las condiciones climáticas favorables de los valles de Piura. Ventajas competitivas que garantizan ofrecerle a los consumidores un abastecimiento de fruta constante. 
Estas condiciones, sumadas a los esfuerzos del estado peruano por abrir nuevos mercados (Acuerdos Comerciales y Tratados de Libre Comercio) permiten afirmar que estamos frente a un escenario optimista que conlleva a fomentar la siembra de nuevas áreas de cultivo y al desarrollo de proyectos de inversión para promover la exportación de banano orgánico.

\subsubsection{Cinco fuerzas competitivas.}

Maroto (2007) explica que el modelo de las cinco fuerzas competitivas “...nos permite detectar oportunidades y amenazas en el sector. Para lo cual se debe analizar: (1) Rivalidad entre competidores (2) Analizar el poder negociador de los proveedores (3) Analizar el poder negociador de los Clientes (4) Identificar a los competidores potenciales (5) Identificar la amenaza de productos sustitutos.” (p.86)

\section{Ilustración 1: El Modelo de las Cinco Fuerzas}

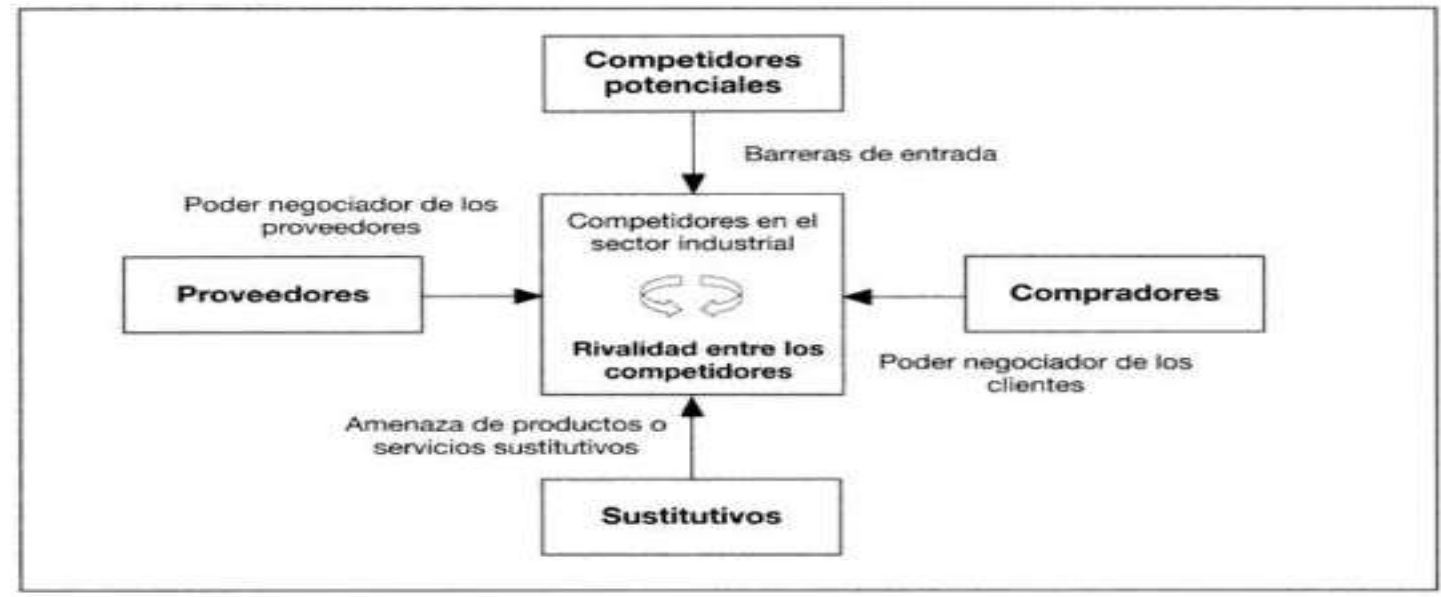

Fuente y elaboración: Tomado de "Estrategia Competitiva, Porter, M. E. (1985)"

Porter (1996) nos dice que "el éxito de una empresa depende de saber aprovechar mejor que los competidores, los factores externos favorables y de tener la capacidad de combatir aquellos factores desfavorables." (p.26) 
2.1.2.1.la rivalidad entre competidores existentes.

Porter (1996), nos dice que "la intensidad de la competencia es el resultado de una serie de factores, entre los que destacan:

a. A mayor número de competidores equilibrados, la competencia será mayor.

b. Cuando se reduce el ritmo de crecimiento de la industria, la competencia se incrementará.

c. A mayor capacidad instalada en el sector, la competencia será mayor.

d. A más empresas interesadas en tener éxito en una industria, mayor será la competencia, ya que pueden estar dispuestos a sacrificar temporalmente resultados.

e. Cuando los competidores son muy distintos en la forma de entender el negocio, la competencia aumentará.” (p.37)

Los productores de banano orgánico se han venido asociando en cooperativas o asociaciones encargadas de comprar, procesar y comercializar la fruta de sus socios productores. Muchas de estas organizaciones han conseguido cumplir los requisitos necesarios para exportar directamente a Europa y Estados Unidos. Sin embargo, muchas de ellas aún no consiguen cumplir estos requisitos $\mathrm{y}$ venden la fruta a empresas o asociaciones agro exportadoras.

$\mathrm{La}$ industria viene en crecimiento sostenido. La preferencia por el banano orgánico peruano viene en aumento. El ministerio de agricultura y riego (2015) nos indica que las exportaciones de banano orgánico peruano crecieron $94 \%$ en los últimos cinco 
años, posicionando al Perú como uno de los principales proveedores de este producto a nivel mundial. Este rápido crecimiento de la industria la hace muy atractiva.

El ingreso a esta industria implica el conocimiento de la siembra y mantenimiento de los cultivos. Para los competidores directos este conocimiento es compartido, razón por la cual podemos afirmar que los costos fijos o de almacenamiento representan una neutralidad respecto al atractivo de la industria.

Debido al crecimiento de la industria, las cooperativas buscan aumentar el número de socios para incrementar los volúmenes de fruta vendida. Esto implica, convencer a los productores de otros cultivos (ejemplo: arroz, coco, mango, limón) para que incursionen en la siembra de banano orgánico bajo el modelo del cooperativismo. A la fecha, esta política de cambios ha sido lenta, lo cual origina que la industria siga siendo atractiva.

En resumen, la industria es atractiva porque existe un conocimiento compartido de los procesos de siembra, lavado y distribución entre todos los competidores; la demanda está en crecimiento, se requiere de un aumento de las áreas de producción y hay una baja diversidad entre los competidores.

A continuación, se muestra un cuadro resumen de todo lo analizado respecto a la rivalidad entre competidores: 
Tabla 6: Atractivo de la Rivalidad entre Competidores

\begin{tabular}{|c|c|c|c|c|c|c|c|}
\hline $\begin{array}{l}\text { Actual } \\
\text { Futuro }\end{array}$ & & $\begin{array}{l}8 \\
8 \\
8 \\
2 \\
2 \\
z \\
z \\
z\end{array}$ & 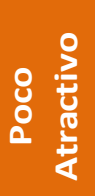 & $\begin{array}{l}0 \\
\frac{2}{2} \\
\frac{1}{3} \\
2\end{array}$ & 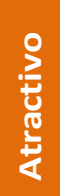 & 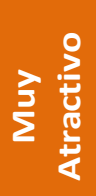 & \\
\hline $\begin{array}{l}\text { 1. Número de competidores } \\
\text { igualmente equilibrados }\end{array}$ & Importante & & & & & & Bajo \\
\hline $\begin{array}{l}\text { 2. Crecimiento relativo de } \\
\text { la Industria }\end{array}$ & Lento & & & & & & Rápido \\
\hline $\begin{array}{l}\text { 3. Costos Fijos o } \\
\text { de almacenamiento }\end{array}$ & Alto & & & & & & Bajo \\
\hline $\begin{array}{l}\text { 4. Aumentos de áreas } \\
\text { de producción }\end{array}$ & $\begin{array}{r}\text { Grandes } \\
\text { Aumentos }\end{array}$ & & & & & & $\begin{array}{l}\text { Pequeños } \\
\text { Aumentos }\end{array}$ \\
\hline $\begin{array}{l}\text { 5. Diversidad de } \\
\text { competidores }\end{array}$ & Alta & & & & & & Baja \\
\hline
\end{tabular}

Fuente y elaboración propia, siguiendo las recomendaciones de Arnoldo Hax y Nicolás Majluf. Estrategias para el liderazgo competitivo. 2004

\subsubsection{2.entrada potencial de nuevos competidores.}

Porter (1996) nos dice que “...la mejor forma de impedir el ingreso de nuevos competidores es:

a. Las barreras contra el ingreso pueden incluir la necesidad de lograr rápidamente economías de escala.

b. Diferenciación del producto

c. Grandes necesidades de capital para poder competir

d. La necesidad de obtener tecnología y conocimientos técnicos especializados

e. Efecto de la experiencia

f. Restricciones Gubernamentales y Sociales

g. Ubicaciones geográficas poco deseables

h. Potencial de saturación del mercado" (p.28) 
Debido a la creciente demanda por el banano orgánico peruano, el aumento del volumen de producción con la intención de obtener costes de producción unitarios más reducidos no disuade al ingreso de nuevos competidores, ya que el aumento de la productividad se puede realizar con la implementación de mejoras agrícolas o la aplicación de la tecnología. En resumen, actualmente las economías de escala son pequeñas haciendo muy atractiva la industria para la entrada de nuevos competidores. Dado que el banano orgánico es el mismo, independientemente de quien lo produzca, la diferenciación del producto es neutral respecto al atractivo de la industria.

Los requerimientos de capital para incursionar en la siembra de banano orgánico son relativamente bajos. Una de las dificultades que tendrían los nuevos competidores es conseguir hectáreas suficientes juntas y/o cercanas que justifiquen una gran inversión de capital.

Actualmente, los pequeños productores cuentan con rentabilidad en el cultivo de banano orgánico y forman parte de una asociación y/o cooperativa que comercializa su producción, razones por las cuales no están dispuestos a vender sus predios agrícolas. Esto conlleva a cualquier nuevo competidor, a salir a la búsqueda de tierras en venta que hayan sembrado otros cultivos (en los valles de Sullana la mayoría de cultivos siembran banano orgánico o arroz), obligándolo a invertir gran cantidad de capital en habilitar las tierras adquiridas para el nuevo sembrío, aumentando los costos de producción y el riesgo de adquirir enfermedades de otros cultivos. 
Sin embargo, las actuales empresas exportadoras, han visto el potencial de negocio del banano orgánico $\mathrm{y}$, muchas de ellas vienen realizando una integración hacia atrás, invirtiendo directamente en la adquisición de tierras de cultivo a fin de asegurar su abastecimiento para atender su mercado.

En la actualidad, cualquier nuevo competidor tiene acceso a la tecnología y a los conocimientos técnicos especializados para poder iniciarse en el negocio de siembra de banano orgánico. El riesgo del ingreso de nuevos competidores radica en que verían el negocio de una manera muy distinta a la de las asociaciones y/o cooperativas que se preocupan por el bienestar colectivo de los socios productores, mientras que el nuevo competidor se preocuparía por la rentabilidad pudiendo originar en el futuro una guerra de precios donde el beneficiado sería el agro exportador.

El efecto de experiencia es muy importante a la hora de llevar los cultivos. La aplicación de insumos inapropiados a los cultivos podría originar que no pasasen las pruebas de calidad invalidando la fruta para ser comercializada en el mercado internacional.

Contar con cortadores de fruta con experiencia garantiza la buena presentación final del producto, evita el manchado de la fruta y reduce las mermas de productividad. El efecto de la experiencia hace que el mercado sea poco atractivo para el ingreso de nuevos competidores, ya que para contar con ella se debe incurrir en costos adicionales. 
Los subsidios otorgados por el estado a través de diversos programas desarrollados por el ministerio de agricultura (agroideas, procompite, PNIA, etc.) originan que la industria sea poco atractiva para el ingreso de nuevos competidores. Estos programas buscan el desarrollo de las asociaciones y/o cooperativas debido a que el crecimiento de estas ayudará a mejorar la calidad de vida de los socios productores; además, de generar puestos de trabajo masivos.

Sin embargo, si continúa la integración hacia atrás de las empresas agroexportadoras, la visión del negocio cambiará a una visión de rentabilidad. Es decir, cuando las agroexportadoras aseguren su abastecimiento para atender su mercado internacional, dejarán de comprarle a las asociaciones y/o cooperativas, reduciendo el precio de compra y/o dejando de comprarle fruta. Eso supondría que los socios productores se vean perjudicados en sus ingresos y que muchas personas se queden sin empleo.

Una estrategia recomendada sería evitar la venta de tierras agrícolas a las agroexportadoras, eso implica incrementar el número de socios productores en cada organización y a la vez invertir en tecnología y capital humano para en el futuro más próximo iniciarse en la exportación de banano orgánico de manera directa. De acuerdo a lo analizado, la integración hacia atrás realizada por las actuales empresas agroexportadoras obliga a las pequeñas asociaciones y/o cooperativas a mejorar la calidad de su producto, invertir en tecnología para disponer de centros de empaque y contar con las certificaciones necesarias para exportar directamente a nuevos mercados. 
En conclusión podemos decir que la industria es medianamente atractiva para el ingreso de nuevos competidores porque si bien se puede desarrollar la siembra de banano orgánico con buenas economías de escala, no existen restricciones en el acceso a la tecnología de punta y no se requiere de la inversión de grandes capitales; existen tres limitantes que todo nuevo competidor debe tener en cuenta: (1) las cooperativas cuentan con políticas de subsidio por parte del estado (2) se requiere de personal con mucha experiencia para los procesos de siembra y cosecha de la fruta (3) no existen terrenos agrícolas en venta, razón por la cual de incursionar se requiere realizar ofertas de compra a muy alto precio que encarecería la inversión.

A continuación, se muestra un cuadro resumen de todo lo analizado respecto a la entrada de nuevos competidores:

Tabla 7: Atractivo Para la Entrada de Nuevos Competidores

\begin{tabular}{|c|c|c|c|c|c|c|c|}
\hline $\begin{array}{l}\text { Actual } \\
\text { Futuro }\end{array}$ & & 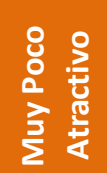 & 융 월 & $\begin{array}{l}\stackrel{0}{2} \\
\frac{7}{3} \\
\text { z }\end{array}$ & 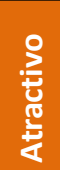 & 龸害 & \\
\hline 1. Economías de Escala & Pequeñas & & & & & & Grandes \\
\hline $\begin{array}{l}\text { 2. Diferenciación del } \\
\text { Producto }\end{array}$ & Baja & & & & & & Alta \\
\hline $\begin{array}{l}\text { 3. Requerimientos de } \\
\text { Capital }\end{array}$ & Alto & & & & & & Bajo \\
\hline $\begin{array}{l}\text { 4. Acceso a Tecnología de } \\
\text { Punta }\end{array}$ & Restringido & & & & & & Amplio \\
\hline 5. Efecto de la Experiencia & $\begin{array}{r}\text { Muy } \\
\text { Importante }\end{array}$ & & & & & & $\begin{array}{l}\text { Sin } \\
\text { Importancia }\end{array}$ \\
\hline $\begin{array}{l}\text { 6. Restricciones y Subsidios } \\
\text { Gubernamentales y Sociales }\end{array}$ & Bajas & & & & & & Altas \\
\hline
\end{tabular}

Fuente y elaboración propia, siguiendo las recomendaciones de Arnoldo Hax y Nicolás Majluf. Estrategias para el liderazgo competitivo. 2004 
2.1.2.3.Desarrollo potencial de productos sustitutos.

Porter (1996), dice que la presencia de productos sustitutos pone un tope al precio que se puede cobrar antes de que los consumidores cambien al producto sustituto. Estos límites de precio determinan la ganancia máxima y provocan una competencia más intensa entre rivales.

Debido a que la organización se dedica a la comercialización de banano orgánico, este producto no cuenta con un producto sustituto directo porque el agro exportador sólo se dedica a comprar y exportar banano orgánico.

2.1.2.4.Poder de negociación de los proveedores.

Porter (1996) nos dice que "los proveedores afectan la competencia de la industria, sobre todo cuando:

a. Hay un gran número de proveedores

b. Cuando hay pocas materias primas

c. Cuando el costo de cambiar de materia prima es especialmente alto." (p.47)

Debido a que los proveedores de fruta son los socios productores podemos decir que el poder de negociación de los proveedores es bajo. Los socios de la cooperativa son los encargados de elegir al directorio y gerentes de la organización. Por este motivo, las estrategias desarrolladas por ellos siempre van orientadas en conseguir mejoras y beneficios para la comunidad. En conclusión, el poder de negociación de los proveedores es bajo. 
2.1.2.5.Poder de negociación de los clientes.

Porter (1996) nos dice que “...los consumidores obtienen mayor poder de negociación considerando los siguientes factores:

a. Si son importantes para el vendedor

b. Si pueden cambiar a otras marcas o a productos sustitutos sin incurrir en gastos excesivos

c. Amenaza de los compradores de integración hacia atrás

d. Amenaza de la industria de integración hacia adelante

e. Rentabilidad de los Clientes" (p.45)

Podemos afirmar que el poder negociador de los compradores es medio porque para las cooperativas las agroexportadoras son muy importantes para la comercialización de su fruta. La agroexportadora conoce los índices de producción, costos de siembra y proceso de la fruta y, las limitaciones de las pequeñas cooperativas (en especial las referidas a las certificaciones). Por este motivo, suele establecer los precios de compra de acuerdo a sus intereses. Sin embargo, debido al crecimiento de la demanda de banano orgánico peruano en el mundo, las empresas agroexportadoras compiten por conseguir el mayor abastecimiento de fruta por parte de las cooperativas y/o asociaciones de fruta. No es fácil encontrar nuevos proveedores de fruta. En resumen, podemos concluir que la industria es moderadamente atractiva.

A continuación, se muestra un cuadro resumen de todo lo analizado respecto al poder de negociación de los clientes: 
Tabla 8: Atractivo Para el Poder de Negociación de los Clientes

\begin{tabular}{|c|c|c|c|c|c|c|c|}
\hline $\begin{array}{l}\text { Actual } \\
\text { Futuro }\end{array}$ & & $\begin{array}{l}80 \\
8 \\
8 \\
2 \\
2 \\
z \\
z \\
\Sigma \\
\Sigma\end{array}$ & 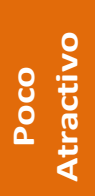 & \begin{tabular}{l}
0 \\
$\frac{2}{2}$ \\
\multirow{2}{0}{} \\
$Z$
\end{tabular} & $\begin{array}{l}0 \\
\frac{3}{4} \\
\frac{z}{0} \\
\frac{0}{4}\end{array}$ & 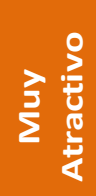 & \\
\hline 1. Importancia para el vendedor & Alta & & & & & & Baja \\
\hline $\begin{array}{l}\text { 2. Disponibilidad de cambiar de } \\
\text { proveedor sin gastos excesivos }\end{array}$ & Alta & & & & & & Baja \\
\hline $\begin{array}{l}\text { 3. Amenaza de los clientes de } \\
\text { integración hacia atrás }\end{array}$ & Alto & & & & & & Bajo \\
\hline $\begin{array}{l}\text { 4. Amenza de la industria de } \\
\text { integración hacia adelante }\end{array}$ & Baja & & & & & & Alta \\
\hline 5. Rentabilidad de los Clientes & Baja & & & & & & Alta \\
\hline
\end{tabular}

Fuente y elaboración propia, siguiendo las recomendaciones de Arnoldo Hax y Nicolás Majluf. Estrategias para el liderazgo competitivo. 2004

\subsubsection{Nuevas fuerzas del análisis externo.}

Downes \& Mui (2014) introducen tres nuevas fuerzas complementarias al modelo de las cinco fuerzas competitivas: Digitalización, Desregulación y Globalización.

\section{Ilustración 2: Las Tres Nuevas Fuerzas}

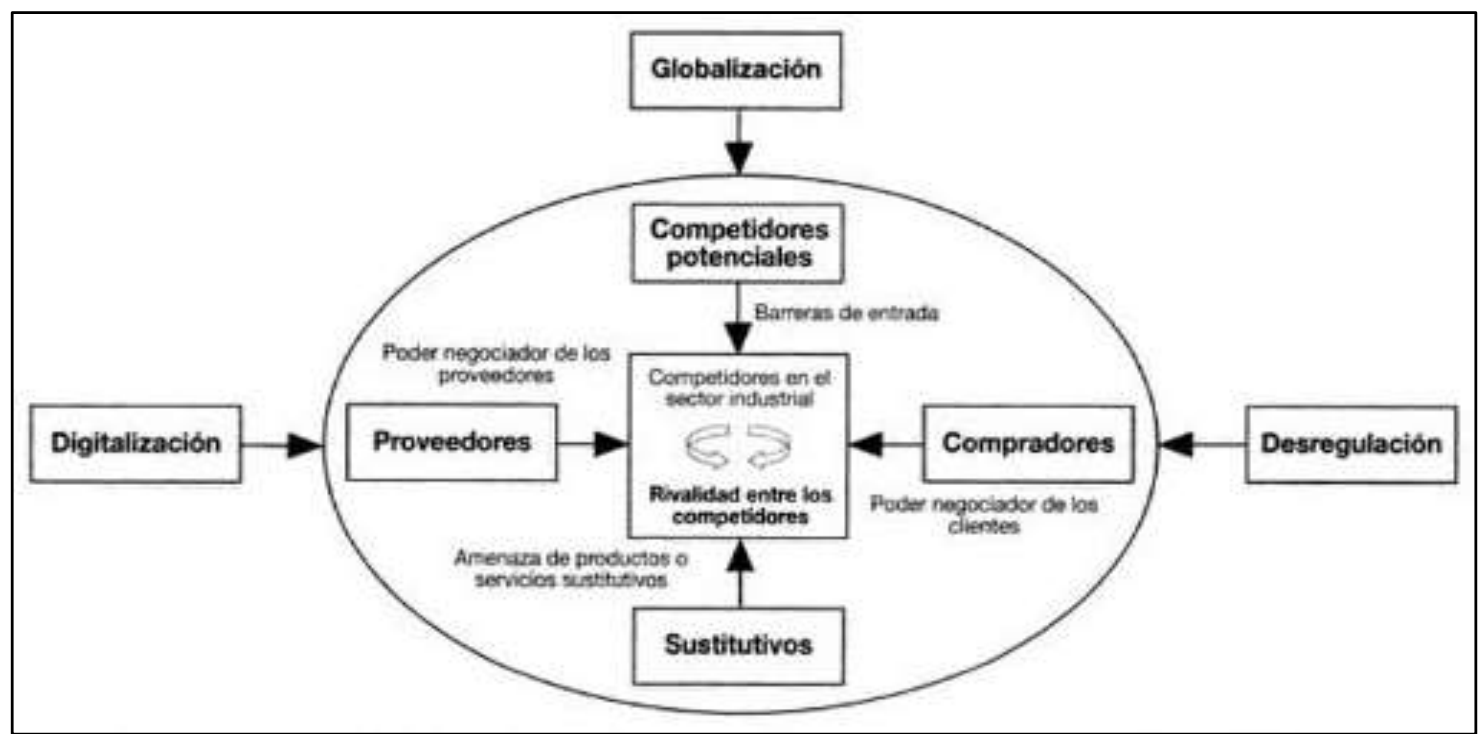

Fuente: Tomado de “Estrategias Digitales para dominar el mercado, Downes y Mui”. 2014 


\subsubsection{Digitalización.}

Downes \& Mui (2014) nos dicen: "Los ordenadores y el ancho de banda se hacen tan baratos que su precio es casi despreciable. Al bajar los precios, los competidores y el mercado fuerzan a las organizaciones a utilizar sistemas de información, redes políticas, bases de datos abiertas y entornos colaborativos." (p.95)

El reto para las asociaciones y/o cooperativas es iniciarse en la exportación de su producción. Para ello, deben invertir en tecnologías de información que les permita conocer el comportamiento de sus mercados. Hoy mismo, deberían contar con la tecnología necesaria para monitorear el precio internacional del banano orgánico a fin de poder presionar a las empresas agro exportadoras a pagar un justiprecio por la fruta que les proveen.

\subsubsection{Globalización.}

Downes \& Mui (2014) nos dicen: "Las mejoras en el transporte y las comunicaciones han hecho que muchas empresas puedan realizar operaciones a nivel global, ya que es cada vez más fácil tejer una red de socios y proveedores. Esto facilita la idea de un comercio sin fronteras. " (p.96)

Es importante desarrollar su propia marca internacional. Tener una página web ayudaría a contactar con importadores para iniciar la exportación de la fruta de manera directa. El uso de las comunicaciones a nivel global le permitirá obtener mejores precios y beneficios en favor de sus socios productores. 
Chavéz, J. (2012): "en un mundo que tiende a la globalización, cada empresa y actividad económica debe competir con sus similares ubicadas en cualquier lugar del mundo. Para sobrevivir, deben transformar las ventajas comparativas en ventajas competitivas".

\subsubsection{Desregulación.}

Downes \& Mui (2014) nos dicen: "En la mayoría de sectores existe alguna forma de regulación. El mercado libre se convierte en un mejor regulador que el gobierno. La desregulación fomenta la competencia, la innovación y el desarrollo tecnológico." (p.98).

Chavéz, J. (2012) "En el comercio internacional, la firma de acuerdos comerciales significa reducción de aranceles y prohibiciones regulatorias de exportación e importación de productos; es decir, las regulaciones existentes se corrigen para fomentar el intercambio comercial entre países. Sin embargo, los países abiertos al comercio exterior deben diseñar medidas macroeconómicas que permitan a las empresas privadas desarrollar ventajas competitivas sin restricciones, a fin de poder competir en igualdad de condiciones a nivel internacional”.

Los medios de comunicación han permitido promocionar el consumo del banano orgánico en el mundo. La firma de acuerdos comerciales abre nuevos mercados para el banano orgánico. A continuación, se muestra un cuadro resumen de los acuerdos comerciales vigentes y en negociación del Perú: 
Ilustración 3: Acuerdos Comerciales del Perú

\begin{tabular}{|c|c|c|c|c|c|}
\hline \multicolumn{6}{|c|}{ 1. Acuerdos Comerciales Vigentes } \\
\hline Organización Mundial del Comercio & $\stackrel{=}{=}$ & Estados Unidos & & Japón & \\
\hline Comunidad Andina & 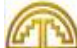 & Canadá & & Panamá & 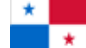 \\
\hline MERCOSUR & $\frac{\because}{\text { Mencosur }}$ & Singapur & $(\therefore)$ & Unión Europea & \\
\hline Cuba & & China & $\star$ & Costa Rica & \\
\hline Foro de Cooperación Asia Pacífico & & Asociación Europea Libre Comercio & & Venezuela & \\
\hline Chile & & Corea del Sur & & Alianza del Pacífico & तै है \\
\hline Mexico & * & Tailandia & & Honduras & \\
\hline \multicolumn{6}{|c|}{ 2. Acuerdos Comerciales por Entrar en Vigencia } \\
\hline Guatemala & (2) & Acuerdo de Asociación Transpacífico & IPP & Brasil & \\
\hline \multicolumn{6}{|c|}{ 3. Acuerdos Comerciales en Negociación } \\
\hline Programa DOHA para el Desarrollo & $\mathrm{d}$ & Acuerdo de Comercio de Servicios & TISA & El Salvador & $\theta$ \\
\hline Turquía & $C^{*}$ & India & () & & \\
\hline
\end{tabular}

Fuente: (“Acuerdos Comerciales del Perú, www.acuerdoscomerciales.gob.pe”, 2016) Elaboración Propia

Luego de realizar el análisis de las cinco fuerzas competitivas y las tres nuevas fuerzas se identificaron las siguientes oportunidades y amenazas:

\section{Oportunidades}

- Aumentar las exportaciones por el alto reconocimiento del banano orgánico peruano en el mundo.

- Seguir exportando porque el banano orgánico no tiene producto sustituto.

- Escaso número de competidores principales conduce a una rivalidad más baja y oportunidades oligopólicas.

- Exportar a nuevos mercados promovidos por la firma de acuerdos comerciales.

- Obtener ventajas competitivas para exportar banano orgánico acogiéndose a las políticas de promoción agraria implementadas por el estado.

- Aumentar las cantidades exportadas de banano orgánico, considerando la globalización de la tendencia por el consumo de productos sanos fomenta la comercialización de productos orgánicos. 


\section{Amenazas:}

- Alta dependencia para con los compradores.

- La integración hacia atrás desarrollada por los compradores.

- Posible incursión de grandes inversionistas en la siembra y comercialización del banano orgánico.

- Vulnerabilidad a los cambios climáticos: Inundaciones por el Fenómeno El Niño o Sequías por el Fenómeno La Niña.

- Políticas agrarias inestables y fluctuación del precio del dólar.

\subsection{Análisis de mercado.}

Hax y Majluf (2004) nos dicen que "es importante analizar las tendencias favorables y desfavorables que afectan al mercado identificando con claridad los factores que influyen en un potencial crecimiento o decrecimiento del mismo”. (p.56)

Para identificar el comportamiento y potencial del mercado de la industria del banano orgánico procederemos a precisar la nomenclatura arancelaria que identifica al plátano y banano orgánico:

\section{Ilustración 4: Partida Arancelaria del Banano Orgánico}

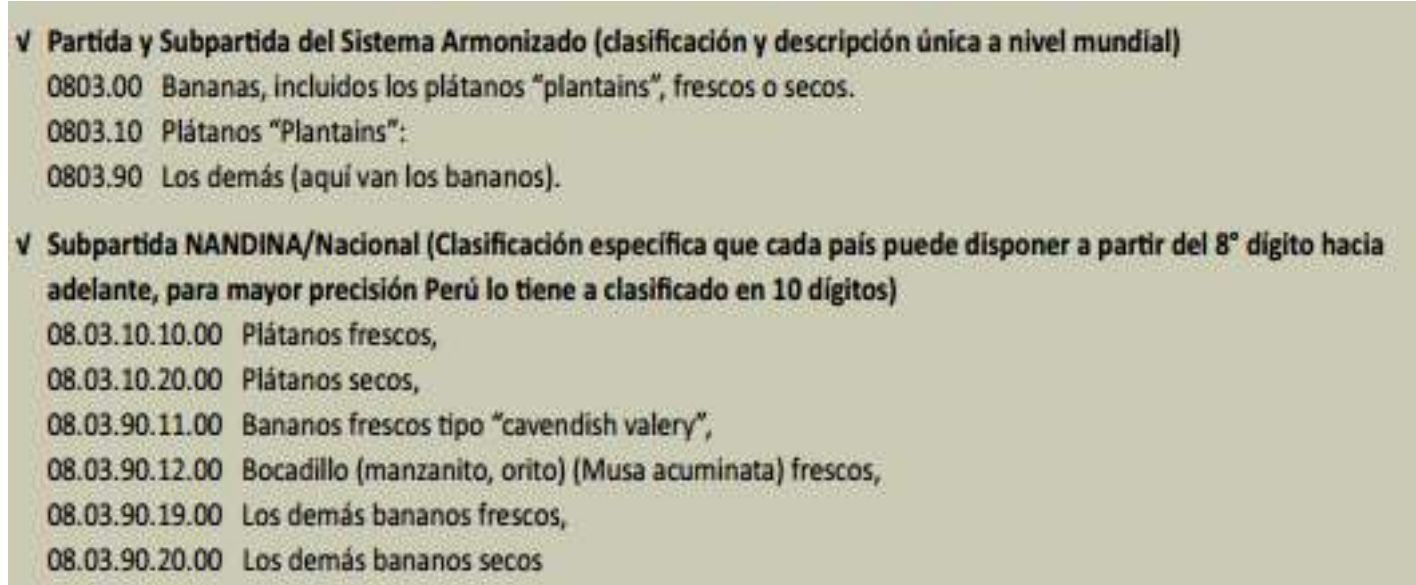

Fuente: "Exportaciones peruanas de banano orgánico, ministerio de agricultura y riego" 2016.

El banano orgánico en el mundo se comercializa bajo la partida arancelaria: 08.03.90.11.00 "Bananos frescos tipo cavendish valery". 
Dado que toda la fruta procesada por la cooperativa es comprada por un único cliente (Cooperativa Apbosmam), el análisis del mercado de la cooperativa sería muy limitado. Sin embargo, debido a que cualquier suceso o variación en el mercado internacional afectaría la demanda del banano orgánico, consideramos necesario analizar el comportamiento del mercado para todo el sector; el mismo que analizamos a continuación:

\subsubsection{Mercado potencial.}

Pelaez (2009), "El mercado potencial es aquel mercado conformado por el conjunto de clientes que no consume el producto que deseamos ofrecer, debido a que no tienen las características exigidas del segmento al que deseamos vender, porque consumen otro producto o porque le compran a la competencia, ya sea uno similar o un sustituto”. (p.25)

Trademap (2016) afirma que entre los años 2011 y 2015, en promedio, las importaciones mundiales de plátanos y bananos bordearon los catorce billones de dólares americanos con una tasa de crecimiento del 2.5\%; es decir, mantiene un aumento del consumo de esta fruta.

Es importante resaltar que en el último año China incrementó sus importaciones de plátanos y bananos de cuatrocientos millones a cerca de ochocientos millones; mientras que los más importantes países importadores en los últimos años han decrecido sus importaciones.

A continuación, se muestra dos cuadros resúmenes de los principales países importadores de plátanos a nivel mundial: 
Tabla 9: Importaciones Mundiales de Plátano y Banano

\begin{tabular}{|l|r|r|r|r|r|}
\hline \multicolumn{1}{|c|}{ País } & \multicolumn{1}{c|}{$\mathbf{2 0 1 1}$} & \multicolumn{1}{c|}{$\mathbf{2 0 1 2}$} & \multicolumn{1}{c|}{$\mathbf{2 0 1 3}$} & \multicolumn{1}{c|}{$\mathbf{2 0 1 4}$} & \multicolumn{1}{c|}{$\mathbf{2 0 1 5}$} \\
\hline MUNDO & $\mathbf{1 3 , 6 8 4 , 8 3 3}$ & $\mathbf{1 3 , 1 2 4 , 9 8 7}$ & $\mathbf{1 4 , 1 6 1 , 3 8 6}$ & $\mathbf{1 4 , 7 9 3 , 3 6 0}$ & $\mathbf{1 4 , 0 3 9 , 5 8 3}$ \\
\hline Estados Unidos de América & $2,326,782$ & $2,434,847$ & $2,528,026$ & $2,563,417$ & $2,589,477$ \\
\hline Bélgica & $1,605,629$ & $1,429,261$ & $1,594,666$ & $1,511,666$ & $1,165,119$ \\
\hline Alemania & 987,105 & 953,485 & $1,128,581$ & $1,127,009$ & 981,412 \\
\hline Rusia, Federación de & 949,499 & 921,385 & 996,388 & 957,741 & 909,850 \\
\hline Japón & 905,705 & 888,770 & 816,677 & 811,322 & 844,282 \\
\hline Reino Unido & 849,943 & 810,106 & 840,428 & 830,261 & 834,105 \\
\hline China & 401,728 & 365,858 & 335,913 & 812,611 & 772,943 \\
\hline Italia & 551,104 & 484,778 & 531,054 & 542,354 & 482,177 \\
\hline Francia & 463,478 & 475,488 & 557,444 & 510,580 & 457,762 \\
\hline Canadá & 388,633 & 391,477 & 410,809 & 427,000 & 414,893 \\
\hline Países Bajos & 244,057 & 245,841 & 237,482 & 278,567 & 331,987 \\
\hline Corea, República de & 245,522 & 249,921 & 253,202 & 321,111 & 317,116 \\
\hline Polonia & 181,396 & 168,016 & 247,039 & 277,184 & 268,312 \\
\hline Arabia Saudita & 174,279 & 202,371 & 199,916 & 218,343 & 258,266 \\
\hline Argentina & 143,694 & 153,506 & 194,631 & 216,454 & 215,730 \\
\hline Suecia & 168,845 & 180,712 & 174,752 & 193,780 & 193,646 \\
\hline España & 152,548 & 160,053 & 194,376 & 240,721 & 192,277 \\
\hline * Cifras en Miles de Dólares Americanos & & & & \\
\hline
\end{tabular}

Fuente: "Importaciones mundiales de bananos y plátanos, http://www.trademap.org, 2016".

Elaboración Propia

Tabla 10: Importaciones Mundiales de Plátano y Banano

\begin{tabular}{|l|r|r|r|r|r|}
\hline \multicolumn{1}{|c|}{ País } & \multicolumn{1}{c|}{$\mathbf{2 0 1 1}$} & \multicolumn{1}{c|}{$\mathbf{2 0 1 2}$} & \multicolumn{1}{c|}{$\mathbf{2 0 1 3}$} & \multicolumn{1}{c|}{$\mathbf{2 0 1 4}$} & \multicolumn{1}{c|}{$\mathbf{2 0 1 5}$} \\
\hline MuNDO & $\mathbf{1 9 , 6 8 6 , 3 6 7}$ & $\mathbf{1 8 , 6 9 9 , 0 0 7}$ & $\mathbf{2 1 , 6 6 0 , 0 4 9}$ & $\mathbf{2 0 , 8 5 7 , 9 5 4}$ & $\mathbf{2 0 , 9 8 9 , 2 2 5}$ \\
\hline Estados Unidos de América & $\mathbf{4 , 3 9 7 , 5 7 8}$ & $\mathbf{4 , 6 4 4 , 6 4 4}$ & $\mathbf{4 , 8 6 8 , 1 2 7}$ & $\mathbf{4 , 8 9 2 , 4 2 1}$ & $\mathbf{4 , 9 3 9 , 4 2 4}$ \\
\hline Alemania & $1,295,137$ & $1,203,272$ & $1,365,953$ & $1,397,745$ & $1,400,594$ \\
\hline Bélgica & $1,403,918$ & $1,326,839$ & $1,432,256$ & $1,375,230$ & $1,271,431$ \\
\hline Rusia, Federación de & $1,307,600$ & $1,255,608$ & $1,339,142$ & $1,274,644$ & $1,226,511$ \\
\hline Reino Unido & $1,094,028$ & $1,062,614$ & $1,169,563$ & $1,150,793$ & $1,153,194$ \\
\hline China & 818,675 & 626,039 & 514,784 & $1,127,168$ & $1,073,843$ \\
\hline Japón & $1,064,746$ & $1,086,748$ & 975,394 & 946,946 & 959,927 \\
\hline Italia & 668,400 & 637,166 & 675,030 & 709,308 & 696,575 \\
\hline Francia & 587,456 & 586,635 & 661,362 & 613,736 & 599,767 \\
\hline Canadá & 506,660 & 527,029 & 557,569 & 571,293 & 579,484 \\
\hline Países Bajos & 308,799 & 326,417 & 297,990 & 335,337 & 457,475 \\
\hline Argentina & 394,881 & 371,821 & 396,310 & 415,302 & 428,245 \\
\hline Polonia & 231,054 & 217,392 & 299,034 & 308,881 & 371,686 \\
\hline Arabia Saudita & 305,710 & 334,322 & 306,141 & 327,860 & 365,609 \\
\hline Corea, República de & 352,671 & 367,960 & 313,604 & 359,124 & 363,479 \\
\hline España & 212,203 & 225,215 & 250,053 & 299,794 & 272,644 \\
\hline * Cifras en Toneladas & & & & \\
\hline
\end{tabular}

Fuente: "Importaciones mundiales de bananos y plátanos, http://www.trademap.org, 2016".

Elaboración Propia 
De acuerdo a la FAO (2016), en los últimos 05 años, las importaciones en toneladas de plátano y banano en el mundo tuvieron un crecimiento aproximado del 7\%; el mismo que debería mantenerse teniendo en cuenta el crecimiento poblacional que tendrán las naciones en los próximos años.

Respecto a la oferta de plátano y banano en el mundo, se observa un crecimiento en la cantidad exportada del $5 \%$ en los últimos cinco años. Cabe resaltar que seis países concentran alrededor del $70 \%$ de las exportaciones del mundo: Ecuador (31\%), Guatemala (11\%), Costa Rica (10\%) Colombia (8\%), Filipinas (6\%) y Bélgica (6\%).

Perú ha registrado un incremento significativo de sus exportaciones. En los últimos cinco años, pasó de exportar 109,390 toneladas a exportar 191,198 toneladas; lo que representa un crecimiento del 75\%. Si bien, de las exportaciones totales del mundo, Perú representa el $0.9 \%$, el crecimiento de las exportaciones nos indica que el plátano y banano peruano viene teniendo buena aceptación en los mercados internacionales.

A continuación, mostramos los cuadros resúmenes de las exportaciones de plátanos y bananos en el mundo: 
Tabla 11: Exportaciones Mundiales de Plátano y Banano

\begin{tabular}{|l|r|r|r|r|r|}
\hline \multicolumn{1}{|c|}{ País } & \multicolumn{1}{c|}{$\mathbf{2 0 1 1}$} & \multicolumn{1}{c|}{$\mathbf{2 0 1 2}$} & \multicolumn{1}{c|}{$\mathbf{2 0 1 3}$} & \multicolumn{1}{c|}{$\mathbf{2 0 1 4}$} & \multicolumn{1}{c|}{$\mathbf{2 0 1 5}$} \\
\hline Mundo & $\mathbf{1 9 , 5 6 0 , 1 4 5}$ & $\mathbf{1 9 , 7 3 3 , 9 0 9}$ & $\mathbf{2 1 , 0 3 6 , 2 3 2}$ & $\mathbf{2 7 , 1 8 9 , 0 0 4}$ & $\mathbf{2 0 , 5 4 0 , 4 4 6}$ \\
\hline Ecuador & $5,778,170$ & $5,205,352$ & $5,460,838$ & $5,977,281$ & $6,287,605$ \\
\hline Guatemala & $1,560,303$ & $2,033,236$ & $2,097,296$ & $2,246,590$ & $2,333,894$ \\
\hline Costa Rica & $1,919,235$ & $1,885,910$ & $1,930,756$ & $2,173,028$ & $1,978,185$ \\
\hline Colombia & $1,915,255$ & $1,834,936$ & $1,643,108$ & $1,799,666$ & $1,684,148$ \\
\hline Filipinas & $2,046,771$ & $2,648,369$ & $3,267,968$ & $7,927,742$ & $1,223,133$ \\
\hline Bélgica & $1,297,171$ & $1,261,038$ & $1,381,200$ & $1,318,975$ & $1,150,981$ \\
\hline Honduras & 516,555 & 901,361 & 895,381 & 635,956 & 689,731 \\
\hline Estados Unidos de América & 516,384 & 530,675 & 563,037 & 578,015 & 586,432 \\
\hline México & 179,838 & 173,919 & 361,823 & 407,387 & 440,703 \\
\hline Alemania & 372,532 & 278,571 & 330,266 & 378,908 & 383,144 \\
\hline República Dominicana & 359,433 & 289,224 & 354,872 & 573,065 & 371,598 \\
\hline Côte d'Ivoire & 320,101 & 339,357 & 210,614 & 326,126 & 323,952 \\
\hline Países Bajos & 131,378 & 138,784 & 169,913 & 253,034 & 315,159 \\
\hline Francia & 254,542 & 266,506 & 283,216 & 306,879 & 287,200 \\
\hline Camerún & 237,275 & 231,802 & 261,457 & 265,276 & 282,515 \\
\hline Panamá & 266,911 & 253,455 & 261,896 & 265,679 & 275,273 \\
\hline Perú & $\mathbf{1 0 9 , 3 9 0}$ & $\mathbf{1 2 1 , 6 7 7}$ & $\mathbf{1 2 4 , 1 4 8}$ & $\mathbf{1 5 9 , 5 8 8}$ & $\mathbf{1 9 1 , 1 9 8}$ \\
\hline * Cifras en Toneladas & \multicolumn{3}{|l}{} & & \\
\hline
\end{tabular}

Fuente: "Importaciones mundiales de bananos y plátanos, http://www.trademap.org, 2016".

Elaboración Propia

Tabla 12: Exportaciones Mundiales de Plátano y Banano

\begin{tabular}{|l|r|r|r|r|r|}
\hline \multicolumn{1}{|c|}{ País } & \multicolumn{1}{c|}{$\mathbf{2 0 1 1}$} & \multicolumn{1}{c|}{$\mathbf{2 0 1 2}$} & \multicolumn{1}{c|}{$\mathbf{2 0 1 3}$} & \multicolumn{1}{c|}{$\mathbf{2 0 1 4}$} & \multicolumn{1}{c|}{$\mathbf{2 0 1 5}$} \\
\hline MUNDo & $\mathbf{9 , 1 6 2 , 8 7 3}$ & $\mathbf{8 , 9 3 7 , 3 1 7}$ & $\mathbf{1 0 , 0 4 5 , 5 6 6}$ & $\mathbf{1 1 , 0 4 0 , 9 1 7}$ & $\mathbf{9 , 9 5 6 , 0 1 0}$ \\
\hline Ecuador & $2,246,350$ & $2,081,987$ & $2,332,207$ & $2,590,205$ & $2,820,053$ \\
\hline Bélgica & $1,316,865$ & $1,284,123$ & $1,418,681$ & $1,335,551$ & 946,780 \\
\hline Costa Rica & $\mathbf{7 2 2 , 1 2 9}$ & 706,741 & 780,183 & 907,683 & 835,264 \\
\hline Colombia & 815,318 & 822,010 & 763,859 & 835,546 & 802,628 \\
\hline Guatemala & 476,321 & 618,314 & 651,954 & 721,443 & 763,620 \\
\hline Estados Unidos de América & 437,335 & 436,302 & 458,087 & 470,247 & 442,611 \\
\hline Filipinas & 471,152 & 647,880 & 963,412 & $1,137,316$ & 439,902 \\
\hline Alemania & 395,790 & 280,731 & 344,037 & 391,873 & 344,824 \\
\hline Países Bajos & 145,034 & 128,373 & 165,010 & 249,783 & 272,548 \\
\hline Honduras & 193,955 & 342,148 & 332,938 & 221,617 & 269,762 \\
\hline República Dominicana & 153,885 & 138,157 & 167,932 & 331,573 & 229,378 \\
\hline Francia & 190,392 & 200,135 & 216,868 & 246,041 & 191,892 \\
\hline México & 76,383 & 69,308 & 161,368 & 179,693 & 185,872 \\
\hline Perú & $\mathbf{7 1 , 1 5 5}$ & 83,615 & 89,045 & 119,416 & 145,287 \\
\hline *Cifras en Miles de Dólares Americanos & \multicolumn{5}{|l}{} \\
\hline
\end{tabular}

Fuente: "Importaciones mundiales de bananos y plátanos, http://www.trademap.org, 2016".

Elaboración Propia 
El cultivo del plátano y banano es considerado semipermanente puesto que todo el año se cultiva con incrementos de producción de hasta un 20\% durante los meses de verano en el hemisferio sur. Esta sobre producción coincide con el invierno de los países del hemisferio norte, países que son los principales mercados para la exportación.

Los precios de exportación del plátano convencional suben cuando disminuye la oferta en el mercado mundial, normalmente por causas climáticas (huracanes y tormentas tropicales en el Caribe, lluvias torrenciales en Ecuador) o sociales (conflictos armados en África). Pero también pueden bajar, sobre todo cuando empieza la temporada de calor en el hemisferio norte y la demanda de frutas con alto contenido calórico (como el banano) es desplazada por otras frutas como la manzana, que son producidas en Europa. Sin embargo, en promedio el precio se ha mantenido casi constante en los últimos años.

\subsubsection{Mercado disponible.}

Kotler (2010) nos dice: "el mercado disponible es el conjunto de consumidores que tienen el deseo, renta y el acceso (que no exista alguna restricción legal o alguna restricción física) que concuerdan a una determinada oferta de mercado." (p.236)

Para la industria en análisis, el mercado disponible está conformado por todas las importaciones y exportaciones de banano orgánico realizadas por todos los países a nivel mundial.

\subsubsection{Análisis de la oferta de banano orgánico.}

En cuanto a la oferta de banano orgánico, existen dos zonas diferenciadas a nivel de producción mundial: 
a. Zona dólar.

Integrada por países centro y sudamericanos, con una producción muy eficiente, en grandes explotaciones, con bajos costos de producción.

b. Los países ACP (África, Caribe y Pacífico) y de Europa.

Con pequeñas explotaciones, métodos de explotación tradicionales y altos costos de producción, sistemas que perduran gracias al mecanismo de protección comercial establecido por diferentes países europeos que les brindan un trato preferencial

De acuerdo a Fruitrop (2012), el banano orgánico debe ser cultivado en condiciones especiales, y esto es posible solo en unas pocas regiones del mundo; a diferencia del banano convencional, el cual puede crecer relativamente fácil en muchas áreas tropicales. El banano convencional, además de ser abonado con urea y sulfatos; requiere de fungicidas y pesticidas para el control de plagas y requiere de mucha agua, la cual se consigue fácilmente en los trópicos.

Sin embargo, para los cultivos de banano orgánico, es imposible hacerlo en los trópicos debido a que el hongo Black Sigatoka crece en esas condiciones y no se puede combatir de manera orgánica. Es necesario sembrar banano orgánico en áreas con menos humedad y lluvias, pero con suficiente agua de los ríos o de fuentes subterráneas. 
En la actualidad no se dispone de recursos estadísticos específicos sobre el mercado de banano orgánico en el mundo, se ha investigado la oferta y demanda del banano orgánico mundial basado en los análisis provenientes de fuentes secundarias como son: programa de apoyo presupuestario a la política de promoción de las exportaciones de productos ecológicos en el marco del Convenio entre el estado peruano y la unión europea, FAO, trademap, fruitrop, ONU, ministerio de agricultura y riego, promperu.

Los principales países exportadores de banano orgánico en el mundo son: República Dominicana, Ecuador, Colombia y Perú.

\section{Ilustración 5: Principales Países Exportadores de Banano}

\section{Orgánico}

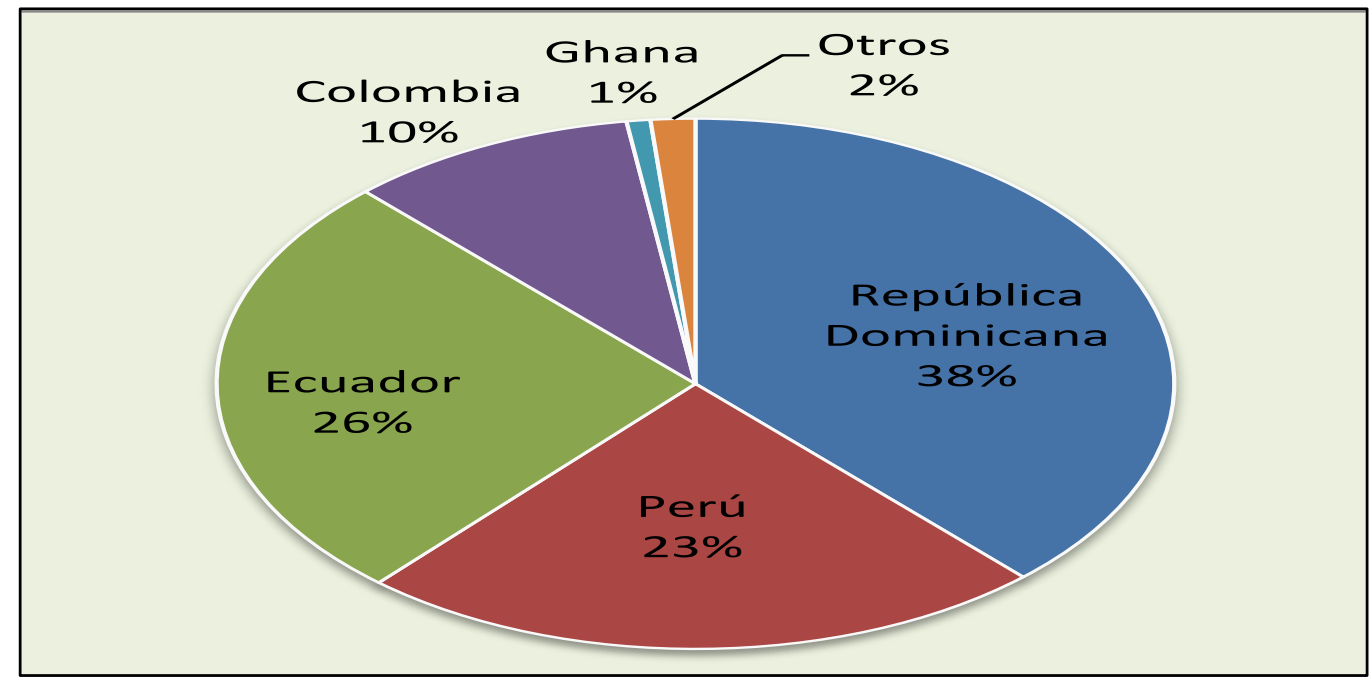

Fuente y elaboración: Tomado de "Análisis del Mercado del Banano Orgánico, www.fruitrop.com, 2012"

El primer exportador de banano orgánico a nivel mundial fue República Dominicana; quien inició la reconversión de sus cultivos de banano convencional a banano orgánico en 1995 . 
Sin embargo, el atractivo del mercado del banano orgánico originó que países con ventajas competitivas favorables para la siembra de banano orgánico, incursionasen en ese mercado. Fue así, que países como Ecuador, Perú, Colombia y Ghana han incursionado como productores en el mercado del banano orgánico.

\section{Ilustración 6: Evolución de Exportaciones de Banano Orgánico}

1999-2010

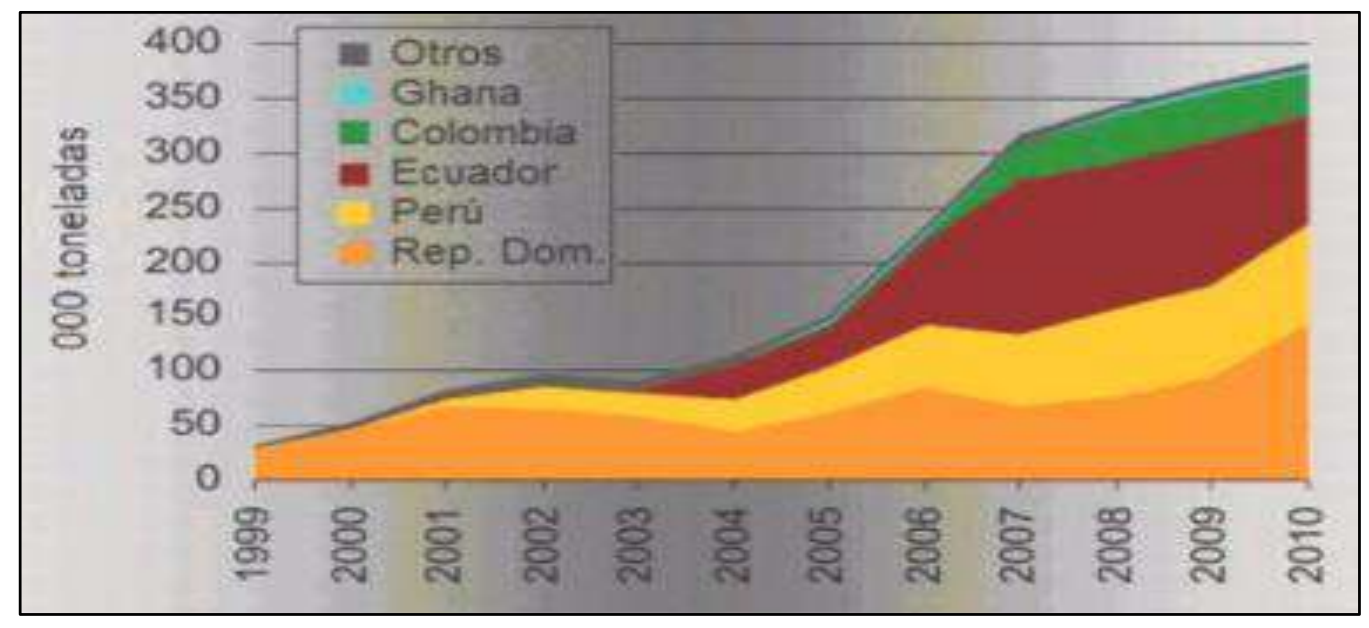

Fuente y elaboración: Tomado de "Análisis del Mercado del Banano Orgánico, www.fruitrop.com”, 2012.

Como se observa en el cuadro anterior, las exportaciones se incrementaron a partir del año 2005 con la incorporación de nuevas hectáreas sembradas de banano orgánico llegando a alcanzar en el 2010 un mercado aproximado de 304 millones de dólares americanos. El mercado en el 2015 se estima en 580 millones de dólares americanos.

De acuerdo a la FAO (2011), República Dominicana es el principal proveedor de banano orgánico en Estados Unidos y la Unión Europa; donde abastece cerca del 50\% del banano orgánico 
consumido por la Unión Europea, repartiéndose por igual el resto del mercado de banano orgánico - casi por igual - entre Colombia, Ecuador y Perú. Sus exportaciones de banano orgánico a Europa se han duplicado entre 2010 y 2013, alcanzando los 140 millones de dólares. Su posición geográfica le permite llegar a ambos mercados a bajo costo.

Sudamérica ha incrementado su producción de banano orgánico en los últimos años. Perú es el país que ha obtenido un producto de mejor calidad, porque ha mejorado sus procesos de siembra y cosecha, cuenta con áreas de cultivo con climas favorables para obtener rendimientos óptimos de cosecha y ha incursionado en nuevos mercados con la firma de acuerdos comerciales promovidos por el estado. Esto ha permitido garantizar un abastecimiento de fruta durante todo el año a los mercados de Europa y Estados Unidos.

A inicios del 2000, el banano orgánico ecuatoriano sufrió un daño en su imagen por un escándalo de certificación orgánica que culminó en la suspensión de la comercialización de su producto en Europa y Estados unidos. El plazo de la suspensión ha pasado y el banano orgánico ecuatoriano viene posicionándose bastante bien.

El banano orgánico colombiano, se exporta principalmente a Estados Unidos. El problema político interno de Colombia (Las guerrillas colombianas y el narcotráfico) han impedido el desarrollo de nuevas áreas de cultivo; razón por la cual los productores colombianos no garantizan un abastecimiento constante de fruta todo el año. 
2.2.2.2. Análisis de la demanda de banano orgánico.

En cuanto a la demanda de banano orgánico, este producto se consume en todo el mundo. Sin embargo, existen dos mercados diferenciados que son quienes lideran el consumo de banano orgánico: el mercado de Estados Unidos y el mercado Unión Europea.

a. mercado de estados unidos

En este mercado el producto se comercializa bajo la partida arancelaria 08.03.90.00.25 "Bananos Orgánicos Certificados". El producto goza de beneficios arancelarios por el Tratado de Libre Comercio firmado con Estados Unidos.

SIICEX (2016) señala el marco normativo establecido para poder exportar al mercado de los Estados Unidos:

- Agencia de Protección Ambiental (EPA) que regula la ley federal de insecticidas, fungicidas, y rodenticidas (FIFRA)

- Food and Drug Administration (FDA) que regula la ley federal de alimentos, medicamentos y cosméticos ACT.

- Departamento de Agricultura de los Estados (USDA) que regula la Ley agrícola de 2014.

- Food Safety and Inspection Service (FSIS) del USDA que regula la ley COOL del 2008

- Contar con la certificación USDA ORGANIC (Certificación orgánica para productos agrícolas, pecuarios y de recolección silvestre) 
De acuerdo a la OCEX Los Ángeles (2016), en el mercado de Estados Unidos la demanda de banano orgánico ha crecido considerablemente debido al cambio de tendencia y hábitos de consumo en los consumidores, destacando el interés por adquirir productos orgánicos y con altos beneficios a la salud.

Según la Asociación de Comercio Orgánico (2016) más de la mitad de los hogares en Estados Unidos compran productos orgánicos y estiman que en el 2015, el mercado del banano orgánico en Estados Unidos alcanzó los 165 millones de dólares americanos; evidenciando un crecimiento del 35\% respecto a la totalidad de importaciones de bananos orgánicos del 2014 que sumaron US\$ 122 millones.

Larrea (2013), afirma que la comercialización de productos orgánicos en Estados Unidos, se realiza a través de supermercados, que vienen introduciendo sus propias marcas. Asimismo, siguen tratando de disminuir su margen de rentabilidad para reducir el precio del producto.

b. mercado de la unión europea

De acuerdo a la Agencia Bio (2015) el 62\% de los europeos consume, al menos ocasionalmente, productos orgánicos una vez al mes. 
Ilustración 7: Comportamiento del Consumidor Europeo

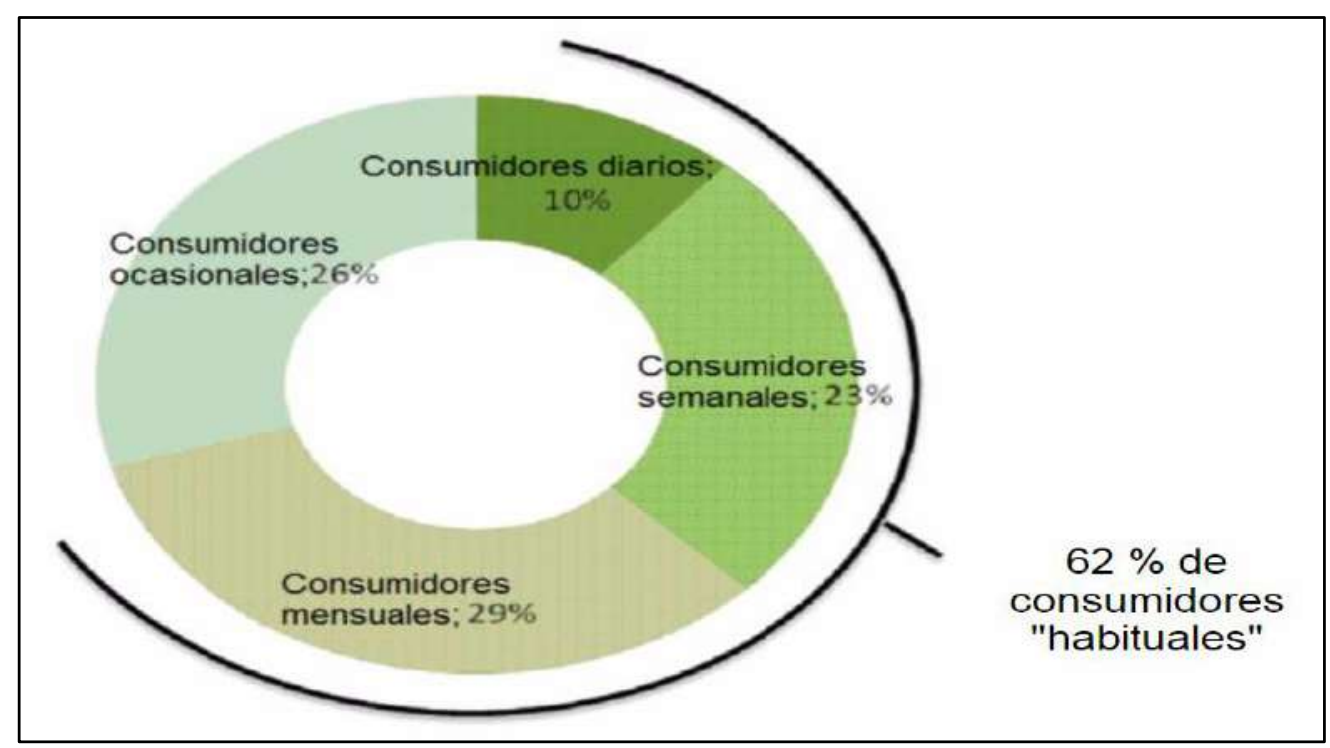

Fuente y Elaboración: Tomado de “Análisis del Comportamiento del Consumidor Europeo, Agencia Bio, 2015"

Los consumidores de productos orgánicos los prefieren por: los beneficios en la su salud, por el cuidado medioambiental, por la calidad y el sabor del producto. Sin embargo, su consumo también se ha visto influenciado por las campañas de concientización en favor del medio ambiente y el temor a la escasez de alimentos a nivel mundial. La principal barrera para el consumo de fruta orgánica sigue siendo el Precio.

En los países de la Unión Europea se han identificado las siguientes tendencias del consumidor:

- Tendencia Saludable: los consumidores son más conscientes de lo que comen.

- Superfoods: Los consumidores prefieren alimentos sanos que proporcionen energía sostenible y rápida. 
- Paleofood: Los consumidores prefieren los productos naturales a los industrializados/procesados.

- Alimentos sin gluten y libres de lactosa, azúcar y grasas.

- Comodidad: Los consumidores cada vez tienen menos tiempo para cocinar y prefieren comprar productos naturales.

- Ecológico: Los consumidores buscan productos certificados que les garantice la inocuidad del producto a consumir.

- Medio ambiente y condiciones sociales: Los consumidores se preocupan más por el cuidado al medioambiente y por el desarrollo social económico de los productores.

En resumen, la demanda de banano orgánico en los dos mercados más grandes mantiene una constante de crecimiento que les garantiza a los productores y exportadores peruanos un consumo de su producto en el tiempo.

\subsubsection{Mercado efectivo.}

Kotler (2010) nos dice "el mercado efectivo es la porción de mercado disponible hacia el cual la empresa desea orientarse y podrían acceder al producto.” (p.237)

Para la industria en análisis, el mercado efectivo está conformado por todas las exportaciones de banano orgánico realizadas por el Perú a nivel mundial. Se estima el mercado efectivo en 151 millones de dólares americanos.

De acuerdo al ministerio de agricultura y riego (2016), los valles de Piura y Tumbes son los principales productores del banano orgánico exportado porque cuentan con importantes ventajas para su producción: 
- La existencia de un ecosistema (clima, temperatura, suelo y agua) favorable, que propicia una baja incidencia del hongo de la Sigatoka Negra; enfermedad cuyo control demanda de grandes dosis de fungicidas químicos. Se estima que en Ecuador y Colombia dicho costo representa el $12 \%$ de los costos de producción.

- Disponibilidad de guano de isla, insumo orgánico necesario para la fertilización de los suelos. Pese a que el actual precio de mercado, de 51.20 soles/saco (precio percibido por los productores como alto), es por lo menos $50 \%$ menor que en otros países como Ecuador y Colombia.

- Bajos costos de reconversión de la producción convencional a la orgánica. Ello debido a que la tecnología convencional es poco intensiva en el uso de insumos químicos, pues la producción de banano está a cargo de pequeños productores. En los últimos 4 años más del $80 \%$ de ellos se han convertido a la producción orgánica.

- Disponibilidad de agua de riego durante todo el año. Los valles cuentan con agua proveniente de los Reservorio de Poechos y San Lorenzo.

- Cercanía al puerto de Paita, que facilita la exportación del producto a un menor costo. 
Tabla 13: Exportaciones Peruanas de banano Orgánico

\begin{tabular}{|c|l|c|r|}
\hline MIERCADO & \multicolumn{1}{|c|}{ PAIS } & PARTICIPACION & \multicolumn{1}{c|}{ US\$ } \\
\hline \multirow{3}{*}{ Norteamérica } & Estados Unidos & $30 \%$ & $45,486,384$ \\
\cline { 2 - 4 } & Canadá & $1 \%$ & $1,516,213$ \\
\hline \multirow{4}{*}{ Unión Europea } & Holanda & $34 \%$ & $51,551,236$ \\
\cline { 2 - 4 } & Alemania & $14 \%$ & $21,226,979$ \\
\cline { 2 - 4 } & Bélgica & $9 \%$ & $13,645,915$ \\
\cline { 2 - 4 } & Finlandia & $4 \%$ & $6,064,851$ \\
\cline { 2 - 4 } & Reino Unido & $1 \%$ & $1,516,213$ \\
\hline \multirow{2}{*}{ Asia } & República de Korea & $4 \%$ & $6,064,851$ \\
\cline { 2 - 4 } & Japón & $\mathbf{1 5 1 , 6 2 1 , 2 8 1}$ \\
\hline
\end{tabular}

Fuente: “Exportaciones Peruanas de Banano Orgánico, Agrodataperu, 2016. Elaboración Propia

En el 2016, las exportaciones peruanas de banano orgánico se realizaron a 18 países alcanzando los 151 millones de dólares. Holanda es el principal destino con 51 millones de dólares (34\% del total) y la principal empresa peruana exportadora es la Cooperativa Agraria APPBOSA; quién exportó 13.8 millones de dólares americanos.

\section{Ilustración 8: Principales Empresas Exportadoras de Banano Orgánico}

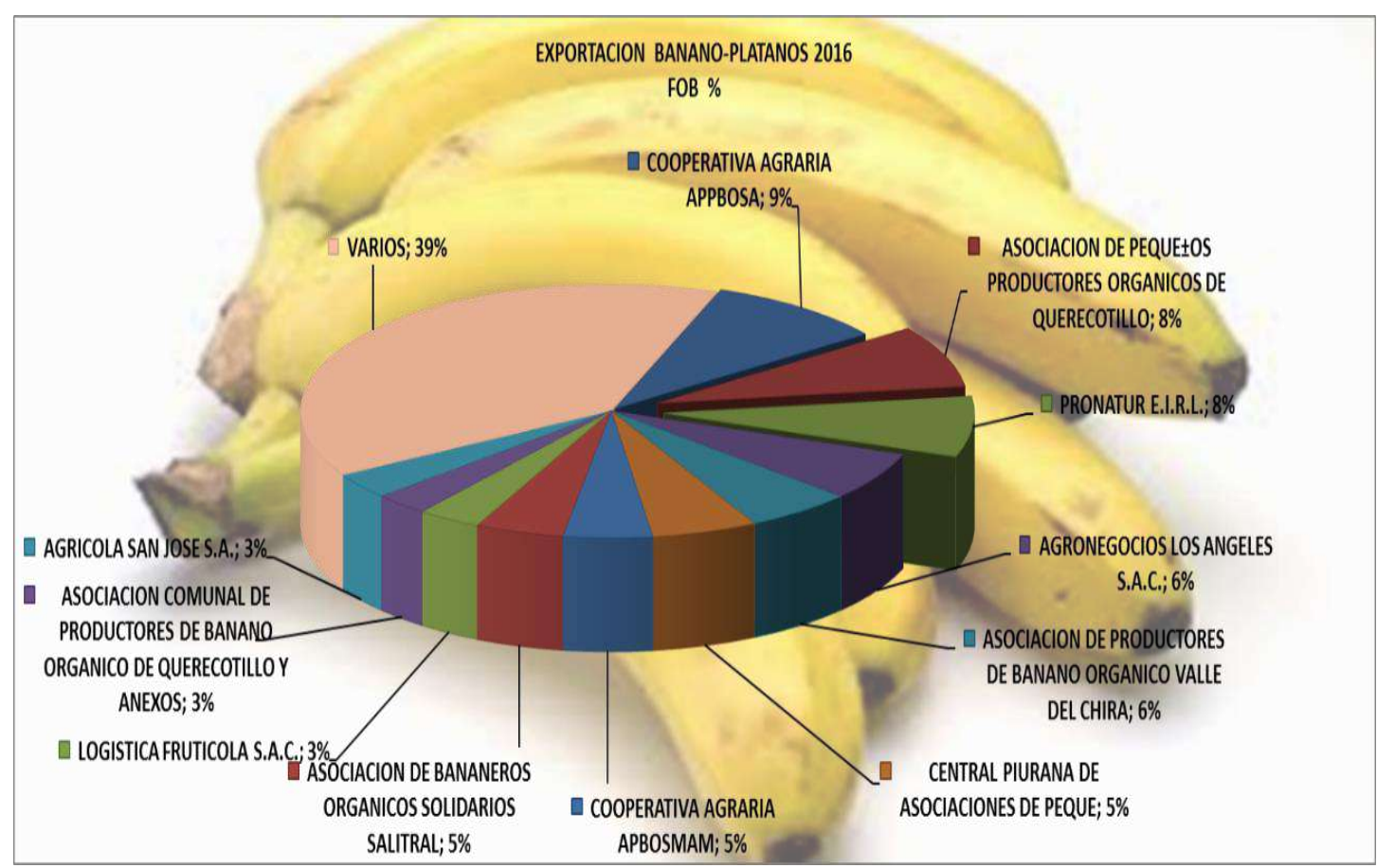

Fuente: "Principales Empresas Peruanas Exportadoras de Banano Orgánico, www.agrodataperu.com, 2016. Elaboración Propia. 


\section{Ilustración 9: Principales Exportadoras de Banano Orgánico Peruano}

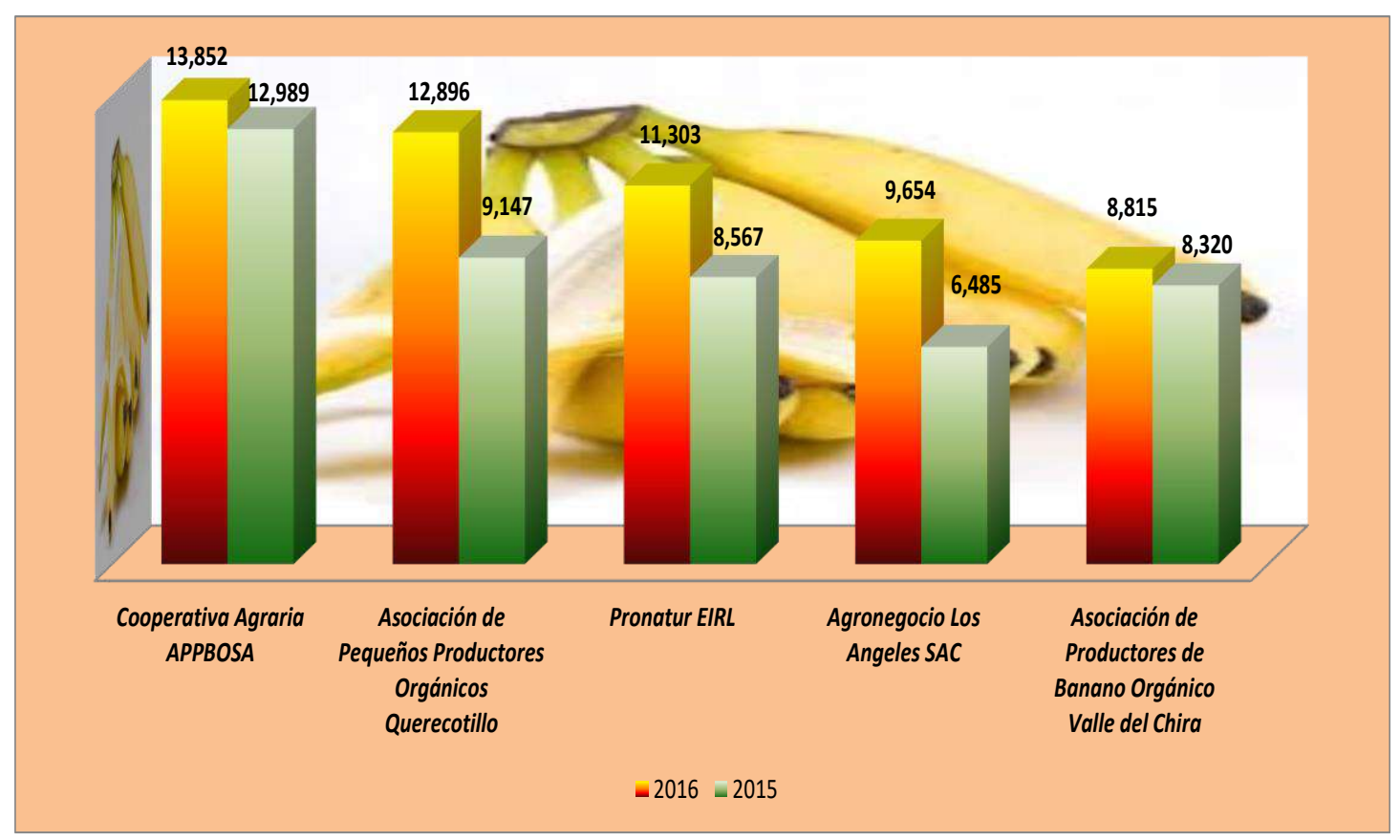

Fuente: "Principales Empresas Peruanas Exportadoras de Banano Orgánico, www.agrodataperu.com, 2016. Elaboración Propia.

Tabla 14: Exportaciones Peruanas en Miles US\$ de Banano Orgánico 2012-2016

\begin{tabular}{|l|r|r|r|r|r|r|r|r|r|r|}
\hline \multirow{4}{*}{ Mes } & \multicolumn{2}{|c|}{$\mathbf{2 0 1 6}$} & \multicolumn{2}{c|}{$\mathbf{2 0 1 5}$} & \multicolumn{2}{c|}{$\mathbf{2 0 1 4}$} & \multicolumn{2}{c|}{$\mathbf{2 0 1 3}$} & \multicolumn{2}{c|}{$\mathbf{2 0 1 2}$} \\
\cline { 2 - 12 } & $\begin{array}{r}\text { Precio FOB } \\
\text { (miles us\$) }\end{array}$ & $\begin{array}{r}\text { Precio } \\
\text { (prom.) }\end{array}$ & $\begin{array}{r}\text { Precio FOB } \\
\text { (miles us\$) }\end{array}$ & $\begin{array}{r}\text { Precio } \\
\text { (prom.) }\end{array}$ & $\begin{array}{r}\text { Precio FOB } \\
\text { (miles us\$) }\end{array}$ & $\begin{array}{c}\text { Precio } \\
\text { (prom.) }\end{array}$ & $\begin{array}{r}\text { Precio FOB } \\
\text { (miles us\$) }\end{array}$ & $\begin{array}{c}\text { Precio } \\
\text { (prom.) }\end{array}$ & $\begin{array}{r}\text { Precio FOB } \\
\text { (miles us\$) }\end{array}$ & $\begin{array}{c}\text { Precio } \\
\text { (prom.) }\end{array}$ \\
\hline Enero & 13,711 & 0.76 & 11,739 & 0.76 & 9,411 & 0.73 & 8,131 & 0.70 & 6,841 & 0.66 \\
\hline Febrero & 12,312 & 0.75 & 10,857 & 0.76 & 7,805 & 0.74 & 7,120 & 0.72 & 6,217 & 0.67 \\
\hline Marzo & 14,731 & 0.75 & 13,565 & 0.76 & 9,081 & 0.73 & 7,012 & 0.72 & 5,819 & 0.68 \\
\hline Abril & 13,664 & 0.75 & 12,327 & 0.76 & 10,426 & 0.74 & 9,275 & 0.73 & 5,593 & 0.68 \\
\hline Mayo & 14,126 & 0.74 & 12,183 & 0.76 & 9,778 & 0.75 & 7,045 & 0.72 & 7,901 & 0.69 \\
\hline Junio & 12,177 & 0.75 & 10,784 & 0.76 & 9,824 & 0.75 & 7,055 & 0.71 & 7,076 & 0.69 \\
\hline Julio & 11,385 & 0.75 & 10,879 & 0.76 & 9,740 & 0.75 & 7,794 & 0.71 & 8,237 & 0.7 \\
\hline Agosto & 12,722 & 0.75 & 11,086 & 0.76 & 9,898 & 0.76 & 6,425 & 0.72 & 6,570 & 0.69 \\
\hline Septiembre & 12,119 & 0.75 & 14,126 & 0.76 & 10,395 & 0.76 & 7,628 & 0.71 & 6,215 & 0.69 \\
\hline Octubre & 11,254 & 0.75 & 12,098 & 0.76 & 9,545 & 0.75 & 6,776 & 0.72 & 7,728 & 0.69 \\
\hline Noviembre & 11,599 & 0.76 & 11,442 & 0.76 & 10,888 & 0.75 & 6,533 & 0.72 & 5,783 & 0.70 \\
\hline Diciembre & 11,817 & 0.76 & 13,390 & 0.76 & 10,972 & 0.75 & 5,765 & 0.73 & 6,892 & 0.70 \\
\hline TOTALES & $\mathbf{1 5 1 , 6 1 7}$ & & $\mathbf{1 4 4 , 4 7 6}$ & & $\mathbf{1 1 7 , 7 6 3}$ & & $\mathbf{8 6 , 5 5 9}$ & & $\mathbf{8 0 , 8 7 2}$ & \\
\hline Promedio & 12,635 & 0.75 & 12,040 & 0.76 & 9,814 & 0.75 & 7,213 & 0.72 & 6,739 & 0.69 \\
\hline Crecimiento & $\mathbf{5 \%}$ & $\mathbf{- 1 \%}$ & $\mathbf{2 2 \%}$ & $\mathbf{1 \%}$ & $\mathbf{1 3 \%}$ & $\mathbf{4 \%}$ & $\mathbf{7 \%}$ & $\mathbf{4 \%}$ & $\mathbf{7 \%}$ & $\mathbf{7 \%}$ \\
\hline
\end{tabular}

Fuente: "Exportaciones Peruanas de Banano Orgánico, www.agrodataperu.com, 2017

Elaboración Propia. 
Tabla 15: Exportaciones Peruanas en Kg. de Banano Orgánico 2012-2016

\begin{tabular}{|c|c|c|c|c|c|}
\hline & 2016 & 2015 & 2014 & 2013 & 2012 \\
\hline Mes & $\begin{array}{c}\text { Kilos } \\
\text { (mil) }\end{array}$ & $\begin{array}{c}\text { Kilos } \\
\text { (mil) }\end{array}$ & $\begin{array}{c}\text { Kilos } \\
\text { (mil) }\end{array}$ & $\begin{array}{c}\text { Kilos } \\
\text { (mil) }\end{array}$ & $\begin{array}{c}\text { Kilos } \\
\text { (mil) }\end{array}$ \\
\hline Enero & 18,007 & 15,366 & 12,895 & 11,537 & 10,340 \\
\hline Febrero & 16,318 & 14,209 & 10,614 & 9,941 & 9,268 \\
\hline Marzo & 19,562 & 17,785 & 12,374 & 9,800 & 8,589 \\
\hline Abril & 18,123 & 16,193 & 14,004 & 12,755 & 8,192 \\
\hline Mayo & 19,019 & 16,076 & 13,088 & 9,833 & 11,528 \\
\hline Junio & 16,186 & 14,282 & 13,071 & 9,868 & 10,311 \\
\hline Julio & 15,156 & 14,355 & 12,946 & 10,910 & 11,725 \\
\hline Agosto & 16,881 & 14,589 & 13,076 & 8,906 & 9,455 \\
\hline Septiembre & 16,103 & 18,682 & 13,698 & 10,747 & 9,003 \\
\hline Octubre & 15,010 & 15,998 & 12,705 & 9,428 & 11,184 \\
\hline Noviembre & 15,327 & 15,147 & 14,456 & 9,042 & 8,281 \\
\hline Diciembre & 15,601 & 17,658 & 14,549 & 7,889 & 9,895 \\
\hline TOTALES & 201,293 & 190,340 & 157,476 & 120,656 & 117,771 \\
\hline Promedio & 16,774 & 15,862 & 13,123 & 10,055 & 9,814 \\
\hline Crecimiento & $6 \%$ & $20 \%$ & $31 \%$ & $2 \%$ & $2 \%$ \\
\hline
\end{tabular}

Fuente: “Exportaciones Peruanas de Banano Orgánico, www.agrodataperu.com, 2017

Elaboración Propia.

Agrodataperu (2016) nos muestra que, en los últimos cinco años, la cantidad exportada de banano orgánico peruano se incrementó en $70 \%$ (Perú pasó de exportar 117,771 toneladas en el 2012 a 201,293 toneladas en el 2016). Las exportaciones en dólares crecieron $87 \%$ en el mismo período de tiempo porque se registró un aumento del precio de 0.69 a 0.75 dólares/kilogramo. (Las exportaciones peruanas en el 2012 fueron de 80.8 millones de dólares mientras que en el 2016 alcanzaron los 151.6 millones de dólares). Este crecimiento sostenido de las exportaciones peruanas de banano orgánico es resultado de la altísima calidad del producto, del aumento del número de hectáreas sembradas y del aumento del consumo de productos orgánicos en los países del hemisferio norte. 
Actualmente, el Perú está negociando un acuerdo comercial con la Unión Europea que permitiría reducir aranceles y abrir todos los mercados de los países que la conforman. Esto mejorará los ingresos de los pequeños productores y consolidar al Perú como uno de los mejores proveedores de banano orgánico del mundo.

Agrodata (2017) informó que las exportaciones de banano orgánico en el primer trimestre se redujeron en $9 \%$ respecto al año anterior. (En el primer trimestre del 2017 se exportaron 49.05 millones de kilos mientras que en el 2016 se exportaron 53.88 millones de kilos). El precio del banano orgánico se mantiene en 0.75 dólares por kilogramo y, se proyecta que las exportaciones de banano orgánico alcancen los 145.6 millones de dólares.

\subsubsection{Mercado objetivo.}

Kotler y Armstrong (2012) nos dicen: “...el mercado objetivo consiste en un conjunto de compradores que tienen necesidades y/o características comunes a los que la empresa u organización decide servir" (p.238)

Lamb, Hair y McDaniel (2011) afirma que: “...el mercado objetivo es un grupo definido que se considera comprará el producto de una empresa con mayor probabilidad.” (p.42)

La American Marketing Asociation (2012), define “...el mercado objetivo (Target Market), como el segmento particular de una población total en el que el detallista enfoca su pericia de comercialización para satisfacer ese sub mercado, con la finalidad de lograr una determinada utilidad". 
La Cooperativa Agraria Alto Grande Santa Sofía le vende la fruta que procesa a la Cooperativa Agraria APBOSMAM, empresa agroexportadora de la Región Piura que se dedica a la producción y exportación de banano orgánico a diferentes empresas:

- Italia

- Alemania

- Estados Unidos

- Holanda
: Organic Sur, Brio Spa

: Port-International

: Tropic Trade, Oké USA

: Agrofair.

Apbosmam se inicia como una asociación en el año 2006 cuya finalidad inicial era la siembra de banano orgánico. Como asociación, en el año 2007 consiguen fondos de INCAGRO del ministerio de agricultura y riego con la finalidad de conseguir las certificaciones: orgánica y comercio justo; objetivo que logran alcanzar en el 2008. En el año 2009, participa del proyecto REPEBAN y consigue los fondos necesarios para la construcción de su primera empacadora fija y en ese mismo año consiguen el apoyo de SwissContac y CEDEPAS norte quienes le obsequian dos líneas de empaque completas. Con el centro de empaque completo, en el 2010 consiguen la certificación Global Gap y en el 2011 realizan exportaciones directas al mercado italiano de 81 contenedores.

Entre los años 2012 y 2013 la asociación pasa a ser cooperativa y como cooperativa consiguen fondos del programa AGROIDEAS con el cual construyen seis nuevos centros de empaque ampliando su capacidad exportadora. A continuación, se muestra la evolución de las exportaciones de Apbosmam: 
Tabla 16: Evolución de las Exportaciones en US\$ de APBOSMAM

\begin{tabular}{|l|c|c|c|c|c|}
\cline { 2 - 6 } \multicolumn{1}{c|}{} & 2016 & 2015 & 2014 & 2013 & 2012 \\
\hline APBOSMAM & $7,580,850$ & $6,356,944$ & $5,465,945$ & $3,441,782$ & $3,393,000$ \\
\hline
\end{tabular}

Fuente: "Exportaciones Peruanas de Banano Orgánico", www.agrodataperu.com, 2017 Elaboración Propia.

Con la formalización de la organización, el apoyo del estado para la adquisición de activos y el crecimiento del mercado internacional, Apbosmam pasó de exportar 251 contenedores en el 2012 a exportar 516 contenedores en el 2016; alcanzando el 5\% de participación del total de exportaciones de banano orgánico peruano. De acuerdo a lo conversado con el gerente general de la Cooperativa Agraria Apbosmam, las lluvias de inicio de año no influyeron significativamente en la producción de los cultivos del valle del Chira. Los cultivos perjudicados se ubican principalmente en Tumbes. En el primer trimestre del 2017 Apbosmam ha exportado 2.18 millones de dólares y proyecta exportar en el año un total de 600 contenedores para alcanzar una exportación anual de 8.81 millones de dólares americanos. De acuerdo a su proyección esperan poder alcanzar los 1,000 contenedores anuales en los siguientes cinco años.

Cabe señalar que la Cooperativa Agraria Apbosmam muestra un crecimiento de ventas constante, una diversificación de sus exportaciones a diferentes países y un aumento de sus inversiones en los últimos años; podemos concluir que se trata de una empresa sólida, financieramente estable y con buenas perspectivas de crecimiento sostenible en el tiempo. Sin embargo, el hecho de ser el principal cliente de la cooperativa lo hace altamente riesgoso; motivo por el cual, urge buscar nuevos clientes a fin de poder diversificar el riesgo. 
El mercado objetivo de la Cooperativa Agraria Alto Grande Santa Sofía está compuesto por todas las organizaciones agro exportadoras peruanas que compran banano orgánico para abastecer a los mercados de Estados Unidos y la Unión Europea que se encuentren dentro del valle del Chira.

El perfil del cliente del mercado objetivo se define en función de:

- Empresas agroexportadoras que adquieren la fruta con certificación “Orgánico", de "Precio Justo" y “Global Gap".

- Empresas agroexportadoras que abastezcan a los mercados de Estados Unidos y la Unión Europea.

- Empresas agroexportadoras ubicadas dentro del Valle del Chira en la provincia de Sullana, departamento de Piura.

A continuación, se muestra la relación de potenciales clientes del mercado objetivo:

- Cooperativa Agraria APPBOSA Participación Mcdo: 9\%

- Agronegocio Los Angeles SAC Participación Mcdo: 6\%

- CEPIBO

Participación Mcdo: 5\%

Respecto a la oferta existente para el mercado objetivo viene dada por la producción de todos los pequeños productores que siembran banano orgánico en el valle del Chira. Trademap (2016) nos dice que, en el Perú, en el año 2015, se sembraron 7,797 hectáreas de banano orgánico; de las cuales el $80 \%$ se siembran en la provincia de Sullana. 
Dado que el mercado del banano orgánico se encuentra en crecimiento, cada año se incrementan los sembríos, aumentando la oferta exportable. Hasta el momento las agroexportadoras siguen comprando la totalidad de las cosechas evidenciando que la demanda sigue en aumento. La competencia entre las agroexportadoras por asegurar el abastecimiento de sus mercados les ha llevado a emitir cartas de intención de compra con las asociaciones y/o cooperativas productoras comprometiéndolas a venderles su producción.

Esto les permite a las asociaciones y/o cooperativas asegurar la venta de su producción concentrando su atención en ser más eficientes en sus procesos para reducir costos y gastos con la finalidad de incrementar su rentabilidad. ("Ver Anexo 1: Carta de Intención de Compra")

\subsection{Análisis de la competencia.}

David (2013), sugiere “...la importancia de identificar a los principales competidores de la compañía, así como sus fortalezas y debilidades particulares en relación con la posición estratégica de la organización en evaluación... Este análisis comparativo arroja importante información estratégica interna” (p. 72)

Para el presente análisis se identificaron los siguientes competidores de la organización a nivel del Valle del Chira en la provincia de Sullana:

- Cooperativa Alto Grande.

- Asociación de Pequeños Productores de Querecotillo.

- Asociación de Pequeños Productores de Banano Orgánico de Samán y Anexos.

- Asociación de Productores de Banano Orgánico del Valle del Chira. 
A continuación, se muestra una tabla resumen de la información de cada una de las empresas:

Tabla 17: Principales Competidores

\begin{tabular}{|c|c|c|c|c|}
\hline Siglas & $C A G$ & $A P P Q$ & APPBOSA & APBOVCHIRA \\
\hline $\begin{array}{l}\text { Nombre } \\
\text { Comercial }\end{array}$ & $\begin{array}{l}\text { Cooperativa } \\
\text { Alto Grande }\end{array}$ & $\begin{array}{l}\text { Asociación de } \\
\text { Pequeños } \\
\text { Productores de } \\
\text { Querecotillo }\end{array}$ & $\begin{array}{lr}\text { Asociación } & \text { de } \\
\text { Pequeños } & \\
\text { Productores } & \text { de } \\
\text { Banano } & \\
\text { Orgánico } & \text { de } \\
\text { Samán } & \text { y } \\
\text { Anexos } & \end{array}$ & $\begin{array}{l}\text { Asociación de } \\
\text { Productores de } \\
\text { Banano Orgánico } \\
\text { del Valle del } \\
\text { Chira }\end{array}$ \\
\hline $\begin{array}{ll}\text { Lugar } & \text { de } \\
\text { Producción } & \\
\text { (Distrito } & \text { y } \\
\text { Provincia) } & \end{array}$ & $\begin{array}{l}\text { Ignacio } \\
\text { Escudero - Piura }\end{array}$ & $\begin{array}{l}\text { Valle del Chira - } \\
\text { Piura }\end{array}$ & $\begin{array}{l}\text { Valle del Chira } \\
\text { - Piura }\end{array}$ & $\begin{array}{l}\text { Valle del Chira - } \\
\text { Piura }\end{array}$ \\
\hline $\begin{array}{l}\text { Producto y } \\
\text { Presentación }\end{array}$ & $\begin{array}{l}\text { Banano } \\
\text { orgánico de } \\
\text { buena calidad en } \\
\text { cajas de } 18 \mathrm{Kg} \text {. }\end{array}$ & $\begin{array}{l}\text { Banano } \\
\text { orgánico de } \\
\text { calidad en cajas } \\
\text { de } 18 \mathrm{Kg} \text {. }\end{array}$ & $\begin{array}{lr}\text { Banano } & \\
\text { orgánico } & \text { con } \\
\text { calidad } & \text { de } \\
\text { exportación } & \text { y } \\
\text { certificación } & \text { de } \\
\text { comercio justo } \\
\text { en cajas de } & 18 \\
\text { Kg. }\end{array}$ & $\begin{array}{l}\text { Banano orgánico } \\
\text { con calidad de } \\
\text { exportación y } \\
\text { certificación de } \\
\text { comercio justo en } \\
\text { cajas de } 18 \mathrm{Kg} \text {. }\end{array}$ \\
\hline $\begin{array}{l}\text { Oferta Anual } \\
\text { (Contenedor) }\end{array}$ & 117 & 468 a 520 & 572 a 624 & 364 a 416 \\
\hline $\begin{array}{l}\text { Calidad del } \\
\text { Producto }\end{array}$ & $\begin{array}{l}\text { Banano } \\
\text { orgánico que } \\
\text { cumple con los } \\
\text { estándares para } \\
\text { ser exportado. } \\
\text { Cuenta con } \\
\text { certificación } \\
\text { orgánica y } \\
\text { comercio justo. }\end{array}$ & $\begin{array}{l}\text { Banano } \\
\text { orgánico de } \\
\text { altísima calidad. } \\
\text { Cuenta con } \\
\text { certificación } \\
\text { orgánica y } \\
\text { comercio justo }\end{array}$ & $\begin{array}{l}\text { Banano } \\
\text { orgánico de } \\
\text { altísima calidad. } \\
\text { Cuenta con } \\
\text { certificación } \\
\text { orgánica, global } \\
\text { gap y comercio } \\
\text { justo }\end{array}$ & $\begin{array}{l}\text { Buena calidad del } \\
\text { producto para ser } \\
\text { exportado. } \\
\text { Cuenta con } \\
\text { certificación } \\
\text { orgánica. }\end{array}$ \\
\hline
\end{tabular}




\begin{tabular}{|c|c|c|c|c|}
\hline Cliente & APBOSMAM & $\begin{array}{l}\text { Exporta } \\
\text { Directamente }\end{array}$ & $\begin{array}{l}\text { Exporta } \\
\text { Directamente }\end{array}$ & $\begin{array}{l}\text { Exporta } \\
\text { Directamente }\end{array}$ \\
\hline $\begin{array}{ll}\text { Países } & \mathrm{de} \\
\text { Destino } & \end{array}$ & & $\begin{array}{l}\text { Holanda } \\
\text { Alemania } \\
\text { Estados Unidos }\end{array}$ & $\begin{array}{l}\text { Holanda } \\
\text { Estados Unidos } \\
\text { Alemania }\end{array}$ & $\begin{array}{l}\text { Holanda } \\
\text { Alemania } \\
\text { Estados Unidos }\end{array}$ \\
\hline $\begin{array}{l}\text { Participación } \\
\text { de Mercado }\end{array}$ & & $8 \%$ & $9 \%$ & $6 \%$ \\
\hline $\begin{array}{l}\text { Imagen de la } \\
\text { Organización }\end{array}$ & $\begin{array}{l}\text { Tiene } \\
\text { experiencia } \\
\text { compartida con } \\
\text { APBOSMAN y } \\
\text { posee un gran } \\
\text { potencial } \\
\text { productivo para } \\
\text { banano } \\
\text { orgánico, } \\
\text { presentando los } \\
\text { mejores niveles } \\
\text { de productividad } \\
\text { y calidad de la } \\
\text { fruta. }\end{array}$ & $\begin{array}{l}\text { Exporta } \\
\text { directamente. } \\
\text { Cuenta con las } \\
\text { tres } \\
\text { certificaciones: } \\
\text { Global Gap, } \\
\text { Orgánica y Fair } \\
\text { Trade }\end{array}$ & $\begin{array}{l}\text { Lidera la Red de } \\
\text { Pequeños } \\
\text { Productores de } \\
\text { Banano de } \\
\text { Comercio Justo } \\
\text { (REPEBAN) } \\
\text { que agrupa a } 7 \\
\text { asociaciones y } \\
\text { se ha convertido } \\
\text { en la principal } \\
\text { central peruana } \\
\text { de productores } \\
\text { de banano. }\end{array}$ & $\begin{array}{l}\text { Tiene socios } \\
\text { estratégicos: } \\
\text {-Flocert } \\
\text {-Cooperativa de } \\
\text { productores de } \\
\text { agrofair (cpaf) } \\
\text {-Grupo hualtaco } \\
\text {-Rrepebancj peru } \\
\text { Cuentas con las } \\
03 \text { certificaciones } \\
\text { necesarias. }\end{array}$ \\
\hline $\begin{array}{l}\text { Contratos de } \\
\text { Exportación }\end{array}$ & & SI & SI & SI \\
\hline $\begin{array}{l}\text { Acceso a } \\
\text { Fuentes de } \\
\text { Financiamien- } \\
\text { to }\end{array}$ & $\begin{array}{l}\text { Financiamiento } \\
\text { Propio }\end{array}$ & $\begin{array}{l}\text { Financiamiento } \\
\text { Propio } \\
\text { Financiamiento } \\
\text { de Clientes }\end{array}$ & $\begin{array}{l}\text { Financiamiento } \\
\text { de Gobiernos } \\
\text { Locales } \\
\text { Financiamiento } \\
\text { de ONGs. }\end{array}$ & $\begin{array}{l}\text { Financiamiento } \\
\text { de Gobiernos } \\
\text { Locales } \\
\text { Financiamiento } \\
\text { de ONGs. }\end{array}$ \\
\hline
\end{tabular}

Fuente: Base de Datos del Ministerio de Agricultura y Riego / Gobierno Regional de Piura 2016.

Elaboración Propia. 
Tabla 18: Matriz del Perfil Competitivo

\begin{tabular}{|c|c|c|c|c|c|c|c|c|c|c|c|}
\hline \multirow[b]{2}{*}{$\begin{array}{c}\text { Factores Críticos } \\
\text { para el Éxito }\end{array}$} & \multirow[b]{2}{*}{ Ponderación } & \multicolumn{2}{|c|}{ CAAG Santia Solía } & \multicolumn{2}{|c|}{$C A G$} & \multicolumn{2}{|c|}{$A P P Q$} & \multicolumn{2}{|c|}{ APPBOSA } & \multicolumn{2}{|c|}{ APBOVCHIRA } \\
\hline & & Calificación & Puntuación & Callificación & Puntuación & Callificación & Puntuación & Calificación & Puntuación & Callificación & Puntuación \\
\hline Calidad del Producto & 0.15 & 3.00 & 0.45 & 3.00 & 0.45 & 4.00 & 0.60 & 4.00 & 0.60 & 4.00 & 0.60 \\
\hline Oferta Anual Contenedores & 0.15 & 3.00 & 0.45 & 2.00 & 0.30 & 4.00 & 0.60 & 4.00 & 0.60 & 4.00 & 0.60 \\
\hline Presentación del Producto & 0.12 & 3.00 & 0.45 & 3.00 & 0.45 & 3.00 & 0.45 & 3.00 & 0.45 & 3.00 & 0.45 \\
\hline Lealtad del Cliente & 0.10 & 1.00 & 0.15 & 1.00 & 0.15 & 2.00 & 0.30 & 3.00 & 0.45 & 2.00 & 0.30 \\
\hline Participación Mercado & 0.10 & 1.00 & 0.15 & 1.00 & 0.15 & 4.00 & 0.60 & 4.00 & 0.60 & 3.00 & 0.45 \\
\hline Experiencia & 0.12 & 2.00 & 0.30 & 2.00 & 0.30 & 4.00 & 0.60 & 4.00 & 0.60 & 3.00 & 0.45 \\
\hline Firma Contrato Exportación & 0.11 & 2.00 & 0.30 & 2.00 & 0.30 & 4.00 & 0.60 & 4.00 & 0.60 & 4.00 & 0.60 \\
\hline Fuentes Financiamiento & 0.15 & 1.00 & 0.15 & 1.00 & 0.15 & 3.00 & 0.45 & 4.00 & 0.60 & 3.00 & 0.45 \\
\hline TOTAL & 1.00 & & 2.40 & & 2.25 & & 4.20 & & 4.50 & & 3.90 \\
\hline
\end{tabular}

Los valores de calificación son los siguientes: 1 = debilidad importante, 2 = debilidad menor, 3 = fortaleza menor, 4 = fortaleza mayor

Fuente: Entrevista al Gerente de la CAAG Santa Sofía y al Presidente de Appbosa 
De acuerdo a la Matriz MPC, las empresas con nivel competitivo más débiles son: Cooperativa Alto Grande y Cooperativa Agraria Alto Grande Santa Sofía y, las empresas con mayores fortalezas competitivas son las empresas APPBOSA, APPQ y APBOVCHIRA.

\subsection{Análisis de la cadena de valor.}

Garralda (2014) nos dice que la cadena de valor ayuda a determinar los fundamentos de la ventaja competitiva de una empresa, por medio de la desagregación ordenada del conjunto de las actividades de la empresa. (p.4)

Porter (1996) nos dice que la cadena de valor es la herramienta empresarial básica para analizar las fuentes de ventaja competitiva. (p.39)

En la cadena de valor del banano orgánico se identificaron a los siguientes participantes:

1. Los agentes económicos de los procesos de producción y empaque.

2. Los agentes económicos del proceso de distribución.

3. Los consumidores intermedios o finales.

El esquema de la cadena de valor exportadora de banano orgánico se inicia con la siembra de cultivos de banano orgánico. En el Perú, este nivel está compuesto en su gran mayoría por pequeños productores, dueños de menos de 1.5 hectáreas $y$, pocos de ellos se encuentran organizados en cooperativas y/o asociaciones.

Son las cooperativas y/o asociaciones quienes actúan como las encargadas de realizar los procesos de lavado y empaque de la fruta. Estas 
cooperativas y/o asociaciones compran la fruta a los socios productores y se encargan de procesarla y venderla directamente a los mercados internacionales o venderla a las empresas agro exportadoras. En cualquiera de los casos, las cooperativas le garantizan un mejor precio al productor.

Como se mencionó anteriormente la articulación con los mercados internacionales puede ser de manera directa (la cooperativa exporta directamente) o mediante las empresas agro exportadoras. En este caso, las empresas agro exportadoras aplican una articulación vertical con los productores implementando en todos los casos la firma de contratos de abastecimiento. A pesar de ello, las empresas agro exportadoras son muy importantes porque actúan como agentes dinamizadores de la cadena de valor agro exportadora.

Es muy importante identificar a las empresas agro exportadoras porque tienen los medios y las facilidades para articularse con los mercados internacionales ayudando a impulsar el crecimiento de las cadenas productivas y de procesamiento. Muchas de estas empresas tienen relaciones simples basadas en contratos de compra-venta con los mercados, pero también muchas de ellas han logrado firmar alianzas estratégicas que les permiten contar con mercados seguros para poder comercializar la fruta de sus proveedores. 
Ilustración 10: Esquema de Valor del Banano Orgánico

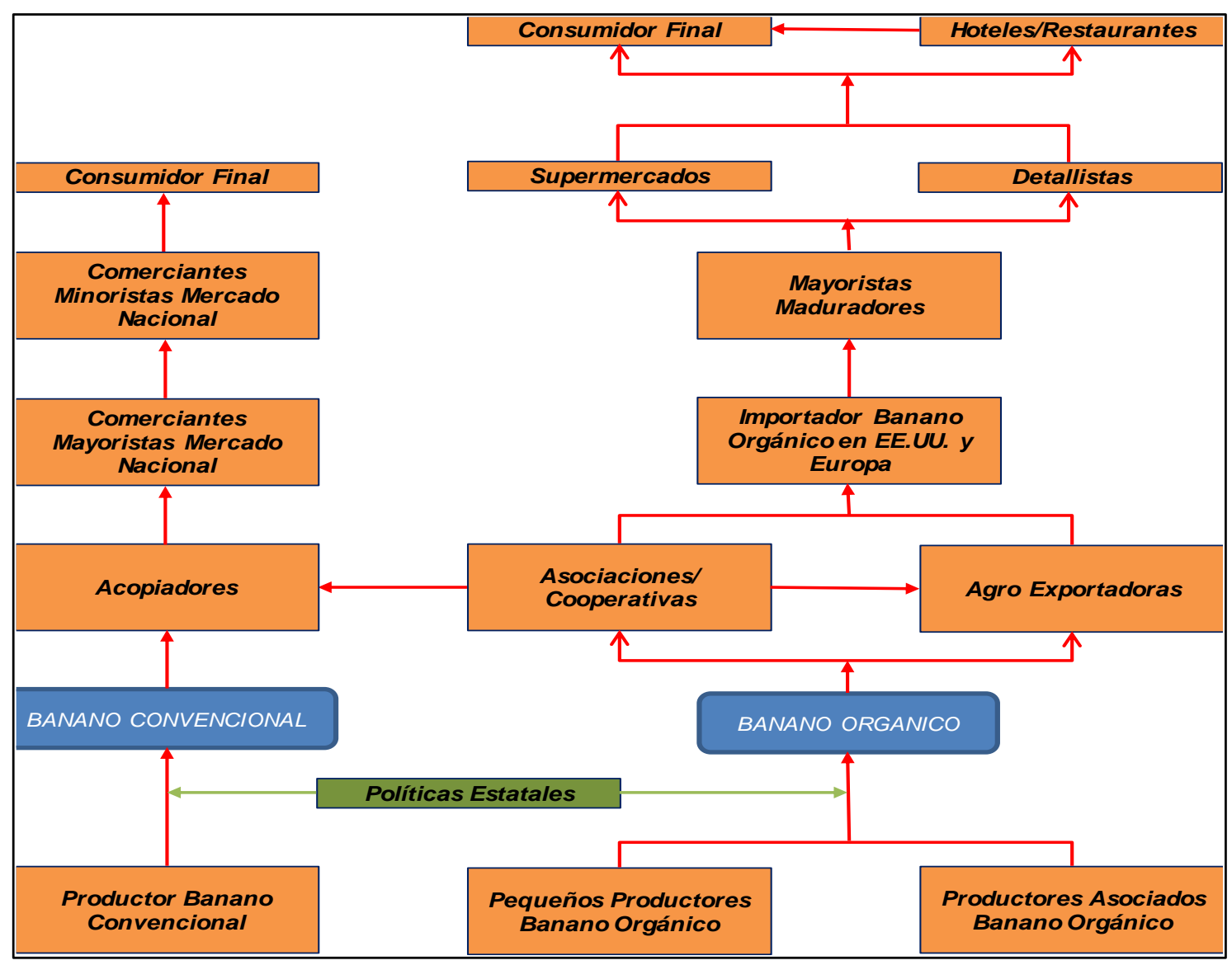

Fuente: "Plan Operativo del Banano Orgánico, Gobierno Regional Piura, 2016. Elaboración Propia

Las políticas de apoyo al agro desarrolladas por el estado esperan lograr a que todos los agricultores se organicen para lograr una producción de alta calidad, integrándose hacia adelante realizando inversiones para la implementación de centros de empaque y paletizados que les permitan exportan directamente a los mercados internacionales.

Este deseo se convierte en un objetivo de supervivencia para los pequeños productores, toda vez que las empresas agro exportadoras, se vienen integrando hacia atrás, invirtiendo directamente en la siembra de banano orgánico con la intención de asegurar el abastecimiento de fruta necesario para atender a sus clientes del mercado internacional. 
Luego de haber realizado el análisis del mercado, la industria y la competencia, podemos llegar a las siguientes conclusiones:

- El mercado potencial de plátanos y bananos en el mundo alcanza los 14 billones de dólares americanos, llegando a crecer el mercado 7\% en los últimos 05 años; siendo China el país con mayor crecimiento en el consumo de bananos y plátanos. La oferta de plátanos y bananos presentó un crecimiento del 5\%.

- Los principales productores de banano orgánico en el mundo son: República Dominicana, Ecuador, Perú, Colombia y Ghana. Las exportaciones de este producto pasaron de 40,000 toneladas en 1999 a cerca de 400,000 toneladas para el 2010 equivalente a aproximadamente 304 millones de dólares americanos.

- Los principales mercados consumidores de banano orgánico en el mundo son: Estados Unidos, La Unión Europea y Asia. En estos mercados vienen creciendo el consumo de productos orgánicos por los beneficios en la salud, cuidado medioambiental y por el sabor del producto.

- El Perú cuenta con ventajas competitivas para la producción de banano orgánico:

- La existencia de un ecosistema favorable

○ Disponibilidad de guano de isla

- Bajos costos de reconversión de banano convencional a orgánico

- Disponibilidad de agua para riego todo el año

- Cercanía al puerto de Paita 
- La oferta de banano orgánico peruano viene creciendo año a año alcanzando un total exportado de aproximadamente 152 millones de dólares americanos como resultado de tener un producto de alta calidad y del aumento del consumo de productos orgánicos en el hemisferio norte.

- Asociaciones y/o cooperativas peruanas que asocian a pequeños productores ya vienen exportando banano orgánico peruano a los principales mercados.

- Debido al crecimiento del consumo de banano orgánico a nivel mundial, las empresas peruanas agro exportadoras se encuentran siempre a la búsqueda de proveedores de banano orgánico, razón por la cual se afirma que en el mercado de banano orgánico la demanda es mayor a la oferta. Esto se confirma con la entrega de cartas de intención de compra de las empresas agro exportadoras ofreciendo múltiples beneficios a sus proveedores (pequeños productores) para que les vendan sus producciones.

- Respecto al Análisis de la competencia, dado que todo lo que producen los pequeños productores se exporta y/o vende a agroexportadoras. El nivel de competencia es bajo. Esto ha llevado a que los competidores orienten sus esfuerzos a implementar políticas y medidas para ser más eficientes en el manejo de sus costos y gastos.

- El desafío para que la industria del banano orgánico siga creciendo y posicionándose a nivel mundial, es la mejora de la competitividad de la cadena productiva para mejorar la oferta exportable. 
- Es de vital importancia continuar invirtiendo en infraestructura para procesar el banano. Esta acción debe ir de la mano con la inversión en investigación y desarrollo para prevenir las plagas en el cultivo y desarrollar medidas de control que minimicen los daños.

- Los productores deben contar con las certificaciones "Orgánica", "Comercio Justo" y "Global Gap" para lograr una mayor presencia y mejorar posicionamiento en uno de los mayores mercados de productos orgánicos del mundo como es el mercado de la Unión Europea. 


\section{CAPÍTULO III}

\section{Plan de marketing y de ventas}

\subsection{Estrategia del producto.}

Kotler y Armstrong (2012) afirman: "un producto es cualquier cosa que se puede ofrecer en un mercado para su atención, adquisición, uso o consumo y que podría satisfacer un deseo o una necesidad. El concepto de producto no está limitado a objetos físicos; cualquier cosa que pueda satisfacer una necesidad se puede llamar producto." (p.243)

De acuerdo al Minagri (2015); los plátanos y bananos son uno de los cultivos más importantes en el mundo porque forma parte esencial de la dieta diaria en muchos países; además de ser fuente de empleo e ingresos en numerosos países en vías de desarrollo.

Estas frutas tienen muchas propiedades y beneficios destacándose:

- Es calmante del sistema nervioso, se utiliza contra el estrés, la ansiedad y la depresión.

- En el deporte, es una fruta ideal por su bajo contenido de grasa y alto contenido de minerales y vitaminas.

- Controla la tensión alta, colesterol y obesidad.

- Puede ser consumida como producto fresco y/o elaborado. 


\subsubsection{Clasificación del producto.}

A continuación, se muestra un cuadro resumen de las especies de Bananos y Plátanos existentes:

\section{Ilustración 11: Especies de Plátanos y Bananos}

\begin{tabular}{|c|c|c|c|c|c|}
\hline Especies & Grupo & Subgrupo & Clones & Otros Nombres & \\
\hline \multirow{8}{*}{$\begin{array}{c}\text { Musa Acuminata } \\
\text { (Consumo fresco-Banano) }\end{array}$} & Diploide AA & Sucner & Baby banana & Lady's Fingerl Bocadillo/Moquicho & 1 \\
\hline & Diploide AAA & $\begin{array}{c}\text { Gross } \\
\text { MichelSeda }\end{array}$ & Gross Michel & Orito/seda & 4 \\
\hline & \multirow{6}{*}{ Triploide AAA } & \multirow{6}{*}{ Cavendish } & Gran Naine & Gran enana/ Chiquita & 3 \\
\hline & & & Dwarf Cavendish & Cavendish (Pequeña Enana/Enano) & 2 \\
\hline & & & Valery & Robusta & \\
\hline & & & Lacatan & Filipino/Montecristo & 1 \\
\hline & & & Williams & Cavendish Gigante & 3 \\
\hline & & & Rojo y Rojo Verde & Morado & 1 \\
\hline \multirow{10}{*}{$\begin{array}{c}\text { Musa Balbisiana } \\
\text { (Consumo cocido-Plátano) }\end{array}$} & \multirow{6}{*}{ Triploide AAB } & \multirow{6}{*}{ Plantain } & French Plantain & Dominico & \\
\hline & & & Horn Plantain & Barraganete/Bellaco & 1 \\
\hline & & & Dominico Harton & & \\
\hline & & & Maqueño & & \\
\hline & & & Manzano/Silk & & 4 \\
\hline & & & Limeño & & \\
\hline & \multirow{2}{*}{ Triploide ABC } & \multirow{2}{*}{ Plantain } & Cuatrofilios & & \\
\hline & & & Pelipita & & \\
\hline & \multirow{2}{*}{ Triploide AAAB } & & FHIA4 & & \\
\hline & & & FHIA21 & & \\
\hline
\end{tabular}

Fuente: Dirección de Inteligencia Comercial e Inversiones Pro Ecuador, 2012

Elaboración: DGPA-DEEIA/MINAGRI

\subsubsection{Diferencias entre banano y plátano.}

Si bien son frutas similares por tratarse de plantas híbridas que comparte un mismo código genético (musa paradisiaca) existe ciertas diferencias entre ellas que se indican a continuación: 
Tabla 19: Diferencias Entre Plátano y Banano

\begin{tabular}{|l|c|c|}
\hline & \multicolumn{1}{|c|}{ Bananos } & Plátanos \\
\hline Presencia Genética & $\begin{array}{l}\text { Mayor presencia genética } \\
\text { de Musa Acuminata }\end{array}$ & $\begin{array}{l}\text { Mayor presencia genética de } \\
\text { Musa Balbisiana permite la } \\
\text { mayor presencia de fécula. }\end{array}$ \\
\hline Humedad & $74 \%$ & $65 \%$ \\
\hline Forma de Consumir & Como fruta de postre & Cocida, asada o en fritura \\
\hline Valores Nutritivos por 100 gramos: & \multicolumn{2}{|c|}{} \\
\hline Agua & $74,2 \mathrm{~g}$ & $65,28 \mathrm{~g}$ \\
\hline Energía & $92 \mathrm{kcal}$ & $0,37 \mathrm{~g}$ \\
\hline Grasa & $0,48 \mathrm{~g}$ & $1,3 \mathrm{~g}$ \\
\hline Proteína & $1,03 \mathrm{~g}$ & $31,89 \mathrm{~g}$ \\
\hline Hidrato Carbono & $23,43 \mathrm{~g}$ & $499 \mathrm{mg}$ \\
\hline Potasio & $396 \mathrm{mg}$ & $0,6 \mathrm{~g}$ \\
\hline Hierro & $0,31 \mathrm{mg}$ & $4 \mathrm{mg}$ \\
\hline Sodio & $1 \mathrm{mg}$ & $3 \mathrm{mg}$ \\
\hline Calcio & $6 \mathrm{mg}$ & $18,4 \mathrm{mg}$ \\
\hline Vitamina C & $9,1 \mathrm{mg}$ & 2012 \\
\hline Fent Conglo & & \multicolumn{2}{|c|}{} \\
\hline
\end{tabular}

Fuente: Consultoría Estudio de la Cadena del Plátano Cárdenas Frida/DGAC, 2012

Elaboración: DGPA-DEEIA/MINAGRI

Habiéndose establecido las diferencias entre plátano y banano, debemos indicar las diferencias entre banano convencional y banano orgánico:

- En el banano convencional, el suelo se fertiliza con urea y sulfatos y, durante el proceso de crecimiento, se aplican pesticidas y fungicidas hasta la cosecha.

- En el banano orgánico, La FAO (2012) considera "orgánicos" a todos aquellos alimentos que en ninguna etapa de su producción se 
le adiciona fertilizantes, herbicidas, pesticidas, químicos o derivados, así como tampoco en los suelos donde son cultivados los productos o las materias primas que forman parte del producto.

Se busca que los bananos orgánicos no incluyan químico alguno. Todo esto forma parte de la certificación orgánica, que para tener validez legal debe ser acreditada por un organismo autorizado.

El banano de la cooperativa es producido orgánicamente cumpliendo con toda la normativa necesaria para ser certificado como tal. Sin embargo, por no poder pagar la supervisión de los campos de los socios productores no ha podido obtener la certificación orgánica.

\section{Tabla 20: Características del Banano Orgánico de Exportación}

\begin{tabular}{|l|l|}
\hline $\begin{array}{l}\text { Caracteristicas } \\
\text { Longitud }\end{array}$ & \multicolumn{1}{|c|}{ Descripción } \\
$\begin{array}{l}\text { Diámetro } \\
\text { (Calibre) } \\
\text { Maduración de } \\
\text { la pulpa }\end{array}$ & Oscila entre 37 y $42 \mathrm{~mm}$. 10.5 pulgadas \\
\hline $\begin{array}{l}\text { Daños } \\
\text { cosméticos }\end{array}$ & $\begin{array}{l}\text { Extensión máxima } 2 \text { pulgadas } \\
\text { cuadradas por caja con rasguños o } \\
\text { cortes que sólo que afecten máximo } \\
\text { a un décimo de la fruta. }\end{array}$ \\
\hline
\end{tabular}

Fuente y elaboración: “Análisis del Mercado del Banano Orgánico, Ministerio de Agricultura y Riego, 2016)

Dado que la cooperativa no cuenta con certificación alguna sobre los campos de producción, toda la fruta es vendida a la cooperativa Apbosmam quien la paletiza y certifica como "orgánica", "comercio justo" y "global gap"; gozando de todos los beneficios que conllevan estas certificaciones. 
Para acceder de manera ventajosa al mercado internacional, no solo se debe tener un producto diferenciado, sino contar con las certificaciones necesarias para comercializar en mercados especiales con ventajas competitiva dentro del mercado mundial.

\subsubsection{Variedad y envasado.}

La variedad predominante en el comercio internacional de banano orgánico es: CAVENDISH. Los bananos orgánicos se exportan en cajas de 18.14 kilogramos. La presentación de la fruta se muestra a continuación:

\section{Ilustración 12: Tipos de Empacado del Banano Orgánico}

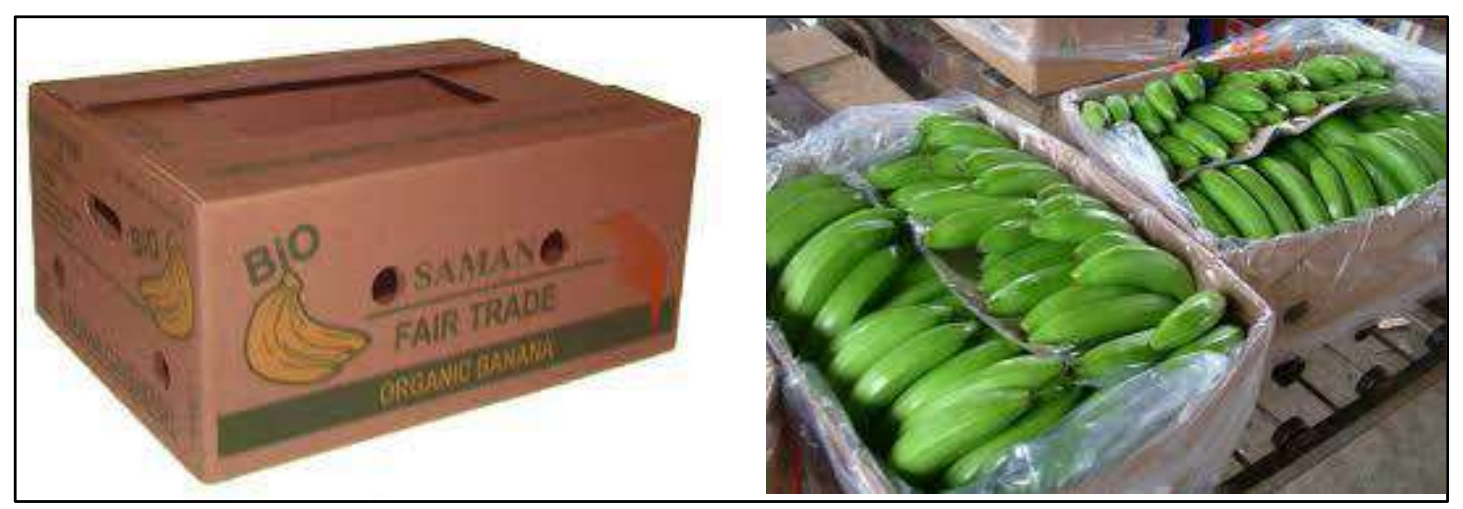

Fuente: Tomado de fotos de la web del Ministerio de Agricultura y Riego, www.minagri.gob.pe, 2016.

Elaboración Propia

Por tratarse de un producto commoditie, no existe una estrategia propiamente establecida para el producto. El proceso de siembra, cosecha, lavado y empacado del banano orgánico es el mismo a nivel mundial. Las diferencias entre los bananos orgánicos del mundo radican en sus características propias como son: longitud, diámetro, maduración de la pulpa y estética. 


\subsection{Estrategia de distribución.}

Lamb, Hair y McDaniel (2011) nos dicen: “un canal de distribución es una estructura de negocios de organizaciones interdependientes que va desde el punto de origen del producto hasta el consumidor, con el propósito de llevar los productos a su destino final de consumo". (p. 50)

Kotler y Armstrong (2012) definen que “...un canal de distribución desplaza bienes y servicios de los productores a los consumidores, y elimina las brechas importantes de tiempo, lugar y posesión que separan los bienes y servicios de quienes los usarán”. (p. 250)

Minagri (2015), los exportadores se localizan en Piura y Tumbes debido a que en estas regiones se encuentran los campos de cultivo y por la cercanía con el puerto de Paita, desde donde se realizan las exportaciones al mercado internacional. El transporte desde los almacenes de las empresas agro exportadoras hasta el puerto de Paita es tercerizado con los terminales portuarios (ALCONSA, NEPTUNIA, RANSA) o con agentes de carga y/o agentes de aduanas quienes se encargan de realizar todos los trámites necesarios como: reservar espacio en buque, organizar la retirada del contenedor del depósito, consolidación en origen, traslado hasta el terminal y realizar el embarque.

A continuación, se muestra el sistema tradicional de distribución del banano orgánico a nivel mundial: 


\section{Ilustración 13: Cadena de Suministro Para Banano Orgánico}

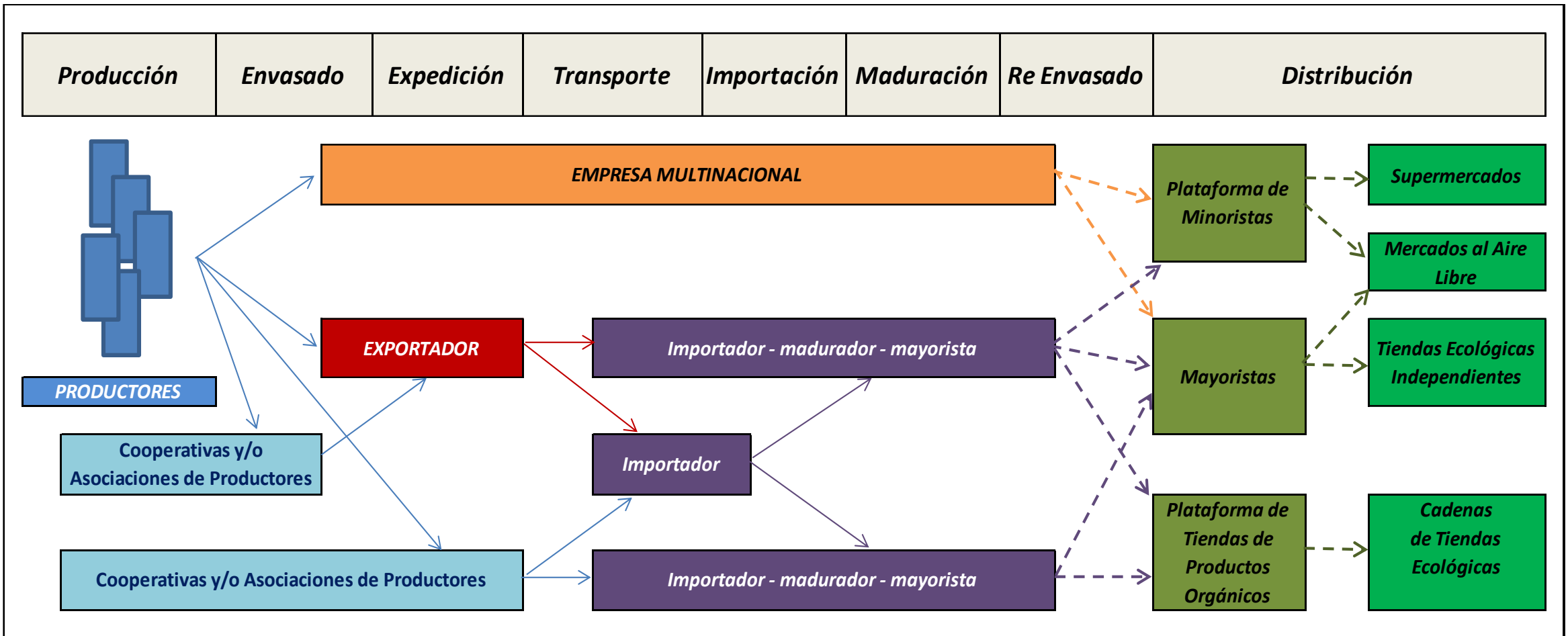

Fuente: "Cadena de Suministro del Banano Orgánico, www.ecozept.fr, 2012"

Elaboración Propia 
Los importadores suelen almacenar, envasar, madurar y distribuir el banano orgánico a sus clientes; dentro de los cuales destacan tres cadenas de comercialización:

- Supermercados, donde los bananos se venden con adhesivos que resaltan que el producto es "Orgánico" y/o "Comercio Justo".

- Minoristas especializados, quienes para poderlo comercializar deben presentarlo en flowpacks (bolsas de plástico transparente) para garantizar una diferenciación de los bananos convencionales.

- Cadenas especializadas en ventas de frutas orgánicas.

Ilustración 14: Banano Orgánico Embolsado y/o con Adhesivos

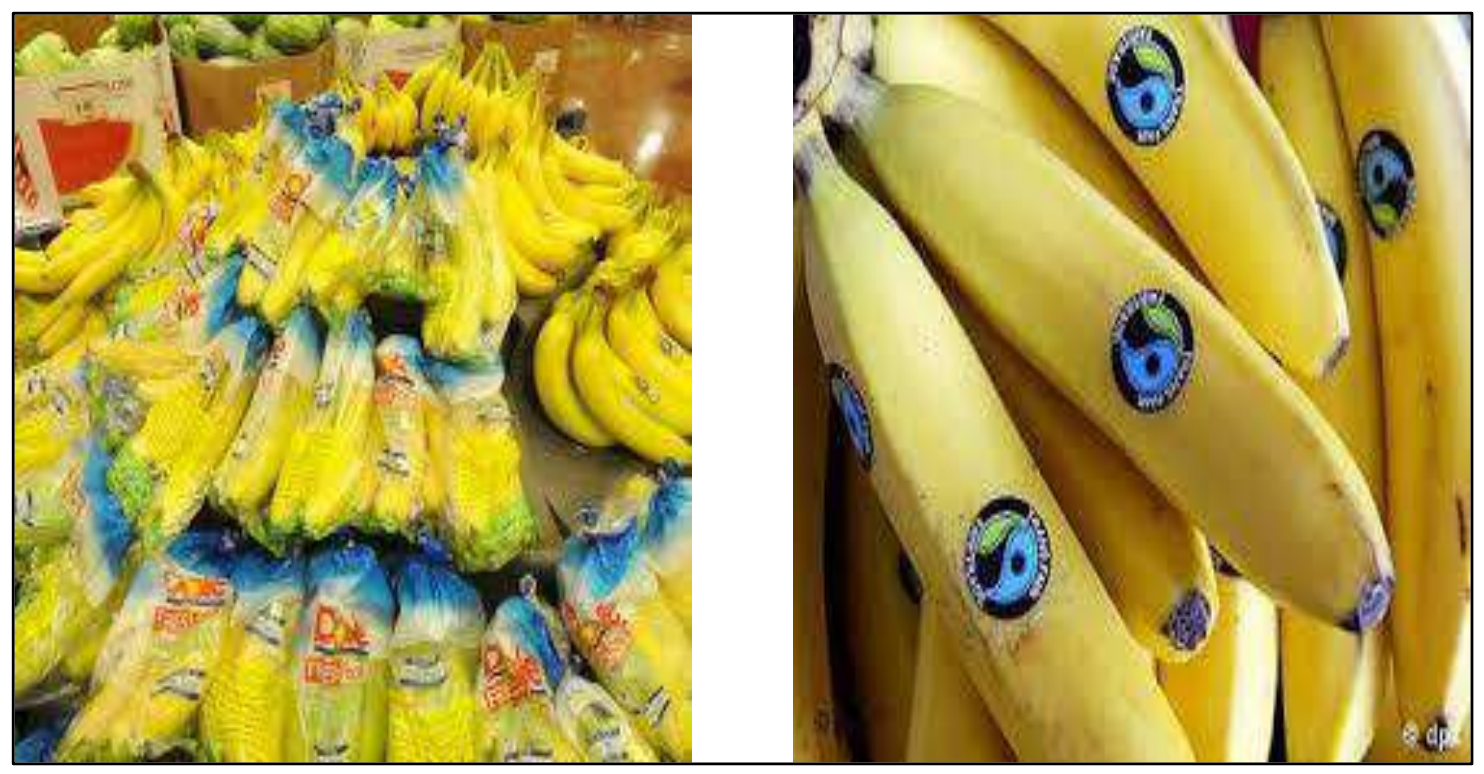

Fuente: "Cadenas de Suministros, www.freshplaza.es, 2014".

Elaboración Propia

Las marcas más conocidas de banano orgánico en el mundo son: Pronatura, Bos (Perú), Cerro Azul (Ecuador), Kini organic (África), Iren (República Dominicana), Ekoke (Perú). 
El banano orgánico de la Cooperativa Agraria Alto Grande Santa Sofía es distribuido en forma coordinada con su socio comercial Apbosmam, empresa exportadora con operaciones comerciales desde 2006 posicionada como una empresa especializada en la exportación de banano orgánico y de comercio justo.

Apbosmam se ha integrado verticalmente con exportadoras de otros países productores y con importadores de los principales países consumidores, lo que les permite un acceso directo a los principales mercados mundiales de productos orgánicos y de comercio justo.

En el 2016, la Cooperativa Agraria Alto Grande Santa Sofía comercializó 100,329 cajas, todas orientadas a la exportación.

La empresa Apbosmam le asegura a la Cooperativa Agraria Alto Grande Santa Sofía la compra de toda su producción para lo cual se compromete:

- Entregar cintas para el banano orgánico

- Proporcionar todo el material, insumos y materiales para el proceso de lavado de la fruta.

Tabla 21: Dinámica Comercial de la Cooperativa Agraria Alto Grande Santa Sofía

\begin{tabular}{|c|c|c|c|c|c|c|}
\hline \multirow{2}{*}{ Año } & \multirow{2}{*}{ Producto } & \multirow{2}{*}{ Cliente } & \multirow{2}{*}{ Contrato } & \multicolumn{2}{|c|}{ Cantidad } & \multirow{2}{*}{$\begin{array}{l}\text { Descripción de la } \\
\text { comercialización }\end{array}$} \\
\hline & & & & Cajas & Soles & \\
\hline 2016 & $\begin{array}{l}\text { Banano } \\
\text { Orgánico }\end{array}$ & APBOSMAM & $\begin{array}{c}\text { Acuerdo } \\
\text { Comercial }\end{array}$ & 100,329 & $2^{\prime} 859,377$ & $\begin{array}{c}\text { La cooperativa entrega } \\
\text { cajas empacadas en el } \\
\text { almacen de } \\
\text { APPBOSMAM }\end{array}$ \\
\hline
\end{tabular}

Fuente: “Informes de Ventas de la CAAA Santa Sofía, Datos Contables, 2016”. Elaboración Propia 
La organización, a través de su aliado comercial Apbosmam, tiene asegurada la venta de su producción, a la vez que los favorece con las certificaciones: Orgánica, Global GAP y Comercio Justo. Si la Cooperativa Alto Grande Santa Sofía consiguiese las tres certificaciones, podría proveer a otros exportadores, dentro de los que destaca como cliente potencial la asociación Appbosa.

En resumen, como la cooperativa le vende su producto únicamente a la cooperativa Apbosmam, no puede implementarse una estrategia de distribución para el banano orgánico vendido. La estrategia de distribución es la misma y aplica a nivel mundial: La fruta es procesada, empacada y vendida a las empresas agro exportadoras; quienes la paletizan y exportan a sus clientes.

\subsection{Estrategia de promoción.}

Stanton, Etzel y Walker (2007), definen: "la promoción como todos los esfuerzos personales e impersonales de un vendedor o representante del vendedor para informar, persuadir o recordar a una audiencia objetivo." (p. 502)

McCarthy y Perreault (2005), afirman que "la promoción consiste en transmitir información entre el vendedor y los compradores potenciales $u$ otros miembros del canal para influir en sus actitudes y comportamientos." (p.60)

El banano orgánico peruano cuenta con el apoyo del estado para promocionarlo en diversos mercados internacionales. Esta promoción 
internacional es llevada a cabo por las Oficinas Comerciales del Perú (OCEX) distribuidas en las principales capitales del mundo.

De acuerdo al ministerio de agricultura y riego (2017), un ejemplo de promoción exitosa es la primera exportación de banano orgánico peruano a Portugal, transacción que fue posible por el apoyo de la OCEX en Lisboa, que establecieron el contacto entre la empresa peruana exportadora Bananeros Orgánicos Solidarios con la empresa importadora Positive Gravity, dedicada al sector agro alimentario en Portugal.

Se destaca que la mercadería recién llegada fue embalada con bolsas de la Marca Perú, las cuales fueron solicitadas y diseñadas por Positive Gravity gracias a la gestión de la OCEX Lisboa para promocionar este distintivo en los productos peruanos que se venden al exterior.

En el caso del banano orgánico comercializado por la Cooperativa Agraria Alto Grande Santa Sofía no requiere de estrategias promocionales porque toda la fruta es comprada por su socio comercial Apbosmam.

\subsection{Estrategia de precio}

Según Lamb, Hair y McDaniel (2011), una estrategia de precios es “...un marco de fijación de precios básico a largo plazo que establece el precio inicial para un producto y la dirección para los movimientos de precios a lo largo del ciclo de vida del producto." (p.56). Según diversos expertos en temas de mercadotecnia, las principales o más usadas estrategias de precios son las siguientes: 
- Estrategia de descremado de precios.

- Estrategia de penetración.

- Estrategia de precios de prestigio.

- Estrategia para cartera de productos.

- Estrategia Orientada a la Competencia

El precio del banano orgánico lo establece el mercado internacional razón por la cual las agroexportadoras son quienes establecen los precios de compra de cada caja de banano orgánico empacado. No es posible establecer una estrategia de precios porque es el mercado internacional quien suele establecerlo.

El comportamiento histórico del precio internacional del banano orgánico ha sido creciente. El precio promedio por kilogramo de banano orgánico exportado durante los meses enero a diciembre del 2013 al 2016 fue $0.75 \mathrm{US} \$ / \mathrm{kg}$. Es decir, la caja de banano orgánico de $18.14 \mathrm{Kg}$ se vendió en el 2016 a un precio promedio de US\$ 13.61. A continuación, se muestra la evolución del precio pagado al banano orgánico peruano:

Tabla 22: Evolución del Precio Internacional del Banano Orgánico

\begin{tabular}{|l|c|c|c|c|}
\hline Concepto & 2013 & 2014 & 2015 & 2016 \\
\hline Valor FOB & $86,560,726$ & $118,797,276$ & $144,482,297$ & $151,621,281$ \\
\hline Kilos & $120,656,017$ & $158,828,276$ & $190,343,985$ & $201,297,661$ \\
\hline $\begin{array}{l}\text { Precio } \\
\text { (US\$ / Kg) }\end{array}$ & 0.72 & 0.75 & 0.76 & 0.75 \\
\hline $\begin{array}{l}\text { Precio } \\
\text { (US\$ / Caja) }\end{array}$ & 13.06 & 13.61 & 13.79 & 13.61 \\
\hline
\end{tabular}

Fuente: "Evolución del Precio del Banano, www.agrodataperu.com, 2017”.

Elaboración Propia 
A la fecha, el precio pagado en chacra - "caja/productor" - es de 6.3 dólares/caja. Respecto al precio pagado a las Asociaciones de Productores - "caja procesada" - el precio pagado es de 9.3 dólares/caja.

De acuerdo a lo indicado por el ministerio de agricultura y riego (2016), los precios del banano orgánico a nivel mundial deberían mantenerse considerando el aumento creciente de la demanda de esta fruta pero que se compensa con el aumento de las áreas productivas a nivel mundial.

\subsection{Proyección de ventas.}

\subsection{1. situación actual - proyección de ventas.}

Para la proyección de la producción de los siguientes 05 años se consideraron los siguientes supuestos:

\section{Tabla 23: Situación Actual - Supuestos de la Producción de Fruta}

\begin{tabular}{|l|c|}
\hline \multicolumn{1}{|c|}{ DESCRIPCIÓN } & CANTIDAD \\
\hline $\begin{array}{l}\text { Número de hectáreas } \\
\text { destinadas a la siembra de } \\
\text { banano orgánico } \\
\text { Número de plantas sembradas } \\
\text { por hectárea }\end{array}$ & $\begin{array}{c}55.65 \\
\text { hectáreas }\end{array}$ \\
\hline $\begin{array}{l}\text { Rendimiento por racima } \\
\text { plantas }\end{array}$ & 20 Kilos \\
\hline $\begin{array}{l}\text { Factor de productividad } \\
\text { Porcentaje de Merma por } \\
\text { Daños en Planta }\end{array}$ & $\begin{array}{c}0.90 \text { Cajas } \\
\text { por racima }\end{array}$ \\
\hline $\begin{array}{l}\text { Porcentaje de Merma por } \\
\text { Daños en Proceso de Lavado }\end{array}$ & $5 \%$ \\
\hline
\end{tabular}

Fuente: Base de Datos, Área contable de la cooperativa, 2017.

Elaboración Propia 
Considerando los supuestos establecidos, la productividad por Hectárea es de 38,250 Kg/Ha (2,125 planta/Ha. * $20 \mathrm{Kg} /$ planta * 0.90). Los productores pueden abastecer a la cooperativa con una producción anual equivalente a:

Producción Anual Banano Orgánico: 38,250 Kg/Ha. x 55.65 Ha.

Producción Anual Banano Orgánico: 2’128,613 Kg.

Esta producción total de banano orgánico producido entra a un primer proceso de selección, donde por data histórica promedio de la empresa, la Merma por Daños en la Planta es: 5.00\%. Así, la merma por daños en planta asciende a 106,431 Kg. (2`128,613 Kg. x 5.00\%). La cantidad de fruta disponible para ingresar al proceso de lavado en las tinas móviles es: 2`022,182 Kg. (2`128,613 Kg. - 106,431 Kg).

Durante el proceso de lavado la fruta sufre daños en su estructura donde, por data histórica promedio de la empresa, se determinó que la merma en el proceso de lavado alcanza el $10.00 \%$ de la fruta procesada. Es decir, que la merma por daños sufridos durante el proceso de lavado asciende a: $202,218 \mathrm{Kg}$. (2’022,182 Kg. x 10.00\%).

La cantidad de fruta disponible para iniciar el proceso de empaque para el mercado internacional es: 1’819,964 Kg. (2`022,182 Kg. 202,218 Kg.) que equivalen a 100,329 cajas de Banano Orgánico de $18.14 \mathrm{Kg}$. cada caja. 
Tabla 24: Situación Actual - Proyección de la Producción de Fruta

\begin{tabular}{|c|c|c|c|c|c|c|}
\hline Concepto & Año Base & Año 1 & Año 2 & Año 3 & Año 4 & Año 5 \\
\hline$N^{\circ}$ Socios & 50 & 50 & 50 & 50 & 50 & 50 \\
\hline Área de los socios productores (Has.) & 55.65 & 55.65 & 55.65 & 55.65 & 55.65 & 55.65 \\
\hline Número Plantas por Hectárea & 2,125 & 2,125 & 2,125 & 2,125 & 2,125 & 2,125 \\
\hline Número Kilos por Racima & 20 & 20 & 20 & 20 & 20 & 20 \\
\hline $\begin{array}{l}\text { Factor Productividad } \\
\text { (Cajas por Racima) }\end{array}$ & 0.90 & 0.90 & 0.90 & 0.90 & 0.90 & 0.90 \\
\hline Productividad ( $\mathrm{Kg} / \mathrm{Ha}$ ) & 38,250 & 38,250 & 38,250 & 38,250 & 38,250 & 38,250 \\
\hline Producción Total (Kg) & $2,128,613$ & $2,128,613$ & $2,128,613$ & $2,128,613$ & $2,128,613$ & $2,128,613$ \\
\hline Merma por Daños en Planta ( \%) & $5 \%$ & $5 \%$ & $5 \%$ & $5 \%$ & $5 \%$ & $5 \%$ \\
\hline Merma por Daños en Planta ( Kg ) & 106,431 & 106,431 & 106,431 & 106,431 & 106,431 & 106,431 \\
\hline $\begin{array}{c}\text { Total Fruta que Ingresa a Proceso } \\
\text { de Lavado }(\mathrm{Kg})\end{array}$ & $2,022,182$ & $2,022,182$ & $2,022,182$ & $2,022,182$ & $2,022,182$ & $2,022,182$ \\
\hline Merma en Proceso de Lavado ( \% ) & $10 \%$ & $10 \%$ & $10 \%$ & $10 \%$ & $10 \%$ & $10 \%$ \\
\hline Merma en Proceso de Lavado ( $\mathrm{Kg}$ ) & 202,218 & 202,218 & 202,218 & 202,218 & 202,218 & 202,218 \\
\hline $\begin{array}{l}\text { Total Fruta Disponible para } \\
\text { Exportación }(\mathrm{Kg})\end{array}$ & $1,819,964$ & $1,819,964$ & $1,819,964$ & $1,819,964$ & $1,819,964$ & $1,819,964$ \\
\hline $\begin{array}{l}\text { Número Cajas de } 18.14 \mathrm{Kg} \\
\text { Disponibles para Exportar }\end{array}$ & 100,329 & 100,329 & 100,329 & 100,329 & 100,329 & 100,329 \\
\hline
\end{tabular}

Fuente: Base de Datos, Área contable de la cooperativa, 2017. Elaboración Propia

Para la proyección de ventas, se han considerado los siguientes supuestos: 
Tabla 25: Situación Actual - Supuestos de Proyección de Ventas

\begin{tabular}{||l|c||}
\hline \hline \multicolumn{1}{|c|}{ DESCRIPCIÓN } & CANTIDAD \\
\hline $\begin{array}{l}\text { Número de cajas disponibles } \\
\text { para exportar. }\end{array}$ & $\begin{array}{c}100,329 \\
\text { Cajas }\end{array}$ \\
$\begin{array}{l}\text { Precio Constante de la Caja de } \\
18.14 \mathrm{Kg} . \text { De Banano Orgánico }\end{array}$ & $\begin{array}{c}9.30 \\
\text { US\$Caja }\end{array}$ \\
$\begin{array}{l}\text { Tipo de cambio estimado por el } \\
\text { Ministerio de Economía y }\end{array}$ & $2016 \ldots 3.30$ \\
$\begin{array}{l}\text { Finanzas proyectado en el } \\
\text { Marco Macroeconómico } \\
\text { Multianual } 2017-2019\end{array}$ & $2017 \ldots 3.37$ \\
\hline
\end{tabular}

Fuente: Base de Datos, Área contable de la cooperativa, 2017. Ministerio de Economía y Finanzas. Elaboración Propia

Considerando los supuestos anteriores hemos proyectado las ventas de la empresa si no realizasen inversión alguna en mejoras tecnológicas:

Tabla 26: Situación Actual - Proyección de Ventas

\begin{tabular}{|c|c|c|c|c|c|c|}
\hline Concepto & Año Base & Año 1 & Año 2 & Año 3 & Año 4 & Año 5 \\
\hline NGRESOS POR VENTA FRUTA: & & & & & & \\
\hline $\begin{array}{c}\text { Número Cajas de 18.14Kg } \\
\text { Disponibles para Exportar }\end{array}$ & 100,329 & 100,329 & 100,329 & 100,329 & 100,329 & 100,329 \\
\hline Precio US\$ / Caja 18.14Kg & 9.30 & 9.30 & 9.30 & 9.30 & 9.30 & 9.30 \\
\hline Total Ingresos ( US\$) & 933,057 & 933,057 & 933,057 & 933,057 & 933,057 & 933,057 \\
\hline Tipo de Cambio & 3.30 & 3.37 & 3.38 & 3.39 & 3.40 & 3.41 \\
\hline Total Ingresos ( S/) & $3,079,090$ & $3,144,404$ & $3,153,734$ & $3,163,065$ & $3,172,395$ & $3,181,726$ \\
\hline
\end{tabular}

Fuente y Elaboración Propia. 


\subsubsection{Situación futura - proyección de ventas.}

Para la proyección del nuevo Plan de Producción debido a la implementación de mejoras en los flujos de los procesos de la cooperativa, se consideraron los siguientes supuestos:

\section{Tabla 27: Situación Futura - Supuestos de la Producción de Fruta}

\begin{tabular}{|l|c|}
\hline \multicolumn{1}{|c|}{ DESCRIPCIÓN } & CANTIDAD \\
\hline $\begin{array}{l}\text { Número de hectáreas } \\
\text { destinadas a la siembra de } \\
\text { banano orgánico }\end{array}$ & $\begin{array}{c}55.65 \\
\text { hectáreas }\end{array}$ \\
$\begin{array}{l}\text { Número de plantas sembradas } \\
\text { por hectárea }\end{array}$ & $\begin{array}{c}2125 \\
\text { plantas }\end{array}$ \\
$\begin{array}{l}\text { Rendimiento por racima } \\
\text { Factor de productividad }\end{array}$ & 20 Kilos \\
\hline $\begin{array}{l}\text { Porcentaje de Merma por } \\
\text { Daños en Planta }\end{array}$ & $\begin{array}{c}0.90 \text { Cajas } \\
\text { por racima }\end{array}$ \\
\hline $\begin{array}{l}\text { Porcentaje de Merma por } \\
\text { Daños en Proceso de Lavado }\end{array}$ & $7 \%$ \\
\hline
\end{tabular}

Fuente: Base de Datos, Área contable de la cooperativa, 2017. Elaboración Propia

Teniendo en cuenta los supuestos anteriores, la producción de banano orgánico comprada a los socios productores que ingresará al Proceso de Lavado en las Tinas es de 2’022,182 Kg. (2`128,613 Kg. $106,431 \mathrm{Kg}$.

En el proceso de lavado la fruta se proyecta reducir el porcentaje de merma a $7.00 \%$ del total de fruta procesada. Es decir, que la merma por daños sufridos durante el proceso de lavado asciende a 141,553 Kg. $\left(2^{\prime} 022,182 \mathrm{Kg} \cdot \mathrm{x} 7.00 \%\right)$. 
La cantidad de fruta disponible para empacarla para el mercado internacional será: 1’880,629 Kg. (2’022,182 Kg. - 141,553 Kg.) que equivalen a 103,673 cajas de Banano Orgánico de $18.14 \mathrm{Kg}$ cada caja. Con la implementación de las mejoras tecnológicas que se piensan implementar, el número de cajas disponible para exportación aumenta de 100,329 a 103,673 .

Tabla 28: Situación Futura - Proyección de la Producción de Fruta

\begin{tabular}{|c|c|c|c|c|c|c|}
\hline Concepto & Año Base & Año 1 & Año 2 & Añ̃o 3 & Año 4 & Año 5 \\
\hline $\mathrm{N}^{0}$ Socios & 50 & 50 & 50 & 50 & 50 & 50 \\
\hline Área de los socios productores (Has.) & 55.65 & 55.65 & 55.65 & 55.65 & 55.65 & 55.65 \\
\hline Número Plantas por Hectárea & 2,125 & 2,125 & 2,125 & 2,125 & 2,125 & 2,125 \\
\hline Número Kilos por Racima & 20 & 20 & 20 & 20 & 20 & 20 \\
\hline \begin{tabular}{|l} 
Factor Productividad \\
(Cajas por Racima)
\end{tabular} & 0.90 & 0.90 & 0.90 & 0.90 & 0.90 & 0.90 \\
\hline Productividad ( Kg / Ha ) & 38,250 & 38,250 & 38,250 & 38,250 & 38,250 & 38,250 \\
\hline Producción Total (Kg) & $2,128,613$ & $2,128,613$ & $2,128,613$ & $2,128,613$ & $2,128,613$ & $2,128,613$ \\
\hline Merma por Daños en Planta (\%) & $5 \%$ & $5 \%$ & $5 \%$ & $5 \%$ & $5 \%$ & $5 \%$ \\
\hline Merma por Daños en Planta (Kg) & 106,431 & 106,431 & 106,431 & 106,431 & 106,431 & 106,431 \\
\hline $\begin{array}{c}\text { Total Fruta que Ingresa a Proceso } \\
\text { de Lavado (Kg ) }\end{array}$ & $2,022,182$ & $2,022,182$ & $2,022,182$ & $2,022,182$ & $2,022,182$ & $2,022,182$ \\
\hline Merma en Proceso de Lavado (\%) & $10.00 \%$ & $7.00 \%$ & $7.00 \%$ & $7.00 \%$ & $7.00 \%$ & $7.00 \%$ \\
\hline Merma en Proceso de Lavado ( $\mathrm{Kg}$ ) & 202,218 & 141,553 & 141,553 & 141,553 & 141,553 & 141,553 \\
\hline $\begin{array}{l}\text { Total Fruta Disponible para } \\
\text { Exportación }(\mathrm{Kg})\end{array}$ & $1,819,964$ & $1,880,629$ & $1,880,629$ & $1,880,629$ & $1,880,629$ & $1,880,629$ \\
\hline $\begin{array}{l}\text { Número Cajas de } 18.14 \mathrm{Kg} \\
\text { Disponibles para Exportar }\end{array}$ & 100,329 & 103,673 & 103,673 & 103,673 & 103,673 & 103,673 \\
\hline
\end{tabular}

Fuente: Base de Datos, Área contable de la cooperativa, 2017. Elaboración Propia 
Para la elaboración del nuevo plan de ventas, se consideraron los mismos supuestos del plan de ventas anterior, pero se añaden los beneficios obtenidos por la exportación de fruta con certificación de comercio justo.

Actualmente los mercados europeo y americano pagan 1.00 dólar adicional por cada caja de banano orgánico exportada a las asociaciones y/o cooperativas de socios productores como reconocimiento económico al productor de cultivos orgánicos.

Tabla 29: Situación Futura - Supuestos de Proyección de Ventas

\begin{tabular}{|c|c|}
\hline DESCRIPCIÓN & CANTIDAD \\
\hline $\begin{array}{l}\text { Número de cajas disponibles } \\
\text { para exportar. }\end{array}$ & $\begin{array}{c}103,673 \\
\text { Cajas }\end{array}$ \\
\hline $\begin{array}{l}\text { Precio Constante de la Caja de } \\
18.14 \mathrm{Kg} \text {. De Banano Orgánico }\end{array}$ & $\begin{array}{c}9.30 \\
\text { us\$/Caja }\end{array}$ \\
\hline $\begin{array}{l}\text { Tipo de cambio estimado por el } \\
\text { Ministerio de Economía y } \\
\text { Finanzas proyectado en el } \\
\text { Marco Macroeconómico } \\
\text { Multianual } 2017-2019\end{array}$ & $\begin{array}{l}2016 \ldots 3.30 \\
2017 \ldots 3.37 \\
2018 \ldots 3.38 \\
2019 \ldots 3.39 \\
2020 \ldots 3.40 \\
2021 \ldots 3.41\end{array}$ \\
\hline $\begin{array}{l}\text { Ingreso Extraordinario por } \\
\text { exportación de Fruta con } \\
\text { Certificación de Comercio Justo }\end{array}$ & $\begin{array}{c}1.00 \\
\text { US\$/Caja }\end{array}$ \\
\hline
\end{tabular}

Fuente: Base de Datos, Área contable de la cooperativa, 2017. Elaboración Propia

Considerando los supuestos anteriores se proyectaron las ventas de la empresa para los siguientes años: 
Tabla 30: Situación Futura - Proyección de Ingresos

\begin{tabular}{|c|c|c|c|c|c|c|}
\hline Concepto & Año Base & Año 1 & Año 2 & Año 3 & Año 4 & Año 5 \\
\hline \multicolumn{7}{|l|}{ INGRESOS POR VENTA FRUTA: } \\
\hline $\begin{array}{l}\text { Número Cajas de } 18.14 \mathrm{Kg} \\
\text { Disponibles para Exportar }\end{array}$ & 100,329 & 103,673 & 103,673 & 103,673 & 103,673 & 103,673 \\
\hline Precio US\$ / Caja 18.14Kg & 9.30 & 9.30 & 9.30 & 9.30 & 9.30 & 9.30 \\
\hline Total Ingresos (US\$) & 933,057 & 964,159 & 964,159 & 964,159 & 964,159 & 964,159 \\
\hline Tipo de Cambio & 3.30 & 3.37 & 3.38 & 3.39 & 3.40 & 3.41 \\
\hline Total Ingresos (Soles) & $3,079,090$ & $3,249,217$ & $3,258,859$ & $3,268,500$ & $3,278,142$ & $3,287,783$ \\
\hline \multicolumn{7}{|l|}{\begin{tabular}{lll|} 
OTROS INGRESOS POR \\
CERTIFICACION:
\end{tabular}} \\
\hline $\begin{array}{l}\text { Número Cajas de } 18.14 \mathrm{Kg} \\
\text { Disponibles para Exportar }\end{array}$ & 100,329 & 103,673 & 103,673 & 103,673 & 103,673 & 103,673 \\
\hline $\begin{array}{l}\text { Pago Adicional por "Comercio Justo" } \\
\text { ( US\$/Caja ) }\end{array}$ & 0 & 1.00 & 1.00 & 1.00 & 1.00 & 1.00 \\
\hline Total Otros Ingresos (US\$) & 0 & 103,673 & 103,673 & 103,673 & 103,673 & 103,673 \\
\hline Tipo de Cambio & 3.30 & 3.37 & 3.38 & 3.39 & 3.40 & 3.41 \\
\hline Total Otros Ingresos (Soles) & 0 & 349,378 & 350,415 & 351,452 & 352,488 & 353,525 \\
\hline TOTAL INGRESOS (Soles) & $3,079,090$ & $3,598,595$ & $3,609,274$ & $3,619,952$ & $3,630,630$ & $3,641,309$ \\
\hline
\end{tabular}

Fuente y Elaboración Propia. 


\section{CAPÍtULO IV}

\section{Plan de operaciones}

\subsection{Ubicación geográfica.}

Hopeman, R. (1986) nos dice “...los sistemas de producción están influenciados por la ubicación de la planta en dos áreas: Influye directamente sobre los costos de las operaciones de producción y sobre la efectividad de la mercadotecnia." (p. 109)

La Cooperativa Agraria Alto Grande Santa Sofía se encuentra ubicada en La Villa Santa Sofía anexo que pertenece al distrito de Ignacio Escudero, provincia de Sullana, Departamento de Piura, en la costa norte del Perú. Para llegar a la Villa Santa Sofía desde la ciudad de Piura, el traslado se realiza en auto en aproximadamente noventa minutos. Desde allí, el traslado hacia los predios agrícolas demora entre 10 y 30 minutos.

\subsection{Infraestructura y equipos.}

Hopeman, R. (1986) nos dice que los insumos de los sistemas de producción incluyen: materia prima, suministros, artículos semis terminados, partes, equipos y herramientas. Para muchas compañías, la ubicación de estos materiales es un factor importante en las decisiones sobre la ubicación de la planta. (p. 149)

La cooperativa cuenta con local alquilado donde realizan reuniones de trabajo y funciona la oficina administrativa. Como organización cuentan con 
los siguientes activos: (1) balanza para el pesaje de la fruta, (2) una unidad de transporte y (3) tres líneas de lavado de fruta (tinas móviles) que son trasladadas a los centros de empaque rústicos distribuidos entre los predios de los socios productores.

Tabla 31: Relación de Activos

\begin{tabular}{|l|r|c|}
\hline \multicolumn{1}{|c|}{ Concepto } & \multicolumn{1}{c|}{ Año 0 } & \% de Uso \\
\hline 03 Tinas Móviles & 41,466 & $100 \%$ \\
\hline Equipos Oficina & 3,897 & $100 \%$ \\
\hline Unidad Trasporte (Moto) & 4,140 & $100 \%$ \\
\hline TOTAL ACTIVOS & $\mathbf{4 9 , 5 0 3}$ & $\mathbf{1 0 0 \%}$ \\
\hline
\end{tabular}

Fuente: Base de Datos, Área contable de la cooperativa, 2017.

Elaboración Propia

La cooperativa no cuenta con un centro de empaque con tina fija, razón por la cual, han construido centros de empaque rústicos distribuidos en diversos puntos entre los predios agrícolas de los socios. Para realizar el proceso de lavado de la fruta, es necesario trasladar a cada centro de empaque rústico las tinas móviles. Cabe resaltar que, por no contar con un centro de empaque con tina fija, no puede obtener la certificación de comercio justo y la certificación global gap; al ser un requisito indispensable exigido por las empresas certificadoras. 


\section{3. proceso productivo.}

\section{Ilustración 15: Proceso Productivo del Banano Orgánico}

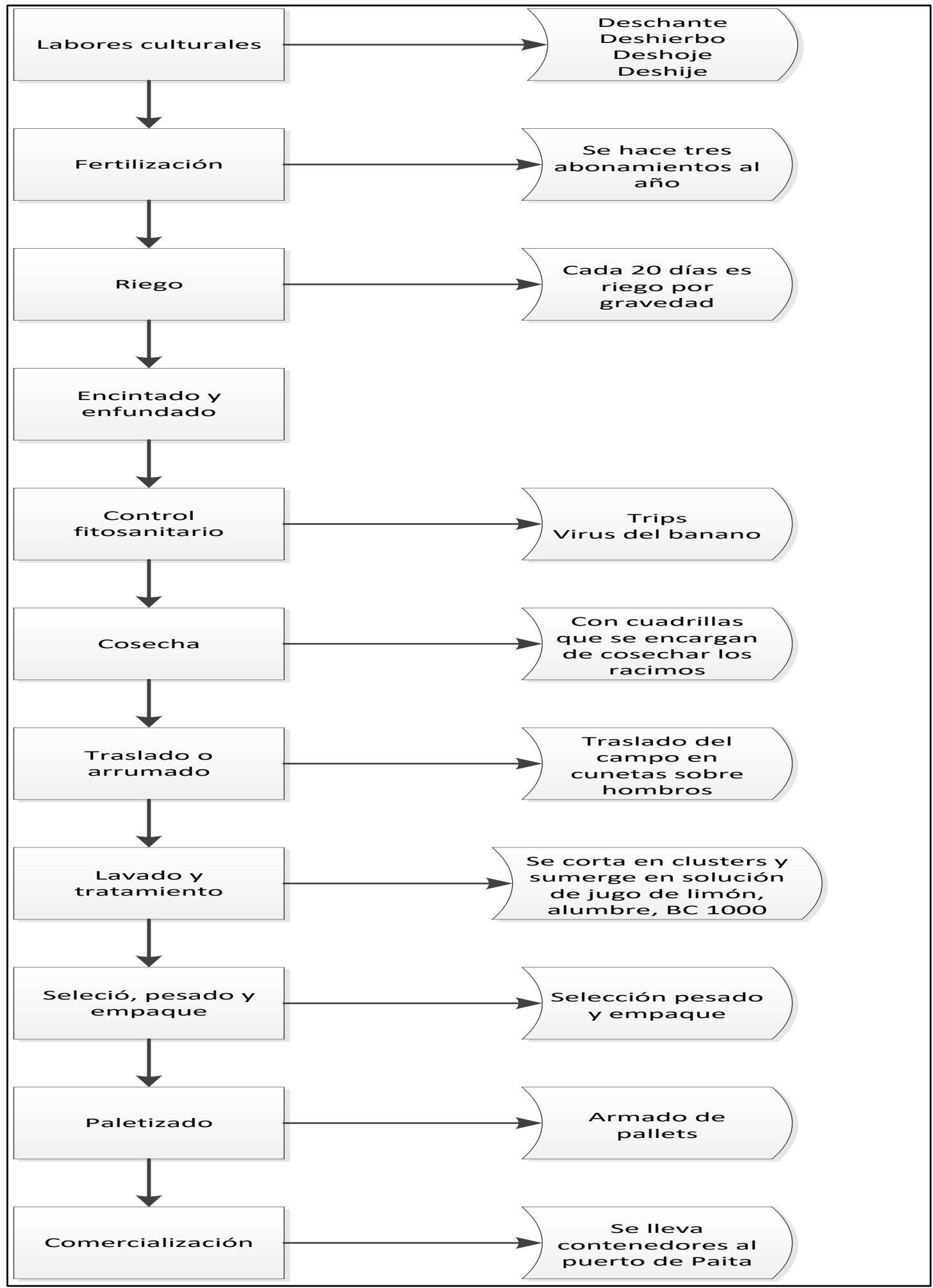

Fuente: Base de Datos, Área contable de la cooperativa, 2017.

Elaboración Propia 
Hopeman, R. (1986) nos dice: “un sistema de producción es un armazón de las actividades dentro del cual ocurre la creación de valor, en un extremo del sistema se encuentran los insumos y, en el otro están los productos o salidas. Conectando las entradas y las salidas existe una serie de procesos, almacenamientos o inspecciones". (p. 175)

Everett (1991) nos dice: "el proceso productivo es una parte de las organizaciones que existe para generar o producir bienes o servicios. En toda organización existe un proceso de conversión. Son necesarios para este proceso los insumos; el proceso por el cual se convierten los insumos; el producto que resulta de esta conversión y los círculos de retroalimentación en el subsistema de operaciones. ” (p. 190)

A continuación, se describe detalladamente el proceso productivo del banano orgánico:

\subsubsection{Manejo del cultivo.}

Para un adecuado manejo del cultivo, es necesario realizar oportunamente las siguientes actividades: Deshierbo, Deshije, Deshoje, Deschante.

\subsubsection{Fertilización.}

Se realiza cada 4 meses, aplicando al suelo: Compost y guano de Isla.

\subsubsection{Riego.}

Se realiza cada 20 días por inundación con agua proveniente del río Chira. 


\subsubsection{Manejo del racimo.}

Un manejo adecuado de la racima garantiza una fruta de óptima calidad para ser exportada. El manejo adecuado de las racimas implica realizar las siguientes actividades: endaipe, enfunde, desflore, deschive, destore y limpieza del enfundado.

\subsubsection{Control de plagas y enfermedades.}

Existen dos enfermedades en la zona:

\subsubsection{Virus del mosaico.}

La enfermedad del rayado del banano, es causada por el virus del rayado del banano (BSV). En el caso de presencia de plantas infestadas por virus del mosaico, estas son retiradas inmediatamente de la plantación.

\subsubsection{Trips de la mancha roja.}

Manchas en la fruta que ocasiona alto porcentaje de merma en la producción. En el caso de trips de la mancha roja, se recomienda realizar labores culturales como: deshierbo, deshoje, deschante, enfunde temprano. Preventivamente se puede aplicar repelentes naturales elaborados a base de ajo y aplicaciones de azufre en polvo y/o caldo sulfo cálcico.

\subsubsection{Cosecha.}

La cosecha se realiza manualmente: se cortan las racimas una a una. El control de cosecha y selección de racimas se hace en campo por los propios productores. 
En este proceso se selecciona las racimas de bananos de primera y de segunda. Las racimas de bananos de primera se envían a los centros de empaque y las racimas de banano de segunda son comercializadas por los propios asociados en los mercados locales.

Esta actividad es realizada tomando en cuenta la edad de la racima, según el color de la cinta. Se cosechan racimos de 8 a 12 semanas de edad desde el enfunde hasta la cosecha.

\subsubsection{Post cosecha.}

En este proceso, se realizan las siguientes actividades:

\subsubsection{Traslado hacia la empacadora.}

Los Bananos de primera son trasladados del campo en cunetas sobre los hombros de los cargadores (disminuyendo la calidad del banano) a los centros de empaque rústicos.

\subsubsection{Lavado y tratamiento.}

Se recibe la fruta, se corta la fruta en clústeres de 3-5 bananos y se sumerge la fruta en una solución de jugo de limón, alumbre y agua.

\subsubsection{Selección, pesado y empaque.}

Fintrac (2016), para la selección de la fruta, ésta no debe tener:

- Golpes, rayones, rajaduras, heridas, magulladuras, quebraduras. 
- La fruta no debe presentar daños por insectos, animales, mancha de látex quemadura de sol, punta de cigarro, cicatrices.

- No deben empacarse dedos delgados o muy gruesos.

- La fruta no debe presentar suciedad, dedos sin aristas, dedos deformes u otros.

Una vez seleccionada la fruta, se les coloca un código de barras con las cintas codificadas, se coloca en bolsas, se extrae el aire de las bolsas, se coloca la fruta dentro de cajas de 18.14 kilogramos, luego se pesa y se trasladada al centro de paletizado.

\subsubsection{Paletizado.}

En el centro de paletizado, las cajas son embaladas en pallets de madera, sujetas con sunchos con grapas metálicas. Cada contenedor consta de 22 pallets (1 080 cajas); y las parihuelas son de tipo europeo. Una vez que los contenedores están llenos, son transportados en camiones al puerto de Paita, ubicado a 45 minutos de la ciudad de Sullana. Desde este puerto son enviados los contenedores a los principales puertos del mercado norteamericano, europeo y asiático.

\subsection{Regulación de licencias y políticas.}

David (2013) nos dice que los gobiernos federales, estatales, locales y extranjeros son importantes reguladores, desreguladores, subvencionadores, empleadores y clientes de la organización. Por tanto, los factores legales pueden representar oportunidades o amenazas clave para la organización. (p. 68) 


\subsubsection{Licencia.}

La cooperativa se constituyó con Partida Registral N 11071682 en Registros Públicos de fecha 09 de enero del 2015. La inscripción se encuentra legalmente constituida, de acuerdo a la legislación peruana.

\subsubsection{Normas de la industria.}

\subsubsection{Certificación de análisis HACCP (hazard analysis critical control points)}

Esta certificación es regulada por el ministerio de salud y la norma R.M. $\mathrm{N}^{\mathrm{o}}$ 482-2005/MINSA, se aplica conforme a lo dispuesto por el reglamento sobre vigilancia y control sanitarios de alimentos y bebidas, reguladas por D.S. No 007-98-SA en su Quinta Disposición Complementaria, Transitoria y Final y a las Directrices para la Aplicación del Sistema de Análisis de Peligros y de los Puntos Críticos de Control (Sistema HACCP).

Esta norma tiene como objetivo: establecer en la industria alimentaria la aplicación de un sistema preventivo de control, que asegure la calidad sanitaria e inocuidad de los alimentos y bebidas, basado en la identificación, evaluación y control de los peligros significativos para cada tipo de producto.

En el caso de los productores de banano orgánico, se requiere de un análisis de la plantación, para realizar la verificación de los estándares higiénicos del procesamiento de la fruta. Para ello, la cooperativa debe preparar su Plan HACCP de conformidad con las disposiciones de la norma R.M. No 482-2005/MINSA, de tal 
forma que su cumplimiento asegure el control de los peligros que resulten significativos para la inocuidad de la fruta a exportar.

Derecho Inspección 15\% UIT (MYPE)

Costo de Inspección

Costo Anual Certificación Análisis HACCP: 1,207.50 soles

\subsubsection{Certificación fitosanitario internacional.}

El certificado fitosanitario internacional $(\mathrm{CFI})$ es un requisito para exportar mercancías de origen vegetal, expedido por el Servicio Nacional de Sanidad Agraria (SENASA) que es un organismo público-técnico especializado adscrito al Ministerio de Agricultura con autoridad oficial en materia de sanidad agraria, calidad de insumos, producción orgánica e inocuidad agroalimentaria.

De acuerdo al SENASA, las exportaciones de los productos agrícolas tradicionales y no tradicionales presentan un crecimiento sostenido en los últimos años. Esta situación, implica una mayor demanda en la ejecución del Sistema de Certificación Fitosanitaria, de forma segura y eficiente, proceso que juega un rol importante en las negociaciones comerciales y a la vez cautela el prestigio internacional logrado por el Perú en el tema de las exportaciones agrícolas.

El CFI es un documento oficial que certifica que las plantas y productos vegetales han sido inspeccionados acorde con procedimientos apropiados y son considerados libres de plagas cuarentenarias y prácticamente libres de otras plagas perjudiciales, 
teniendo en cuenta la actual regulación fitosanitaria del país importador.

El SENASA mediante norma (RD N 0050-2016-MINAGRISENASA-DSV), estableció cinco (05) Categorías de Riesgo Fitosanitario que van de la uno (1) a la cinco (5) en donde están agrupadas las plantas, productos vegetales y otros artículos reglamentados. No todos los productos tienen un riesgo fitosanitario similar, debido a sus características intrínsecas y a su nivel de procesamiento, muchos de ellos disminuyen su nivel de riesgo hasta la mínima expresión.

Para el caso de la exportación de banano orgánico, se requiere del CFI-CRF 2,3,4. Esta certificación otorgada por SENASA, cuenta con validez en los mercados estadounidense y europeo.

Inspección en Almacén del Exportador : 168.30 soles Certificación 43.20 soles

Costo Anual CFI: 211.50 soles

\subsubsection{Certificado de origen.}

El Certificado de Origen es emitido por la Asociación de Exportadores o la Cámara de Comercio de Lima a aquellas empresas que necesitan exportar su mercadería. Para ello, es necesario que el importador cuente con una prueba de origen (certificado de origen o declaración de origen), que cumpla con lo dispuesto en el acuerdo comercial o régimen preferencial bajo el cual se solicitará el trato preferencial en el país de destino de la mercancía. 
Todas las empresas exportadoras de productos agropecuarios requieren del Certificado de Origen.

\section{Certificación (1\% UIT + IGV) : 47.79 soles \\ Costo Anual Certificación Origen: 47.79 soles por contenedor.}

\subsubsection{Certificación orgánica.}

El portal de agricultura orgánica (2011) nos dice "la certificación orgánica es la garantía para asegurar el buen estado y salubridad de un alimento para ser consumido, puesto que permite constatar si el cultivo ha seguido acertadamente las normas de producción orgánica.

Los requisitos varían de país en país e implica generalmente un sistema estándar de producción para crecer, almacenar, procesar, empaquetar, etc".

Cuando una agencia certificadora otorga el sello de certificación al producto, se asegura que el campo ha sido inspeccionado y asegura que el producto es orgánico y libre de materia sintética.

La certificación es útil al consumidor, pero también es útil al productor, porque le ayuda a vender mejor sus productos a mercados diferenciados. La certificación orgánica debe ser realizada por organismos de certificación autorizados y registrados ante la autoridad competente. 
En el Perú las empresas certificadoras más importantes son: Bio Latina, Kiwa - partner for progress, Control Union Certifications.

\section{Costo de Certificación Promedio : $\quad$ : 13,500 soles}

Costo Anual Certificación Orgánica $\quad$ :13,500 soles

\subsubsection{Certificación global g.a.p.}

Control Union (2017), “la certificación global g.a.p., es la aplicación de los estándares para las buenas prácticas agrícolas (en inglés Good Agricultural Practice), promovidas por el Euro Retailer Group (EUREP), que representa a las cadenas de supermercados líderes en el sector alimentario a nivel europeo.

Esta certificación es importante porque desde el 2003, los miembros más importantes del EUREP comenzaron a solicitar a sus proveedores esta certificación. La certificación es aplicable tanto para productos frescos y flores, teniendo como objetivo responder al interés creciente del consumidor por el impacto medioambiental y garantizando la sanidad y seguridad en los alimentos".

La certificación GLOBAL G.A.P. debe ser realizada por organismos de certificación autorizados y registrados ante la autoridad competente.

En el Perú las empresas certificadoras más importantes son: Bio Latina, Kiwa - partner for progress, Control Union Certifications. 
$\underline{\text { Certificación Promedio : } 13,500 \text { soles }}$

Costo Anual Certificación Global G.A.P.: 13,500 soles.

4.4.2.6. Certificación comercio justo (fair trade).

De acuerdo a la FAO (2016), el programa comercio justo busca mejorar el acceso a los mercados y las condiciones comerciales para los pequeños productores y los trabajadores en plantaciones agrícolas.

Para alcanzar esto, el comercio justo contempla un precio mínimo garantizado por el producto que se exporta, más un premio, dinero que las organizaciones de productores deberán usar para mejorar las condiciones de la comunidad. En el caso de la producción en plantaciones, el propósito central es mejorar las condiciones laborales de los trabajadores.

La certificación la otorga la Organización Internacional de Comercio Justo (Fairtrade Labelling Organizations Internacional FLO), una organización encargada de establecer los requisitos del Comercio Justo y certificar. La FLO actualmente cuenta con 17 organizaciones nacionales en Europa, Norteamérica y Japón.

La certificación de Comercio Justo puede ser solicitada por un grupo de productores organizados en una cooperativa, una asociación de agricultores o una plantación con una fuerza laboral organizada. 
Supervisores locales inspeccionan el predio agrícola y una agencia certificadora certificará a la organización de productores. Una vez otorgada la certificación se realiza una inspección anual para verificar que los productores cumplan con los requisitos de Comercio Justo y ver lo que han logrado con el premio de Comercio Justo.

El contar con la certificación de comercio justo, le garantiza a la cooperativa recibir un dólar americano por cada caja de banano orgánico exportado. En Perú, la empresa certificadora autorizada para otorgar este certificado es la empresa FLOCERT Assuring Fairness.

Certificación Promedio : 1,957 euros

Costo Anual Certificación Comercio Justo: 6,890 soles.

La Cooperativa Agraria Alto Grande Santa Sofía realiza su producción y empacado de acuerdo a las normas internacionales de exportación y cuenta con las siguientes certificaciones:

- La Certificación de Análisis HACCP, certificación que se realiza una vez al año.

- El Certificado Fitosanitario, necesario para realizar exportaciones.

El certificado de origen es tramitado por contenedor por el comprador de la fruta empacada, es decir, este costo lo asume la empresa APBOSMAM. Las certificaciones Orgánica, Global G.A.P. y Comercio Justo también son otorgadas por APBOSMAM ya que la organización no cuenta con ellas. 
El no contar con estas certificaciones limita a la organización a buscar otros clientes ya que de contar con dichas certificaciones podría buscar nuevos clientes que le ofrezcan mejores precios por la fruta vendida. Actualmente, el no contar con la certificación de comercio justo, le impide recibir el dólar que debiera recibir por cada caja de banano orgánico exportado. Dado que esta certificación la tiene Apbosmam, es esta organización quien se beneficia de dicho pago adicional.

\subsubsection{Aspectos tributarios y laborales.}

\subsubsection{Impuesto a la renta.}

Sunat (2017), el impuesto a la renta es un impuesto que grava las rentas que provienen del capital, del trabajo o de ambos factores y consiste en el pago anual del 15\% de la renta neta, según la Ley $\mathrm{N}^{\circ} 28810$ que amplió vigencia de la Ley $\mathrm{N}^{\circ}$ 27360, ley sobre las normas de promoción del sector agrario.

\subsubsection{Impuesto general a las ventas.}

Sunat (2017), de acuerdo al texto único ordenado de la ley del impuesto general a las ventas e impuesto selectivo al consumo decreto supremo $\mathrm{N}^{\circ}$ 055-99-EF, las ventas en el país de bananas o plátanos frescos se encuentran dentro de la relación de operaciones exoneradas del Impuesto General a las Ventas.

4.4.3.3.promoción de la inclusión de los productores agrarios en cooperativas.

Mediante la Ley 1816/2012-CR se promueve la inclusión de los productores agrarios en cooperativas. Para ello, crea un 
régimen especial tributario exclusivo para cooperativas agrarias, que se aplica a partir del $1^{\circ}$ de enero del 2013 y va a tener una vigencia de 10 años.

Mediante esta ley, las ventas y prestación de servicios que hagan los socios a su cooperativa o la cooperativa a sus socios, no están gravados con el Impuesto General a las Ventas (IGV).

\subsection{Proyección de costos de producción.}

Actualmente los procesos de producción de la organización son los siguientes:

\subsubsection{Situación actual - proyección del costo de compra de fruta en planta al socio productor.}

La cooperativa le compra las racimas en planta al productor y, se encarga de transportarlas a los centros de empaque rústico donde serán seleccionadas, lavadas y empacadas. En el proceso de selección, la fruta que no califique para ser exportada le es devuelta al productor para que la comercialice en el mercado nacional. La fruta que califica para exportación, le es comprada al productor en razón del número de cajas de $18.14 \mathrm{Kg}$. que se obtuvieron del número de racimas entregadas.

Para la proyección del costo de la compra de fruta para los siguientes años se han considerado los siguientes supuestos:

- En los últimos años el precio pagado al productor por caja de banano orgánico ha sido 6.3 US\$/Caja de $18.14 \mathrm{Kg}$. El precio pagado está en función del precio del mercado internacional, cualquier disminución del precio mundial implica una reducción del precio de 
compra al agricultor. Por tratarse de una cooperativa, cuando ocurren estas variaciones, la reducción del precio de compra es el mismo porcentaje de la reducción del precio internacional.

Dado que se estima que el precio internacional del banano orgánico se mantendrá en $0.75 \mathrm{US} \$ / \mathrm{Kg}$. por los próximos cinco años, estimamos que el precio de compra de la caja al agricultor se mantendrá en 6.3 US\$/Caja.

- Los costos se proyectan al tipo de cambio proyectado por el Ministerio de Economía y Finanzas.

Tabla 32: Situación Actual - Proyección del Costo de Compra de

Fruta

\begin{tabular}{|l|r|r|r|r|r|r|}
\hline \multicolumn{1}{|c|}{ Concepto } & Año 0 & Año 1 & Año 2 & Año 3 & Año 4 & Año 5 \\
\hline Costo Compra de Fruta $(\mathrm{S} /)$ & $\mathbf{2 , 0 8 5 , 8 3 5}$ & $\mathbf{2 , 1 3 0 , 0 8 0}$ & $\mathbf{2 , 1 3 6 , 4 0 1}$ & $\mathbf{2 , 1 4 2 , 7 2 1}$ & $\mathbf{2 , 1 4 9 , 0 4 2}$ & $\mathbf{2 , 1 5 5 , 3 6 3}$ \\
\hline Cantidad Fruta Comprada & 100,329 & 100,329 & 100,329 & 100,329 & 100,329 & 100,329 \\
\hline Costo Fruta Comprada & 6.30 & 6.30 & 6.30 & 6.30 & 6.30 & 6.30 \\
\hline Tipo de Cambio & 3.30 & 3.37 & 3.38 & 3.39 & 3.40 & 3.41 \\
\hline
\end{tabular}

Fuente y elaboración propia

\subsubsection{Situación actual - proyección del costo del proceso de lavado y empaque.}

\subsubsection{Transporte de la fruta al centro de empaque rústico.}

Asbama (2015), para realizar el corte de la racima en la planta, el ayudante pica el pseudotallo a una altura conveniente para que la planta se agobie y el racimo baje suavemente hasta la 
altura en que los cortadores y/o cargadores insertan la barracuda para proceder al corte de la racima.

Una vez cortada la racima, es transportada a los centros de empaques rústicos por intermedio de los cargadores.

\section{Ilustración 16: Corte y Transporte de la Fruta al Centro de}

\section{Empaque}

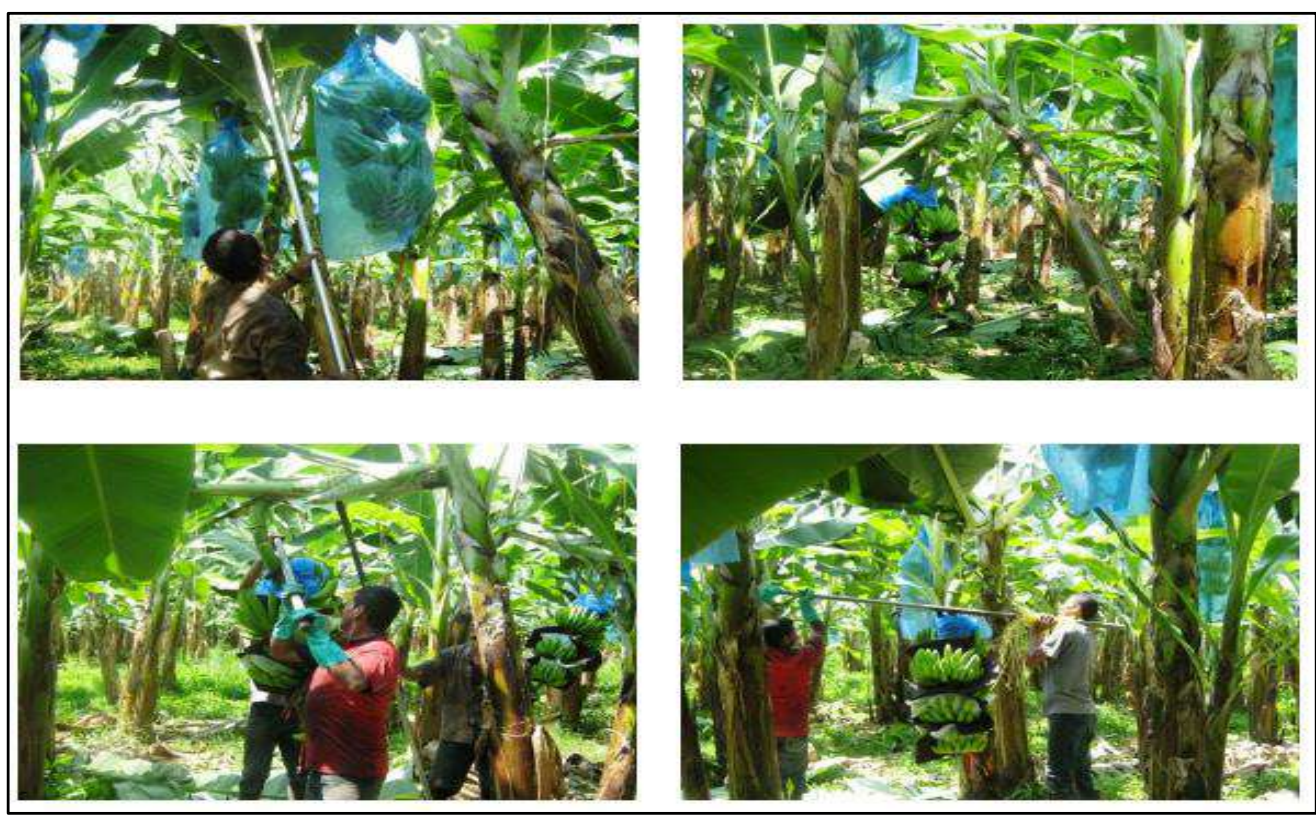

Fuente y Elaboración Propia.

\subsubsection{Proceso de lavado.}

Asbama (2015), una vez que la racima llega al centro de empaque se procede a cortar los clústeres, para lo cual se usa un cuchillo curvo (cuchareta) que permite un corte limpio sin dejar rastros de otros cortes o desgarres.

En esta etapa es muy importante la experiencia del cortador para eliminar los clústeres más pequeños, deformados o que presenten defectos (rasguños, daños causados por insectos, etc.). 
Es en este proceso donde se realiza la primera selección de la fruta y se clasifica la fruta que tienen condiciones de ingresar al proceso de lavado, de la fruta que le será devuelta al productor para que la comercialice en el mercado nacional.

Ilustración 17: Corte de Clústeres

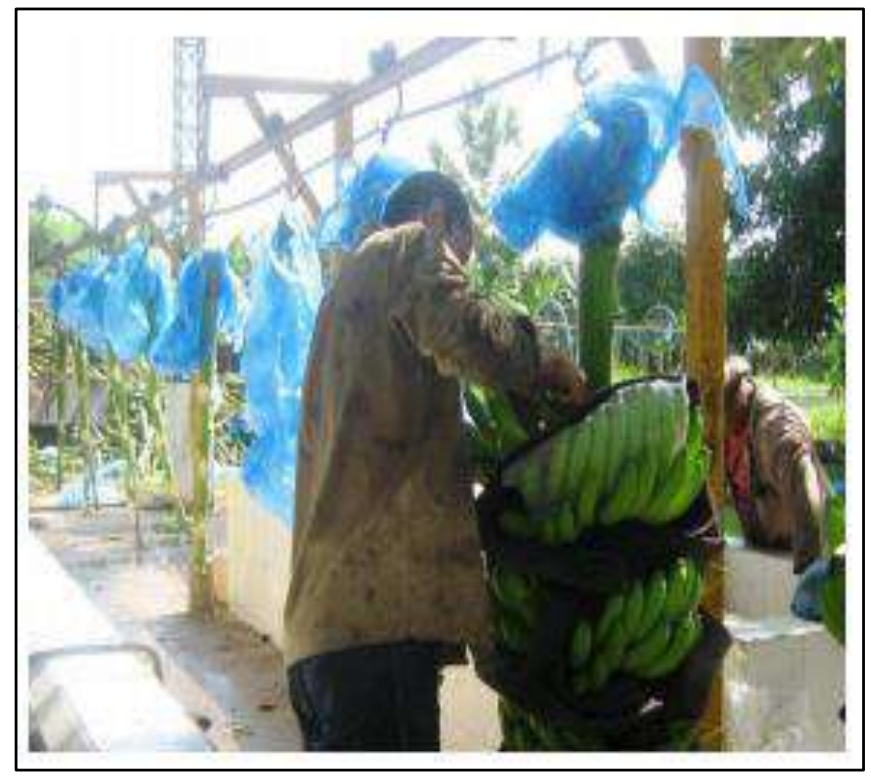

Fuente y Elaboración Propia.

A cada centro de empaque rústico se llevan las tinas móviles para proceder a lavar cuidadosamente la fruta. Los clústeres que fueron seleccionados son depositados en las tinas para iniciar el proceso de lavado. En las tinas móviles, los clústeres permanecen entre doce a veinte minutos dentro del agua para eliminar todo el látex de la fruta. Para realizar el lavado de la fruta, la cooperativa contrata una cisterna que le abastece de agua para llenar las tinas móviles. 


\section{Ilustración 18: Proceso de Lavado}
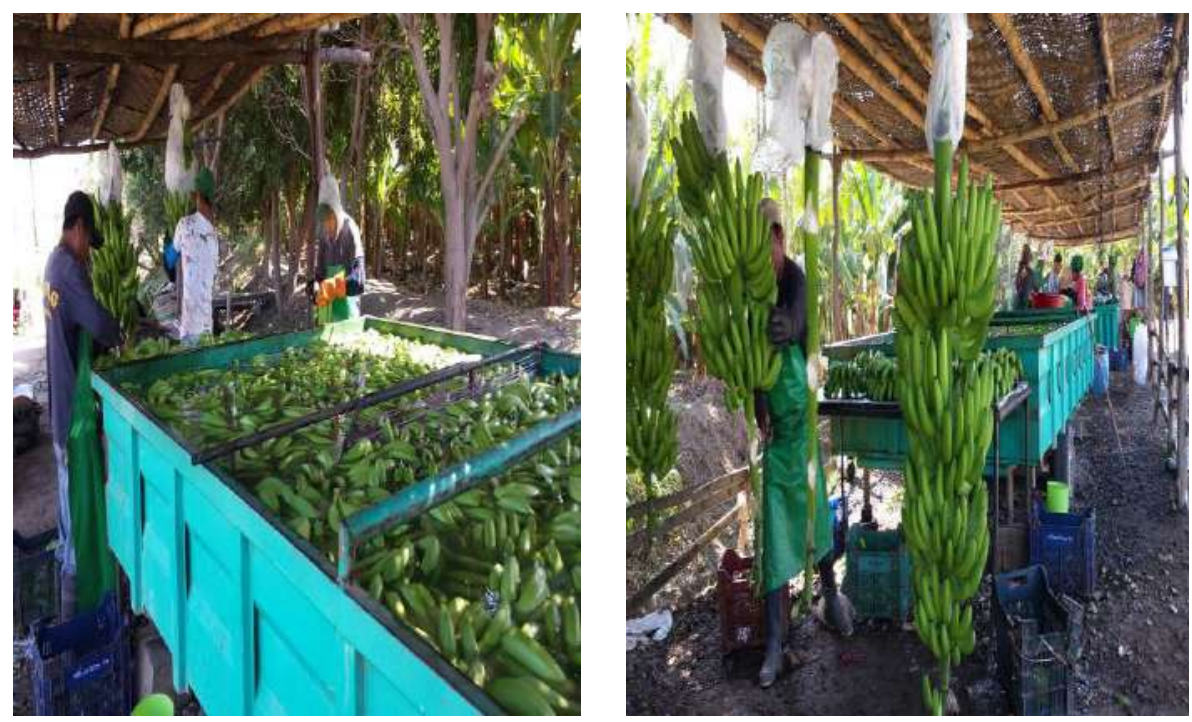

Fuente y Elaboración Propia.

Las tinas móviles son abastecidas de agua en los centros rústicos por una cisterna que diariamente les provee de agua para la realización del proceso de lavado.

La cisterna cobra 100 soles por llenar una tina de lavado de fruta; dado que se utilizan 03 tinas en los procesos de lavado y se trabaja 26 días del mes, el costo de alquiler de la cisterna es de 93,600 soles al año. Los insumos necesarios para realizar el lavado de la fruta son entregados por Apbosmam dentro del acuerdo comercial firmado.

Para el cálculo de la proyección del costo de alquiler de cisterna, se ha aplicado un crecimiento del costo en función del IPC del Perú proyectado por el Ministerio de Economía y Finanzas. 


\subsubsection{Proceso de empaque.}

Una vez terminado lavada la fruta, ésta es retirada de las tinas y colocada en mesas para dejarlas secar. Luego, a la fruta se le coloca las etiquetas distintivas de la marca de Apbosmam y, luego es introducida en bolsas plásticas, quedando listas para ser empacadas.

La fruta embolsada es colocada sobre las bandejas de la balanza, colocando los clústeres necesarios hasta completar el peso de la fruta para cada caja de 18.14 kilogramos. El empaque de la fruta se realiza en cajas de cartón corrugado que son proporcionadas por su cliente Apbosmam.

\section{Ilustración 19: Proceso de Empaque}
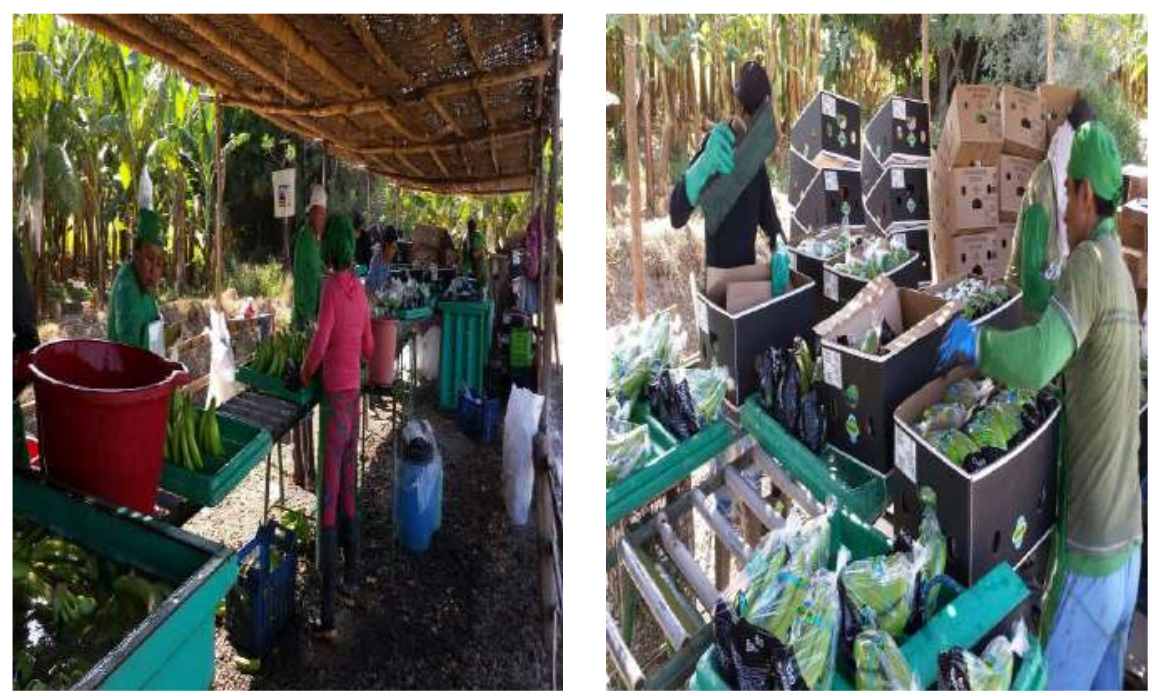

Fuente y Elaboración Propia.

Con la finalidad de garantizar la calidad de la fruta, la cooperativa les entrega a los socios productores las fundas protectoras de la racima en planta cuyo costo anual asciende a 48,581 soles. 
Todos los insumos utilizados en los procesos de lavado y empaque son proporcionados por la empresa Apbosmam. Sin embargo, la cooperativa debe ir a recoger estos insumos hasta los almacenes de su cliente. Adicionalmente, como el proceso de empacado se realiza en los centros rústicos habilitados entre los campos de cultivo, una vez que el banano orgánico se encuentra debidamente empacado, la cooperativa debe trasportar las cajas hasta el centro de paletizado de Apbosmam, ubicado en sus almacenes. Por estos motivos, la cooperativa debe alquilar un camión de carga para realizar ambas tareas. El camión es alquilado todos los días y realiza el siguiente recorrido:

\section{Ilustración 20: Ruta Recorrida por el Camión Furgón Alquilado}

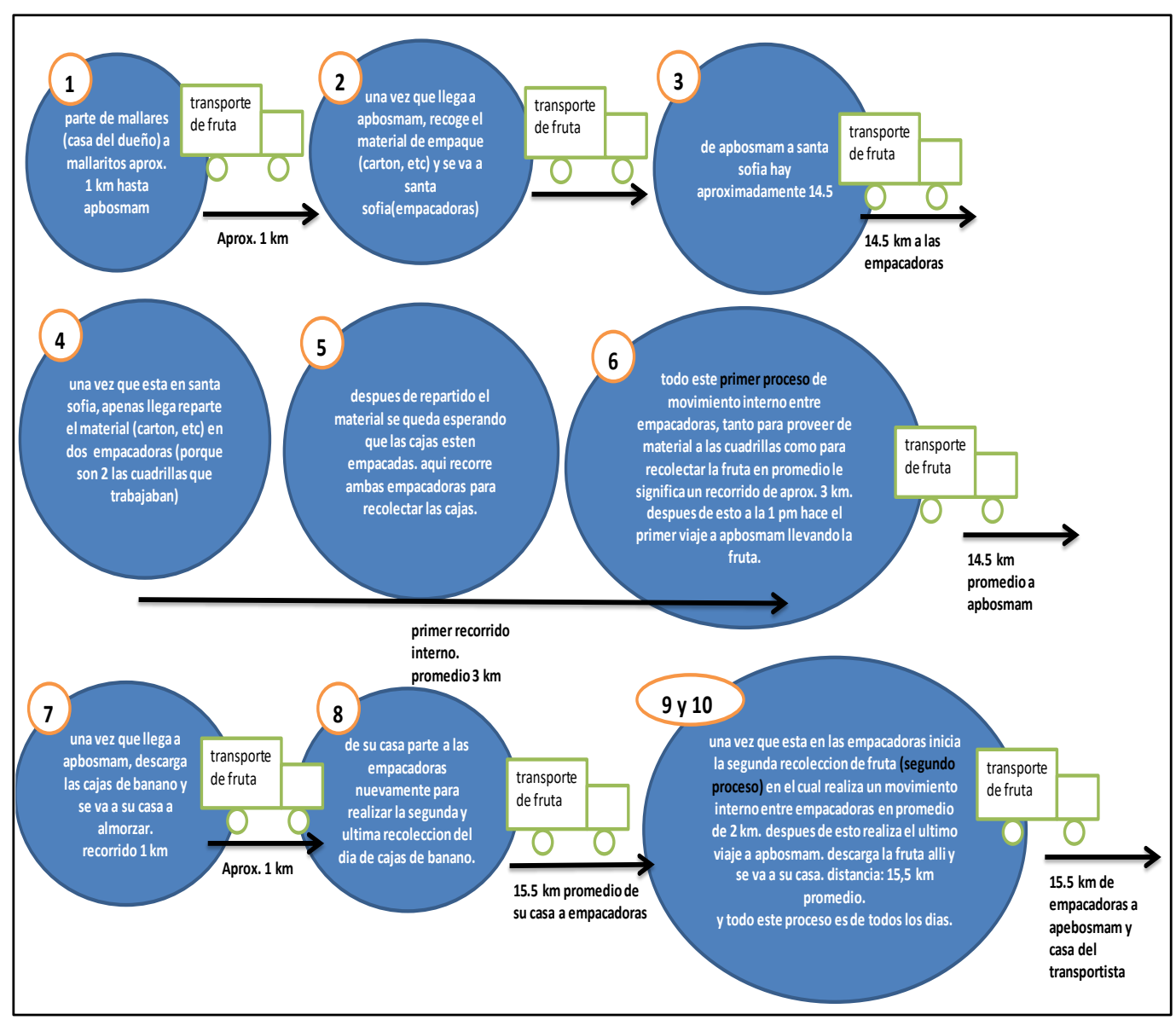

Fuente: "Base de Datos de la cooperativa. Área Contable.2017. Elaboración Propia. 
Por el alquiler del camión la cooperativa paga 320 soles diarios. Dado que el camión se alquila 26 días del mes, el costo de alquiler del camión es de 99,840 soles al año. Para el cálculo de la proyección del costo de alquiler de cisterna, se ha aplicado un crecimiento del costo en función del IPC del Perú proyectado por el Ministerio de Economía y Finanzas.

Para la realización del proceso de corte, transporte, lavado, sellado y empacado de la fruta la empresa cuenta con dos cuadrillas de operarios. Cada cuadrilla está conformada por 16 operarios: 02 cortadores, 06 cargadores, 01 ayudante, 07 lavadores.

Por concepto de pago de operarios la cooperativa realiza un costo mensual:

Tabla 33: Costo de los Operarios

\begin{tabular}{|c|c|c|c|c|r|}
\hline \multirow{2}{*}{ Descripción } & \multirow{4}{*}{ Cantidad } & \multicolumn{4}{|c|}{ Costo Unitario por Operario } \\
\cline { 3 - 6 } & & $\begin{array}{c}\text { Sueldo } \\
\text { Básico }\end{array}$ & $\begin{array}{c}\text { Asignación } \\
\text { Familiar }\end{array}$ & $\begin{array}{c}\text { Essalud } \\
(4 \%)\end{array}$ & TOTAL \\
\hline Cortadores & 4 & 934 & 85 & 37 & 4,227 \\
\hline Cargadores & 12 & 934 & 85 & 37 & 12,680 \\
\hline Ayudante & 2 & 934 & 85 & 37 & 2,113 \\
\hline Lavadores & 14 & 934 & 85 & 37 & 14,793 \\
\hline TOTAL & $\mathbf{3 2}$ & & & & $\mathbf{3 3 , 8 1 2}$ \\
\hline
\end{tabular}

Costo Anual Proyectado

Fuente: "Base de Datos de la cooperativa. Área Contable.2017. Elaboración Propia.

Los salarios de los operarios se ajustarán anualmente en función del IPC del Perú proyectado por el Ministerio de Economía y Finanzas. 
Con la finalidad que los operarios puedan realizar sus labores, la cooperativa les provee de la indumentaria necesaria. Para ello, se adquieren los siguientes implementos por cada operario:

Tabla 34: Indumentaria de los Operarios

\begin{tabular}{|l|r|l|r|}
\hline \multicolumn{1}{|c|}{ Producto } & Importe (S/) & Producto & Importe (S/) \\
\hline Polera & 32.00 & Gorras & 12.00 \\
\hline Botas & 16.00 & Guante Grueso & 27.00 \\
\hline Mandil & 20.00 & Guante Fino & 10.00 \\
\hline Tapabocas & 4.00 & Otros & 12.00 \\
\hline \multicolumn{2}{|c|}{ Costo Total Unitario } & 133.00 \\
\hline
\end{tabular}

Fuente: "Base de Datos de la cooperativa. Área Contable.2017. Elaboración Propia.

Los implementos para los operarios se compran en paquetes de 40 unidades, de manera cuatrimestral llegándose a invertir anualmente un total de 21,280 soles.

Costo unitario implementos por operario: 133.00 soles

Número compras al año

Cantidad comprada por vez

Costo anual de Implementos: $133 * 4 * 40=21,280$ soles

Adicionalmente, la cooperativa paga las certificaciones HACCP y Fitosanitaria Internacional por un total de 1,419 soles anuales.

Parte de los gastos operativos del proceso de lavado de la fruta es la limpieza y mantenimiento de las tinas móviles. Con la finalidad de garantizar la continuidad de los procesos se hace necesario realizar inversiones anuales en: 
a. reparar los centros de empaque rústicos.

La organización tiene como política reparar los centros de empaque rústicos. Por data histórica, el gasto de mantenimiento asciende a 7,000 soles anuales.

b. mantenimiento de tinas móviles.

La cooperativa realiza un mantenimiento mensual a las tinas móviles, el cual consiste en revisar las llantas, fisuras de las tinas y reposición de repuestos. El costo mensual de mantenimiento es de 200 soles. El gasto anual asciende a 2,400 soles.

Reparación Centros Empaque $\quad$ : 7,000 soles

Mantenimiento Tinas Móviles : 2,400 soles

Costo anual de Mantenimiento de Tinas y Centros de Empaque: 9,400 soles

Todos los costos se ajustarán de acuerdo al IPC proyectado por el Ministerio de Economía y Finanzas. En resumen, la proyección de los costos de producción de la cooperativa por concepto de compra de fruta, transporte, proceso de lavado y empaque es: 
Tabla 35: Situación Actual - Proyección de Costos de Producción

\begin{tabular}{|l|r|r|r|r|r|r|}
\hline \multicolumn{1}{|c|}{ Concepto } & Año 0 & Año 1 & Año 2 & Año 3 & Año 4 & Año 5 \\
\hline Costo Compra de Fruta $(\mathrm{S} /)$ & $\mathbf{2 , 0 8 5 , 8 3 5}$ & $\mathbf{2 , 1 3 0 , 0 8 0}$ & $\mathbf{2 , 1 3 6 , 4 0 1}$ & $\mathbf{2 , 1 4 2 , 7 2 1}$ & $\mathbf{2 , 1 4 9 , 0 4 2}$ & $\mathbf{2 , 1 5 5 , 3 6 3}$ \\
\hline Cantidad Fruta Comprada & 100,329 & 100,329 & 100,329 & 100,329 & 100,329 & 100,329 \\
\hline Costo Fruta Comprada & 6.30 & 6.30 & 6.30 & 6.30 & 6.30 & 6.30 \\
\hline Tipo de Cambio & 3.30 & 3.37 & 3.38 & 3.39 & 3.40 & 3.41 \\
\hline
\end{tabular}

\begin{tabular}{|l|r|r|r|r|r|r|}
\hline Costo Proceso Lavado $(\mathrm{S} /)$ & $\mathbf{6 7 9 , 8 7 0}$ & $\mathbf{7 0 0 , 2 6 6}$ & $\mathbf{7 2 0 , 5 7 4}$ & $\mathbf{7 4 1 , 4 7 0}$ & $\mathbf{7 6 2 , 9 7 3}$ & $\mathbf{7 8 5 , 0 9 9}$ \\
\hline Indice de Precios Perú & $3,50 \%$ & $3.00 \%$ & $2,90 \%$ & $2.90 \%$ & $2.90 \%$ & $2.90 \%$ \\
\hline Alquiler Cisterna & 93,600 & 96,408 & 99,204 & 102,081 & 105,041 & 108,087 \\
\hline Alquiler Camión & 99,840 & 102,835 & 105,817 & 108,886 & 112,044 & 115,293 \\
\hline Mano Obra Cuadrillas & 405,750 & 417,922 & 430,042 & 442,513 & 455,346 & 468,551 \\
\hline Costo Indumentaria & 21,280 & 21,918 & 22,554 & 23,208 & 23,881 & 24,574 \\
\hline $\begin{array}{l}\text { Mantenimiento de Tínas y Centros } \\
\text { de Empaque Rústicos }\end{array}$ & 9,400 & 9,682 & 9,963 & 10,252 & 10,549 & 10,855 \\
\hline $\begin{array}{l}\text { Fundas, certificación HACCP, } \\
\text { certificacción CFI }\end{array}$ & 50,000 & 51,500 & 52,994 & 54,530 & 56,112 & 57,739 \\
\hline
\end{tabular}

\begin{tabular}{|l|r|r|r|r|r|r|}
\hline $\operatorname{COSTO}$ TOTAL $(\mathrm{S} /)$ & $2,765,705$ & $2,830,346$ & $2,856,974$ & $2,884,192$ & $2,912,015$ & $2,940,462$ \\
\hline
\end{tabular}

Fuente y elaboración propia

Luego de exponer la situación actual del proceso de lavado y empaque de la cooperativa, identificamos que el problema de la organización se enfoca en una ineficiencia operativa que se refleja en: (1) inadecuadas condiciones para el proceso de lavado y empaque de la fruta, (2) elevados costos de producción (3) riesgo concentrado en un solo cliente.

Las causas que originan el problema son: (1) ausencia de un centro de empaque con tina fija que ayude a reducir el porcentaje de merma en el proceso de lavado de fruta. El contar con un centro de empaque ayuda a obtener las certificaciones: comercio justo y global gap (2) altos costos de traslado de insumos y cajas de fruta de los centros de empaque a los almacenes de 
Apbosmam, (3) falta de certificaciones orgánica, global gap y comercio justo que permitirían recibir el dólar adicional por concepto de comercio justo y buscar nuevos clientes.

\subsubsection{Implementación de mejoras tecnológicas.}

Con la finalidad de mejorar la eficiencia operativa, se elabora este plan de negocios buscando que la organización pueda acogerse al Programa de Compensaciones para la Competitividad bajo la modalidad de Adopción de Tecnología.

De acuerdo a la información publicada en el portal: www.agroideas.gob.pe, el programa tiene como objetivo promover el uso de tecnologías para reducir los costos y/o mejorar los sistemas de producción y la productividad agraria, como medio para mejorar la articulación a mercados.

A través de este incentivo se cofinancia la adquisición de bienes y servicios necesarios para la adopción de tecnología, incluyendo el conjunto de bienes y servicios conexos que se requieran para ello. Para ello, el programa reconoce como mejoras de bienes y servicios:

A. Bienes necesarios para la adopción de tecnología

- Insumos estratégicos para reconversión productiva.

- Insumos estratégicos para la instalación y/o manejo de cultivos.

- Herramientas, equipos y maquinaria

- Vehículos para la mecanización.

- Vehículos mayores para acopio y/o distribución de la producción de la organización agraria. 
- Vehículos menores para la gestión de la cooperativa.

- Infraestructura para dar valor agregado a la producción: almacenamiento, empaque, procesamiento.

- Infraestructura y equipos para riego tecnificado.

B. Servicios conexos especializados vinculados a la(s) tecnología(s) que se están adoptando como:

- Servicios para la producción, transformación y procesamiento como: capacitación y asistencia técnica para la producción y transformación/procesamiento, gestión de calidad, certificaciones (orgánica, comercio justo, entre otras).

- Servicios para la comercialización.

C. Gastos asociados a la provisión de servicios, como:

- Honorarios (servicios especializados como: asesorías, consultorías, proyectos).

- Viáticos (pasajes, movilidad, alojamiento, alimentación, etc).

El monto máximo de aporte del Programa por productor asociado es de 4 UIT, hasta un tope de 300 UIT por organización. Los aportes son No Reembolsables. El porcentaje de cofinanciamiento por parte del Programa varía entre $60 \%$ y $80 \%$, según la magnitud de recursos que le son solicitados. 
Tabla 36: Agroideas - Montos Para Adopción de Tecnología

\begin{tabular}{|c|c|c|}
\hline Valor Total de la Adopción & Agroideas (\%) & Organización (\%) \\
\hline \multirow{2}{*}{ He Tecnología } & $80 \%$ & $20 \%$ \\
\cline { 2 - 3 } & S/. 380,000 $/ 475,000$ & S/. 95,000 \\
\hline \multirow{2}{*}{$\begin{array}{c}\text { Desde S/. 475,001 } \\
\text { Hasta S/ 1 086,800 }\end{array}$} & $70 \%$ & $30 \%$ \\
\cline { 2 - 3 } & S/. 760,760 & S/. 326,040 \\
\hline \multirow{2}{*}{$\begin{array}{c}\text { Desde S/. 1 086,801 } \\
\text { Hasta S/ 1 900,000* }\end{array}$} & $60 \%$ & $40 \%$ \\
\cline { 2 - 3 } & S/. 1,140,000 & S/. 760,000 \\
\hline
\end{tabular}

Fuente y Elaboración: Ministerio y Agricultura y Riego - Agroideas, www.minagri.gob.pe, 2016. * Si el valor de adopción de tecnología es mayor, el progama cofinanciará como máximo S/ 1095000.

Para ser beneficiarias de agroideas, las organizaciones agrarias deben cumplir con tres requisitos fundamentales:

- Ser elegibles, es decir, cumplir con los requisitos de tipo legal y contable establecidos por agroideas,

- Presentar un plan de negocios sostenible y rentable, y

- Contar con la contrapartida al cofinanciamiento ofrecido.

El presente plan de negocios ayudará a la organización a ser elegible para el Programa de Compensaciones para la Competitividad y poder realizar las siguientes acciones que le ayudarán a mejorar la eficiencia operativa de la organización y a buscar nuevos clientes:

\subsubsection{Certificar los campos}

La cooperativa debe adquirir las certificaciones "orgánica", "comercio justo" y "global gap" para poder acceder a los estándares de producción y competitividad exigidos por los mercados internacionales y diferenciados, ofertando así un producto con valor agregado. 
La obtención de la certificación demora aproximadamente tres meses; dos meses para las etapas de identificación de áreas, preparación de los productores, auditoría y levantamiento de observaciones y, un mes para la obtención del certificado. Se accede a estas certificaciones contando permanentemente con un sistema interno de control y la implementación de un sistema de gestión de la calidad.

Estos sistemas se encuentran bajo la responsabilidad de un coordinador (ingeniero agrónomo especialista) y un inspector interno (técnico agrario), que velan por el cumplimiento de las disposiciones, normas y reglamentos exigidos por la certificadora.

Las cotizaciones de las certificaciones se pueden ver en el Anexo 2: Cotizaciones de las Certificaciones: Orgánica, Global Gap y Comercio Justo.

\subsubsection{Mejorar las condiciones de empacado}

El proceso de lavado de la fruta debe realizarse en condiciones tales que permita el retiro del látex, despiece y desinfección de los clústeres de fruta en óptimas condiciones de inocuidad y productividad.

Las tinas móviles de fabricación artesanal son poco profundas y al tratar de lavar la mayor cantidad de fruta posible se lastima por rozamiento con las paredes de la tina y se mancha con látex que no ha logrado retirarse. Por este motivo, se solicitará el cofinanciamiento para la construcción de un centro de empaque con tina fija de mayor densidad de producción y potencial de 
crecimiento, la cual permitirá reducir la merma en el proceso de lavado de fruta. De acuerdo a la experiencia de cooperativas similares que cuentan con centro de empaque con tina fija, las mermas en el proceso de lavado se pueden reducir hasta en un $5.00 \%$.

Además, para poder conseguir la certificación comercio justo y global gap es requisito indispensable contar con un centro de empaque con tina fija. La construcción de la tina fija se realizará en el sector de mayor densidad de producción.

Cabe señalar que para la construcción del centro de empaque fue necesario adquirir los derechos y acciones de un terreno. Por esta se compra se pagaron 5,500 soles como consta en el Anexo 3: Ficha Registral de Compra de Derechos y Acciones. La cotización del centro de empaque se puede ver en el Anexo 4: Cotización del Centro de Empaque.

\subsubsection{Reducir los costos de distribución.}

Adquirir un camión furgón propio reducirá los costos del alquiler de camión para el traslado de fruta procesada desde los centros de empaque hacia el almacén del cliente Apbosmam; ayudará a evitar pérdidas por sobre maduración de la fruta empacada no transportada y sanciones pecuniarias por demora en la entrega comprometida. La cotización del camión se puede ver en el Anexo 5: Cotización del Camión y en el Anexo 6: Cotización de la Carrocería Tipo Furgón. 
Sin embargo, también se proyecta realizar algunas inversiones, financiadas al $100 \%$ con fondos propios de la cooperativa:

\subsubsection{4.comprar tres tinas móviles.}

Debido a las distancias de los predios agrícolas, no será posible trasladar toda la fruta al centro de empaque fijo. Por este motivo, seguirán utilizándose las tinas móviles para el lavado de la fruta distante. Se estima que las tinas deberán reponerse en 04 años, razón por la cual se proyecta adquirir 03 tinas móviles nuevas en dicho año por un valor estimado de 60,000 soles.

En resumen, se proyectan realizar las siguientes inversiones:

\section{Tabla 37: Proyección de Inversiones Tecnológicas}

\begin{tabular}{|l|r|}
\hline \multicolumn{1}{|c|}{ Conce pto } & \multicolumn{1}{|c|}{ Año 0 } \\
\hline $\begin{array}{l}\text { Camión y Carrocería Tipo } \\
\text { Furgón }\end{array}$ & 171,320 \\
\hline $\begin{array}{l}\text { Terreno Centro Empaque } \\
\text { Construcción de Centro } \\
\text { Empaque con Tina Fija }\end{array}$ & 105,000 \\
\hline Certificación Orgánica & 13,500 \\
\hline Certificación Global G.A.P. & 13,500 \\
\hline Certificación Comercio Justo & 6,890 \\
\hline INVERSION TOTAL & 315,710 \\
\hline
\end{tabular}

Fuente y Elaboración Propia 


\subsubsection{Situación futura - proyección del costo de compra de fruta en planta al socio productor.}

Por la construcción del centro de empaque con tina fija se reducirá la merma del proceso de lavado de fruta de $10 \%$ a $7 \%$. Si bien es cierto que, por experiencias de cooperativas similares, se puede lograr una reducción del porcentaje de merma hasta en 5\%, para la evaluación del proyecto suponemos conservadoramente que la reducción será sólo del $3 \%$ porque se seguirán usando las tinas móviles en varios procesos.

Teniendo en cuenta esta mejora en el proceso de lavado de fruta, se ha estimado que el número de cajas con calidad de exportación aumentará de 100,329 a 103,673.

Los demás supuestos para la proyección de los costos anuales por concepto de compra de fruta son similares a los establecidos para proyectar los costos de compra sin realizar mejora tecnológica alguna.

Tabla 38: Situación Futura - Proyección del Costo de Compra de

Fruta

\begin{tabular}{|l|r|r|r|r|r|r|r|}
\hline \multicolumn{1}{|c|}{ Concepto } & Año 0 & Año 1 & Año 2 & Año 3 & Año 4 & Año 5 \\
\hline \begin{tabular}{|l|r|r|r|r|r|r|}
\hline Costo Compra de Fruta & $2,085,835$ & $2,201,083$ & $2,207,614$ & $2,214,145$ & $2,220,677$ & $2,227,208$ \\
\hline Cantidad Fruta Comprada & 100,329 & 103,673 & 103,673 & 103,673 & 103,673 & 103,673 \\
\hline Costo Fruta Comprada & 6.30 & 6.30 & 6.30 & 6.30 & 6.30 & 6.30 \\
\hline Tipo de Cambio & 3.30 & 3.37 & 3.38 & 3.39 & 3.40 & 3.41 \\
\hline
\end{tabular}
\end{tabular}

Fuente y elaboración propia 


\subsubsection{Situación futura - proyección del costo del proceso de lavado y empaque.}

\subsubsection{Transporte de la fruta a los centros de empaque.}

Debido a que se cuenta con un nuevo centro de empaque con tina fija para el proceso de lavado y empaque de la fruta, es necesario contratar una cuadrilla adicional de 14 trabajadores para que operen en el nuevo centro de empaque. Esto significa que el nuevo costo anual por pago a cuadrillas será:

Tabla 39: Situación Futura - Proyección del Costo de Operarios

\begin{tabular}{|c|c|c|c|c|r|}
\hline \multirow{2}{*}{ Descripción } & \multirow{3}{*}{ Cantidad } & \multicolumn{4}{|c|}{ Costo Unitario por Operario } \\
\cline { 3 - 6 } & & $\begin{array}{c}\text { Sueldo } \\
\text { Básico }\end{array}$ & $\begin{array}{c}\text { Asignación } \\
\text { Familiar }\end{array}$ & $\begin{array}{c}\text { Essalud } \\
(4 \%)\end{array}$ & TOTAL \\
\hline Cortadores & 6 & 934 & 85 & 37 & 6,340 \\
\hline Cargadores & 18 & 934 & 85 & 37 & 19,020 \\
\hline Ayudante & 3 & 934 & 85 & 37 & 3,170 \\
\hline Lavadores & 19 & 934 & 85 & 37 & 20,076 \\
\hline TOTAL & $\mathbf{4 6}$ & & & & $\mathbf{4 8 , 6 0 5}$ \\
\hline
\end{tabular}

Costo Anual Proyectado 583,265

Fuente y elaboración propia

4.5.5.2. Proceso de lavado.

En el proceso de corte de las racimas en clústeres o manos no se realizará modificación alguna.

Sin embargo, el proceso de lavado y empaque de la fruta se realizará de las siguientes maneras: 
a. nuevo centro de empaque con tina fija.

El centro de empaque con tina fija construido, por ser de mayor capacidad, permite un lavado de la fruta más eficiente, eliminándose en mayor medida el látex de la misma y reduciendo las manchas en la fruta.

Este nuevo centro de empaque, requiere del pago de un nuevo gasto por concepto de mantenimiento y limpieza. El cual se ha estimado en 500 soles semanales, que equivalen a un gasto anual de 26,000 soles (500 soles * 52 semanas); el mismo que se irá ajustando de acuerdo al IPC para los siguientes años.

b. centros de empaque rústicos con tinas móviles.

Debido a la lejanía de algunos productores del centro de empaque, es necesario continuar utilizando las tinas móviles. Por este motivo, se mantendrá el gasto de mantenimiento de las 03 tinas y centros de empaque rústicos estimados en 9,400 soles anuales; el mismo que se irá ajustando de acuerdo al IPC para los siguientes años.

Para poder realizar el lavado de la fruta, la cooperativa mantendrá el contrato de compra de agua con su actual proveedor para que le abastezca de agua con cisterna para llenar las tinas donde se realizan los procesos de lavado. Se ha estimado que el consumo de agua aumentará para poder abastecer a la nueva tina del centro de empaque. Se proyecta un costo anual por consumo de agua de 124,800 soles; el mismo que se irá ajustando de acuerdo al IPC para los siguientes años. 
Costo Mensual Alquiler Cisterna: 10,400 soles

Costo Anual Alquiler Cisterna: 10,400 soles $* 12=124,800$

\subsubsection{Proceso de empaque.}

Para garantizar la calidad de la fruta, la cooperativa seguirá entregando a los socios productores las fundas protectoras para la fruta, las cuales representan un costo anual de 48,581 soles. Adicionalmente, la cooperativa seguirá pagando las certificaciones HACCP y Fitosanitaria Internacional por un total de 1,419 soles anuales.

Se mantendrá el contrato con Apbosmam para que todos los insumos utilizados en el proceso de lavado y empacado continúen siendo proporcionados por ellos.

El costo anual por compra de implementos para los operarios se mantiene en 21,280 soles; el mismo que se irá ajustando de acuerdo al IPC proyectado por el Ministerio de Economía y Finanzas.

La empresa debe recoger los insumos hasta los almacenes del comprador $\mathrm{y}$, debe trasportar las cajas empacadas hasta el centro de paletizado de Apbosmam, ubicado en sus almacenes.

En las nuevas inversiones se proyecta adquirir un camión furgón en reemplazo del servicio de alquiler del camión. Evaluamos ambos escenarios: el escenario actual por concepto de 
alquiler de camión furgón versus los gastos proyectados por la adquisición del camión furgón:

\section{SITUACION ACTUAL}

- La empresa alquila el camión furgón a 320 soles por viaje.

- El promedio de viajes diarios es: 01 Viaje

- La empresa trabaja 26 días al mes.

Por lo tanto, se ha proyectado un costo anual por alquiler del Camión de Carga de 99,840 soles. Los flujos de caja de los siguientes años se irán ajustando de acuerdo al IPC.

26 días $* 12$ meses $* 1$ viaje diario $* 320$ soles $=99,840$ Soles

Tabla 40: Situación Actual - Costo Alquiler de Camión Furgón

\begin{tabular}{|l|r|r|r|r|r|r|}
\hline & \multicolumn{1}{|c|}{ Año 0 } & \multicolumn{1}{c|}{ Año 1 } & \multicolumn{1}{|c|}{ Año 2 } & \multicolumn{1}{|c|}{ Año 3 } & \multicolumn{1}{c|}{ Año 4} & \multicolumn{1}{c|}{ Año 5 } \\
\hline Gasto Anual Alquilar Camión & 99,840 & 102,835 & 105,817 & 108,886 & 112,044 & 115,293 \\
\hline Indice de Precios Perú & $3.50 \%$ & $3.00 \%$ & $2.90 \%$ & $2.90 \%$ & $2.90 \%$ & $2.90 \%$ \\
\hline TOTAL & & 102,835 & 105,817 & 108,886 & 112,044 & 115,293 \\
\hline
\end{tabular}

Fuente y elaboración propia

\section{SITUACION FUTURA}

Supuestos:

- El Camión de Carga del proveedor recorrerá en promedio 65 $\mathrm{Km}$., considerando un recorrido similar al que actualmente realiza el camión de carga alquilado. El Valor del camión y la carrocería furgón asciende a 171,320 soles. 
- De acuerdo a la opinión de expertos, la opinión del gerente del concesionario vendedor del camión y de dueños de Camiones similares al que se pretende adquirir, el rendimiento por Galón Diésel oscila entre 25 y $35 \mathrm{Km}$. en zonas rurales.

Para el presente análisis hemos considerado el escenario más conservador y estamos tomando un Rendimiento de $25 \mathrm{Km}$. por Galón.

- El costo por galón diésel en la zona es: 11.00 Soles

- Teniendo en cuenta los datos anteriores, el consumo proyectado de combustible para el camión furgón es:

(65 Km. por Día / 25 Km. por Galón): 2.60 Galones Diarios (2.60 Galones Diarios * 11 Soles Galón * 26 días * 12 meses)

Costo anual proyectado de compra de combustible: 8,923 Soles

- La compra del camión furgón implica la contratación de un chofer y un ayudante.

Al primero se le pagará un salario mensual de 1,500 soles y al segundo un salario mensual de 900 soles.

El costo anual por contratación de personal asciende a:

2,400 soles $* 14$ sueldos al año $=33,600$ soles anuales

- La compra del camión furgón implica realizar un gasto promedio mensual, por concepto de mantenimiento de vehículo y compra de repuestos, estimado en 800 soles. El gasto anual por mantenimiento del camión furgón es: 800 soles $* 12$ veces al año $=9,600$ soles anuales

Todos los costos se han calculado con precios actuales, razón por la cual para los flujos proyectados se han ajustado al IPC. 
Tabla 41: Costo Proyectado por Compra de Camión Furgón

\begin{tabular}{|l|r|r|r|r|r|r|}
\cline { 2 - 7 } \multicolumn{1}{c|}{} & \multicolumn{1}{|c|}{ Año 0 } & \multicolumn{1}{c|}{ Año 1} & \multicolumn{1}{c|}{ Año 2} & \multicolumn{1}{c|}{ Año 3} & \multicolumn{1}{c|}{ Año 4} & \multicolumn{1}{c|}{ Año 5} \\
\hline Indice de Precios Perú & $3.50 \%$ & $3.00 \%$ & $2.90 \%$ & $2.90 \%$ & $2.90 \%$ & $2.90 \%$ \\
\hline Compra Camion Furgón & $-171,320$ & & & & & \\
\hline Consumo Combustible & 8,923 & 9,191 & 9,457 & 9,731 & 10,014 & 10,304 \\
\hline Pago Operarios & 33,600 & 34,608 & 35,612 & 36,644 & 37,707 & 38,801 \\
\hline Mantenimiento Camiones & 9,600 & 9,888 & 10,175 & 10,470 & 10,773 & 11,086 \\
\hline TOTAL & $-171,320$ & 53,687 & 55,244 & 56,846 & 58,494 & 60,191 \\
\hline
\end{tabular}

Fuente y elaboración propia

Teniendo en cuenta que la inversión necesaria para la compra del camión es de 171,320 soles y que el costo por alquilar un camión furgón es mayor que la suma de los costos de adquirirlo, podemos afirmar que los flujos de caja generados por la reducción de costos, justifica la compra del camión furgón. A continuación, se muestra el cuadro comparativo de ambos escenarios con el cálculo del flujo de caja incremental:

Tabla 42: Cuadro Comparativo de Alquilar o Comprar Camión SITUACION ACTUAL: ALQUILAR CAMION CARGA

\begin{tabular}{|l|r|r|r|r|r|r|}
\hline & \multicolumn{1}{|c|}{ Año 0 } & \multicolumn{1}{|c|}{ Año 1 } & \multicolumn{1}{|c|}{ Año 2 } & \multicolumn{1}{|c|}{ Año 3 } & \multicolumn{1}{|c|}{ Año 4 } & \multicolumn{1}{|c|}{ Año 5 } \\
\hline Gasto Anual Alquilar Camión & 99,840 & 102,835 & 105,817 & 108,886 & 112,044 & 115,293 \\
\hline Indice de Precios Perú & $3.50 \%$ & $3.00 \%$ & $2.90 \%$ & $2.90 \%$ & $2.90 \%$ & $2.90 \%$ \\
\hline TOTAL & & 102,835 & 105,817 & 108,886 & 112,044 & 115,293 \\
\hline
\end{tabular}

SITUACION FUTURA: COMPRAR CAMION CARGA

\begin{tabular}{|l|r|r|r|r|r|r|}
\cline { 2 - 7 } \multicolumn{1}{c|}{} & \multicolumn{1}{c|}{ Año 0 } & \multicolumn{1}{c|}{ Año 1 } & \multicolumn{1}{c|}{ Año 2 } & \multicolumn{1}{c|}{ Año 3 } & \multicolumn{1}{c|}{ Año 4} & \multicolumn{1}{c|}{ Año 5 } \\
\hline Indice de Precios Perú & $3.50 \%$ & $3.00 \%$ & $2.90 \%$ & $2.90 \%$ & $2.90 \%$ & $2.90 \%$ \\
\hline Compra Camion Furgón & $-171,320$ & & & & & \\
\hline Consumo Combustible & 8,923 & 9,191 & 9,457 & 9,731 & 10,014 & 10,304 \\
\hline Pago Operarios & 33,600 & 34,608 & 35,612 & 36,644 & 37,707 & 38,801 \\
\hline Mantenimiento Camiones & 9,600 & 9,888 & 10,175 & 10,470 & 10,773 & 11,086 \\
\hline TOTAL & $-171,320$ & 53,687 & 55,244 & 56,846 & 58,494 & 60,191 \\
\hline
\end{tabular}


En conclusión, luego de realizar las inversiones, los costos proyectados de la cooperativa por concepto de compra de fruta, transporte, proceso de lavado y empaque ascenderán a:

Tabla 43: Situación Futura - Proyección de Costos de Producción

\begin{tabular}{|c|c|c|c|c|c|c|}
\hline Concepto & Año 0 & Año 1 & Año 2 & Año 3 & Año 4 & Año 5 \\
\hline Costo Compra de Fruta & $2,085,835$ & $2,201,083$ & $2,207,614$ & $2,214,145$ & $2,220,677$ & $2,227,208$ \\
\hline Cantidad Fruta Comprada & 100,329 & 103,673 & 103,673 & 103,673 & 103,673 & 103,673 \\
\hline Costo Fruta Comprada & 6.30 & 6.30 & 6.30 & 6.30 & 6.30 & 6.30 \\
\hline Tipo de Cambio & 3.30 & 3.37 & 3.38 & 3.39 & 3.40 & 3.41 \\
\hline Costo Proceso Lavado ( S/ ) & 679,870 & 874,596 & 899,960 & 926,058 & 952,914 & 980,549 \\
\hline Indice de Precios Perú & $3.50 \%$ & $3.00 \%$ & $2.90 \%$ & $2.90 \%$ & $2.90 \%$ & $2.90 \%$ \\
\hline Alquiler Cisterna & 124,800 & 128,544 & 132,272 & 136,108 & 140,055 & 144,116 \\
\hline Alquiler Camión & 99,840 & & & & & \\
\hline Camión - Combustible & & 9,191 & 9,457 & 9,731 & 10,014 & 10,304 \\
\hline Camión - Chofer y Ayudante & & 34,608 & 35,612 & 36,644 & 37,707 & 38,801 \\
\hline Camión - Mantenimiento & & 9,888 & 10,175 & 10,470 & 10,773 & 11,086 \\
\hline Mano Obra Cuadrillas & 405,750 & 583,265 & 600,180 & 617,585 & 635,495 & 653,925 \\
\hline Costo Indumentaria & 21,280 & 21,918 & 22,554 & 23,208 & 23,881 & 24,574 \\
\hline Mantenimiento Centro Empaque & & 26,000 & 26,754 & 27,530 & 28,328 & 29,150 \\
\hline \begin{tabular}{|l|} 
Mantenimiento de Tinas y \\
Centros de Empaque Rústicos
\end{tabular} & 9,400 & 9,682 & 9,963 & 10,252 & 10,549 & 10,855 \\
\hline $\begin{array}{l}\text { Fundas, certificación HACCP, } \\
\text { certificacción CFI }\end{array}$ & 50,000 & 51,500 & 52,994 & 54,530 & 56,112 & 57,739 \\
\hline COSTO TOTAL ( S/ ) & $2,765,705$ & $3,075,679$ & $3,107,574$ & $3,140,204$ & $3,173,591$ & $3,207,757$ \\
\hline
\end{tabular}

Fuente y elaboración propia 


\section{CAPÍtULO V}

\section{Plan de recursos humanos}

\subsection{Organización funcional.}

Chiavenato (2000) define a la organización como “...un sistema de actividades conscientemente coordinadas, formado por dos o más personas, cuya cooperación recíproca es esencial para la existencia de la organización." (p.65)

Ferrell, Hirt, Adriaenséns, Flores y Ramos (2004) afirman que la organización consiste en ensamblar y coordinar los recursos humanos, financieros, físicos, de información y otros, que son necesarios para lograr las metas, y en actividades que incluyan atraer a gente a la organización, especificar las responsabilidades del puesto, agrupar tareas en unidades de trabajo, dirigir y distribuir recursos y crear condiciones para que las personas y las cosas funcionen para alcanzar el máximo éxito.

\subsubsection{La organización formal.}

Chiavenato (2000) afirma que "la organización formal comprende una estructura organizacional con directrices, normas y reglamentos, rutinas y procedimientos, que expresan cómo la organización pretende que sean las relaciones entre los órganos, cargos y ocupantes, con la finalidad de alcanzar sus objetivos." (p. 70) 


\subsubsection{Organización informal.}

Chiavenato (2000) afirma que "la organización informal consiste en medios no oficiales pero que influyen en la comunicación, la toma de decisiones y el control de una organización". (p. 75)

Hitt, Black y Porter (2011) nos dicen que, “...aunque prácticamente todas las organizaciones tienen cierto nivel de formalización, también todas las organizaciones, incluso las más formales, tienen un cierto grado de informalización." (p. 35)

Teniendo en cuenta las definiciones anteriores, podemos afirmar que la Cooperativa Agraria Alto Grande Santa Sofía se enmarca en una estructura organizacional funcional y formal, de cooperativismo agrario, siendo responsables de decidir e implementar las acciones operativas, financieras y comerciales de la organización: el Gerente General y los diversos consejos que la conforman.

\subsection{Organigrama}

Franklin (2007) define el organigrama como “...la representación gráfica de la estructura orgánica de una institución o de una de sus áreas, en la que se muestran las relaciones que guardan entre sí los órganos que la componen." (p. 123)

Asimismo, Franklin propone la siguiente clasificación de organigramas:

- Por su naturaleza, pueden existir organigramas micro administrativos, macro administrativos y meso administrativos.

- Por su ámbito, pueden ser generales y específicos. 
- Por su contenido, pueden ser integrales, funcionales y de puestos.

- Por su presentación, pueden ser verticales, horizontales, mixtos, de bloque.

Considerando los tipos de organigrama definidos por Franklin (2007), podemos afirmar que la empresa cuenta con un organigrama funcional porque incluye las principales funciones que tienen asignadas, además de las unidades y sus interrelaciones. Este tipo de organigrama es de gran utilidad para capacitar al personal y presentar a la organización en forma general.

A continuación, presentamos el organigrama actual de la cooperativa:

Ilustración 21: Organigrama de la Cooperativa Agraria Alto Grande Santa Sofía

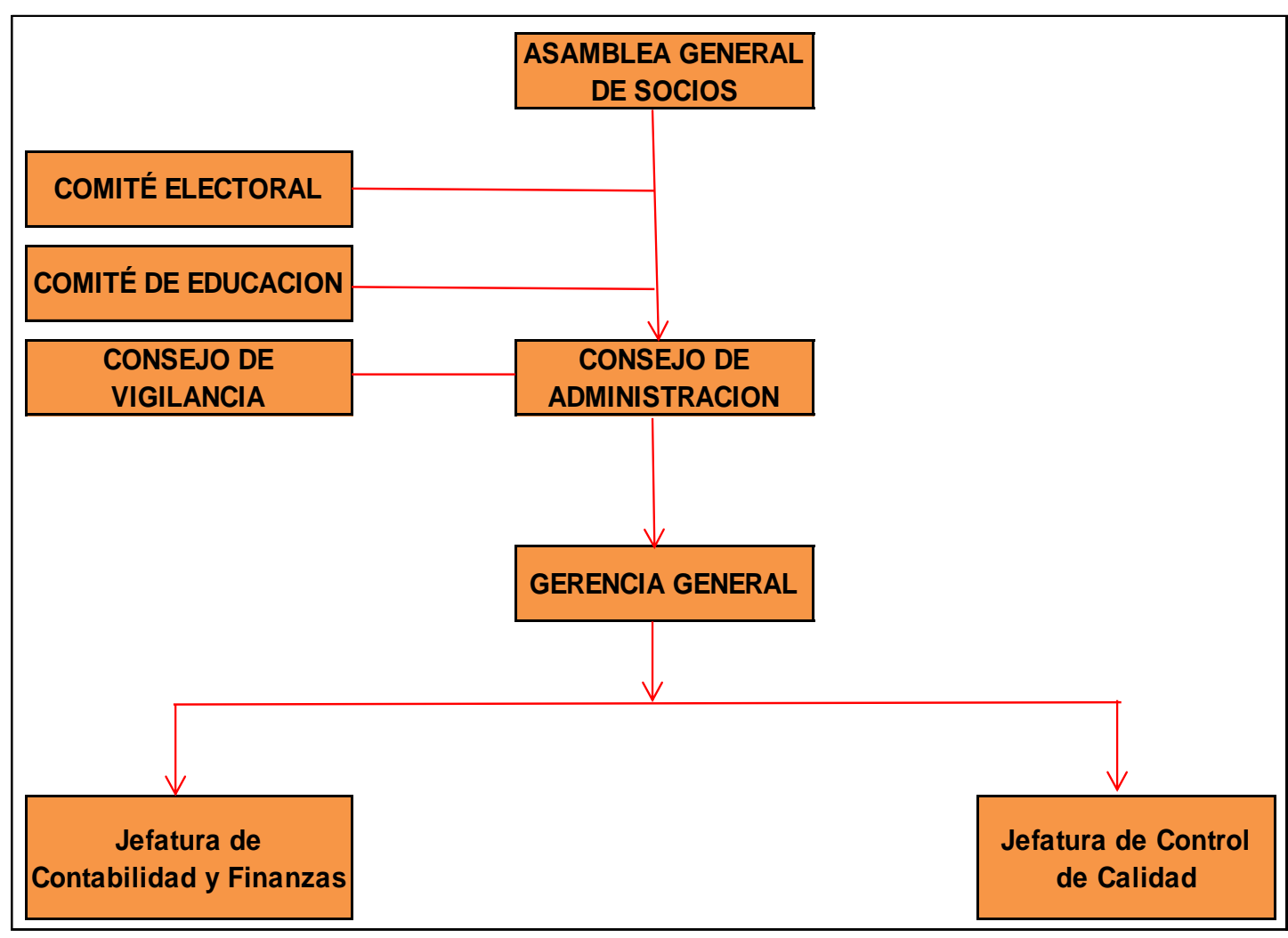

Fuente y elaboración propia 


\subsubsection{Análisis organizacional.}

\subsubsection{Asamblea general de socios.}

La Asamblea General de socios está conformada por todos los socios de la cooperativa. Es la encargada de definir los lineamientos y objetivos de la cooperativa y tiene la responsabilidad de decidir las inversiones a largo plazo.

Todas las decisiones que se toman en la asamblea general de socios se realizan por voto participativo, siendo necesario para la aprobación de una decisión la mayoría simple de los miembros que hubiesen asistido a una asamblea. Las asambleas son presididas por el presidente del consejo de administración.

\subsubsection{Consejo de administración.}

El consejo de administración es el encargado de supervisar las gestiones realizadas por la gerencia general y de elaborar las estrategias para alcanzar el crecimiento de la organización. Los miembros del consejo de administración no perciben salario alguno por ejercer sus funciones. El consejo de administración está conformado por agricultores.

\subsubsection{Consejo de vigilancia.}

El consejo de vigilancia es el encargado de supervisar que las decisiones y estrategias tomadas por el gerente general y/o el consejo de administración se realicen de acuerdo a los estatutos y normativas de la organización. Los miembros del consejo de vigilancia no perciben salario alguno por ejercer sus funciones. El consejo de vigilancia está conformado por agricultores. 


\subsubsection{Comité de educación.}

El comité de educación es el encargado de organizar capacitaciones para los socios a fin de aprender, desarrollar e implementar mejoras en los procesos de siembra, manejo de cultivos y cosecha; a fin de obtener mejores ingresos $\mathrm{y} / \mathrm{o}$ beneficios para los socios productores. Los miembros del consejo de educación no perciben salario alguno por ejercer sus funciones. El comité de educación está conformado por agricultores.

\subsubsection{Comité electoral.}

El comité electoral es el encargado de organizar las elecciones para los cambios de los miembros de todos los comités. Los miembros del consejo electoral no perciben salario alguno por ejercer sus funciones. El comité de educación está conformado por agricultores.

\subsubsection{Gerente general.}

El gerente general es el encargado de gestionar la cooperativa, administrando los recursos de la misma de manera eficiente y ordenada.

Actualmente, el gerente general percibe un ingreso mensual de 1,692 soles. El puesto lo ejerce un joven agricultor con secundaria completa y con diplomados en finanzas y administración llevados en IPAE. Sin embargo, el crecimiento de la cooperativa con las nuevas inversiones hace necesario que el Gerente General cuente con un nuevo perfil. A continuación, se muestra el perfil del sugerido: 
Tabla 44: Perfil del Gerente General

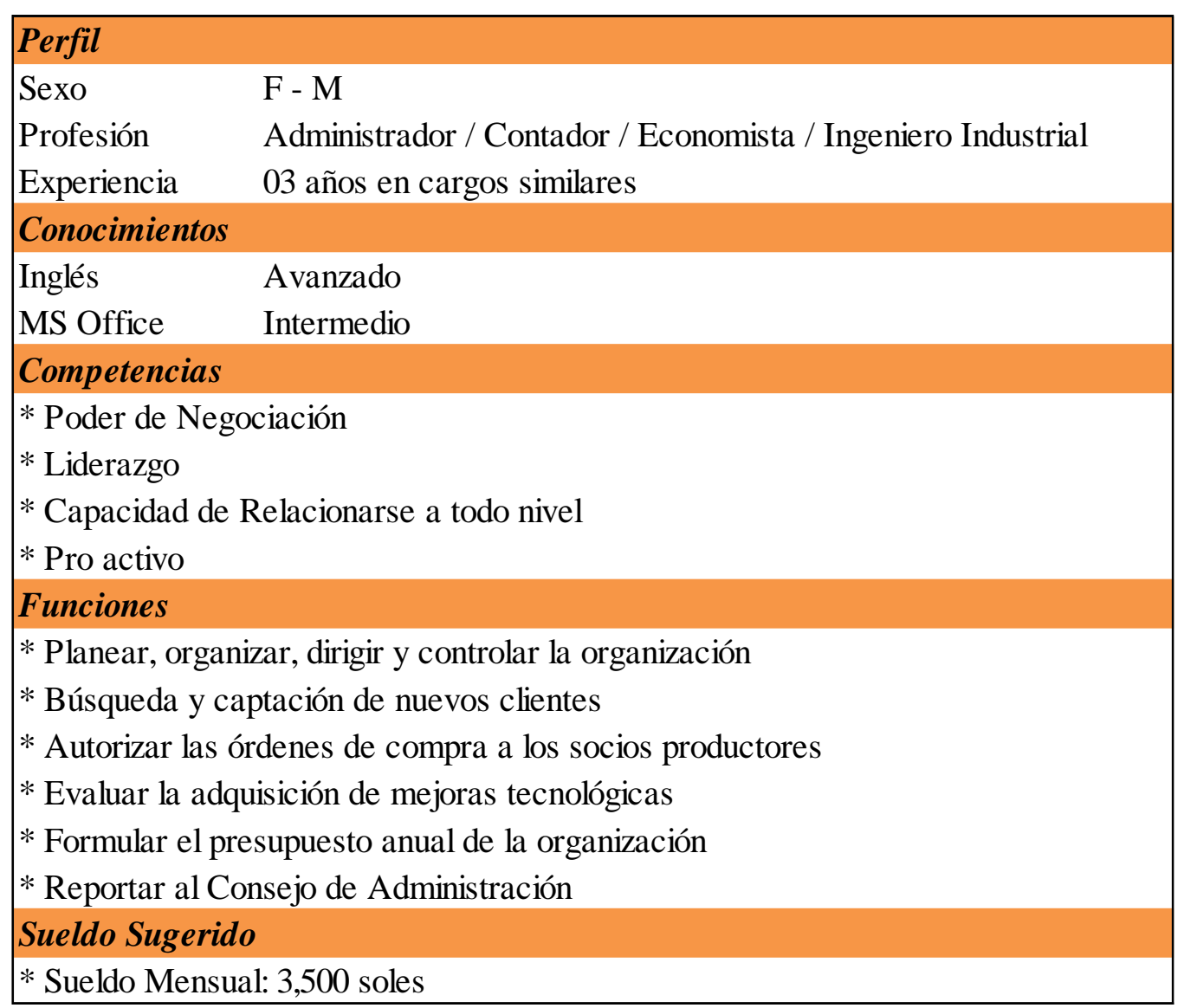

Fuente y elaboración propia siguiendo las recomendaciones de las tablas de la Tesis: "Implementación del servicio de vending de zumo de naranja". Universidad San Ignacio de Loyola. Autores: Barrios, Becerra, Dejo, Pazos, Rojas. 2015.

Bajo la responsabilidad del gerente se encuentran: La jefatura de control y calidad y la jefatura de contabilidad y finanzas.

a. Jefatura de Control y Calidad

Es la encargada de la gestión de los procesos productivos de la organización. El puesto actualmente representa un gasto mensual de 1,500 soles. A continuación, se muestra el perfil sugerido: 
Tabla 45: Perfil del Jefe de Control y Calidad

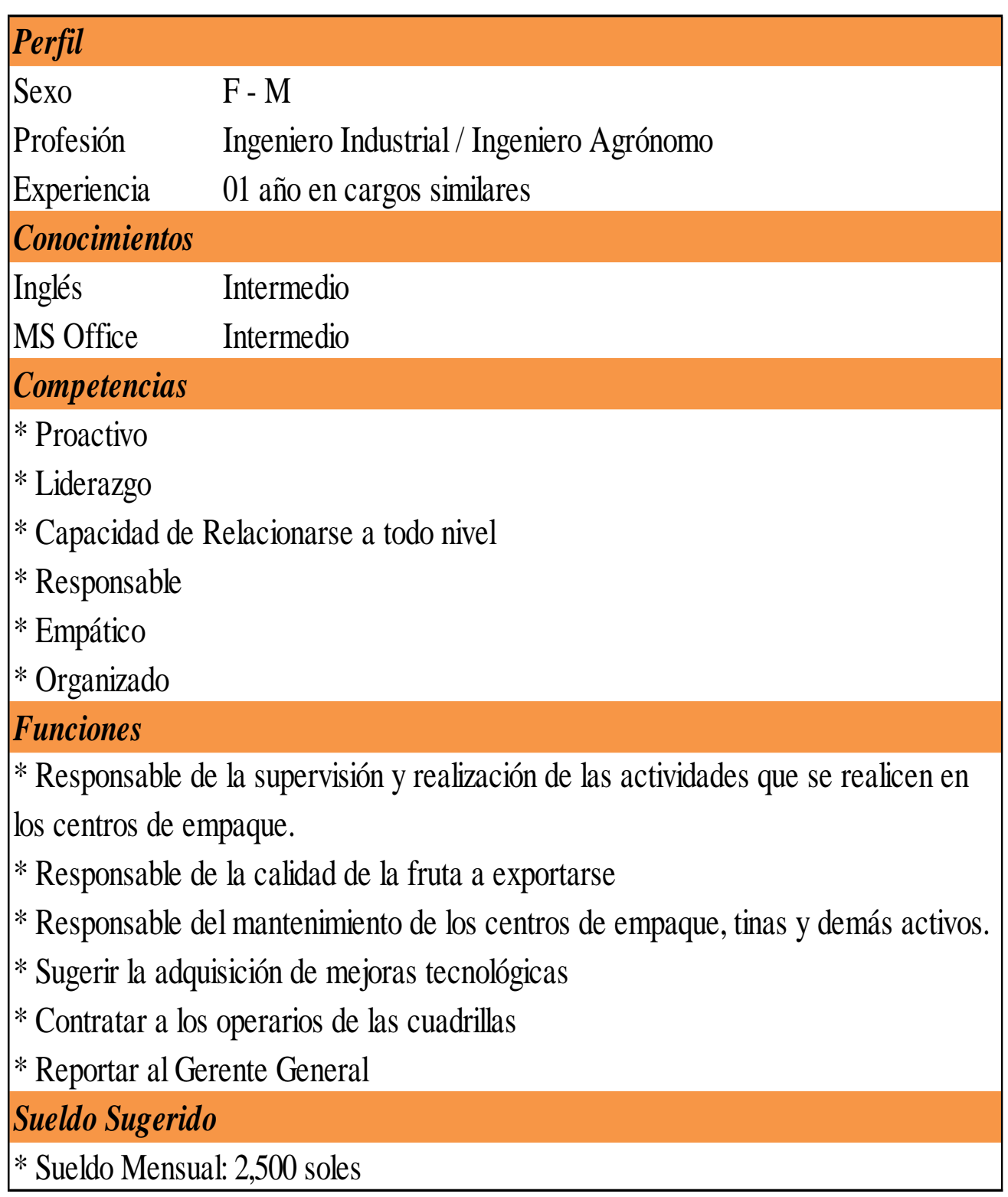

Fuente y elaboración propia siguiendo las recomendaciones de las tablas de la Tesis: "Implementación del servicio de vending de zumo de naranja". Universidad San Ignacio de Loyola. Autores: Barrios, Becerra, Dejo, Pazos, Rojas. 2015.

Bajo su responsabilidad se encuentran los operarios. A continuación, se sugiere el perfil que debe tener cada uno de ellos: 
Tabla 46: Perfil del Operario

$\begin{array}{|ll|}\text { Perfil } & \\ \text { Sexo } & \text { F - M } \\ \text { Profesión } & \text { Secundaria completa } \\ \text { Experiencia } & 01 \text { años en cargos similares } \\ \text { Competencias } & \\ \text { * Responsable, Organizado y Honesto } \\ \text { * Pulcritud y Buen Trato } \\ \text { Funciones } \\ \text { * Responsable del corte de las racimas } \\ \text { * Responsable del traslado de la fruta a los centros de empaque } \\ \text { * Responsable de cortar los clústeres de las racimas } \\ \text { * Responsable del lavado de la fruta } \\ \text { * Responsable del sellado y empaque de la fruta } \\ \text { * Reportar al Jefe de control y calidad }\end{array}$

Fuente y elaboración propia siguiendo las recomendaciones de las tablas de la Tesis: "Implementación del servicio de vending de zumo de naranja". Universidad San Ignacio de Loyola. Autores: Barrios, Becerra, Dejo, Pazos, Rojas. 2015.

b. Jefatura de contabilidad y finanzas

Encargada del manejo contable y financiero. Actualmente, el responsable percibe un ingreso mensual de 1,300 soles y, junto a él trabaja un asistente contable, quien percibe un ingreso mensual de 900 soles. A continuación, se muestra el perfil sugerido: 
Tabla 47: Perfil del Jefe de Contabilidad y Finanzas

\begin{tabular}{|c|c|}
\hline Perfil & \\
\hline Sexo & $\mathrm{F}-\mathrm{M}$ \\
\hline Profesión & Contador \\
\hline Experiencia & 03 años en cargos similares \\
\hline Conocimien & \\
\hline Inglés & Avanzado \\
\hline MS Office & Intermedio \\
\hline Competenci & \\
\hline * Analítico y & activo \\
\hline * Capacidad & Relacionarse a todo nivel \\
\hline * Responsab & Organizado y Honesto \\
\hline Funciones & \\
\hline * Responsab & e la teneduría de los libros contables \\
\hline * Responsab & e la presentación de las declaraciones anuales a la sunat \\
\hline * Responsab & e la elaboración de la información contable necesaria para la \\
\hline evaluación d & gestión financiera de la organización \\
\hline * Reportar a & rente General \\
\hline Sueldo Suge & \\
\hline * Sueldo Me & al: 2,500 soles \\
\hline
\end{tabular}

Fuente y elaboración propia

\subsection{Políticas de recursos humanos.}

Las políticas sugeridas para constituir bases sólidas para la gestión de los recursos humanos de la Cooperativa Agraria Alto Grande Santa Sofía son:

\section{- Responsabilidad}

El trabajador es responsable de las tareas asignadas. 
- Relaciones interpersonales

El buen trato entre colaboradores basado en el respeto, la honestidad y la confianza, fomentan un buen clima laboral. Se valorará la disposición a ayudar a los demás. Cualquier ruptura a estos principios serán considerados como faltas graves y generarán el despido del colaborador.

\section{- Remuneración}

La cooperativa remunera a su personal acorde a los precios que paga el mercado. Las remuneraciones incluyen el salario y los beneficios sociales correspondientes.

- Política de salud y seguridad de los trabajadores

El manejo de salubridad en el proceso de empaque garantiza que la fruta exportada llegué en óptimas condiciones de higiene a los mercados internacionales.

La cultura de seguridad se basa en la prevención y cumplimiento de la ley $\mathrm{N}^{\circ} 29783$ "Reglamento Interno de seguridad y salud del ministerio de economía y finanzas".

Los gastos de personal actuales y proyectados para los siguientes años se estiman: 
Tabla 48: Situación Actual - Gasto de Personal

\begin{tabular}{|c|c|c|c|c|c|}
\hline \multirow[b]{2}{*}{ Descripción } & \multirow[b]{2}{*}{ Cantidad } & \multicolumn{4}{|c|}{ Costo Unitario } \\
\hline & & $\begin{array}{l}\text { Sueldo } \\
\text { Básico }\end{array}$ & $\begin{array}{l}\text { Asignación } \\
\text { Familiar }\end{array}$ & $\begin{array}{c}\text { Essalud } \\
(4 \%)\end{array}$ & TOTAL \\
\hline Gerente General & 1 & 1545 & 85 & 62 & 1,692 \\
\hline Asistente Contable & 1 & 865 & 0 & 35 & 900 \\
\hline Contador & 1 & 1250 & 0 & 50 & 1,300 \\
\hline Ingeniero de campo & 1 & 1442 & 0 & 58 & 1,500 \\
\hline TOTAL & 4 & & & & 5,392 \\
\hline
\end{tabular}

Costo Anual Proyectado

64,700

\begin{tabular}{|c|c|c|c|c|c|c|}
\hline Concepto & Año 0 & Año 1 & Año 2 & Año 3 & Año 4 & Año 5 \\
\hline Indice de Precios Perú & $3.50 \%$ & $3.00 \%$ & $2.90 \%$ & $2.90 \%$ & $2.90 \%$ & $2.90 \%$ \\
\hline Planilla de Administración: & 64,700 & 66,641 & 68,574 & 70,562 & 72,609 & 74,714 \\
\hline Gerente General & 20,300 & 20,909 & 21,515 & 22,139 & 22,781 & 23,442 \\
\hline Asistente Contable & 10,800 & 11,124 & 11,447 & 11,779 & 12,120 & 12,472 \\
\hline Contador & 15,600 & 16,068 & 16,534 & 17,013 & 17,507 & 18,015 \\
\hline Ingeniero de campo & 18,000 & 18,540 & 19,078 & 19,631 & 20,200 & 20,786 \\
\hline
\end{tabular}

Fuente: Base de Datos de la Cooperativa, Área Contable, 2017. Elaboración propia

Habiéndose analizado el factor humano de la organización, podemos observar que existe un gran riesgo para la sostenibilidad de la organización:

- Las autoridades que dirigen la organización no cuentan con los conocimientos mínimos necesarios para garantizar la implementación de estrategias de gestión, comerciales y financieras que les permitan consolidarse en el tiempo. 
- Existen problemas de agencia entre los socios directivos (autoridades) y el resto de socios. Al estar la dirección de la organización en manos de algunos socios, estos buscarán imponer sus intereses; los cuales pueden ser distintos al de los demás socios.

Considerando las inversiones que se van a realizar es necesario tomar las siguientes acciones, a fin de mitigar el riesgo del factor humano:

\section{- Contratación de un nuevo gerente general}

Se requiere contratar un profesional que sea capaz de integrar los valores culturales y sociales propios del cooperativismo con los valores económicos y empresariales buscando el beneficio de todos los socios. Es necesario la contratación de un profesional que cumpla con el perfil sugerido para el puesto de gerente general.

\section{- Contratación de un técnico agrario}

Urge contratar un técnico agrícola con la finalidad de elaborar, supervisar y controlar los procesos y exigencias establecidas por las certificadoras para poder renovar las certificaciones cada año. A continuación, se muestra el perfil sugerido: 
Tabla 49: Perfil del Técnico Agrario

\begin{tabular}{|ll|}
\hline Perfil & \\
Sexo & M \\
Profesión & Ingeniero Agrónomo \\
Experiencia & 01 año en cargos similares \\
Conocimientos & \\
Inglés & Intermedio \\
MS Office $\quad$ Intermedio & \\
Competencias & \\
* Proactivo, Liderazgo \\
* Capacidad de Relacionarse a todo nivel \\
* Responsable, Empático y Organizado \\
Funciones \\
* Responsable del cumplimiento de las exigencias establecidas por las \\
certificadoras. \\
* Sugerir la adquisición de mejoras tecnológicas \\
* Coordinar la contratación de los operarios de las cuadrillas \\
* Reportar al Jefe de Control y Calidad \\
Sueldo Sugerido \\
* Sueldo Mensual: 1,800 soles \\
\hline
\end{tabular}

Fuente y elaboración propia siguiendo las recomendaciones de las tablas de la Tesis: "Implementación del servicio de vending de zumo de naranja". Universidad San Ignacio de Loyola. Autores: Barrios, Becerra, Dejo, Pazos, Rojas. 2015.

Luego de la implementación de las mejoras tecnológicas, los gastos de personal proyectados para los siguientes cinco años se estiman: 
Tabla 50: Situación Futura - Gastos de Personal

\begin{tabular}{|l|c|c|c|c|c|}
\hline \multirow{2}{*}{ Descripción } & \multirow{3}{*}{ Cantidad } & \multicolumn{4}{|c|}{ Costo Unitario } \\
\cline { 3 - 6 } & & $\begin{array}{c}\text { Sueldo } \\
\text { Básico }\end{array}$ & $\begin{array}{c}\text { Asignación } \\
\text { Familiar }\end{array}$ & $\begin{array}{c}\text { Essalud } \\
(4 \%)\end{array}$ & TOTAL \\
\hline
\end{tabular}

\begin{tabular}{|c|c|c|c|c|r|}
\hline Gerente General & 1 & 3385 & 85 & 135 & 3,605 \\
\hline Asistente Contable & 1 & 891 & 0 & 36 & 927 \\
\hline Contador & 1 & 1486 & 0 & 59 & 1,545 \\
\hline Técnico Agrario & 1 & 1783 & 0 & 71 & 1,854 \\
\hline Ingeniero de campo & 1 & 2394 & 85 & 96 & 2,575 \\
\hline TOTAL & $\mathbf{0}$ & & & & $\mathbf{1 0 , 5 0 6}$ \\
\hline
\end{tabular}

Costo Anual Proyectado

126,072

\begin{tabular}{|c|c|c|c|c|c|c|}
\hline Concepto & Año 0 & Año 1 & Año 2 & Año 3 & Año 4 & Año 5 \\
\hline Indice de Precios Perú & $3.50 \%$ & $3.00 \%$ & $2.90 \%$ & $2.90 \%$ & $2.90 \%$ & $2.90 \%$ \\
\hline Planilla de Administración: & 64,700 & 126,072 & 129,728 & 133,490 & 137,361 & 141,345 \\
\hline Gerente General & 20,300 & 43,260 & 44,515 & 45,805 & 47,134 & 48,501 \\
\hline Asistente Contable & 10,800 & 11,124 & 11,447 & 11,779 & 12,120 & 12,472 \\
\hline Contador & 15,600 & 18,540 & 19,078 & 19,631 & 20,200 & 20,786 \\
\hline Técnico Agrario & & 22,248 & 22,893 & 23,557 & 24,240 & 24,943 \\
\hline Ingeniero de campo & 18,000 & 30,900 & 31,796 & 32,718 & 33,667 & 34,643 \\
\hline
\end{tabular}

Fuente y elaboración propia 


\section{Capítulo VI}

\section{Plan financiero}

Chou (2006) dice: "La planificación financiera es la construcción del modelo económico-financiero mismo... proyectando el comportamiento financiero de la futura empresa bajo los supuestos analizados. Es la base instrumental del análisis de sensibilidad”. (p. 35)

En este capítulo elaboraremos los flujos de caja económico que nos permitan analizar la factibilidad de invertir de acuerdo a la planificación planteada por la cooperativa para reducir sus costos de procesos e incrementar sus ingresos.

\section{1.inversiones}

\subsubsection{Inversiones en activo fijo.}

De acuerdo a lo indicado por el Estado de Situación Financiera, la cooperativa cuenta con los siguientes activos: 03 tinas móviles, 01 unidad de transporte (moto) y equipos de oficina. Si la empresa no se acoge al programa de agroideas, la proyección de inversión en activo fijo consiste en reponer los activos que se van deteriorando.

En conclusión, si la empresa no realiza inversión alguna en mejoras tecnológicas, la composición del activo fijo proyectada para los siguientes 05 años será la que se muestra en la tabla 47. 
Tabla 51: Situación Actual - Proyección de la Composición del Activo

Fijo

\begin{tabular}{|l|r|r|r|r|r|l|}
\hline \multicolumn{1}{|c|}{ Concepto } & \multicolumn{1}{|c|}{ Año 0 } & Año 1 & Año 2 & Año 3 & Año 4 & Año 5 \\
\hline 03 Tinas Móviles & 41,466 & & & & 35,000 & \\
\hline Equipos Oficina & 3,897 & & & 5,000 & & \\
\hline Unidad Trasporte (Moto) & 4,140 & & & 5,000 & & \\
\hline Activos Totales & 49,503 & - & - & 10,000 & 35,000 & \\
\hline
\end{tabular}

DEPRECIACION ACTIVOS

\begin{tabular}{|l|r|r|r|r|r|r|}
\hline \multicolumn{1}{|c|}{ Depreciacion } & \multicolumn{1}{|c|}{ Año 0 } & Año 1 & Año 2 & Añ̃o 3 & Año 4 & Año 5 \\
\hline 03 Tinas Móviles & 8,293 & 8,293 & 8,293 & 8,293 & 8,293 & 7,000 \\
\hline Equipos Oficina & 974 & 974 & 974 & 974 & 1,250 & 1,250 \\
\hline Unidad Trasporte (Moto) & 828 & 828 & 828 & 828 & 828 & 1,000 \\
\hline Depreciación Total & 10,095 & 10,095 & 10,095 & 10,095 & 10,371 & 9,250 \\
\hline
\end{tabular}

Fuente: "Estado de Situación Financiera, Área Contable, 2016.” Elaboración propia

Si la empresa se acoge al programa de agroideas, la composición del activo fijo proyectada para los siguientes 05 años será de acuerdo al siguiente cronograma:

- Inmediatamente, construir un centro de empaque y adquirir un camión furgón.

- En el año 03, reponer los equipos de oficina y la moto.

- En el año 05, reponer las tinas móviles.

Así, la composición del activo fijo proyectada para los siguientes 05 años y el cálculo de su depreciación será la que se muestra en la tabla 48. 
Tabla 52: Situación Futura - Proyección del Activo Fijo

\begin{tabular}{|l|r|r|r|r|r|r|}
\hline \multicolumn{1}{|c|}{ Concepto } & \multicolumn{1}{|c|}{ Año 0 } & \multicolumn{1}{|c|}{ Año 1 } & Año 2 & \multicolumn{1}{|c|}{ Año 3 } & Año 4 & Año 5 \\
\hline 03 Tinas Móviles & 41,466 & & & & 35,000 & \\
\hline Equipos Oficina & 3,897 & & & 5,000 & & \\
\hline Unidad Trasporte (Moto) & 4,140 & & & 5,000 & & \\
\hline $\begin{array}{l}\text { Camión y Carrocería Tipo } \\
\text { Furgón }\end{array}$ & 171,320 & & & & & \\
\hline Terreno Centro Empaque & 5,500 & & & & & \\
\hline $\begin{array}{l}\text { Construcción de Centro } \\
\text { Empaque con Tina Fija }\end{array}$ & 105,000 & & & & & \\
\hline \multicolumn{1}{|c|}{ Activos Totales } & 331,323 & & & 10,000 & 35,000 & \\
\hline
\end{tabular}

DEPRECIACION DE ACTIVOS

\begin{tabular}{|l|r|r|r|r|r|r|}
\hline \multicolumn{1}{|c|}{ De preciacion } & \multicolumn{1}{|c|}{ Año 0 } & \multicolumn{1}{|c|}{ Año 1 } & \multicolumn{1}{c|}{ Año 2 } & \multicolumn{1}{|c|}{ Año 3 } & \multicolumn{1}{c|}{ Año 4 } & \multicolumn{1}{c|}{ Año 5 } \\
\hline 03 Tinas Móviles & 8,293 & 8,293 & 8,293 & 8,293 & 8,293 & 7,000 \\
\hline Equipos Oficina & 974 & 974 & 974 & 974 & 974 & 1,000 \\
\hline Unidad Trasporte (Moto) & 828 & 828 & 828 & 828 & 828 & 1,000 \\
\hline $\begin{array}{l}\text { Camión y Carrocería Tipo } \\
\text { Furgón }\end{array}$ & & 34,264 & 34,264 & 34,264 & 34,264 & 34,264 \\
\hline Terreno Centro Empaque & & - & - & - & - & - \\
\hline $\begin{array}{l}\text { Construcción de Centro } \\
\text { Empaque con Tina Fija }\end{array}$ & & 10,500 & 10,500 & 10,500 & 10,500 & 10,500 \\
\hline \multicolumn{1}{|c|}{ De preciación Total } & 10,095 & 54,859 & 54,859 & 54,859 & 54,859 & 53,764 \\
\hline
\end{tabular}

Fuente: "Estado de Situación Financiera, Área Contable, 2016." Elaboración propia

\subsubsection{Inversiones en capital de trabajo.}

Kafka (2004) dice: "el capital de trabajo tiene su base en la cadena de producción-venta-producción. Usualmente la venta se da con posterioridad a la producción, lo que requiere de dinero para adquirir materia prima, pagar la mano de obra y cubrir cualquier gasto indirecto." (p. 56) 
Tresierra, A. (2016) dice "el método del Flujo de Caja ayuda a determinar el capital de trabajo de un proyecto. Este método consiste en elaborar el flujo de caja operativo del negocio y determinar el déficit que debe ser cubierto para poder operar. Lo recomendable es elaborar un flujo de caja para todo el período de operación (un año, un semestre, dependiendo de la empresa), para determinar cuál será el máximo requerimiento de capital de trabajo y prever las inversiones necesarias." (p. 8)

Si la empresa no se acoge al programa de agroideas, los flujos de caja operativos proyectado nos indican que no hay necesidad de financiar un aumento del capital de trabajo:

Tabla 53: Situación Actual - Proyección del Capital de Trabajo

\begin{tabular}{|c|c|c|c|c|c|c|}
\hline Detalle & Año 0 & Año 1 & Año 2 & Año 3 & Año 4 & Año 5 \\
\hline INGRESOS & $3,079,090$ & $3,144,404$ & $3,153,734$ & $3,163,065$ & $3,172,395$ & $3,181,726$ \\
\hline Costo Compra de Fruta & $2,085,835$ & $2,130,080$ & $2,136,401$ & $2,142,721$ & $2,149,042$ & $2,155,363$ \\
\hline Costo Proceso Lavado & 679,870 & 700,266 & 720,574 & 741,470 & 762,973 & 785,099 \\
\hline Gasto Administración & 137,700 & 141,831 & 145,944 & 150,176 & 154,532 & 159,013 \\
\hline Flujo Caja Operativo & 175,685 & 172,227 & 150,816 & 128,697 & 105,849 & 82,251 \\
\hline Flujo Acumulado & 175,685 & 347,912 & 498,728 & 627,425 & 733,274 & 815,525 \\
\hline
\end{tabular}

Fuente y Elaboración propia

Si la cooperativa realiza las inversiones en mejoras tecnológicas, los flujos de caja operativos proyectado nos indican que no hay necesidad de financiar un aumento del capital de trabajo: 
Tabla 54: Situación Futura - Proyección del Capital de Trabajo

\begin{tabular}{|l|r|r|r|r|r|r|}
\hline \multicolumn{1}{|c|}{ Detalle } & \multicolumn{1}{c|}{ Año 0 } & \multicolumn{1}{c|}{ Año 1 } & \multicolumn{1}{c|}{ Año 2 } & \multicolumn{1}{c|}{ Año 3 } & \multicolumn{1}{c|}{ Año 4 } & \multicolumn{1}{c|}{ Año 5 } \\
\hline INGRESOS & $3,079,090$ & $3,598,595$ & $3,609,274$ & $3,619,952$ & $3,630,630$ & $3,641,309$ \\
\hline Costo Compra de Fruta & $2,085,835$ & $2,201,083$ & $2,207,614$ & $2,214,145$ & $2,220,677$ & $2,227,208$ \\
\hline Costo Proceso Lavado & 679,870 & 874,596 & 899,960 & 926,058 & 952,914 & 980,549 \\
\hline Gasto Administración & 137,700 & 236,169 & 243,018 & 250,065 & 257,317 & 264,779 \\
\hline Flujo Caja Ope rativo & $\mathbf{1 7 5 , 6 8 5}$ & $\mathbf{2 8 6 , 7 4 8}$ & $\mathbf{2 5 8 , 6 8 2}$ & $\mathbf{2 2 9 , 6 8 3}$ & $\mathbf{1 9 9 , 7 2 2}$ & $\mathbf{1 6 8 , 7 7 3}$ \\
\hline
\end{tabular}

Fuente y Elaboración propia

\subsubsection{Inversiones en activos intangibles.}

$\mathrm{Si}$ la cooperativa no se acoge al programa de agroideas, la cooperativa no realizará inversión alguna en activos intangibles.

Sin embargo, al acogerse al programa de agroideas se realiza una inversión en activos intangibles que se amortizan en doce meses. Esta inversión corresponde al pago que se realizará para adquirir las certificaciones orgánica, global gap y comercio justo.

Dado que la primera certificación se realiza con aporte del estado, este pago se registrará contablemente como un activo intangible. Las futuras renovaciones de las certificaciones serán consideradas como gasto administrativo.

A continuación, se muestra la relación de activos intangibles que se piensan adquirir: 
Tabla 55: Situación Futura - Inversión en Activos Intangibles

\begin{tabular}{|c|c|c|c|c|c|c|}
\hline Concepto & Año 0 & Año 1 & Año 2 & Año 3 & Año 4 & Año 5 \\
\hline Certificación Orgánica & 13,500 & & & & & \\
\hline Certificación Global G.A.P. & 13,500 & & & & & \\
\hline Certificación Comercio Justo & 6,890 & & & & & \\
\hline Activos Totales & 33,890 & & & & & \\
\hline
\end{tabular}

AMORTIZACION DE ACTIVOS INTANGIBLES

\begin{tabular}{|c|c|c|c|c|c|c|}
\hline Depreciacion & Año 0 & Año 1 & Año 2 & Año 3 & Año 4 & Año 5 \\
\hline Certificación Orgánica & & 13,500 & & & & \\
\hline Certificación Global G.A.P. & & 13,500 & & & & \\
\hline Certificación Comercio Justo & & 6,890 & & & & \\
\hline Amortivación Total & & 33,890 & & & & \\
\hline
\end{tabular}

Fuente y Elaboración propia

\section{2. financiamiento}

Sapag (2000) dice: "una de las variables que más influye en el resultado de la evaluación de un proyecto es la tasa de descuento empleada en la actualización de sus flujos de caja. La utilización de una tasa de descuento inapropiada puede inducir un resultado errado en la evaluación”. (p. 325)

A continuación, se describen los supuestos y cálculos realizados para determinar la tasa de descuento del proyecto.

\subsubsection{Costo de oportunidad.}

Sapag (2000) nos dice que el costo de oportunidad corresponde a aquella tasa que se utiliza para determinar el valor actual de los flujos futuros que genera un proyecto y representa la rentabilidad que se le debe exigir a la inversión por renunciar a un uso alternativo de los recursos en proyectos de riesgos similares. (p. 326)

Todo proyecto de inversión involucra una cuantía de recursos conocidos hoy a cambio de una estimación de mayores retornos a futuro, 
sobre los que no existe certeza. Por ello, en el costo de capital debe incluirse un factor de corrección por el riesgo que enfrenta.

Para calcular el Costo del Capital Propio, hemos utilizado el Modelo CAPM. Por ello, hemos calculado el Costo del Capital Propio en Estados Unidos utilizado la siguiente fórmula:

$$
K_{e(u s a)}=R_{f}+\beta\left(R_{m}-R_{f}\right)
$$

Donde:

Ke(usa) : Es el costo del capital propio

Rf : Es la tasa libre de riesgo

$\beta \quad$ : Es el Beta Desapalancado

$\mathrm{Rm}-\mathrm{Rf} \quad$ : Es el riesgo de mercado

Para calcular el Costo de Capital en el Perú, al Ke(usa) le sumaremos el Riesgo País Perú. A este resultado lo multiplicamos por la correlación de la inflación del Perú respecto a la Inflación de Estados Unidos y, le sumaremos el riesgo del negocio. Por tratarse de una empresa en marcha, se le sumará un riesgo del 3.00\%.

$$
K_{e(\text { perú })}=\left[\left(K_{e(u s a)}+R P\right) *\left(\frac{I \text { Perú }}{I U S A}\right)\right]+F C
$$

Donde:

$\operatorname{Ke}($ perú) : Es el costo del capital propio en Perú

Ke(usa) : Es el costo del capital propio EE.UU.

RP : Es el riesgo país

I Perú $\quad$ : Es el promedio de la inflación peruana en diez años 
I USA : Es la inflación promedio de EE.UU. en diez años

FC : Factor de Corrección por riesgo del negocio

6.2.1.1.La tasa libre de riesgo $\left(R_{f}\right)$.

La tasa libre de riesgo es la referente al rendimiento de los bonos de estadounidenses a un plazo de 3 meses porque la calificación del Perú en el mercado internacional no acredita a los bonos peruanos como bonos libres de riesgo. De acuerdo a las investigaciones realizadas por Damodaran y publicadas en su página web, la Tasa Libre de Riesgo es: $3.42 \%$.

Tabla 56: Tasa Libre de Riesgo

\begin{tabular}{|c|c|c|}
\hline S\&P 500 & 3-month T.Bill & 10-year T. Bond \\
\hline
\end{tabular}

Arithmetic Average

\begin{tabular}{|c|c|c|c|}
\hline $1928-2016$ & $11.42 \%$ & $3.46 \%$ & $5.18 \%$ \\
\hline $1967-2016$ & $11.45 \%$ & $4.88 \%$ & $7.08 \%$ \\
\hline $2007-2016$ & $8.65 \%$ & $0.74 \%$ & $5.03 \%$ \\
\hline
\end{tabular}

Geometric Average

\begin{tabular}{|c|c|c|c|}
\hline $1928-2016$ & $9.53 \%$ & $3.42 \%$ & $4.91 \%$ \\
\hline $1967-2016$ & $10.09 \%$ & $4.83 \%$ & $6.66 \%$ \\
\hline $2007-2016$ & $6.88 \%$ & $0.73 \%$ & $4.58 \%$ \\
\hline
\end{tabular}

Fuente y Elaboración: “Current Data-Damodaran, http://pages.stern.nyu.edu/ adamodar/, 2017.”

\subsubsection{Riesgo de mercado $\left(R_{m}\right)$.}

La tasa de riesgo de mercado utilizada es la referente al rendimiento del indicador S\&P 500 de la Bolsa de Valores de New York en el mayor plazo posible de análisis. De acuerdo a las investigaciones realizadas por Aswath Damodaran y publicadas en su página web el riesgo de mercado asciende a $9.53 \%$. 
Tabla 57: Tasa Riesgo de Mercado

\begin{tabular}{|l|l|l|} 
S\&P 500 & 3-month T.Bill & 10-year T. Bond \\
\hline
\end{tabular}

Arithmetic Average

\begin{tabular}{|c|c|c|c|}
\hline $1928-2016$ & $11.42 \%$ & $3.46 \%$ & $5.18 \%$ \\
\hline $1967-2016$ & $11.45 \%$ & $4.88 \%$ & $7.08 \%$ \\
\hline $2007-2016$ & $8.65 \%$ & $0.74 \%$ & $5.03 \%$ \\
\hline
\end{tabular}

Geometric Average

\begin{tabular}{|c|c|c|c|}
\hline $1928-2016$ & $9.53 \%$ & $3.42 \%$ & $4.91 \%$ \\
\hline $1967-2016$ & $10.09 \%$ & $4.83 \%$ & $6.66 \%$ \\
\hline $2007-2016$ & $6.88 \%$ & $0.73 \%$ & $4.58 \%$ \\
\hline
\end{tabular}

Fuente y Elaboración: “Current Data-Damodaran, http://pages.stern.nyu.edu/ adamodar/, 2017."

\subsubsection{Beta des apalancado $(\beta)$.}

El Beta sin apalancamiento mide la sensibilidad del retorno de la acción ante variaciones en el mercado. De acuerdo a la información proporcionada por Damodaran en su página web, para la evaluación de proyectos agrícolas, se deberá considerar un Beta Des apalancado de 0.59. (Ver Anexo 07: Betas Publicados por Damodaran a febrero 2017).

\subsubsection{Costo capital usa ( $\left.K_{\text {e(usa) }}\right)$.}

Considerando la tasa libre de riesgo, la tasa de riesgo de mercado y la beta des apalancada del sector procederemos a calcular el Costo de Capital de Estados Unidos.

$$
\begin{gathered}
K_{e(u s a)}=R_{f}+\beta\left(R_{m}-R_{f}\right) \\
K_{e(u s a)}=3.42 \%+0.59(9.53 \%-3.42 \%) \\
K_{e(u s a)}=7.0249 \%
\end{gathered}
$$


6.2.1.5.Riesgo país.

Damodaran (2016), el riesgo país es un índice que intenta medir el grado de riesgo que entraña un país para las inversiones extranjeras. De acuerdo a JP Morgan el riesgo país del Perú a enero 2017 es 1.66\%. (Ver Anexo 08: Riesgo País Perú)

\subsubsection{Inflación Perú / inflación usa.}

De acuerdo a las publicaciones del BCR del Perú la inflación promedio histórica del Perú de los últimos años fue 3.39\%, mientras que la inflación promedio en el mismo período de tiempo de los Estados Unidos fue 2.0032\%.

Tabla 58: Inflación Histórica del Perú y Estados Unidos

\begin{tabular}{|c|r|}
\hline \multicolumn{2}{|c|}{ Infiación Perú } \\
\hline $\mathbf{2 0 0 7}$ & $3.90 \%$ \\
\hline $\mathbf{2 0 0 8}$ & $6.70 \%$ \\
\hline $\mathbf{2 0 0 9}$ & $0.20 \%$ \\
\hline $\mathbf{2 0 1 0}$ & $2.10 \%$ \\
\hline $\mathbf{2 0 1 1}$ & $4.70 \%$ \\
\hline $\mathbf{2 0 1 2}$ & $2.60 \%$ \\
\hline $\mathbf{2 0 1 3}$ & $2.90 \%$ \\
\hline $\mathbf{2 0 1 4}$ & $3.20 \%$ \\
\hline $\mathbf{2 0 1 5}$ & $4.40 \%$ \\
\hline $\mathbf{2 0 1 6}$ & $3.20 \%$ \\
\hline Promedio & $3.3900 \%$ \\
\hline
\end{tabular}

\begin{tabular}{|c|r|}
\hline \multicolumn{2}{|c|}{ Infiación EE.UU. } \\
\hline $\mathbf{2 0 0 7}$ & $4.08 \%$ \\
\hline $\mathbf{2 0 0 8}$ & $4.28 \%$ \\
\hline $\mathbf{2 0 0 9}$ & $0.03 \%$ \\
\hline $\mathbf{2 0 1 0}$ & $2.63 \%$ \\
\hline $\mathbf{2 0 1 1}$ & $1.63 \%$ \\
\hline $\mathbf{2 0 1 2}$ & $2.93 \%$ \\
\hline $\mathbf{2 0 1 3}$ & $1.60 \%$ \\
\hline $\mathbf{2 0 1 4}$ & $1.58 \%$ \\
\hline $\mathbf{2 0 1 5}$ & $-0.09 \%$ \\
\hline $\mathbf{2 0 1 6}$ & $1.37 \%$ \\
\hline Promedio & $2.0032 \%$ \\
\hline
\end{tabular}

Fuente: "Estadísticas Económicas del Perú e Indicadores Macroeconómicos de los Países, https://estadisticas.bcrp.gob.pe/estadisticas/series/anuales/resultados/PM05197PA/html http://es.global-rates.com/estadisticas-economicas/inflacion/indice-de-precios-alconsumo/ipc/estados-unidos.aspx, 2017). Elaboración Propia

Considerando la inflación promedio de ambos países, hemos calculado el indicador de "Inflación Perú / Inflación Usa", el cual asciende a: 1.692292332 . 


\subsubsection{Factor de corrección.}

Teniendo en cuenta que la inversión se realiza en una empresa en marcha que pertenece al sector agrícola, hemos considerado un factor de corrección del $5.00 \%$.

\subsubsection{Costo capital Perú ( ke (Perú) )}

Procederemos a calcular el costo de capital Perú:

$$
\begin{gathered}
K_{e(\text { perú })}=\left[\left(K_{e(\text { usa })}+R P\right) *\left(\frac{I \text { Perú }}{I U S A}\right)\right]+F C \\
K_{e(\text { perú })}=\left[(7.0249 \%+1.66 \%) *\left(\frac{3.3900 \%}{2.0032 \%}\right)\right]+5.00 \% \\
K_{e(\text { perú })}=19.697390 \%
\end{gathered}
$$

\subsubsection{Costo de deuda.}

Sapag (2000) nos dice: "la medición del costo de la deuda, ya sea que la empresa utilice bonos o préstamos, se basa en el hecho de que éstos deben reembolsarse en una fecha futura específica, en un monto generalmente mayor que el obtenido originalmente." (p. 329)

Dado que la organización no mantiene deuda alguna con terceros y que las inversiones a realizarse serán financiadas: $80 \%$ por Agroideas bajo fondos no reembolsables y el $20 \%$ por la cooperativa con fondos propios, el Costo de la Deuda para el presente proyecto es cero. 


\subsubsection{Costo promedio ponderado de capital}

Sapag (2000) nos dice: “...una vez que se ha definido el costo de la deuda $\left(K_{d}\right)$ y la rentabilidad exigida por el capital propio $\left(K_{e}\right)$, se debe calcular una tasa de descuento ponderada $\left(K_{o}\right)$ que incorpore los dos factores en la proporcionalidad adecuada." (p. 340)

$$
K_{o}=K_{d}(1-t)\left(\frac{D}{D+C}\right)+K_{e}\left(\frac{C}{D+C}\right)
$$

Donde:

Ko : Es el Costo Promedio Ponderado de Capital

Ke $\quad$ : Es el Costo del Capital Propio

Kd : : Es el costo de la deuda

t $\quad$ : Es la Tasa de Impuesto a la Renta

D : Es la Deuda Total de la Empresa

C : Es el Capital de la Empresa

Para el presente caso, el $\mathrm{K}_{\mathrm{o}}$ será igual al $\mathrm{K}_{\mathrm{e}}$ porque la organización no se financia con recursos de terceros con costo.

\subsection{Presupuesto base}

\subsubsection{Presupuesto de ventas.}

Considerando la información analizada en el apartado 3.5 del Capítulo III: Plan de Marketing y Ventas, los flujos de ingresos proyectados son: 


\subsubsection{Situación actual - presupuesto de ingresos}

Si la empresa no realiza inversión alguna en mejoras tecnológicas, el número de cajas disponibles para exportación es 100,329; las mismas que se proyectan vender a un precio de 9.30 US\$/Caja. Los ingresos en dólares se solarizan al tipo de cambio proyectado por el Marco Macroeconómico Multianual del Ministerio de Economía y Finanzas (2016).

Tabla 59: Situación Actual - Presupuesto de Ingresos

\begin{tabular}{|c|c|c|c|c|c|c|}
\hline \multicolumn{1}{|c|}{ Concepto } & Año Base & Año 1 & Año 2 & Año 3 & Año 4 & Año 5 \\
\hline INGRESOS POR VENTA FRUTA: & & & & & & \\
\hline $\begin{array}{l}\text { Número Cajas de 18.14Kg } \\
\text { Disponibles para Exportar }\end{array}$ & 100,329 & 100,329 & 100,329 & 100,329 & 100,329 & 100,329 \\
\hline Precio US\$ / Caja 18.14Kg & 9.30 & 9.30 & 9.30 & 9.30 & 9.30 & 9.30 \\
\hline Total Ingresos ( US\$) & 933,057 & 933,057 & 933,057 & 933,057 & 933,057 & 933,057 \\
\hline Tipo de Cambio & 33.30 & 3.37 & 33.38 & 3.39 & 3.40 & 3.41 \\
\hline Total Ingresos ( S/ ) & $3,079,090$ & $3,144,404$ & $3,153,734$ & $3,163,065$ & $3,172,395$ & $3,181,726$ \\
\hline
\end{tabular}

Fuente y Elaboración propia

\subsubsection{Situación futura - presupuesto de ingresos}

Si la empresa realiza las inversiones en mejoras tecnológicas, la empresa conseguirá dos beneficios:

- El número de cajas disponibles para exportación aumentará de 100,329 a 103,673; las mismas que se proyectan vender a un precio de 9.30 US\$/Caja.

- Al obtener las certificaciones: orgánica, global gap y comercio justo, la empresa obtendrá el pago adicional por concepto de comercio justo. Este pago adicional es de 1.00 US\$/Caja exportada. 
Tabla 60: Situación Futura - Presupuesto de Ingresos

\begin{tabular}{|c|c|c|c|c|c|c|}
\hline Concepto & Año Base & Año 1 & Año 2 & Año 3 & Año 4 & Año 5 \\
\hline \multicolumn{7}{|l|}{ INGRESOS POR VENTA FRUTA: } \\
\hline $\begin{array}{l}\text { Número Cajas de } 18.14 \mathrm{Kg} \\
\text { Disponibles para Exportar }\end{array}$ & 100,329 & 103,673 & 103,673 & 103,673 & 103,673 & 103,673 \\
\hline Precio US\$ / Caja 18.14Kg & 9.30 & 9.30 & 9.30 & 9.30 & 9.30 & 9.30 \\
\hline Total Ingresos (US\$) & 933,057 & 964,159 & 964,159 & 964,159 & 964,159 & 964,159 \\
\hline Tipo de Cambio & 3.30 & 3.37 & 3.38 & 3.39 & 3.40 & 3.41 \\
\hline Total Ingresos (Soles) & $3,079,090$ & $3,249,217$ & $3,258,859$ & $3,268,500$ & $3,278,142$ & $3,287,783$ \\
\hline \multicolumn{7}{|l|}{$\begin{array}{l}\text { OTROS INGRESOS POR } \\
\text { CERTIFICACION: }\end{array}$} \\
\hline $\begin{array}{l}\text { Número Cajas de } 18.14 \mathrm{Kg} \\
\text { Disponibles para Exportar }\end{array}$ & 100,329 & 103,673 & 103,673 & 103,673 & 103,673 & 103,673 \\
\hline $\begin{array}{l}\text { Pago Adicional por "Comercio Justo" } \\
\text { ( US\$/Caja ) }\end{array}$ & 0 & 1.00 & 1.00 & 1.00 & 1.00 & 1.00 \\
\hline Total Otros Ingresos (US\$) & 0 & 103,673 & 103,673 & 103,673 & 103,673 & 103,673 \\
\hline Tipo de Cambio & 3.30 & 3.37 & 3.38 & 3.39 & 3.40 & 3.41 \\
\hline Total Otros Ingresos (Soles) & 0 & 349,378 & 350,415 & 351,452 & 352,488 & 353,525 \\
\hline TOTAL INGRESOS (Soles) & $3,079,090$ & $3,598,595$ & $3,609,274$ & $3,619,952$ & $3,630,630$ & $3,641,309$ \\
\hline
\end{tabular}

Fuente y Elaboración propia

\subsubsection{Presupuesto de costos.}

Considerando la información analizada en el apartado 4.5 del Capítulo IV: Plan de Operaciones, los flujos de costos proyectados son:

\subsubsection{Situación actual - presupuesto de costos}

El presupuesto de costos actual de la cooperativa está compuesto por: 
- El costo de compra de fruta: El mismo que está en función directa del precio internacional.

- El costo de proceso de Lavado y Empaque conformado por: El alquiler de la cisterna, el alquiler del camión furgón, el pago de mano de obra de las cuadrillas de operarios, la indumentaria de los operarios, el mantenimiento de las tinas y centros de empaque, las fundas para la fruta que se regala al agricultor, las certificaciones HACCP y CFI.

Tabla 61: Situación Actual - Presupuesto de Costos

\begin{tabular}{|c|c|c|c|c|c|c|}
\hline Concepto & Año 0 & Año 1 & Año 2 & Año 3 & Año 4 & Año 5 \\
\hline Costo Compra de Fruta (S/) & $2,085,835$ & $2,130,080$ & $2,136,401$ & $2,142,721$ & $2,149,042$ & $2,155,363$ \\
\hline Cantidad Fruta Comprada & 100,329 & 100,329 & 100,329 & 100,329 & 100,329 & 100,329 \\
\hline Costo Fruta Comprada & 6.30 & 6.30 & 6.30 & 6.30 & 6.30 & 6.30 \\
\hline Tipo de Cambio & 3.30 & 3.37 & 3.38 & 3.39 & 3.40 & \\
\hline
\end{tabular}

\begin{tabular}{|c|c|c|c|c|c|c|}
\hline Costo Proceso Larado (S/) & 679,870 & 700,266 & 720,574 & 741,470 & 762,973 & 785,099 \\
\hline Indice de Precios Perú & $3.50 \%$ & $3.00 \%$ & $2.90 \%$ & $2.90 \%$ & $2.00 \%$ & $2.00 \%$ \\
\hline Alquiler Cisterna & 93,600 & 96,408 & 99,204 & 102,081 & 105,041 & 108,087 \\
\hline Alquiler Camión & 99,840 & 102,835 & 105,817 & 108,886 & 112,04 & 115,293 \\
\hline Mano Obra Cuadrillas & 405,750 & 417,922 & 430,042 & 44,513 & 455,346 & 460,551 \\
\hline Costo Indumentaria & 21,280 & 21,918 & 22,54 & 23,208 & 23,881 & 24 \\
\hline $\begin{array}{l}\text { Mantenimiento de Tinas y Centros } \\
\text { de Empaque Rústicos }\end{array}$ & 9,400 & 9,682 & 9,963 & 10,252 & 10,549 & 10,8 \\
\hline $\begin{array}{l}\text { Fundas, certificación HACCP, } \\
\text { certificacción CFI }\end{array}$ & 50,000 & 51,500 & 52,994 & 54,530 & 56,112 & J, \\
\hline
\end{tabular}

\begin{tabular}{|l|r|r|r|r|r|r|}
\hline COSTOTOTAL $(S /)$ & $2,765,705$ & $2,830,346$ & $2,856,974$ & $2,884,192$ & $2,912,015$ & $2,940,462$ \\
\hline
\end{tabular}

Fuente y Elaboración propia 


\subsubsection{2. situación futura - presupuesto de costos}

La empresa tiene previsto construir un centro de empaque fijo que le ayudará a reducir la merma del proceso de lavado de fruta en $3 \%$. Adicionalmente se tiene previsto la adquisición de un camión furgón en reemplazo del gasto pagado por el alquiler de un camión furgón. Por último, se invertirá en certificar los campos con las certificaciones: orgánica, global gap y comercio justo con la finalidad de obtener el dólar adicional por concepto de pago de comercio justo.

El nuevo presupuesto de costos proyectado de la cooperativa será:

- El costo de compra de fruta: El mismo que está en función directa del precio internacional.

- El costo de proceso de Lavado y Empaque conformado por: El alquiler de la cisterna, los costos relacionados con el camión furgón adquirido, la indumentaria de los operarios, el mantenimiento de las tinas y centros de empaque, las fundas para la fruta que se regala al agricultor, las certificaciones HACCP y CFI. El pago de mano de obra de las cuadrillas de operarios. Este último costo se incrementa por la necesidad de contratar una cuadrilla adicional. 
Tabla 62: Situación Futura - Presupuesto de Costos

\begin{tabular}{|l|l|l|l|l|l|l|}
\hline Concepto & Año o & Año 1 & Año 2 & Año 3 & Año 4 & Año 5 \\
\hline
\end{tabular}

\begin{tabular}{|l|r|r|r|r|r|r|}
\hline Costo Compra de Fruta & $2,085,835$ & $2,201,083$ & $2,207,614$ & $2,214,145$ & $2,220,677$ & $2,227,208$ \\
\hline Cantidad Fruta Comprada & 100,329 & 103,673 & 103,673 & 103,673 & 103,673 & 103,673 \\
\hline Costo Fruta Comprada & 6.30 & 6.30 & 6.30 & 6.30 & 6.30 & 6.30 \\
\hline Tipo de Cambio & 3.30 & 3.37 & 3.38 & 3.39 & 3.40 & 3.41 \\
\hline
\end{tabular}

\begin{tabular}{|l|r|r|r|r|r|r|}
\hline Costo Proceso Lavado (S/) & 679,870 & 874,596 & 899,960 & 926,058 & 952,914 & 980,549 \\
\hline Indice de Precios Perú & $3,50 \%$ & $3,00 \%$ & $2,90 \%$ & $2,90 \%$ & $2,90 \%$ & $2.90 \%$ \\
\hline Alquiler Cisterna & 124,800 & 128,544 & 132,272 & 136,108 & 140,055 & 144,116 \\
\hline Alquiller Camión & 99,840 & & & & & \\
\hline Camión - Combustible & & 9,191 & 9,457 & 9,731 & 10,014 & 10,304 \\
\hline Camión - Chofery y Ayudante & & 34,608 & 35,612 & 36,644 & 37,707 & 38,801 \\
\hline Camión - Mantenimiento & & 9,888 & 10,175 & 10,470 & 10,773 & 11,086 \\
\hline Mano Obra Cuadrillas & 405,750 & 583,265 & 600,180 & 617,585 & 635,495 & 653,925 \\
\hline Costo Indumentaria & 21,280 & 21,918 & 22,554 & 23,208 & 23,881 & 24,574 \\
\hline Mantenimiento Centro Empaque & & 26,000 & 26,754 & 27,530 & 28,328 & 29,150 \\
\hline $\begin{array}{l}\text { Mantenimiento de Tinas y } \\
\text { Centros de Empaque Rísticos }\end{array}$ & 9,400 & 9,682 & 9,963 & 10,252 & 10,549 & 10,855 \\
\hline $\begin{array}{l}\text { Fundas, certificación HACCP, } \\
\text { certificacción CFI }\end{array}$ & 50,000 & 51,500 & 52,994 & 54,530 & 56,112 & 57,739 \\
\hline
\end{tabular}

\begin{tabular}{|l|r|r|r|r|r|r|}
\hline COSTO TOTAL (S) & $2,765,705$ & $3,075,679$ & $3,107,574$ & $3,140,204$ & $3,773,591$ & $3,207,757$ \\
\hline
\end{tabular}

Fuente y Elaboración propia

\subsubsection{Presupuesto de gastos administrativos.}

Considerando la información analizada en el Capítulo V: Plan de Recursos Humanos se proyectaron gastos de personal administrativo. Para elaborar los presupuestos de gastos administrativos se han considerado: 


\subsubsection{Situación actual - presupuesto de gastos administrativos}

El presupuesto de gastos administrativos actual de la cooperativa está compuesto por la planilla de personal administrativo, materiales diversos, pago de servicios y alquileres, pago de capacitaciones y movilidad.

Tabla 63: Situación Actual - Presupuesto de Gastos Administrativos

\begin{tabular}{|l|r|r|r|r|r|r|r|}
\hline \multicolumn{1}{|c|}{ Concepto } & \multicolumn{1}{|c|}{ Año 0 } & \multicolumn{1}{|c|}{ Año 1 } & \multicolumn{1}{|c|}{ Año 2 } & \multicolumn{1}{|c|}{ Año 3 } & Año 4 & Año 5 \\
\hline Indice de Precios Perú & $3.50 \%$ & $3.00 \%$ & $2.90 \%$ & $2.90 \%$ & $2.90 \%$ & $2.90 \%$ \\
\hline Planilla de Administración: & $\mathbf{6 4 , 7 0 0}$ & $\mathbf{6 6 , 6 4 1}$ & $\mathbf{6 8 , 5 7 4}$ & $\mathbf{7 0 , 5 6 2}$ & $\mathbf{7 2 , 6 0 9}$ & $\mathbf{7 4 , 7 1 4}$ \\
\hline Gerente General & 20,300 & 20,909 & 21,515 & 22,139 & 22,781 & 23,442 \\
\hline Asistente Contable & 10,800 & 11,124 & 11,447 & 11,779 & 12,120 & 12,472 \\
\hline Contador & 15,600 & 16,068 & 16,534 & 17,013 & 17,507 & 18,015 \\
\hline Ingeniero de campo & 18,000 & 18,540 & 19,078 & 19,631 & 20,200 & 20,786 \\
\hline Materiales Diversos & $\mathbf{2 4 , 0 0 0}$ & $\mathbf{2 4 , 7 2 0}$ & $\mathbf{2 5 , 4 3 7}$ & $\mathbf{2 6 , 1 7 5}$ & $\mathbf{2 6 , 9 3 4}$ & $\mathbf{2 7 , 7 1 5}$ \\
\hline Servicios y Alquileres & $\mathbf{2 4 , 0 0 0}$ & $\mathbf{2 4 , 7 2 0}$ & $\mathbf{2 5 , 4 3 7}$ & $\mathbf{2 6 , 1 7 5}$ & $\mathbf{2 6 , 9 3 4}$ & $\mathbf{2 7 , 7 1 5}$ \\
\hline Capacitaciones & $\mathbf{1 5 , 0 0 0}$ & $\mathbf{1 5 , 4 5 0}$ & $\mathbf{1 5 , 8 9 8}$ & $\mathbf{1 6 , 3 5 9}$ & $\mathbf{1 6 , 8 3 4}$ & $\mathbf{1 7 , 3 2 2}$ \\
\hline Movilidad & $\mathbf{1 0 , 0 0 0}$ & $\mathbf{1 0 , 3 0 0}$ & $\mathbf{1 0 , 5 9 9}$ & $\mathbf{1 0 , 9 0 6}$ & $\mathbf{1 1 , 2 2 2}$ & $\mathbf{1 1 , 5 4 8}$ \\
\hline Total Gasto Administrativo & $\mathbf{1 3 7 , 7 0 0}$ & $\mathbf{1 4 1 , 8 3 1}$ & $\mathbf{1 4 5 , 9 4 4}$ & $\mathbf{1 5 0 , 1 7 6}$ & $\mathbf{1 5 4 , 5 3 2}$ & $\mathbf{1 5 9 , 0 1 3}$ \\
\hline
\end{tabular}

Fuente y Elaboración propia

\subsubsection{Situación futura - presupuesto de gastos administrativos}

La implementación de mejoras tecnológicas obliga a la cooperativa en la necesidad de contratar personal calificado para la gestión de las nuevas responsabilidades. El presupuesto de gastos administrativos proyectado de la cooperativa está compuesto por la planilla de personal administrativo, materiales diversos, pago de servicios y alquileres, pago de capacitaciones, pago de renovación de certificaciones y pago de movilidad. 
Tabla 64: Situación Futura - Presupuesto de Gastos Administrativos

\begin{tabular}{|c|c|c|c|c|c|c|}
\hline Concepto & Año 0 & Año 1 & Año 2 & Año 3 & Año 4 & Año 5 \\
\hline Indice de Precios Perú & $3.50 \%$ & $3.00 \%$ & $2.90 \%$ & $2.90 \%$ & $2.90 \%$ & $2.90 \%$ \\
\hline Planilla de Administración: & 64,700 & 126,072 & 129,728 & 133,490 & 137,361 & 141,345 \\
\hline Gerente General & 20,300 & 43,260 & 44,515 & 45,805 & 47,134 & 48,501 \\
\hline Asistente Contable & 10,800 & 11,124 & 11,447 & 11,779 & 12,120 & 12,472 \\
\hline Contador & 15,600 & 18,540 & 19,078 & 19,631 & 20,200 & 20,786 \\
\hline Técnico Agrario & - & 22,248 & 22,893 & 23,557 & 24,240 & 24,943 \\
\hline Ingeniero de campo & 18,000 & 30,900 & 31,796 & 32,718 & 33,667 & 34,643 \\
\hline Materiales Diversos & 24,000 & 24,720 & 25,437 & 26,175 & 26,934 & 27,715 \\
\hline Servicios y Alquileres & 24,000 & 24,720 & 25,437 & 26,175 & 26,934 & 27,715 \\
\hline Capacitaciones & 15,000 & 15,450 & 15,898 & 16,359 & 16,834 & 17,322 \\
\hline Certificaciones & - & 34,907 & 35,919 & 36,961 & 38,033 & 39,135 \\
\hline Movilidad & 10,000 & 10,300 & 10,599 & 10,906 & 11,222 & 11,548 \\
\hline Total Gasto Administrativo & 137,700 & 236,169 & 243,018 & 250,065 & 257,317 & 264,779 \\
\hline
\end{tabular}

Fuente y Elaboración propia

\subsection{Estados financieros proyectados.}

\subsubsection{Estado de situación financiera.}

Considerando la información de los presupuestos de ingresos, costos y gastos hemos elaborado los estados de situación financieros proyectados; tanto para la situación donde no se realiza inversión alguna como para la situación donde la cooperativa realiza las inversiones.

\subsubsection{Situación actual - estados de situación financiera}

En la tabla 63 se muestran los estados de situación financiera proyectados para los siguientes años considerando que la empresa sólo realizará inversiones para reponer sus activos actuales, se reparten el $60 \%$ de los dividendos entre los socios de la cooperativa y no se mantendrán cuentas por pagar a los socios. 
Tabla 65: Situación Actual - Estado de Situación Financiera Proyectado

\begin{tabular}{|c|c|c|c|c|c|c|}
\hline & Año 0 & Año 1 & Año 2 & Año 3 & Año 4 & Año 5 \\
\hline Activo Corriente & 193,008 & 225,082 & 258,795 & 274,521 & 256,998 & 265,863 \\
\hline Efectivo y Equivalentes de Efectivo & 183,834 & 167,916 & 201,489 & 217,075 & 199,412 & 208,137 \\
\hline Cuentas por Cobrar a Trabajadores & 1,625 & 10,000 & 10,000 & 10,000 & 10,000 & 10,000 \\
\hline Tributos por Pagar (Pago a Cuenta IR) & 7,549 & 47,166 & 47,306 & 47,446 & 47,586 & 47,726 \\
\hline Activo No Corriente & 39,408 & 39,408 & 39,408 & 49,408 & 84,132 & 85,253 \\
\hline Inmuebles, Maquinaria y Equipo Bruto & 49,503 & 49,503 & 49,503 & 59,503 & 94,503 & 94,503 \\
\hline Depreciación Acumulada & 10,095 & 10,095 & 10,095 & 10,095 & 10,371 & 9,250 \\
\hline Inmuebles, Maquinaria y Equipo Neto & 39,408 & 39,408 & 39,408 & 49,408 & 84,132 & 85,253 \\
\hline TOTAL ACTIVOS & 232,416 & 264,489 & 298,203 & 323,929 & 341,130 & 351,116 \\
\hline Pasivo Corriente & 45,607 & 24,320 & 21,108 & 17,790 & 14,322 & 10,950 \\
\hline Tributos Por Pagar & 3,442 & 24,320 & 21,108 & 17,790 & 14,322 & 10,950 \\
\hline Cuentas por Pagar a Socios & 42,165 & - & - & - & - & - \\
\hline Pasivo No Corriente & - & - & - & - & - & - \\
\hline Patrimonio & 186,809 & 240,170 & 277,095 & 306,139 & 326,808 & 340,165 \\
\hline Capital Social & 46,057 & 46,057 & 46,057 & 46,057 & 46,057 & 46,057 \\
\hline Resultados Acumulados & - & 56,300 & 111,425 & 159,270 & 199,595 & 232,057 \\
\hline Resultados del Ejercicio & 140,751 & 137,812 & 119,612 & 100,811 & 81,156 & 62,051 \\
\hline TOTAL PASIVOS Y PATRIMONIO & 232,416 & 264,489 & 298,203 & 323,929 & 341,130 & 351,116 \\
\hline
\end{tabular}

Fuente y Elaboración propia

\subsubsection{Situación futura - estado de situación financiera}

En la tabla 64 se muestran los estados de situación financiera proyectados considerando que la empresa realizará las inversiones en mejoras tecnológicas financiadas con fondos no reembolsables del programa Agroideas. Este importe se contabilizará como capital adicional. Asimismo, como la inversión realizada genera una eficiencia en costos, el aumento de utilidades permitirá aumentar el reparto de las ganancias de $60 \%$ a $80 \%$. 
Tabla 66: Situación Futura - Estado de Situación Financiera Proyectado

\begin{tabular}{|c|c|c|c|c|c|c|}
\hline & Año 0 & Año 1 & Año 2 & Año 3 & Año 4 & Año 5 \\
\hline Activo Corriente & 193,008 & 309,548 & 320,580 & 315,907 & 280,342 & 276,599 \\
\hline Efectivo y Equivalentes de Efectivo & 183,834 & 265,050 & 280,292 & 279,969 & 248,898 & 249,198 \\
\hline Cuentas por Cobrar a Trabajadores & 1,625 & 10,000 & 10,000 & 10,000 & 10,000 & 10,000 \\
\hline Tributos por Pagar (Pago a Cuenta IR) & 7,549 & 34,498 & 30,288 & 25,938 & 21,444 & 17,401 \\
\hline Activo No Corriente & 39,408 & 276,464 & 276,464 & 286,464 & 321,464 & 322,559 \\
\hline Inmuebles, Maquinaria y Equipo Bruto & 49,503 & 331,323 & 331,323 & 341,323 & 376,323 & 376,323 \\
\hline Depreciación Acumulada & 10,095 & 54,859 & 54,859 & 54,859 & 54,859 & 53,764 \\
\hline Inmuebles, Maquinaria y Equipo Neto & 39,408 & 276,464 & 276,464 & 286,464 & 321,464 & 322,559 \\
\hline TOTAL ACTIVOS & 232,416 & 586,011 & 597,043 & 602,370 & 601,805 & 599,158 \\
\hline Pasivo Corriente & 45,607 & 34,498 & 30,288 & 25,938 & 21,444 & 17,401 \\
\hline Tributos Por Pagar & 3,442 & 34,498 & 30,288 & 25,938 & 21,444 & 17,401 \\
\hline Cuentas por Pagar a Socios & 42,165 & - & & - & - & \\
\hline Pasivo No Corriente & - & $\cdot$ & - & - & $\cdot$ & - \\
\hline Patrimonio & 186,809 & 551,514 & 566,756 & 576,432 & 580,362 & 581,757 \\
\hline Capital Social & 46,057 & 46,057 & 46,057 & 46,057 & 46,057 & 46,057 \\
\hline Capital Adicional & & 281,820 & 281,820 & 281,820 & 281,820 & 281,820 \\
\hline Resultados Acumulados & - & 28,150 & 67,247 & 101,574 & 130,970 & 155,273 \\
\hline Resultados del Ejercicio & 140,751 & 195,486 & 171,631 & 146,981 & 121,515 & 98,607 \\
\hline TOTAL PASIVOS Y PATRIMONIO & 232,416 & 586,011 & 597,043 & 602,370 & 601,806 & 599,159 \\
\hline
\end{tabular}

Fuente y Elaboración propia

\subsubsection{Estado de resultados.}

Considerando la información de los presupuestos de ingresos, costos y gastos hemos elaborado los estados de resultados proyectados; tanto para la situación donde no se realiza inversión alguna como para la situación donde la cooperativa realiza inversiones en mejoras tecnológicas. 


\subsubsection{Situación actual - estado de resultados}

En la tabla 63 se muestran los estados de resultados proyectados para los siguientes años considerando que la empresa sólo realizará inversiones para reponer sus activos actuales y mantendrá sus políticas de costos y gastos de manera similar a las actuales.

Tabla 67: Situación Actual - Estados de Resultados Proyectados

\begin{tabular}{|c|c|c|c|c|c|c|}
\hline Rubro & Año 0 & Año 1 & Año 2 & Año 3 & Año 4 & Año 5 \\
\hline (t) Ventas & $3,079,090$ & $3,144,404$ & $3,153,734$ & $3,163,065$ & $3,172,395$ & $3,181,726$ \\
\hline (-) Costo de ventas & $2,765,705$ & $2,830,346$ & $2,856,974$ & $2,884,192$ & $2,912,015$ & $2,940,462$ \\
\hline (=) Utilidad bruta & 313,385 & 314,058 & 296,760 & 278,873 & 260,381 & 241,264 \\
\hline -) Gasto administrativo & 137,700 & 141,831 & 145,944 & 150,176 & 154,532 & 159,0 \\
\hline -) Depreciación & 10,095 & 10,095 & 10,095 & 10,095 & 10,371 & 9,250 \\
\hline$\Leftrightarrow=$ Utilidad operativa & 165,500 & 162,131 & 140,721 & 118,601 & 95,478 & 73, \\
\hline \multicolumn{7}{|l|}{ (-) Casto financiero } \\
\hline \multicolumn{7}{|l|}{ (t) Ingresos extraordinarios } \\
\hline \multicolumn{7}{|l|}{ (-) Egresos extraordinarios } \\
\hline (E) Utilidad Antes de impuestos & 165,590 & 162,131 & 140,721 & 118,601 & 95,478 & 73, \\
\hline (-) impuestos & 24,838 & 24,320 & 21,108 & 17,790 & 14,322 & 10 \\
\hline (=) Utilidad neta & 140,751 & 137,812 & 119,612 & 100,811 & 81,156 & 62,0 \\
\hline
\end{tabular}

Fuente y Elaboración propia

\subsubsection{Situación futura - estado de resultados}

En la tabla 62 se muestran los estados de resultados proyectados para los siguientes años considerando que la empresa realizará inversiones en mejoras tecnológicas. 
Tabla 68: Situación Futura - Estados de Resultados Proyectados

\begin{tabular}{|l|r|r|r|r|r|r|}
\hline \multicolumn{1}{|c|}{ Rulbro } & \multicolumn{1}{c|}{ Año 0 } & \multicolumn{1}{c|}{ Año 1 } & \multicolumn{1}{c|}{ Año 2 } & \multicolumn{1}{c|}{ Año 3 } & \multicolumn{1}{c|}{ Año 4 } & \multicolumn{1}{c|}{ Año 5 } \\
\hline (+) Ventas & $\mathbf{3 , 0 7 9 , 0 9 0}$ & $\mathbf{3 , 5 9 8 , 5 9 5}$ & $\mathbf{3 , 6 0 9 , 2 7 4}$ & $\mathbf{3 , 6 1 9 , 9 5 2}$ & $\mathbf{3 , 6 3 0 , 6 3 0}$ & $\mathbf{3 , 6 4 1 , 3 0 9}$ \\
\hline (-) Costo de ventas & $2,765,705$ & $3,075,679$ & $3,107,574$ & $3,140,204$ & $3,173,591$ & $3,207,757$ \\
\hline (=) Utilidad bruta & 313,385 & $\mathbf{5 2 2 , 9 1 6}$ & $\mathbf{5 0 1 , 7 0 0}$ & $\mathbf{4 7 9 , 7 4 8}$ & $\mathbf{4 5 7 , 0 3 9}$ & $\mathbf{4 3 3 , 5 5 2}$ \\
\hline (-) Gasto administrativo & 137,700 & 236,169 & 243,018 & 250,065 & 257,317 & 264,779 \\
\hline -) Depreciación & 12,000 & 56,764 & 56,764 & 56,764 & 56,764 & 52,764 \\
\hline (=) Utilidad operativa & 163,685 & 229,984 & 201,918 & 172,919 & 142,958 & 116,009 \\
\hline -) Gasto financiero & & & & & & \\
\hline (+) Ingresos extraordinarios & & & & & & \\
\hline (-) Egresos extraordinarios & & & & & & \\
\hline (=) Utilidad Antes de impuestos & 163,685 & 229,984 & 201,918 & 172,919 & 142,958 & 116,009 \\
\hline$(-)$ impuestos* & 24,553 & 34,498 & 30,288 & 25,938 & 21,444 & 17,401 \\
\hline (=) Utilidad neta & 139,132 & 195,486 & 171,631 & 146,981 & 121,515 & 98,607 \\
\hline
\end{tabular}

Fuente y Elaboración propia

\subsubsection{Flujo de caja incremental.}

Sapag (2000) nos dice “...contrariamente a lo que mucha gente piensa, la gran mayoría de las evaluaciones de proyectos no son para estudiar la conveniencia de crear nuevas empresas, sino para determinar si es rentable o no implementar un proyecto de mejora en una empresa que ya está funcionando.” (p. 268)

Lira (2013) nos dice que, en el flujo de caja de un proyecto, interesa sólo la rentabilidad incremental. En otras palabras, lo que varía por el proyecto es lo único que interesa cuando se le evalúa; esto quiere decir que solo debe tomarse en cuenta en la evaluación los beneficios y costos asociados a la ejecución del proyecto, o los efectos que este pueda tener en las operaciones de la empresa. (p. 151) 
Como la cooperativa se encuentra en marcha, es importante calcular el flujo de caja incremental del proyecto. Para ello es necesario proyectar los flujos de caja económicos sin considerar la inversión en mejoras tecnológicas y proyectar el flujo de caja económico de la cooperativa, luego de realizar las inversiones. La diferencia de ambos flujos de caja será el flujo de caja incremental que nos permitirá evaluar la viabilidad del proyecto.

\subsubsection{Situación actual - flujo de caja económico}

Considerando la información de los presupuestos de ingresos, costos, gastos administrativos, gasto de depreciación y la política de inversiones de la cooperativa, se procedió a elaborar el flujo de caja económico. Dado que la cooperativa mantendrá su continuidad en el tiempo, se ha considerado un flujo perpetuo que será igual al flujo de caja del último año.

Debido a que la empresa financiará las inversiones con recursos propios, el flujo de financiamiento neto es igual a cero; razón por la cual el flujo de caja económico es igual al flujo de caja financiero.

A continuación, se muestra el Flujo de Caja Económico actual de la cooperativa; proyectando los flujos sin considerar la inversión para mejoras tecnológicas. 
Tabla 69: Situación Actual - Flujo de Caja Económico

\begin{tabular}{|c|c|c|c|c|c|c|c|}
\hline \multirow{2}{*}{ Rubro } & \multirow{2}{*}{ Año 0} & \multicolumn{6}{|c|}{ Plan Anval Provectiado } \\
\hline & & Año 1 & Año 2 & Año 3 & Año 4 & Año 5 & Perpetuidad \\
\hline (t) Ingresos por ventas & & $3,144,404$ & $3,153,734$ & $3,163,065$ & $3,172,395$ & $3,181,726$ & $3,181,726$ \\
\hline (-) Costos y gastos operativos & & $2,972,177$ & $3,002,918$ & $3,34,368$ & $3,066,546$ & $3,099,475$ & $3,099,475$ \\
\hline (-) Impuestos & & 24,320 & 21,108 & 17,790 & 14,322 & 10,50 & 10,50 \\
\hline$(=)$ Flujo de caja operativo (A) & & 147,907 & 129,708 & 110,907 & 91,527 & 71,301 & 71,301 \\
\hline (-) Inversón en activos & - & - & - & 10,000 & 35,000 & - & \\
\hline (-) Inversión en capital trabajo & & - & - & - & - & - & - \\
\hline (E) Flujo de inversión (B) & - & - & 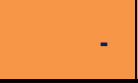 & $-10,000$ & $-35,000$ & - & \\
\hline Plujo de Caja Bconómico $(A)+(B)$ & & 147,007 & 129,708 & 100,907 & 56,527 & 71,301 & 71,301 \\
\hline
\end{tabular}

Fuente y Elaboración propia

\subsubsection{2. situación futura - flujo de caja económico}

Habiéndose identificado que la cooperativa presenta problemas enfocados en inadecuadas condiciones del proceso de empacado de la fruta y a elevados costos de producción; es necesario que la organización realice las siguientes inversiones dentro del Programa de Compensaciones para la Competitividad:

- Cofinanciar las certificaciones: orgánica, global gap y comercio justo.

- Cofinanciar la construcción de un centro de empaque

- Cofinanciar la compra de un camión furgón. 
Debido a que la empresa financiará las inversiones con recursos propios, el flujo de financiamiento neto es igual a cero; razón por la cual el flujo de caja económico es igual al flujo de caja financiero.

Dado que la cooperativa mantendrá su continuidad en el tiempo, se ha considerado un flujo perpetuo que será igual al flujo de caja del último año.

Tabla 70: Situación Futura: Flujo de Caja Económico

\begin{tabular}{|c|c|c|c|c|c|c|c|}
\hline \multirow{2}{*}{ Rubro } & \multirow{2}{*}{ Año 0} & \multicolumn{6}{|c|}{ Plan Anual Projectado } \\
\hline & & Año 1 & Año 2 & Año 3 & Año 4 & Año 5 & Perpetuidad \\
\hline (t) Ingresos por ventas & & $3,998,95$ & $3,609,274$ & $3,619,952$ & $3,630,630$ & $3,641,309$ & $3,641,309$ \\
\hline (-) Costos y gastos operativos 31 & & $3,311,448$ & $3,350,591$ & $3,390,269$ & $3,430,008$ & $3,472,536$ & $3,772,536$ \\
\hline (-) Implestos & & 34,498 & 30,288 & 25,938 & 21,44 & 17,401 & 17,401 \\
\hline$\Leftrightarrow$ Flujo de caja operativo (A) & & 252,250 & 228,395 & 203,745 & 178,79 & 151,371 & 151,371 \\
\hline (-) Inversión en activos & 315,710 & - & - & 10,000 & 35,000 & - & . \\
\hline (-) Inversón en capital trabajo & & - & - & - & - & - & - \\
\hline (=) Flujo de inversión ( $B$ ) & $-315,710$ & & & $-10,000$ & $-35,000$ & & \\
\hline Flujo de Caja Bconónico $(A)+(B)$ & $.315,710$ & 252,250 & 228,395 & 193,745 & 143,279 & 151,371 & 151,371 \\
\hline
\end{tabular}

Fuente y Elaboración propia

\subsection{Evaluación de la rentabilidad.}

Para la evaluación de la rentabilidad se analizarán tres variables fundamentales: la Tasa Interna de Retorno, el Valor Actual Neto y el Plazo de Recuperación. 


\subsubsection{La tasa interna de retorno (TIR).}

Sapag (2000) nos dice que "el criterio de la TIR evalúa el proyecto en función de una única tasa de rendimiento por período con la cual la totalidad de los beneficios actualizados son exactamente iguales a los desembolsos expresados en moneda actual.” (p. 388)

Dado que la inversión se financia con recursos propios, se debe calcular la tasa interna de retorno económica (TIRE), para lo cual se considera la inversión realizada y los flujos de caja económicos incrementales generados por el proyecto. El cálculo de la TIRE es necesario para evaluar la rentabilidad esperada por el accionista; para ello, la TIRE es comparada con el costo de oportunidad del accionista, debidamente ajustada por el riesgo del proyecto.

Tabla 71: Cálculo de la Tasa Interna de Retorno Económica

\begin{tabular}{|l|r|r|r|r|r|r|r|}
\hline \multirow{2}{*}{ Rubro } & \multicolumn{7}{c|}{ Años } \\
\cline { 2 - 7 } & \multicolumn{1}{c|}{0} & \multicolumn{1}{c|}{1} & \multicolumn{1}{c|}{2} & \multicolumn{1}{c|}{3} & \multicolumn{1}{c|}{5} & \multicolumn{1}{c|}{ Perpetuidad } \\
\hline FFCC Económico con PNT (A) & $-315,710$ & 252,250 & 228,395 & 193,745 & 143,279 & 151,371 & 151,371 \\
\hline FFCC Económico sin PNT (B) & - & 147,907 & 129,708 & 100,907 & 56,527 & 71,301 & 71,301 \\
\hline $\begin{array}{l}\text { Flujo de Caja Económico Incrementa } \\
\text { (A) -(B) }\end{array}$ & $-315,710$ & 104,343 & 98,687 & 92,839 & 86,751 & 80,070 & 80,070 \\
\hline
\end{tabular}

\begin{tabular}{|c|c|}
\hline Indicador & Resultado \\
\hline TIR Económica (TIRE) - \% & $28.88 \%$ \\
\hline
\end{tabular}

Fuente y Elaboración propia

La TIRE resultante es $28.88 \%$, una rentabilidad mayor al costo de capital propio del $19.69 \%$, lo cual nos indica que el proyecto es rentable.

Como la inversión no es financiada con ninguna institución financiera el Flujo de Financiamiento Neto es igual a cero; razón por la cual el Flujo de Caja Financiero es igual al Flujo de Caja Económico. 
Por este motivo, la tasa interna de retorno económica es igual a la tasa interna de retorno financiera.

Tabla 72: Cálculo de la Tasa Interna de Retorno Financiera

\begin{tabular}{|l|r|c|c|c|c|c|r|}
\hline \multirow{2}{*}{ Rubro } & \multicolumn{7}{|c|}{ Años } \\
\cline { 2 - 8 } & 0 & 1 & 2 & 3 & 4 & 5 & Perpetuidad \\
\hline FFCC Financiero con PNT (A) & $-315,710$ & 252,250 & 228,395 & 193,745 & 143,279 & 151,371 & 151,371 \\
\hline FFCC Financiero sin PNT (B) & - & 147,907 & 129,708 & 100,907 & 56,527 & 71,301 & 71,301 \\
\hline $\begin{array}{l}\text { Flujo de Caja Financiero Incremental } \\
\text { (A) -(B) }\end{array}$ & $-315,710$ & 104,343 & 98,687 & 92,839 & 86,751 & 80,070 & 80,070 \\
\hline
\end{tabular}

\begin{tabular}{|c|c|}
\hline Indicador & Resultado \\
\hline TIR Financiero (TIR F) - \% & $28.88 \%$ \\
\hline
\end{tabular}

Fuente y Elaboración propia

\subsubsection{El valor actual neto (VAN).}

Sapag (2000) nos dice que "el criterio del valor actual neto plantea que el proyecto debe aceptarse si su VAN es igual o superior a cero, donde el VAN es la diferencia entre todos sus ingresos y egresos expresados en moneda actual." (p. 381)

Para determinar el valor actual neto económico (VANE) del proyecto se utilizarán los flujos de caja económicos incrementales y serán descontados a la tasa de descuento calculada. 
Tabla 73: Cálculo del Valor Actual Neto Económico

\begin{tabular}{|c|c|c|c|c|c|c|c|}
\hline \multirow{2}{*}{ Rubro } & \multicolumn{7}{|c|}{ Años } \\
\hline & 0 & 1 & 2 & 3 & 4 & 5 & Perpetuidad \\
\hline FFCC Económico con PNT (A) & $-315,710$ & 252,250 & 228,395 & 193,745 & 143,279 & 151,371 & 151,371 \\
\hline FFCC Económico sin PNT (B) & - & 147,907 & 129,708 & 100,907 & 56,527 & 71,301 & 71,301 \\
\hline $\begin{array}{l}\text { Flujo de Caja Económico Incremental } \\
\text { (A) -(B) }\end{array}$ & $-315,710$ & 104,343 & 98,687 & 92,839 & 86,751 & 80,070 & 80,070 \\
\hline
\end{tabular}

\begin{tabular}{|c|r|}
\hline Indicador & Resultado \\
\hline VAN Económico (VANE) - (S/.) & 134,764 \\
\hline
\end{tabular}

Fuente y Elaboración propia

El valor actual neto económico resultante es: 134,764 soles, cifra mayor a cero, lo cual nos indica que el proyecto es rentable.

Como la inversión no es financiada con ninguna institución financiera el Flujo de Financiamiento Neto es igual a cero; razón por la cual el Flujo de Caja Financiero es igual al Flujo de Caja Económico. Por este motivo, el valor actual neto financiero es igual a 134,764 soles.

Tabla 74: Cálculo del Valor Actual Neto Financiero

\begin{tabular}{|l|r|c|c|c|c|c|r|}
\hline \multirow{2}{*}{ Rubro } & \multicolumn{7}{|c|}{ Años } \\
\cline { 2 - 7 } & 0 & 1 & 2 & 3 & 4 & 5 & Perpetuidad \\
\hline FFCC Financiero con PNT (A) & $-315,710$ & 252,250 & 228,395 & 193,745 & 143,279 & 151,371 & 151,371 \\
\hline FFCC Financiero sin PNT (B) & - & 147,907 & 129,708 & 100,907 & 56,527 & 71,301 & 71,301 \\
\hline Flujo de Caja Financiero Incremental \\
(A) -(B)
\end{tabular}

\begin{tabular}{|c|c|}
\hline Indicador & Resultado \\
\hline VAN Financiero (VAN F) - (S/.) & 134,764 \\
\hline
\end{tabular}

Fuente y Elaboración propia 


\subsubsection{El plazo de recuperación.}

Sapag (2000) nos dice que "el criterio del plazo de recuperación determina el número de períodos necesarios para recuperar la inversión inicial, resultado que se compara con el número de períodos aceptables por la empresa." (p. 394)

Aplicando la fórmula tenemos:

Plazo Recuperación $=\frac{\text { Inversión Inicial }}{\text { Flujos de Caja }}$

Plazo Recuperación $=\frac{315,710}{104,343+98,687+92,839+86,751}$

El plazo de recuperación de la inversión inicial se logra en 3.23 años desde la puesta en marcha del proyecto. De acuerdo a lo conversado con los dirigentes de la organización, su expectativa de recuperación de la inversión era de 07 años. Al ser el plazo de recuperación menor al plazo expectante de los dirigentes de la cooperativa, el proyecto es factible de ser realizado.

Si consideramos el valor del dinero en el tiempo, el payback del proyecto se calcula descontando los flujos de caja generados a la tasa del costo de oportunidad: 
Tabla 75: Plazo de Recuperación Descontado

\begin{tabular}{|c|c|c|c|c|c|c|c|c|}
\hline \multirow{2}{*}{ Rubro } & \multicolumn{8}{|c|}{ Años } \\
\hline & 0 & 1 & 2 & 3 & 4 & 5 & 6 & 7 \\
\hline $\begin{array}{l}\text { Flujo de Caja Financiero Incremental } \\
\text { (A) -(B) }\end{array}$ & $-315,710$ & 104,343 & 98,687 & 92,839 & 86,751 & 80,070 & 80,070 & 12, \\
\hline Tasa de Descuento & $19.6974 \%$ & & & & & & & \\
\hline $\begin{array}{l}\text { Flujo de Caja Financiero Descontado } \\
\left(S=C^{*}(1+i)^{\Lambda_{n}}\right.\end{array}$ & $-315,710$ & 87,172 & 68,879 & 54,135 & 42,261 & 32,587 & 27,225 & \\
\hline
\end{tabular}

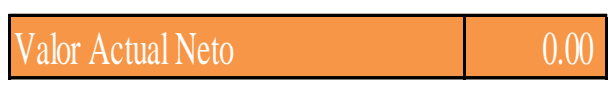

Fuente y Elaboración propia

De acuerdo a la proyección de flujos descontados al costo de oportunidad, la inversión de 315,710 soles se recupera en un plazo de 06 años y 102 días.

Luego de realizar la evaluación de la rentabilidad en tres aspectos fundamentales como son: (1) el valor actual neto económico (VANE = 134,764 soles), (2) la tasa interna de retorno económica (TIRE = $28.88 \%$ ) y el plazo de recuperación de la inversión $(\mathrm{PR}=6.28$ años) podemos concluir que el proyecto es rentable y se debe poner en marcha.

\subsection{Análisis de la sensibilidad.}

Sapag (2000) nos dice que el riesgo de un proyecto se define como la variabilidad de los flujos de caja reales respecto a los estimados. Mientras más grande sea esta variabilidad, mayor es el riesgo del proyecto. De esta forma, el riesgo se manifiesta en la variabilidad de los rendimientos del proyecto, puesto que se calculan sobre la proyección de los flujos de caja. (p. 379) 
Chou (2006) nos dice: "El análisis de sensibilidad deberá probar la resistencia del proyecto al impacto de factores negativos. Se deberá calcular cuál es el impacto de estos factores en la rentabilidad del proyecto (TIRE). Considerar el riesgo en la evaluación de un proyecto de inversión se define como el proceso de desarrollar la distribución de probabilidades de algunos de los criterios económicos o parámetros de la evaluación. La incertidumbre es la incapacidad de predecir situaciones futuras y el riesgo es la variación de un valor esperado entre resultados inciertos." ( $p .45)$

Salinas (1998) nos dice que la probabilidad subjetiva es la medida asignada a la valoración subjetiva hecha por un analista de la probable ocurrencia de un evento. Se basa en la información que dispone esta persona en un momento dado, es decir, en su estado de información. La probabilidad subjetiva es la manera relevante - y en muchas situaciones la única - de asignar probabilidades a una ocurrencia. La idea fundamental en este tipo de asignación es que la probabilidad es un número que usamos para describir nuestra certeza sobre la ocurrencia de un evento. (p. 72)

Para la implementación del análisis de incertidumbre y probabilidades hemos calculado el "Z" (De una distribución normal estadística) a partir del valor esperado, del costo de oportunidad del proyecto y de la variable en forma estandarizada. El "Z" nos ayudará a determinar la probabilidad acumulada que la TIRE sea menor al costo de oportunidad del proyecto.

Se medirá el riesgo del proyecto considerando variaciones en los flujos de caja y su impacto en la TIRE originados por: variaciones en el dólar recibido por concepto de comercio justo, variaciones en el porcentaje de merma del lavado de fruta y variaciones en la productividad de los socios productores. 


\subsubsection{Variaciones en el dólar recibido por concepto de comercio justo.}

De acuerdo a las entrevistas y conversaciones sostenidas con los socios productores en diversas asambleas, se pudo determinar que existe un $40 \%$ de probabilidad que los socios mantengan bajo la gestión de la cooperativa el dólar recibido por concepto de comercio justo; un $30 \%$ de los socios es de la opinión de entregar 0.10 centavos al agricultor y un $30 \%$ opinó que dicha entrega debería ser de 0.20 centavos.

Luego de calcular las variaciones del beneficio recibido, se calcularon las TIRE equivalentes para cada escenario y procedimos a calcular la probabilidad que la TIRE del proyecto sea mayor al costo de oportunidad. Para ello utilizamos el método de "análisis de incertidumbre y probabilidades". Este cálculo nos muestra que dicha probabilidad es del $48.68 \%$.

Tabla 76: Análisis de Sensibilidad - Dólar Adicional por Caja

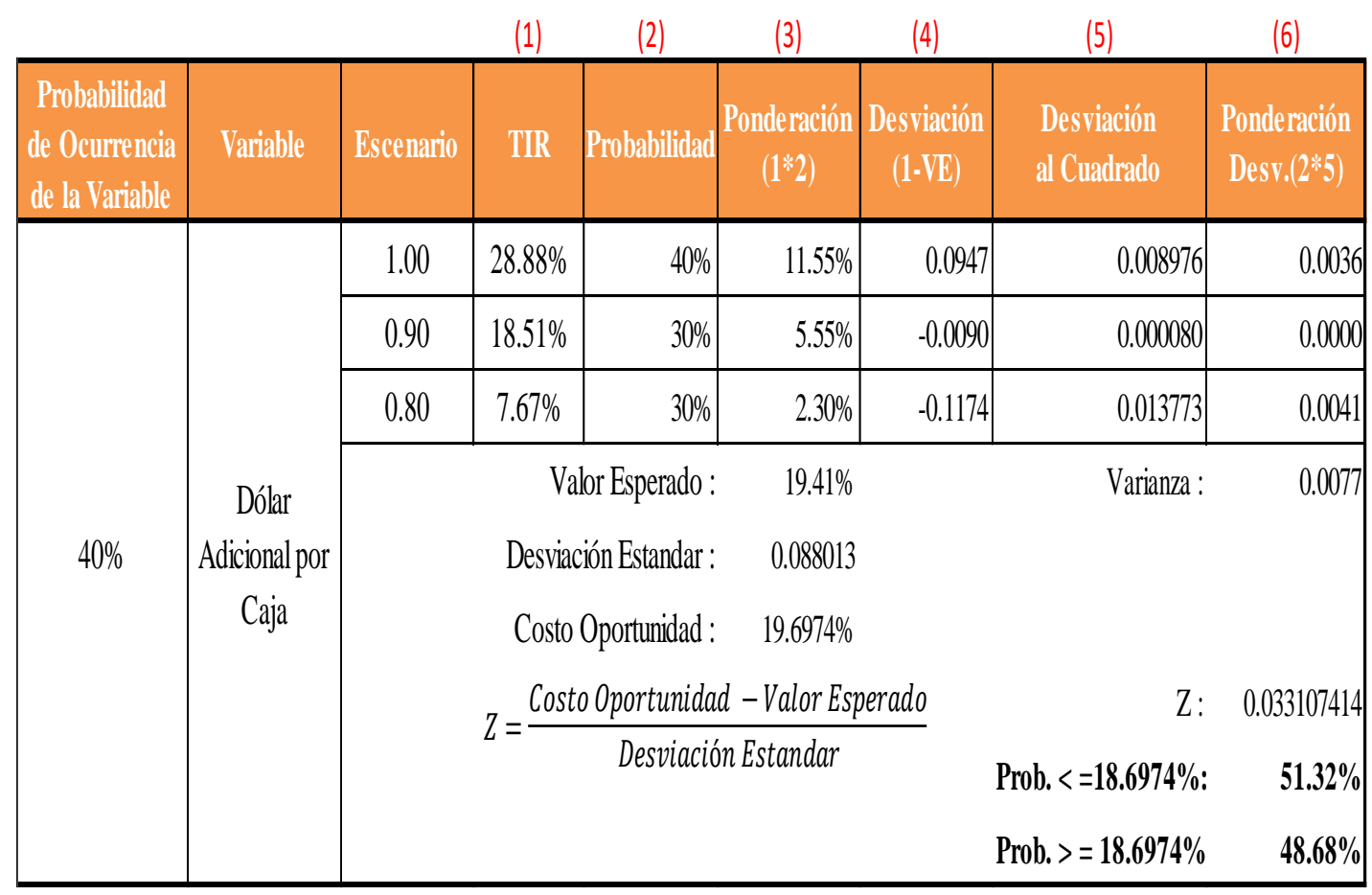

Fuente y Elaboración propia 


\subsubsection{Variaciones en el porcentaje de merma del lavado de fruta}

En entrevistas sostenidas con gerentes de cooperativas similares, con el jefe del programa agroideas en Piura y con el director regional del ministerio de agricultura, se les consultó ¿cuál es la probabilidad que luego de construir un centro de empaque fijo el porcentaje de merma se redujese de $5 \%$ a $3 \%$ o menos? Con sus respuestas, pudimos determinar que existe un $55 \%$ de probabilidad que el porcentaje de merma de lavado de fruta se reducirá a $3 \%$; un $25 \%$ que se reduzca en $2 \%$ y un $20 \%$ que se reduzca en $1 \%$.

Luego de calcular las variaciones del beneficio recibido, se calcularon las TIRE equivalentes para cada escenario y procedimos a calcular la probabilidad que la TIRE del proyecto sea mayor al costo de oportunidad. Para ello utilizamos el método de "Análisis de incertidumbre y probabilidades". Este cálculo nos muestra que dicha probabilidad es del $96.31 \%$.

\section{Tabla 77: Análisis de Sensibilidad - \% de Merma del Lavado Fruta}

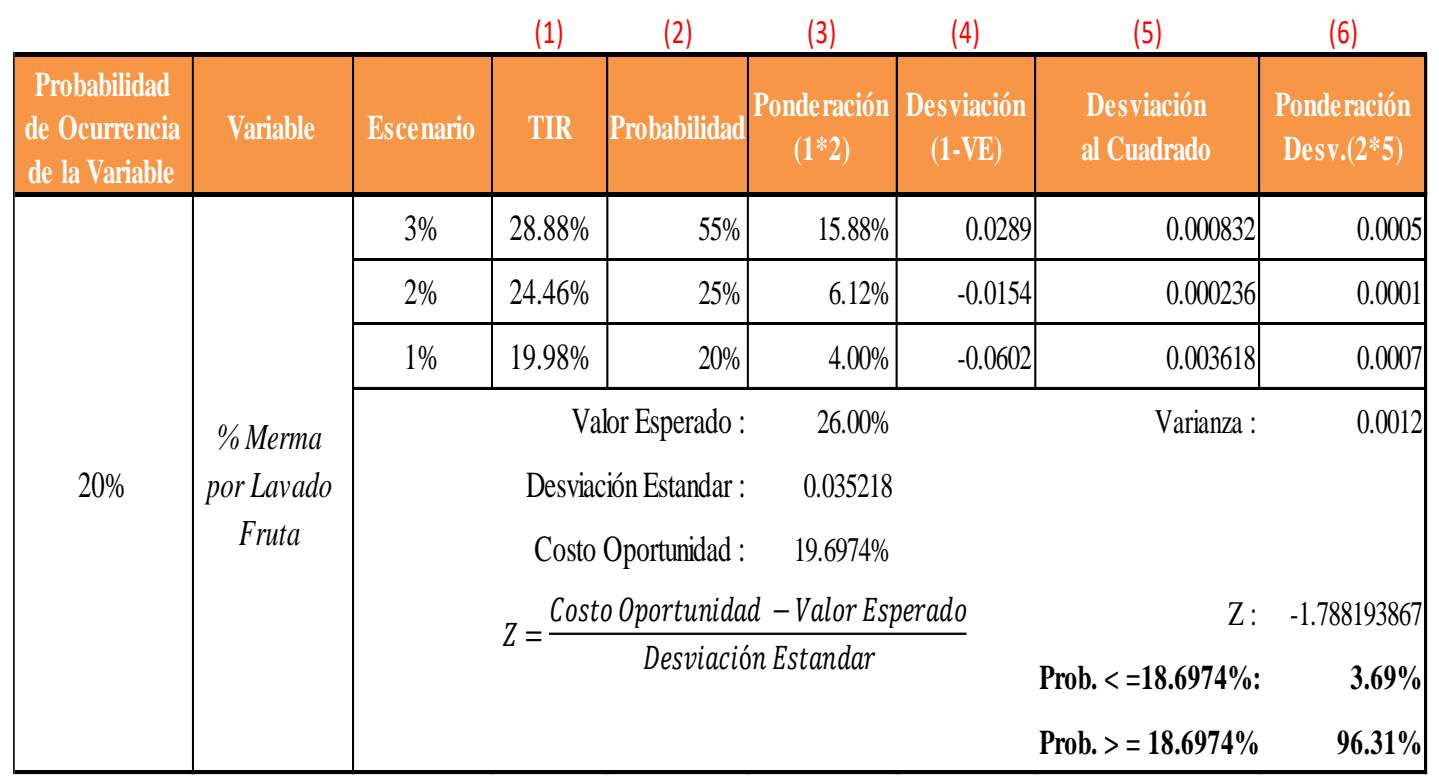

Fuente y Elaboración propia 


\subsubsection{Variaciones en la productividad de la plantación.}

El factor de productividad de las plantas se ve influenciado principalmente por factores climatológicos, siendo el más influyente el fenómeno el niño.

Revisando la información de los últimos 35 años del sistema nacional de información de recursos hídricos para el monitoreo del fenómeno el niño (2017) se pudo establecer que la probabilidad que ocurra un fenómeno del niño débil es del $16.57 \%$ y que ocurra un fenómeno del niño fuerte es del 5.71\%.

Cabe señalar que cuando ocurre un fenómeno débil, el factor de productividad (de acuerdo a data histórica de agroideas) se reduce a 0.81; mientras que cuando ocurre un fenómeno fuerte se reduce a 0.72 .

Luego de calcular las variaciones del beneficio recibido, se calcularon las TIRE equivalentes para cada escenario y procedimos a calcular la probabilidad que la TIRE del proyecto sea mayor al costo de oportunidad. Para ello utilizamos el método de "Análisis de incertidumbre y probabilidades". Este cálculo nos muestra que dicha probabilidad es del $82.00 \%$. 
Tabla 78: Análisis de Sensibilidad - Productividad de la plantación

\begin{tabular}{|c|c|c|c|c|c|c|c|c|}
\hline & & & (1) & (2) & (3) & (4) & (5) & (6) \\
\hline $\begin{array}{l}\text { Probabilidad } \\
\text { de Ocurrencia } \\
\text { de la Variable }\end{array}$ & Variable & Escenario & TIR & Probabilidad & $\begin{array}{c}\text { Ponderación } \\
(1 * 2)\end{array}$ & $\begin{array}{c}\text { Desviación } \\
(1-V D)\end{array}$ & $\begin{array}{l}\text { Desviación } \\
\text { al Cuadrado }\end{array}$ & $\begin{array}{l}\text { Ponderación } \\
\text { Desv.(2*5) }\end{array}$ \\
\hline \multirow{9}{*}{$40 \%$} & \multirow{9}{*}{$\begin{array}{c}\text { Factor } \\
\text { Productividad } \\
\text { Agricultor }\end{array}$} & 0.90 & $28.88 \%$ & $77.72 \%$ & $22.45 \%$ & 0.0322 & 0.001040 & 0.0008 \\
\hline & & 0.81 & $17.48 \%$ & $16.57 \%$ & $2.90 \%$ & -0.0818 & 0.006684 & 0.0011 \\
\hline & & 0.72 & $5.49 \%$ & $5.71 \%$ & $0.31 \%$ & -0.2017 & 0.040665 & 0.0023 \\
\hline & & \multicolumn{5}{|c|}{ Valor Esperado : $\quad 25.66 \%$} & \multirow[t]{3}{*}{ Varianza : } & 0.0042 \\
\hline & & \multirow{2}{*}{\multicolumn{3}{|c|}{$\begin{array}{l}\text { Desviación Estandar } \\
\text { Costo Oportunidad }\end{array}$}} & 0.065097 & & & \\
\hline & & & & & $19.6974 \%$ & & & \\
\hline & & & \multirow{2}{*}{\multicolumn{4}{|c|}{$Z=\frac{\text { Costo Oportunidad }- \text { Valor Esperado }}{\text { Desviación Estandar }}$}} & Z: & -0.915265228 \\
\hline & & & & & & & Prob. $<=18.6974 \%$ : & $18.00 \%$ \\
\hline & & & & & & & Prob. $>=18.6974 \%$ & $82.00 \%$ \\
\hline
\end{tabular}

Fuente y Elaboración propia

Teniendo en cuenta la información obtenida en fuentes primarias y secundarias, se asignó de manera subjetiva una probabilidad de ocurrencia de la siguiente manera: $40 \%$ de probabilidad que ocurran variaciones en el dólar que se recibe por concepto de comercio justo, $40 \%$ de probabilidad que ocurran variaciones en el factor de productividad del agricultor y $20 \%$ de probabilidad que ocurran variaciones en el porcentaje de merma del proceso de lavado de fruta.

Considerando que esta asignación de probabilidades y las probabilidades calculadas en los escenarios anteriormente presentados, podemos determinar la probabilidad - del proyecto - que la TIR sea mayor al costo de oportunidad. En este caso la probabilidad es del $71.53 \%$. 
Tabla 79: Probabilidad que la TIR sea mayor que el Costo de Oportunidad

\begin{tabular}{|ccc|}
\hline \multicolumn{2}{|l|}{ Probabilidad Total : } & \\
\hline $40 \%$ & Dólar Adicional por Caja & 0.1947 \\
$20 \%$ & Porcentaje Merma en Lavado Fruta & 0.1926 \\
$40 \%$ & Factor Productividad del Agricultor & 0.3280 \\
& & 0.7153 \\
\hline Probabilidad que la TIRE > Costo Oportunidad: & $71.53 \%$ \\
\hline
\end{tabular}

Fuente y Elaboración propia

Considerando que los flujos de caja económicos son iguales a los flujos de caja financieros por no existir un flujo de financiamiento neto, la sensibilidad realizada es la misma para una TIR económica que para la TIR financiera. 


\section{CAPÍTULO VII}

\section{Conclusiones y recomendaciones}

\subsection{Conclusiones.}

A continuación, detallaremos las conclusiones a las que hemos llegado a partir de nuestra investigación:

a. El problema de la organización se puede explicar en tres frentes: (1) poco profesionalismo del gerente general, jefaturas y directivos, (2) necesidad de captar nuevos socios para poder crecer en áreas productivas, (3) inadecuadas condiciones del proceso de lavado y empaque junto a elevados costos de producción; originados por la necesidad de mejorar las condiciones de los procesos, reducir los costos de distribución y certificar los campos.

b. La cooperativa en el marco de la ejecución del presente proyecto, acogiéndose al programa de Agroideas tiene previsto:

- Adquirir las certificaciones: orgánico, comercio justo y global gap.

- Construir un centro de empaque con tina fija.

○ Comprar un camión furgón.

c. El proyecto tiene los siguientes indicadores económicos:

- El proyecto tiene una TIRF de $28.88 \%$ que es mayor que el costo de oportunidad de $19.697390 \%$.

- El VANF del proyecto es de 134,764 que es mayor a cero. 
○ El PR es 06 años y 102 días. De acuerdo a lo conversado con los dirigentes de la organización, su expectativa era de 07 años. El Plazo de recuperación es razonable, considerando que se trata de un proyecto agrícola.

○ La probabilidad de éxito del proyecto es del $71.53 \%$.

d. Teniendo en cuenta los análisis cualitativos y cuantitativos favorables realizados y, que los indicadores económicos se muestran razonables, hemos determinado la viabilidad del proyecto, por lo que se sugiere realizar la inversión.

\subsection{Recomendaciones}

A continuación, detallaremos las conclusiones a las que hemos llegado a partir de nuestra investigación:

a. Se recomienda a la cooperativa iniciar la captación de nuevos socios a fin de poder incrementar su área productiva y poder llenar al menos un contenedor semanal de fruta.

b. Se recomienda la contratación de personal calificado para poder seguir mejorando las condiciones productivas y alcanzar su objetivo de poder exportar directamente a los mercados internacionales.

c. Se recomienda seguir mejorando los indicadores de productividad en el traslado de la fruta a fin de poder aumentar la cantidad de fruta exportable. Para ello, con la liquidez obtenida con la ejecución del proyecto, podrían invertir en la compra e instalación de Cable Vía para mejorar el traslado de la fruta. 
d. Se recomienda seguir mejorando los indicadores de productividad en el porcentaje de merma de la fruta en planta. Para ello, sería conveniente invertir en capacitaciones para los socios productores a fin de mejorar sus rendimientos de racimas por planta con la implementación de mejores técnicas de siembra y mantenimientos de la plantación. 
ANEXOS 


\section{Anexo 1: Carta de Intención de Compra}

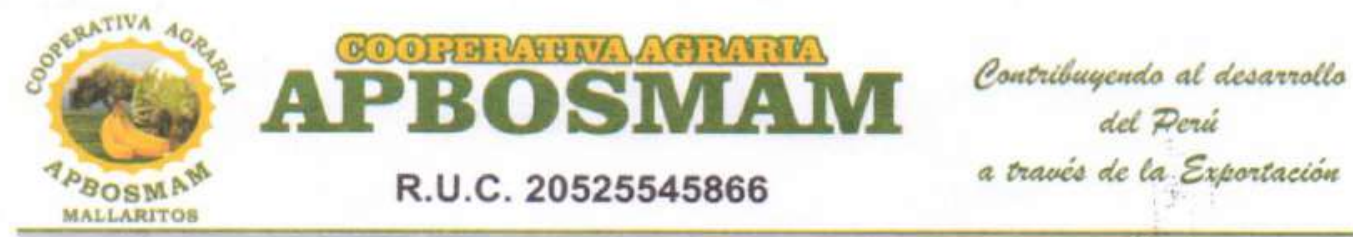

"Año de la Diversificación Productiva y del Fortalecimiento de la Educación"

Sullana, 03 de Enero de 2017

COOPERATIVA AGRARIA ALTO GRANDE SANTA SOFIA - COOPAG

Sr. Presidente.

Sr. Gerente.

De nuestra consideración:

Tengo el agrado de dirigirme a Ud. para saludarlos y, a su vez, desearles éxitos en el nuevo emprendimiento bananero, y confirmar nuestra intención de adquirir el banano orgánico de su representada.

APBOSMAM, es una empresa exportadora peruana, con actividad desde el año 2006 y con operaciones comerciales y de indole social en los Valles del Chira (Sullana), posicionada como una empresa especializada en la exportación de banano orgánico y de comercio justo y con otros estándares comerciales mundialmente reconocidos. Cumple actualmente un rol importante en los establecimientos de cadenas de agro negocios de banano orgánico y de comercio justo con pequeños agricultores organizados, permitiéndoles acceder a mercados internacionales.

APBOSMAM es una empresa integrada verticalmente con exportadoras en los paises productores $e$ importadores en los paises consumidores, esto le permite acceso directo a los principales mercados mundiales de productos orgánicos y de comercio justo. APBOSMAM, busca generar desarrollo a través de la comercialización de sus productos a los mercados internacionales y promoviendo a la vez el empoderamiento de los pequeños productores $y$ asociados.

Es en ese contexto, que le confirmo la intención de compra del banano orgánico que producirá vuestra organización, por lo que le solicitamos gestionen su certificación propia para poder negociar en los volúmenes que pactemos con un precio de caja de acuerdo a la situación del mercado.

La empresa pone a su disposición los servicios:

- Capacitaciones técnicas de campo de manera permanente y acceso a los talleres de productividad.

Capacitaciones y talleres para manejo financiero del campo.

Capacitaciones organizativas a solicitud de la cooperativa.

Capacitaciones sobre el uso de la prima fairtrade (Comercio Justo)

Acompañamiento a largo plazo en el crecimiento de la organización.

Capacitaciones y talleres de manejo orgánico de la finca y preparatorios para las auditorias.

Acceso a las auditorias internas permanentes para garantizar la calidad orgánica de su fruta.

Cartas de intención como aval ante entidades financieras. 


\begin{tabular}{|c|c|c|}
\hline $\log _{\mathrm{e}}$ & 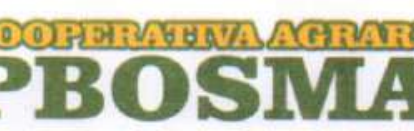 & $\begin{array}{c}\text { Cantribuyenda al desarralla } \\
\text { del Perú }\end{array}$ \\
\hline MPOSMAN" & R.U.C. 20525545866 & a través de la. Expontación \\
\hline
\end{tabular}

- Análisis de suelo por cada productor a la 3ra parte del costo.

Entrega de fundas y cintas para banano de alto calibre que garantice la durabilidad de su banano.

Pago oportuno de la cosecha. Actualmente se hace a los 7 dias.

Ampliar el Acceso al "Fondo de abonamiento para banano de pequeños productores", el cual se descontara de la misma comercialización.

Se garantiza la cosecha de todo el banano.

Proporcionar todo el material de primera mano y/o insumos y materiales para el proceso.

Proporcionar agua para el proceso y/o transporte de la fruta, desde el campo hasta el almacén.

Todo lo ofrecido es realidad gracias a varios proyectos obtenidos por la empresa y al apoyo de los actuales ntes y del fortalecimiento de las cadenas con los que trabajamos.

Sin más y a la espera de sus gratas órdenes me despido.

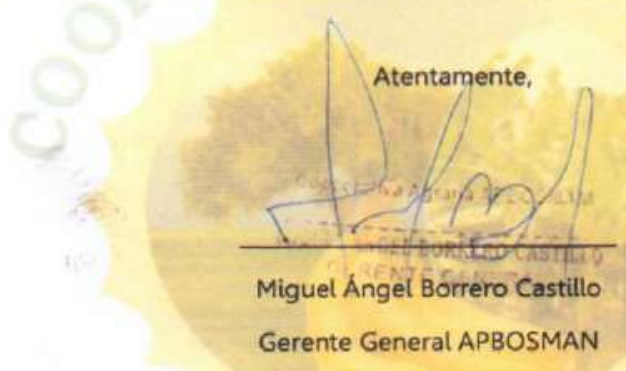

Calle Sánchez Cerro S/N Cas. Mallaritos - Marcavelica - Sullana - Piura Telf. 073-630290 RPC 969386602 E-mail: apbosmam_2007@yahoo.es Pagina Web: www.apbosmam.com 


\section{Anexo 2: Cotizaciones de Certificaciones}

1. Certificación comercio justo
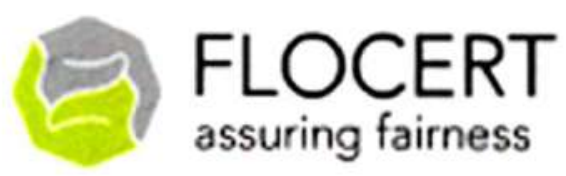

assuring fairness
RoCERT GmbH Bonner Talave $17 \%$

53120 Btorn Germany

Tel: $\quad+496722892483-0$

Fax +490012282093.120

emait infoofb-cerenet

Coceerasiva Aoraria Ato Grando Sarta Sefia

Sc. Inon Carlos Judrez Corroa

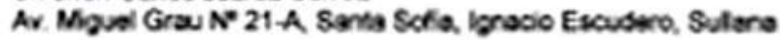

Sorea schie

Pon

Dase: $27111 / 2016$

Estimado Sr. Jhen Carios tutraz Correa :

En primer lugar, queremos agradecer su irterbs en Farrade y el ervilo de todos los documentos neceserios para la sciciciod

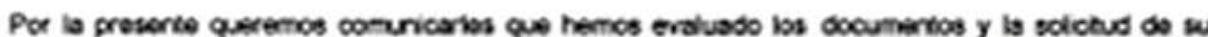
orparizasion Cooperativa Agraria Als Granss Sorta Sofia , y el resulbdo ha sido satistactorio Se he

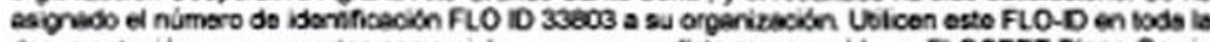
dooumentación con sus socies comeroisies y con su enalists responsabile on FLOCERT Dians Grais Deenda. Asi misma, tengan en cuscts que la esigneción de esto FLO ID no implice automaticamente lo certificacion de su crganizadón (viase mas adslante).

Nos gustaria aprowochar la oportunidad para informales de los peboimos pasos on al proceso de cersficecion Fartrade:

\section{Cuota de certuffexion inicial}

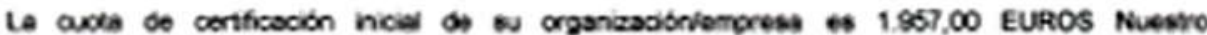
departomento do finarzes les envierb la factura corresponderte en los probimos dies. Por fevor tome nots as al page debe recizarte artes de que pueds tener bas la audnoria inicia. Tergan on

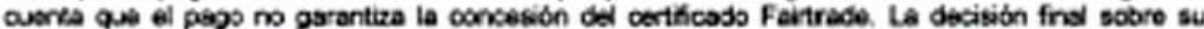
corthososo fartrade recso scbro FLOCERT.

Preceso de auditorla:

Su analista respensable FLOCERT Ciana Gercia Obando les asignara un ausiorid de FLOCERT que lavara a cabo la primera aucitoria a su organización. El auditerla se pendrá en cortacto con ustedes pera fia una fecha para la audiocria o irformarles sobre et procedimionto da la misma y los

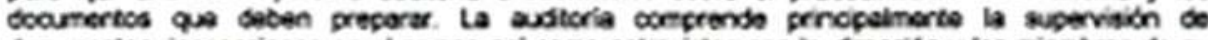
documertos, inspecticnes en el carpo asi comb ertevistas con la drocoion y las mientros do su orpenizicich

Para podir preparar de manere adecusds la audtoria les queremos pedir tambibn qu se tamilancen con los Criterios Fartrade y con los Criterios de Cumpimierio FLOCERT. Estos dos

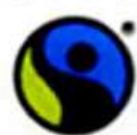

EARTRAOE 
documbrtos reffejan les condocones que su orgarizasion dete amplir para obtener al Certficado Farrase

Padrán encontrar las Crinerios de Cumpimiento FLOCERT y los Criterias Fartrade en sus respectivas

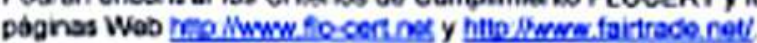

Para cualquer itcormscion, no dude en conestar oon su andista rasponsabis de FLOCERT Diana

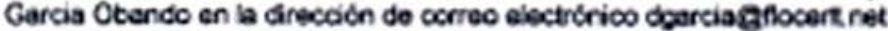

\begin{tabular}{|c|c|}
\hline Iean: & DCse370s01981909151431 \\
\hline$N^{0}$ de cuenta: & 1909151431 \\
\hline $\begin{array}{l}\text { Benco del } \\
\text { bernficianc: }\end{array}$ & $\begin{array}{l}\text { Sparkasen Kcein Born } \\
\text { Direcoion Finmencenter 712, Themas Mann-Str. 61, 53111 Bom, Genmary }\end{array}$ \\
\hline Benticiono: & FLOCERT GmbH \\
\hline CSAlos BIC.SWHFT: & cossoes3 \\
\hline
\end{tabular}

Nos gustaria que nos confinera la recepción de esta certa. Agradecemos wu interba y compremiso, y les ceesarces un funco Axito en el sistema Fairtrada

Seludos cordalos.

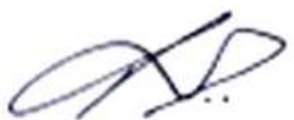

Sugumar Raman

Drecter of Operations

FLOCENT Ontur 


\section{Certificación orgánica}

Nombre: COOPERATIVA AGRARIA ALTO GRANDE SANTA SOFIA - COOPAG

Attn.: JHON CARLOS JUAREZ CORREA

Direcciōn AV. MIGUEL GRAU NRO. 21 INT. A VILLA SANTA SOFIA (PREG X RICHARD REYES X LA ENTRADA)PIURA - SULLANA - IGNACIO ESCUDERO

Ciudad PIURA

Pais: PERU

Lima, 17 DE NOVIEMBRE DE 2016

TEMA: Oferta por la inspección y certificación del programa de certificación de Control Union Certifications (CUC) I Perú (CU)** (marcar los programas que aplican)

\begin{tabular}{|c|c|c|c|c|c|c|}
\hline Orgánico & EU* & USDA/NOP* & $\mathrm{x}$ & EFAPA $\cdots$ & FIPA $\cdots$ & \\
\hline & \multicolumn{6}{|c|}{ 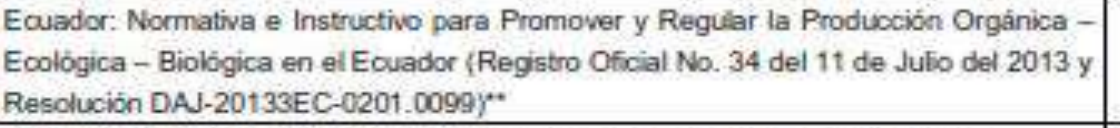 } \\
\hline & \multicolumn{5}{|c|}{$\begin{array}{l}\text { Perú: Reglamento Técrico para los productos orgánicos DS No 044-2006-AG } \\
\text { SENASA*" }\end{array}$} & $\mathrm{x}$ \\
\hline & \multicolumn{5}{|c|}{$\begin{array}{l}\text { Costa Rica: Decreto 29782-MAG del Ministerio de Agricultura y Ganadería de Costa } \\
\text { Rica ". }\end{array}$} & \\
\hline & \multicolumn{5}{|c|}{ 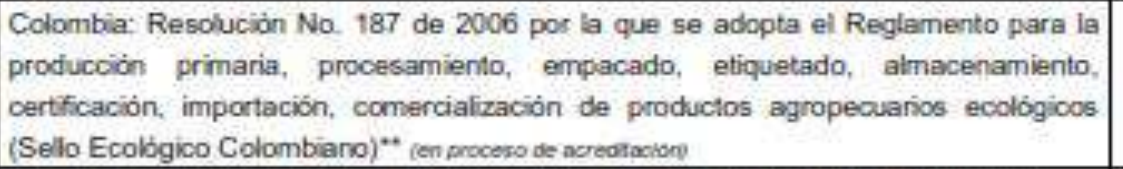 } & \\
\hline & \multicolumn{5}{|c|}{ Brasil- Decreto 6323 - Regudamentaçä́ da Lei dos Orgänicos 10.831/2003 Brasit"* } & \\
\hline & \multicolumn{5}{|c|}{ Paraguay Reglamento organico Nacional Resolución Na. 143/11 - SENAVE* } & \\
\hline & \multicolumn{5}{|c|}{ Aplicación para el programa Bürd Friendiy." } & \\
\hline \multirow{4}{*}{$\begin{array}{l}\text { Insumo EU } \\
\text { (Input) }\end{array}$} & \multirow{4}{*}{\multicolumn{2}{|c|}{ Material protección cultivo }} & $\mathrm{EU}^{*}$ & \multirow{4}{*}{$\begin{array}{l}\text { Fertízante y Mejorador del } \\
\text { suelo }\end{array}$} & $\mathrm{EU}^{*}$ & \\
\hline & & & USDA* & & USDA: & \\
\hline & & & JAS: & & JAS: & \\
\hline & & & RTPO** & & RTPO** & \\
\hline \multicolumn{7}{|l|}{$\begin{array}{l}\text { Alimento } \\
\text { Mascotas* }\end{array}$} \\
\hline
\end{tabular}

Estimado St, Jhan Juárez:

Gracias por mostrar interés en las actividades de Control Union (CU). Basándonos en la información del Formato de Aplicación, se ha calculado la siguiente oferta para (COCPERATIVA AGRARIA ALTO GRANDE SANTA SOFIA COOPAG) (en adelante denominado "El Cliente"):

\section{Nuestro plan de inspección anual para usted}

Basándonos en el Formato de Aplicación CU, se planificarản 6 dias de inspección (incluyendo dias de viaje) para la inspecciónvauditoria y servicios administratwos por año calendario. Por favor tenga en cuenta que el numero de dias establecido arriba es un estimado. Luego de la inspección inicial realizada por CU, el nümero real de dias de inspección se determinará en funciòn de si en la opánión exclusiva de CU más o menos dias de inspecciön son necesarios. Por favor, tambièn considerar que CU está obligado a levar a cabo audthorias anunciadas asi como no amunciadas.

Indicar periodo de audtoria: Insertar mesiperiodo de auditoria planificeda (CU tiene el derecho de modificar este periodo, previa notificación al Cliente)

Ret. no:

ORGOFFER.LOH10 7 L.BPA 
2. La tarifa anual de licencia

Basándonos en el plan de inspección descrito arriba la tarïa anual de licencia para la inspección y certificación será: (en b sucesivo "Tarifa Anuar)

2.1 Tarifa de Inspección y Certificación (incluye impuestes) ${ }^{|2|}$. $\quad$ Sl. 13.500 .00 it

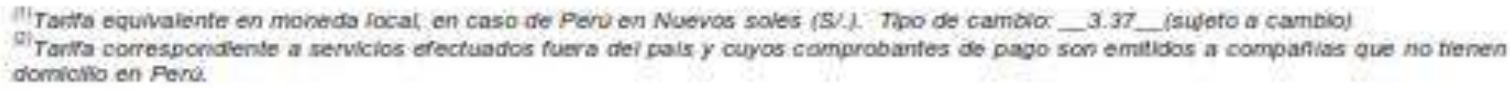

PARA UN GRUPO DE PRODUCTORES, PROCESO, OFICINA ADMINISTRATIVA.

DATOS DE CONTROL UNION PERÚ SAC:

RUC: 20504194796

Dirección: AV, PETIT THOUARS NRO. 4653 (PISO 6 - OFIC. 603) LIMA - LIMA - MIRAFLLRES

NÚMEROS DE CUENTA:

BCP SOL $193-1704576-0-38$

BIF SOL 7000095059

COOOIGO DE CUENTA INTERBANCARIA DEL BCP:

002-193-001704576038-10 (SOLES)

CÓDIGO DE CUENTA INTERBANCARIA DEL BIF:

03810210700009505904 (SOLES)

CUENTA PARA DETRACCION

Cuenta corriente: $00-000-816523$

La tarifa anual de icencia comprende: visita(s) de inspección, actividades de inspección y reporte(s) de certficación;

Si la decisión de certificación es "positiva", la Tarëa Anual de licencia incluye:

- Un certificado de alcance:

- Inclusión de su proyecto en la página web de CU, como titular del certficado.

Lo siguiente $\mathrm{m} Q$ está incluido en la Tarifa Anual de licencia:

(i) Gastos de análisis (si fueran necesarics. Excepto sólo para clientes NOP);

(ii) Gastos de viajes y viáticos de los auditores (incluyendo, pero no Imitedo a, alojamiento);

(iii) Gastos incurridos por envio de certificados y muestras por correo registrado; que serán cargados a la cuenta del Clente basado en los gastos actuales;

(vi) Servicios adicionales solictados en el Formato de Aplicación como Servicio Adicional (certificado adicional) certificados de importación o transacción:

(v) Evaluación y aprobación de etiquetas:

(vi) Evaluación y aprobación de especificación de productos:

(vii) Para Ukrania, Azerbaijan, Belanus, Georgia, Kazalchstan, Kyrgyzstan, Mobdova (y Transnistria), Tajikistan, Uzbekistan gastos extras de muestreo antes del envio de cada embarque (certificado de importación de inspección ITC) de alimentos o piensos orgáricos (requista de la Cornisión Europea a partir del 29r05/2015)

Lo mencionado artericmente será cargado en su cuenta basándonos en nuestros gastos reales.

3. Documentos y Regulaciones Aplicables por CU

Los siguientes documentos (en adelante: los "Documertos") son apicables a esta oferta, si usted fima y regresa esta Carta Oferta entra en un acuerdo con CU para ser parte de programa de certificación de CU; de ésta manera el cierte explicitamente acepta todos los têrminos y condiciones establecidos en los siguientes Documentos:

\begin{tabular}{|c|c|}
\hline Programas Aplicables & Documento \\
\hline Para todos los progranas & $\begin{array}{l}\text { - Terminos de Contrato de CUC* / CuP"* (Anewa i) } \\
\text { - Terminos y Condiclanes de Negocio (1999) } \\
\text { - Reguación de inspección de CUC* / CuP". }\end{array}$ \\
\hline
\end{tabular}

Ref. no:

ORGOFFER. LOTMOTLIPA 


\begin{tabular}{|c|c|}
\hline para el programa organico de certificacion Eu* & 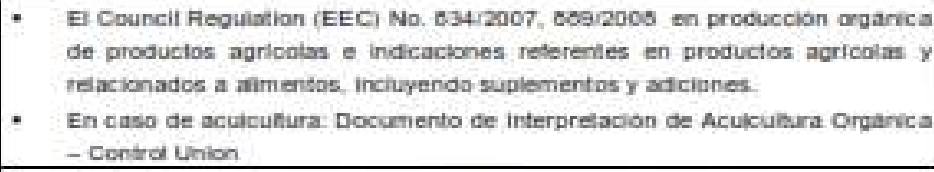 \\
\hline $\begin{array}{l}\text { pora el programa oroanico de certincacion } \\
\text { uscanNop- }\end{array}$ & Programa Organico Nacional, USDA Estadas Unidoa de Amenca \\
\hline para el progrma organico de cetificacion JAS* & Estandares agricolas de Japan, MAFF Japon \\
\hline para Serbla* & Seblan Organic Production and Organic Products Act \\
\hline $\begin{array}{l}\text { para INPUT materiales de proteccion de } \\
\text { cultivos: }\end{array}$ & $\begin{array}{l}\text { - Los estandares relevantes de crganion (EU, USDA o JAS) } \\
\text { - Estandar en ferilizantes y mejoradtoces del sueio de CU }\end{array}$ \\
\hline $\begin{array}{l}\text { Dara INPUT fertilzantes } y \text { mejoradores dei } \\
\text { Duelo* }\end{array}$ & $\begin{array}{l}\text { - Los estandares relevantes de crganion (EU, USDA o JAS) } \\
\text { - Estandar en materiales de proteccion de cultivoe de CU }\end{array}$ \\
\hline $\begin{array}{l}\text { pora ef nrograma de Alimentas para Mascotas } \\
\text { de CU. }\end{array}$ & CU Estandar en aimento organtco para mascotas \\
\hline 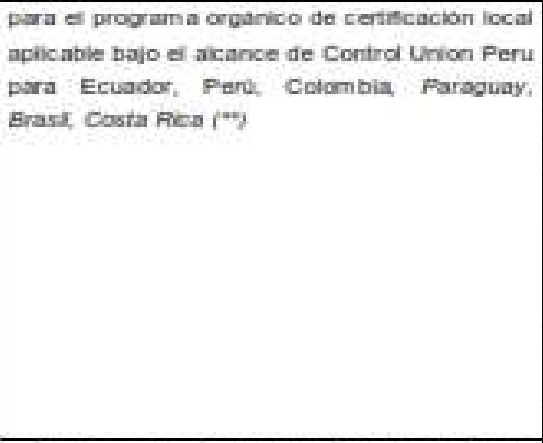 & 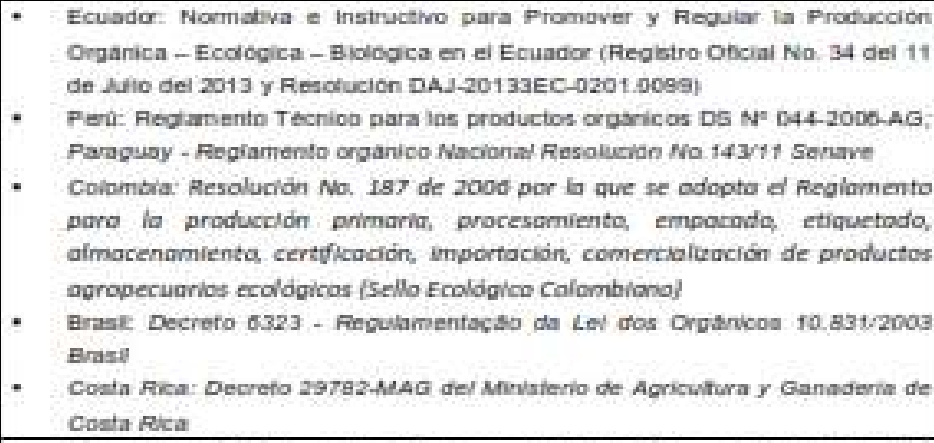 \\
\hline $\begin{array}{l}\text { Para el trograma Bird Friendfr bajo el atcance } \\
\text { de Control Union Pero ("*) }\end{array}$ & 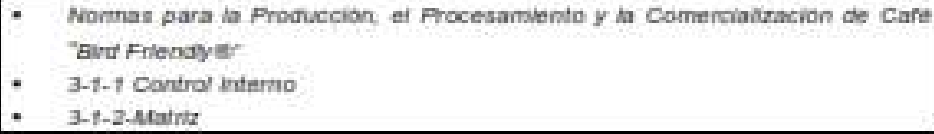 \\
\hline
\end{tabular}

Los documentos mencionados arriba pueden ser encontrados en Internet en la Pägina Web de CU Hitp:iflcucpublications.controlunion.conv' y los relacionados al alcance de Control Unión Perù los encontrará en hetp:l/www cuperu,com/portallesicuclouc-terminos-y-condiciones. Por favor, informar si usted desea recibir copias impresas de éstos documentos para errviárselos.

\section{Condiciones Especiales de Pago}

Artes de que CU lleve a cabo la inspección inicial el Clente deberá cancelar la Tarfảa Arual total establecida arriba por CU. Al final del año, se calculará la cuota real incurrida por el Cliente $y$, o bien se cargara el saldo restante o reembolsará al Cliente, en funciỏn de si dicho saldo es positivo o negativo.

La factura será normalmente erviada por CU una vez al afio, o alrededor de la misma fecha cada afio. La fata de pago por parte del Cliente dará hugar a un retraso de la auditoria totamente atribuble al Ciente y (propuesta para NOP), la revocación del certificado antes de la conclusión del proceso de auditoria por CU (por favor tome en cuenta que el plazo propuesto hasta la decisión de certificación es de cuatro (4) meses desde la fecha de inicio de la planficación por CU. El pago a destiempo tambiên puede ocasionar (propuesta para NOP) la suspensión del certificado del Cliente de inmediato, el periodo de suspensión podrá martenerse incluso hasta la fecha de expiración del certificado.

CU podrá. modificar unilateraimente la Tarifa Anual del Clente, en caso que el alcance o la ubicación de las actividades cambie durante el an̂o calendario, esta modificación se aplicará en el aflo calendario siguiente. Los clentes registrados, como 'Clente", estân obligados a comunicar oportunamente las actualizaciones de datos.

Dias de viaje y costos (incluyendo pero no limitado a. los gastos de subsistencia)

CU tene como objetivo mantener esos costos al minimo y dividirios entre otros clientes en el área geográfica del Cliente. CU trata de lograr esto mediante la realización de otras inspecciones en el área del Cliente durante el mismo periodo de tiempo, sujeto a disponibilidad. En el caso que CU realice otras inspecciones durante el mismo periodo de tiempo en los tèminos indicados, los gastos de viaje se dividirän ertre todos los Clertes que son irspeccionados en la misma el àrea geogräfica, incluyendo al Cliante y CU compensara la diferencia en el importe de la factura final del Cliente.

Ref. no- 


\title{
5. Acuerdo
}

Por favor firme esta Carta Oferta y devuelva una copia si estâ de acuerdo con su cortenido. Luego de recibir el pago de la Tarifa Anual, CU planificará la fecha defnitiva para la inspección inicial y le irformará al Clente del misma. Cualquier acuerdo entre CU y el Cliente será renovado automáticamente cada año por otro periodo de un (1) año calendario, a no ser que exista una cancelación escrita por parte del clente.

CU deberá recibir y aprobar el Plan del Sistema Orgánico Orgánico para todos los programas orgánicos conrespondierte antes de la auditoria.

De acuerdo a la cláusta 4.1 de los Términos de Contrato anexo al presente documento, las inspecciones serán Ievadas a cabo por persanal calificado, localizedo en la oficina principal o cualquiera de las oficinas responsables, quienes están sujetos irrestrictamente a los lineamientas establecidos en el Arexo. A2 Código de Conchucta y Corfidencialidad fimados entre el inspectarlaudifor y Contro Uniòn Peni / Control Union Certifications

Asimismo, el Cliente deberá mantener un registro de todas las quejas conocidas con respecto al cumplimiento de los requistos de la certficación y pone tales registros a disposición de CU cuando se le solicita; toma las acciones adecuedas respecto a tales quejas y a las deficiencias que se encuentran en los productos que afectan a la conformidad con bs requisitos de certficación; asi como documenta las acciones tomadas.

\section{Validez}

Esta oferta es välida solo cuando ha sido frmada por una persona autorizada del cliente, dicha autorización se evidencia por un extracto de registro mercanti váäido o una copia de los estatutos actuales de asociacián del Cliente. Esta oferta será valida por dos (2) meses después a partir de la fecha indicada en esta Carta Oferta.

Esta oferta remplaza y sustiluye todas las ofertas anteriores emitidas por CU.

Corfio en que esta oterta satisface sus necesidades y deseos. Por favor no dude en contactame si tiene cualquier pregunta adicional o comentario, o en caso de que algo no esté claro.

Espero recibir su respuesta positiva.

Atentamente,

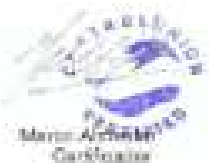

En nombre del Director Gerente Fiorela Bustamante

[MARCO ALMESTAR]

\section{Certificador}

\author{
Anexol \\ Términos de Contralo de Control Union Peru SAC (CUP)** \\ Términos de Contrato de Control Union Certifications (CUC)* \\ Términos y Condiciones de Negocio (1999)
}

Ref. no: 


\section{POR FAVOR DEVOLVER ESTA COPIA FIRMADA}

\section{Aceptación de la declaración por el aplicante}

El abajo firmante acepta esta Carta de Oferta y se compromete a cumplir con las obligaciones dispuestas en los documentos siguientes (incluyendo, pero no limitado con el pago del total de la deuda de honorarios total):

(i) los términos y condiciones de esta Carta Oferta; y

(ii) los términos y condiciones de los Documentos mencionados en el punto tres (3) de la Carta Oferta, los cuales se consideran aplicables al acuerdo entre Control Unión Certifications / Perú y el Cliente;

"Para programas dentro del alcance de Control Union Certifications considerar los Términos de Contrato de Contral Union Certifications y los Términos y Condiciones de Negocio de 1999.

"Para programas dentro del alcance de Contral Union Perú considerar los Términos de Contrato de Control Unión Perú y los Términos y Candiciones de Negocio de 1999.

Yo confirmo que el Formato de Aplicación ha sido llenado honestamente y que dicho Formato de Aplicación forma parte integral del acuerdo entre CUC / CUP y el Cliente.

NOMBRE DE LA COMPANIA: COOPERATIVA AGRARIA ALTO GRANDE SANTA SOFIA - COOPAG

REPRESENTANTE LEGAL: JHON CARLOS JUAREZ CORREA

CARGO EN LA COMPANIIA:

FIRMA:

FECHA: 17 DE NOVIEMBRE DE 2016

Ref, no: 
Anevo: :

Teminos de contrato apleables a las actuidades de inspeccion y certificacion de Control Union Pert s.A.C, en adelante denominada in "Compafta" y al Aplicarite, denominadio en adelante el "Princlpar.

1. General

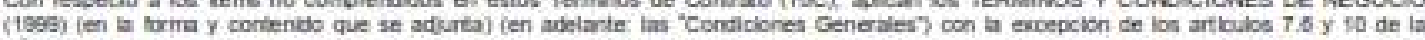

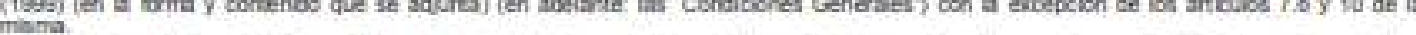

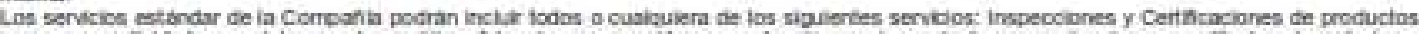

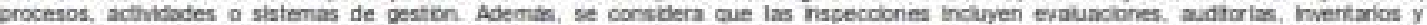
viglancla

$2 . \quad$ Carta Oterta

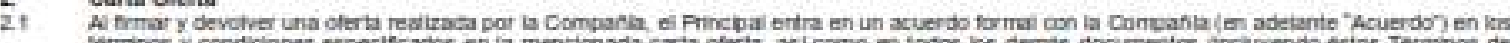

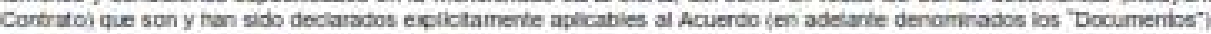

3. Celogaciones y limitaclones des Princloa

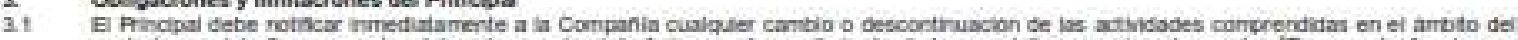

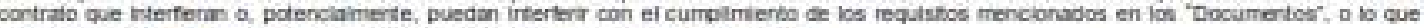
polenciaimente podran cambiar ef ambibo def coritrilo de immedato a fa Coirparta

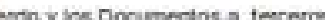

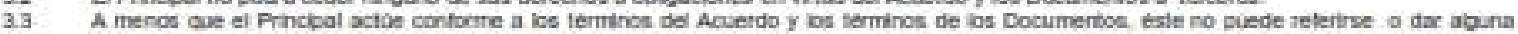

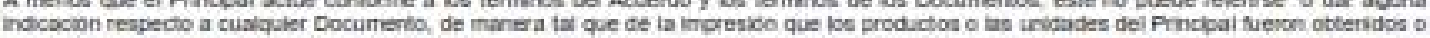

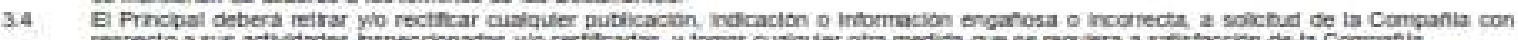

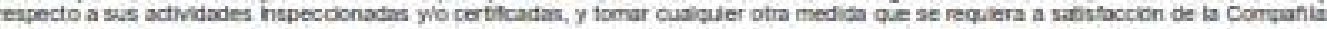

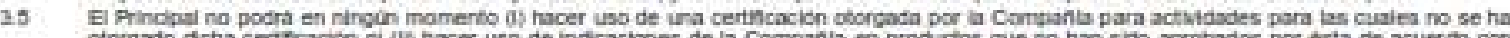

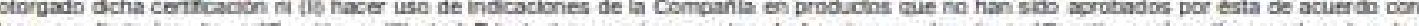

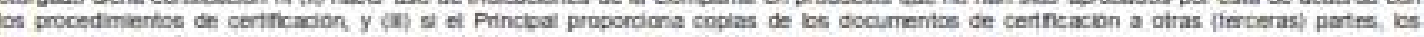

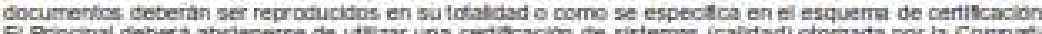

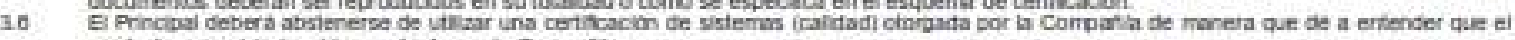
producto a seividio ha sido acrobudo por la Corpania.

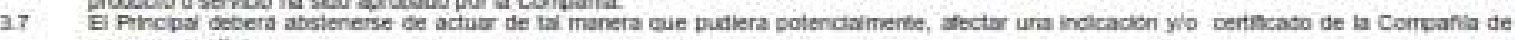
movera negativa.

30. Ei Pinctpai debera infornar de inmediato a ia Coripasia en cuarto conozca el uso inconscto ylo no autoriado de una ridcacion de ia Conporia ylo una publicacisn engancss o incorreda que se retera a la Combania.

4. inspecion

4. La Companta levard a cato ias inspecciones o dispondra que ura tercera porte a leve eh su representacion, de acuerdo a ios terminos de los

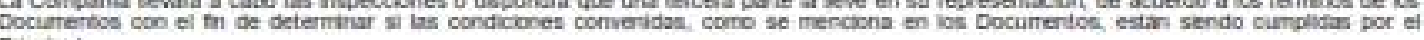
Frincpat.

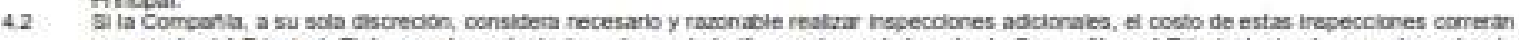

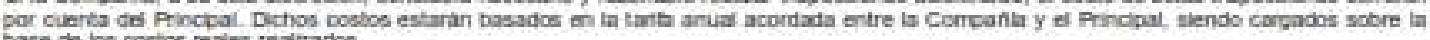
tase in los coetios reales realuadce.

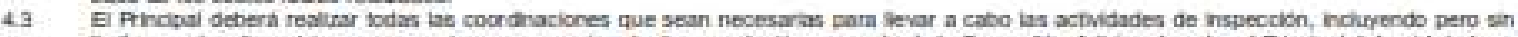

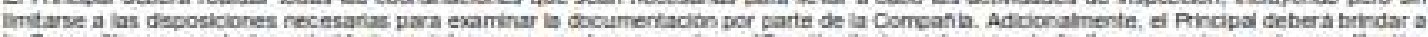
a Comparia y a cualquer autoridad que intervenga en el proceso de certifcacoen ancluyendo pero sin Imitar a orgarismos de acredtacion.

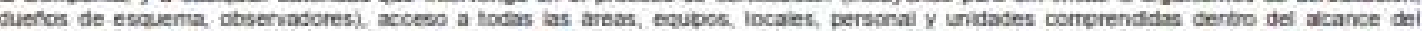

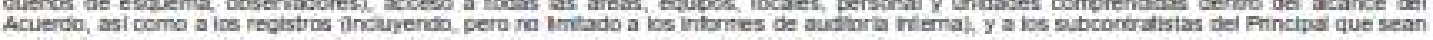

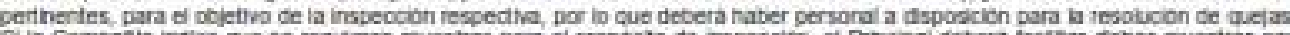

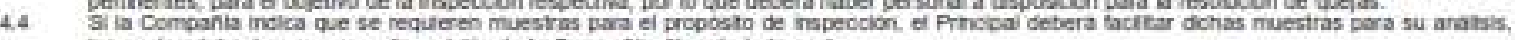
tas cuales deteran penerse a daposicion de la Compania, itive de tado costa.

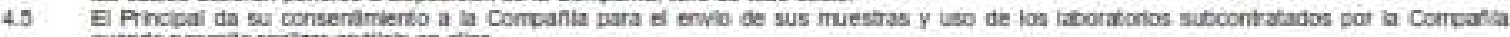
cuando necelde realitar antistas en elios.

5. Certsicado

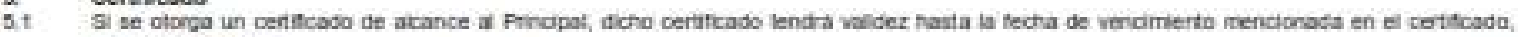
siempite y cuando:

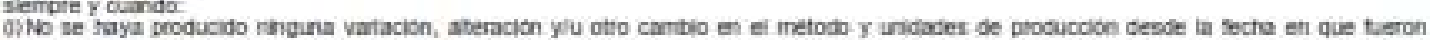
ispeccioriodos los mismos que teran certicados en hase a dicha hepections y

10 E Acuerdo no se haya teminada por oualquler rasobi

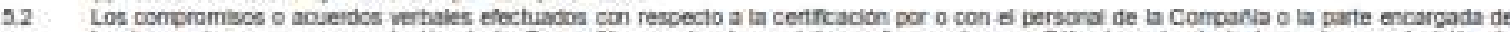

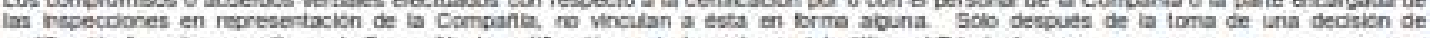

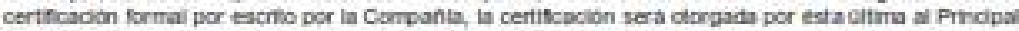

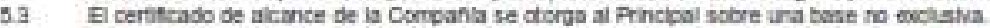

a. Conflidencialidar

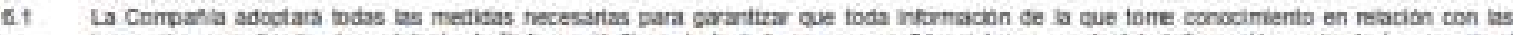

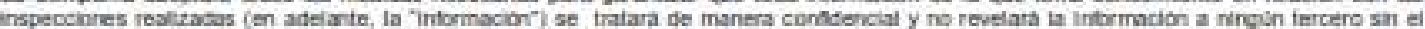

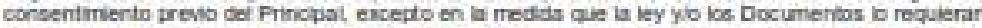

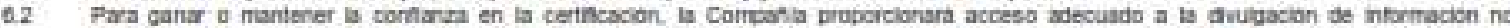

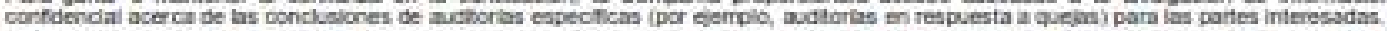

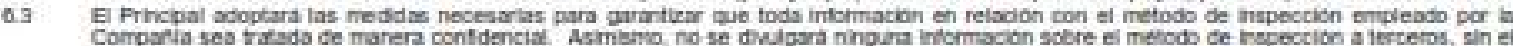
consentmiento previo y por escrto de ia Compania, saivo que la ley yio los Documerice lo requeran.

7. Indicaclones

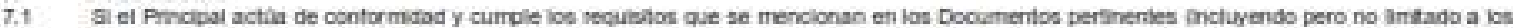

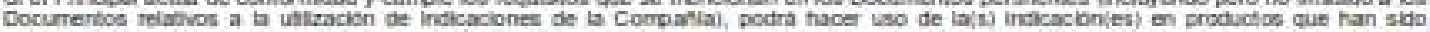

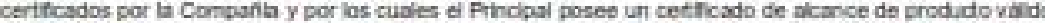

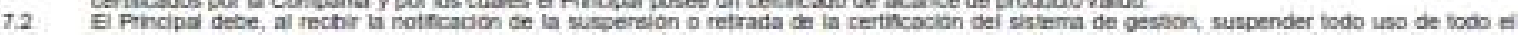

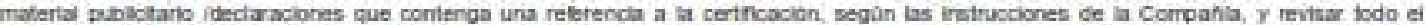
moberial puticitario cuanda el alcance de la certincarion se hava reducion.

7.3 El dereche a usar las indicadiones oe la Comporla se otopa al Prindipai sntre una basse no exctusia

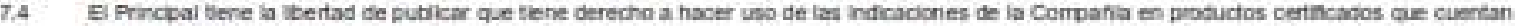
con un certiscoste de arance.

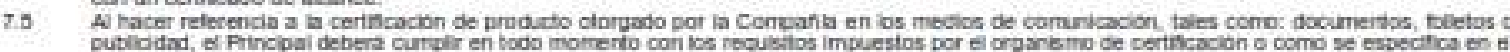
escuerna de ceteftacion

Ref. no:

ORGOFFER LOH110.7) SPA 

inarcas de obnilonidad, y sobne la informacion reacionada con et producto.

\section{Modincacion de los documentos}

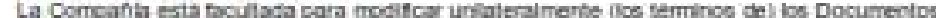

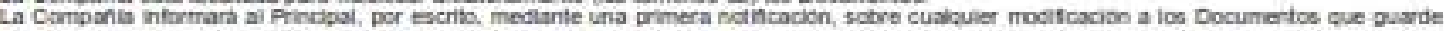

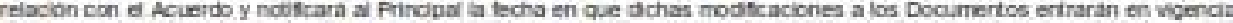

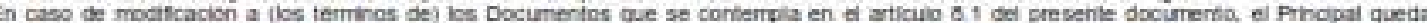

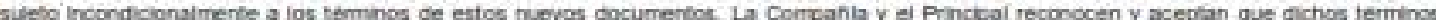

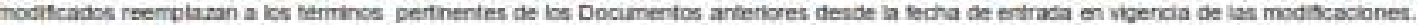

2. Responsabilidad e indermntzacion

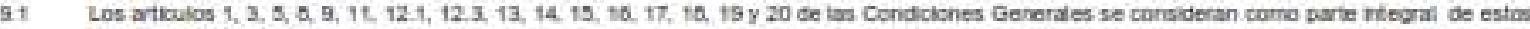
Terminos de Contrata

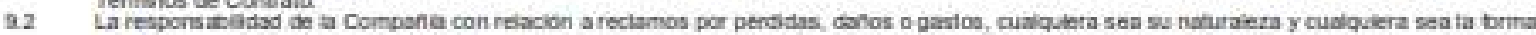

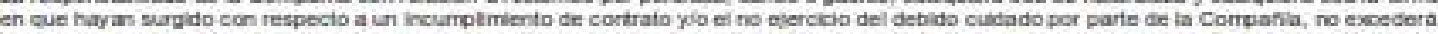

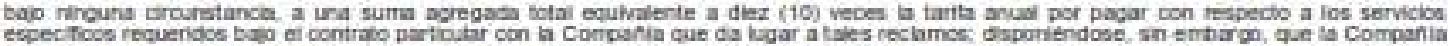

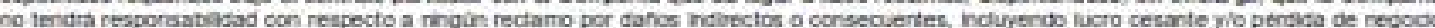

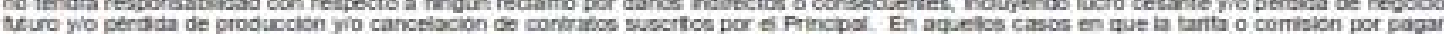

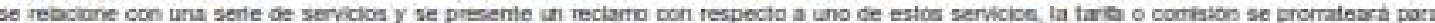
los fines de esto parratb mediarte reterencia al ilempo estmodo requerido pora lesar a cabo casta servicin

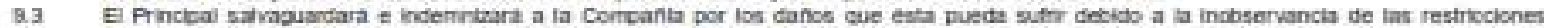
gubernarnertaes irternacionales de inportadon y eqporiacon por parte dei Frinctpal

\section{Comislones}

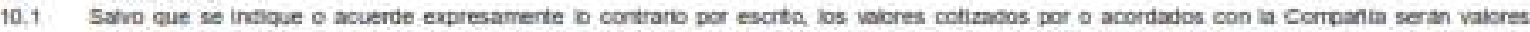

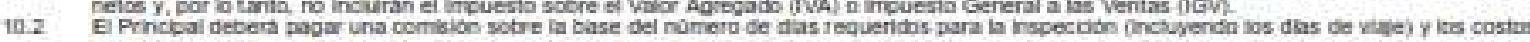

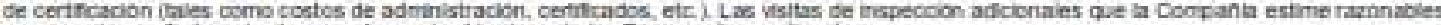
Y necesarias se tacturaran de acuerdo con ios temmos de los Docunernas pertinentes.

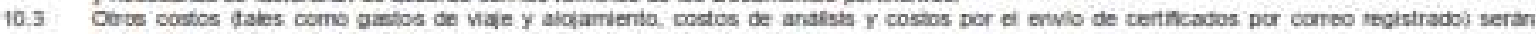

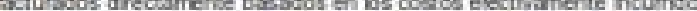

10.4 La Companta se reserva ef derecho de variar la tarta acortaca tasada en chas de holces nacionales (interracionafes) o en a poitica de is

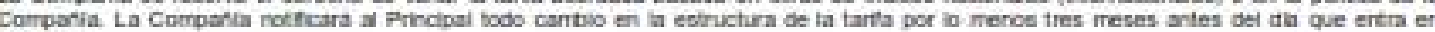
vioencia.

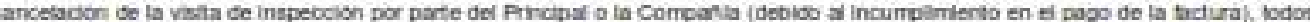

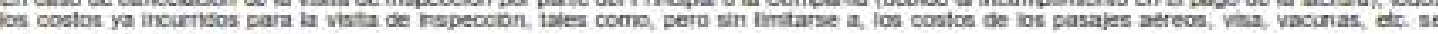
corparan en bodo caso al Pincipa.

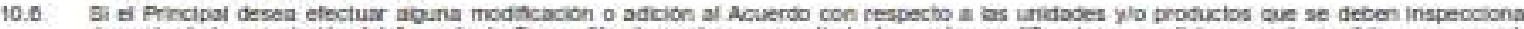

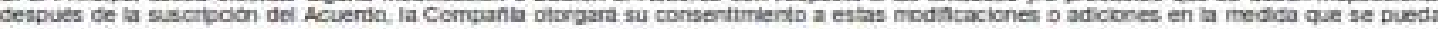
experar manatiemetile que ast Comporia carpara di integro de tales costins adiclonaiss at Pinclpai.

11. Pago

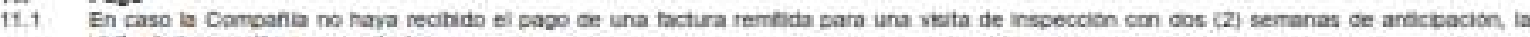

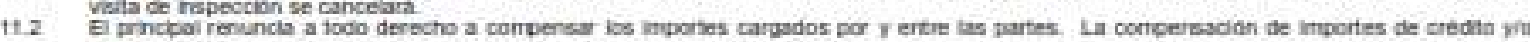
reclarns con papos peridertes a la Comcahla esta esresanente prohtida

12. Plazos de vipenda y resctucioen

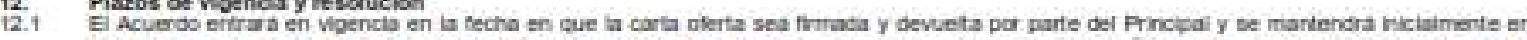

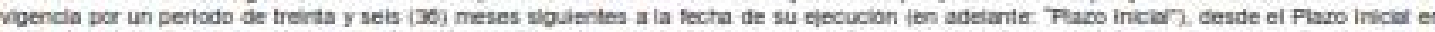

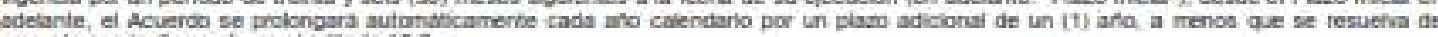
acuerdo con io dspuesto on et antivio 12.2

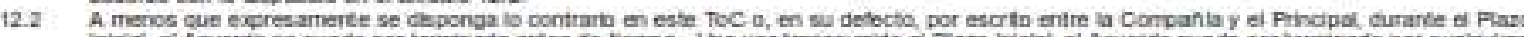

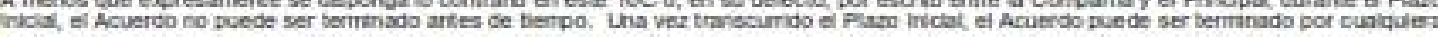

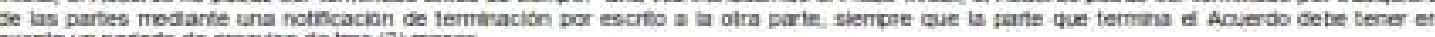
cuenta in periode de creaviso de tres (a) meses.

12.3 La Componta podra resolver el Aouerdo con eleclo imedlato por razones de hourcimiento grave, medimte cotincacion escrta al Princhai, sin necesidad de coresiderar un periods de noafcacion en los sioulentes evertos:

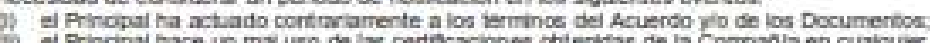

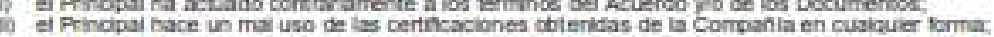

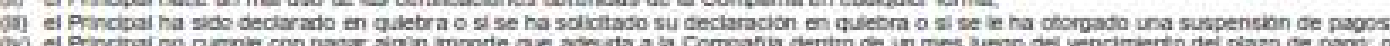

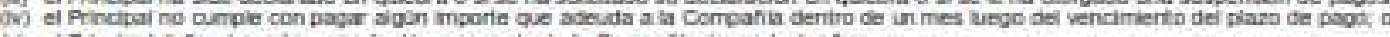

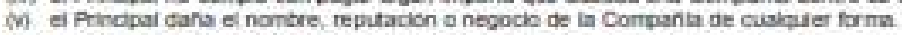

124 En caso de resolucion del Acuerdo por cualsuiar motivo.

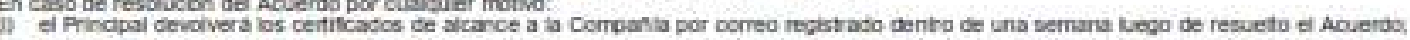

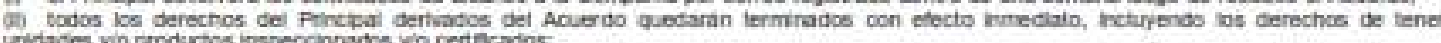
ridades yio productos inapeccionados yo centheados:

(ii) la Compatia no estara bojo la obiligacion de reenbotsar la comision ya cancesada por el firicipa:

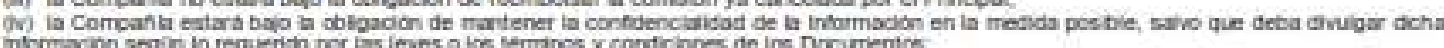
informacion segun lo requerido por tas feyes a los termines y condicones de loc Ducimentos.

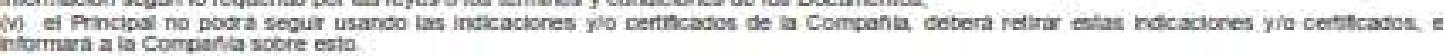

13. Apelaciones

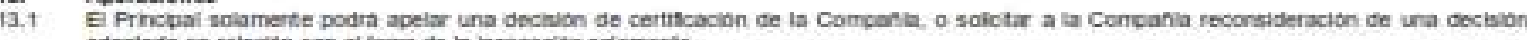

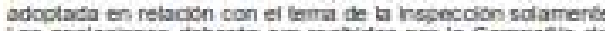

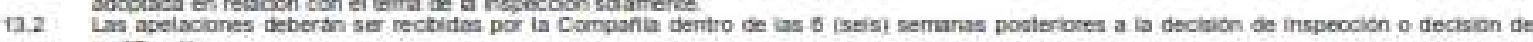
certhcacicm.

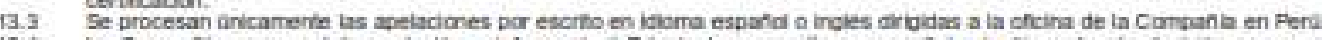

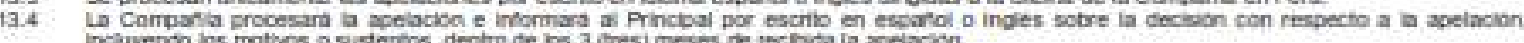
incluyerido las mathos o susterbos, dentra de las a (res) meses de recibida ia apelacion.

14. Disputa, ley aplicatie y costos (extra) juafiales

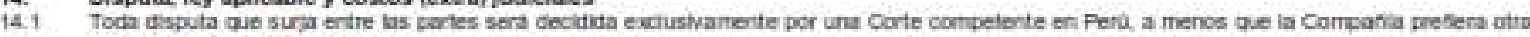
conle competerte intemacions:

Todos los acuerdos celetrados ertre la Concatila y ei Princtpal estan sujetos a las leyes peruanas

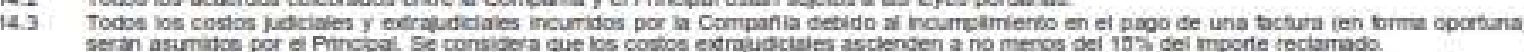

Ref. no: 
1. Generat

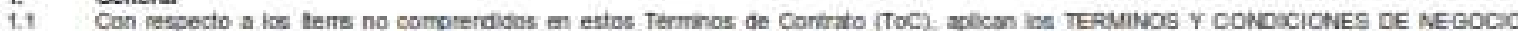

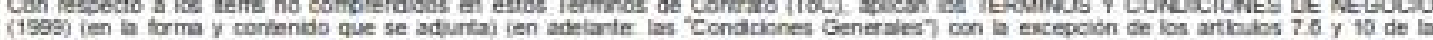

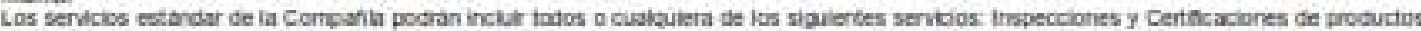

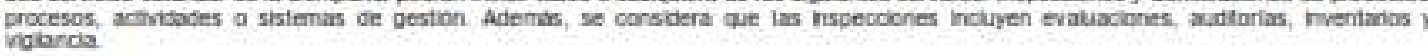

2 Carta otert

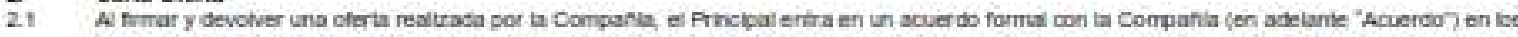

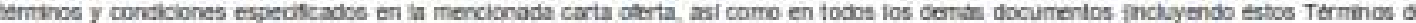

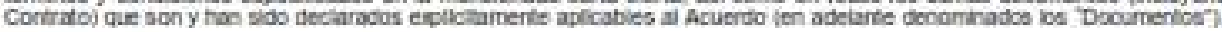

3. Collgadones y limitaciones del Princtos

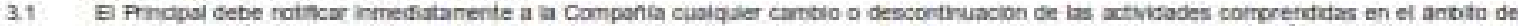

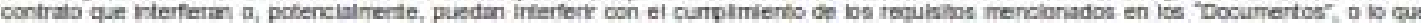

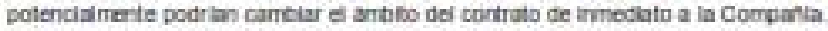

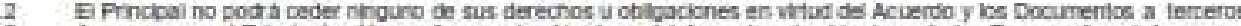

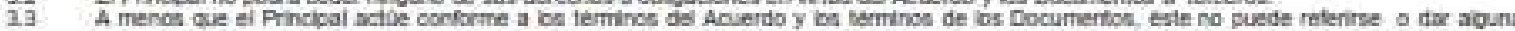

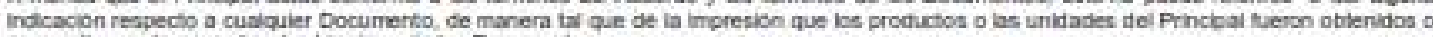
se montienen de acuertos a las fermicos de ins Documentos.

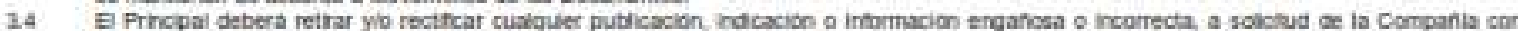

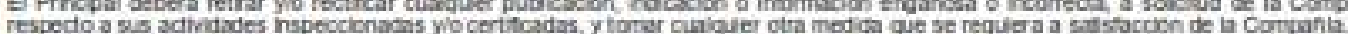

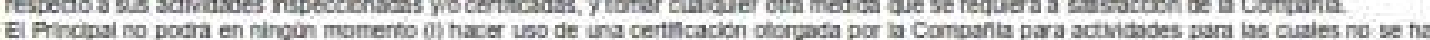

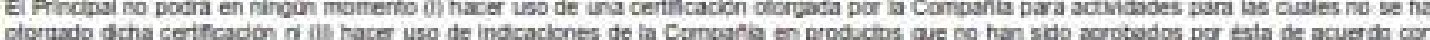

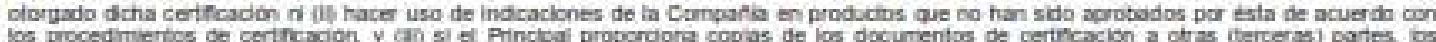

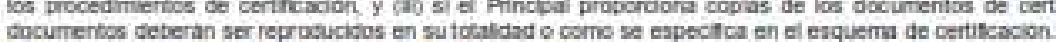

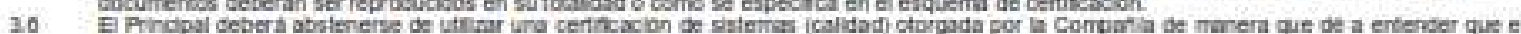
El Principal deberia abstenerse de utitur ina centacac

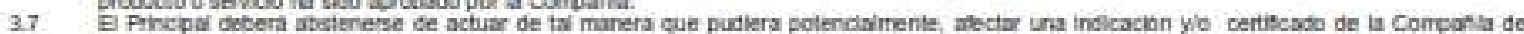
E Frincipar dobera negativa

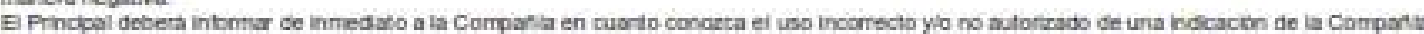
yolo ins pubicacion engonosin o incorneda que se refera a la Componts

4. Inspeccion

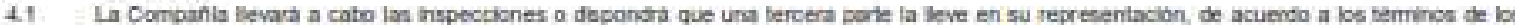

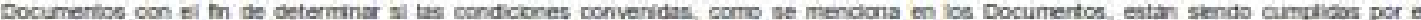
Anincal

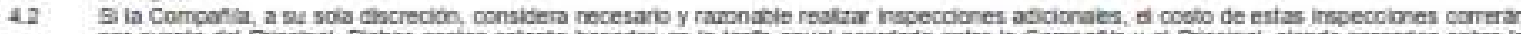

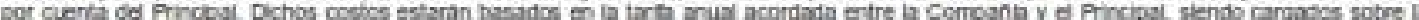
base de los costos reales sealizados.

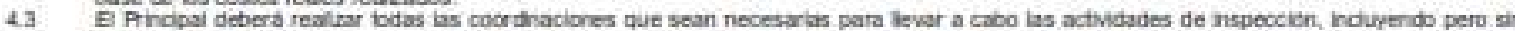

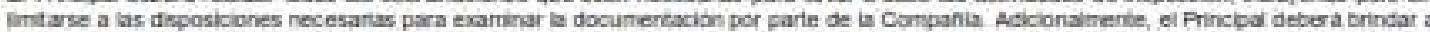

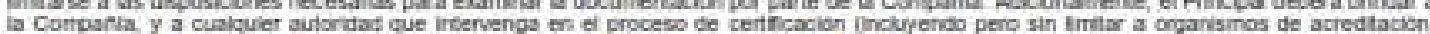

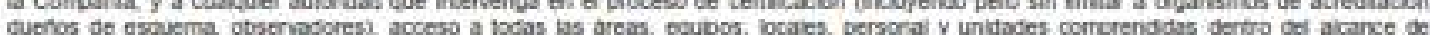

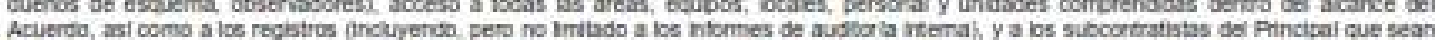

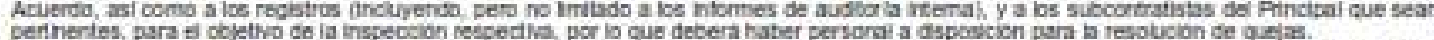

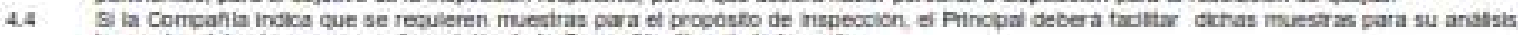

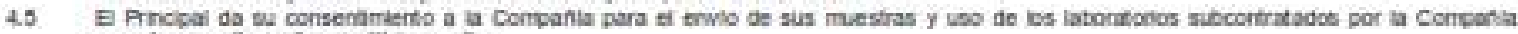
coundo nerente reatrar analks on eilos

5. Certetcado

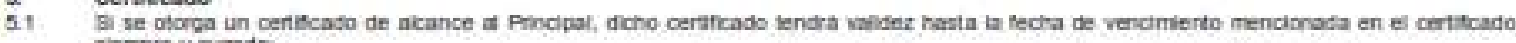
sempre youando.

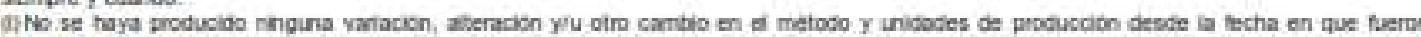
repeccionados los mismes que tiernn certícados en base a decha repecoion y

aD E Acuerdo no se haya teminado por coafiquer ranon.

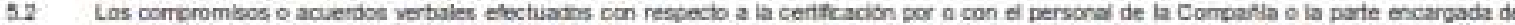

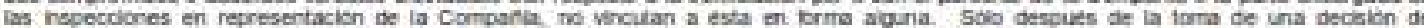

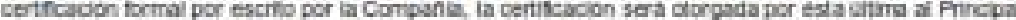

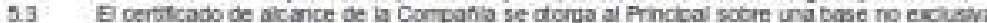

a. Confidencielildas

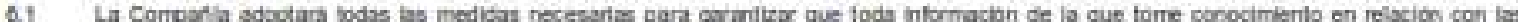

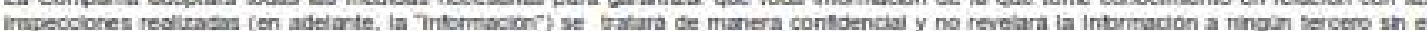

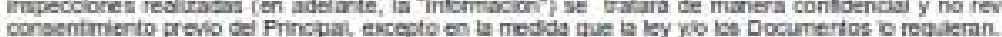

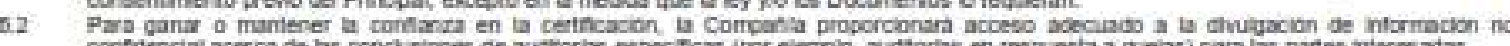
confidencial acerca de las concheoprares

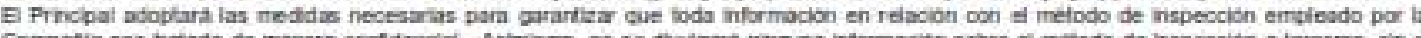

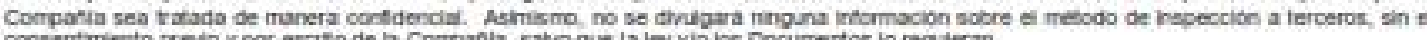
consentmiento previo y por escito de is Combania, salvo que la ley yio los Documertos io requieran.

7. Indicaciones

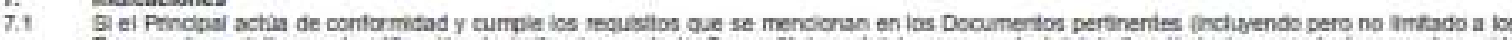

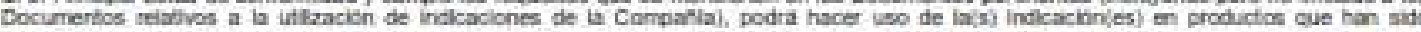
certifcados por la Companta y por los cuales el Prvolpal posee in cetficado de alcarce de produdo vando

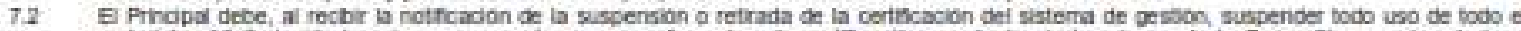

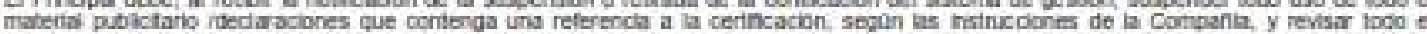
material puticitano cuarda el alcance de ta certilicacion se haya rocucido.

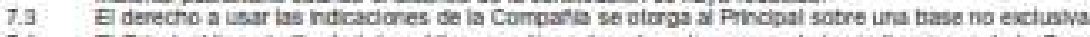

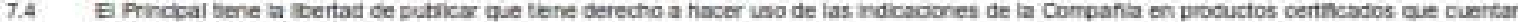
con un certiscado de alcance.

Ref. no:

ORGOFFER L01190.72 SPA 


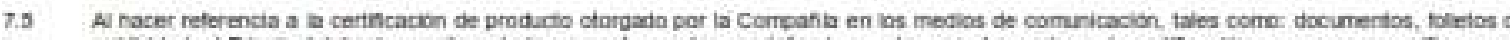

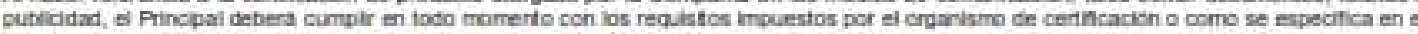

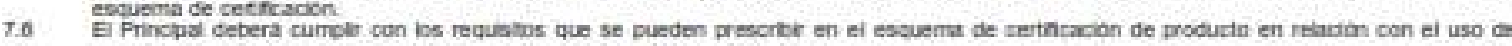

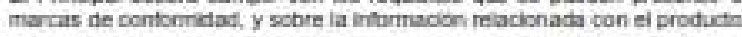

\section{Modincacion de los documentos}

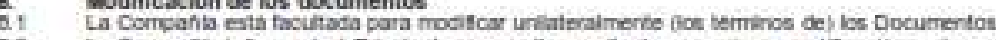

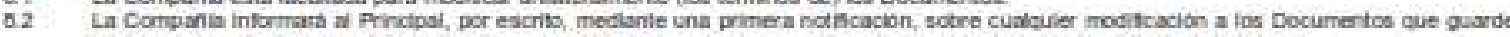

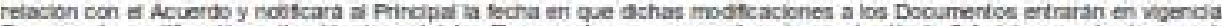

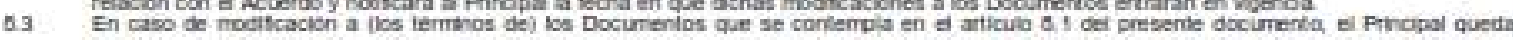

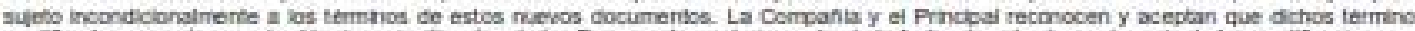

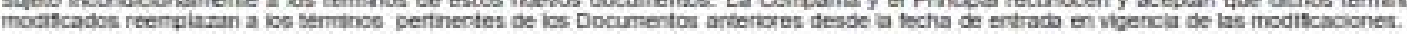

\section{Responsabilidad e indemntzacion}

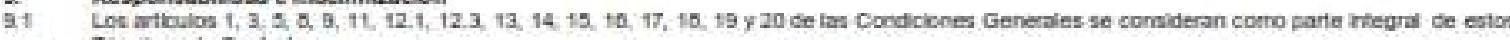

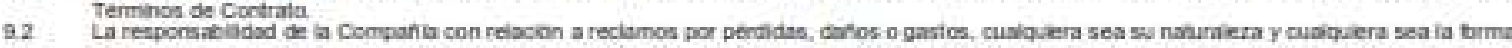

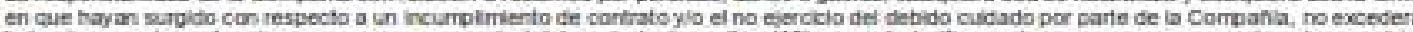

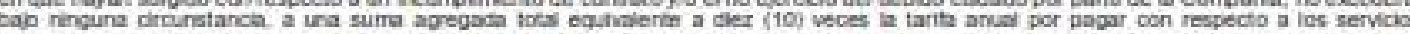

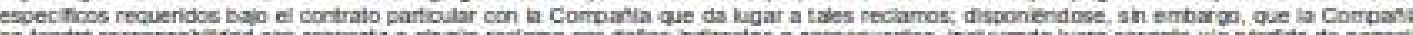

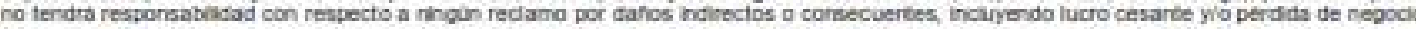

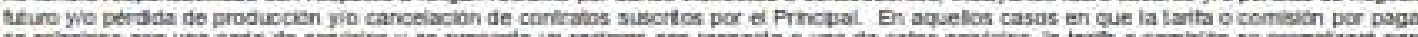
se relacione con una serie de servicios y se pleserde un reciamo con respecio a uno de estos servidos, la tarta o comizion se promateara para

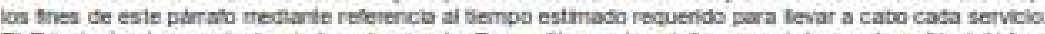

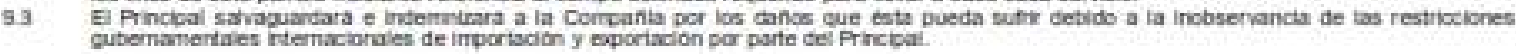

\section{Comislones}

10,1 Salvo que se inilique o scuerte exptesamerte b cortrario por escrta, los valores ootizados por a acordados con ia Contiania seran valores

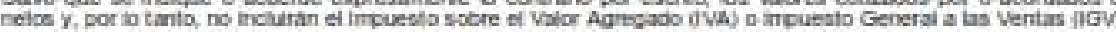

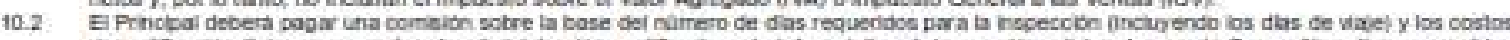

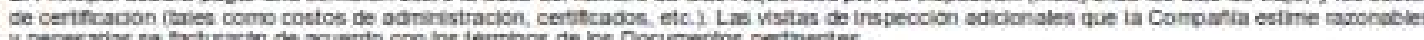
y recesarias ge facturartn de acuerdo con los termhos de los Documerbos pertinertes

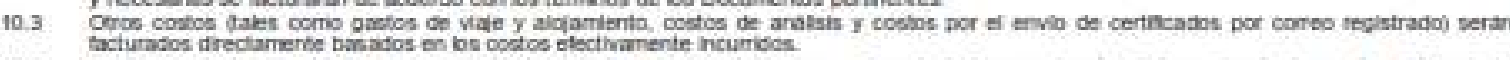

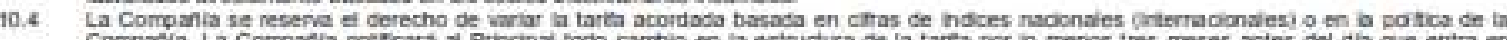

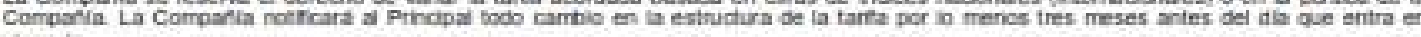
vigencia.

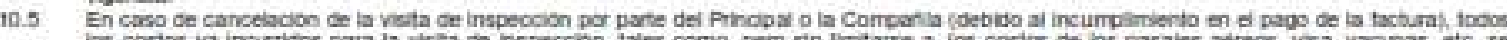

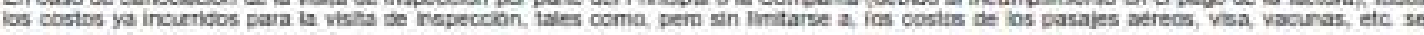
carguran en fodo caso al Pindpa.

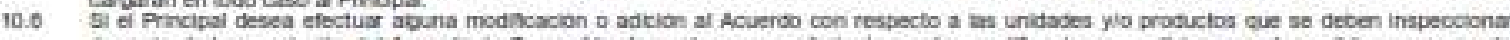
despues de la suscripcon del Acuerdo, la Compana ctarjars su consentmiento a estas modifcaciones a adicones en la medida que se pueda

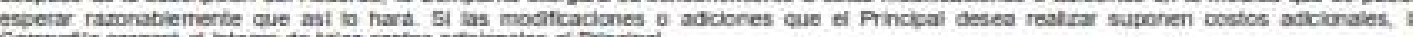

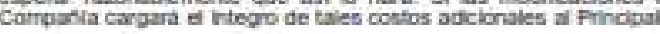

11. Pago

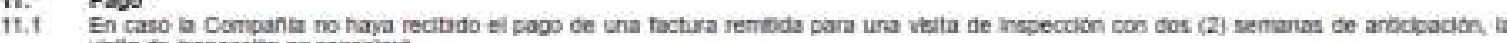
istia de rispeccion se cancelar

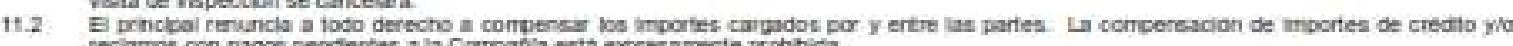

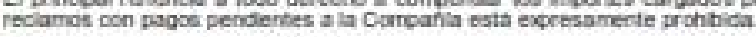

12. Plaros de vipencla y resolucion

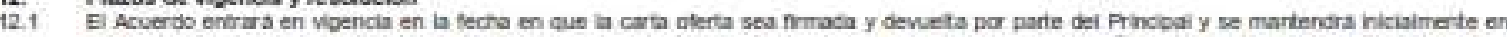

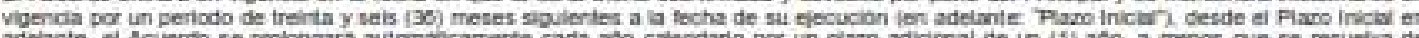

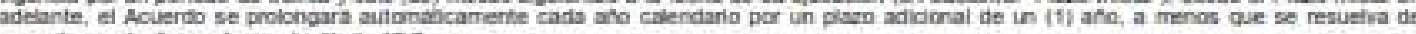

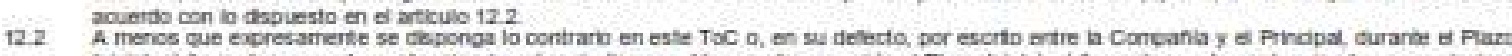

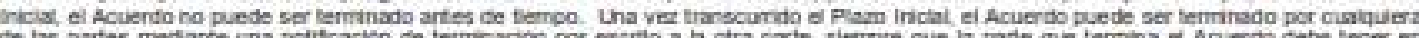

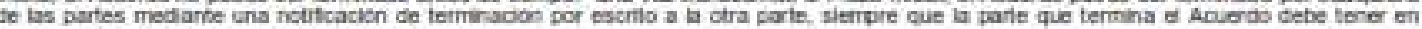
cuenta un periodo de prearise de tres (3) meses.

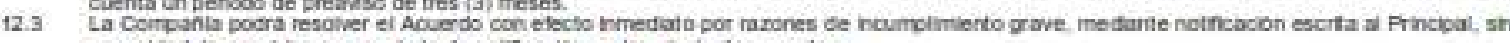
hecesistad de considerat un periodo de nobitcacion en los siguertes evertos:

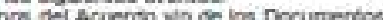

(vil) el Principal race un mul iso de las ceribcacoones obterktas de la Companta en cualquier forma

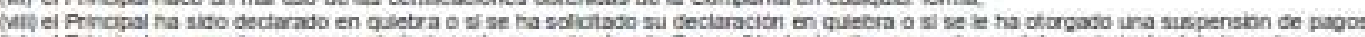

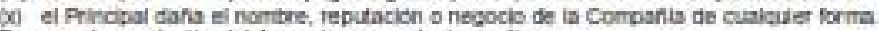

12.4 En casso de resclución del Aojerdo por cualculer inotivo:

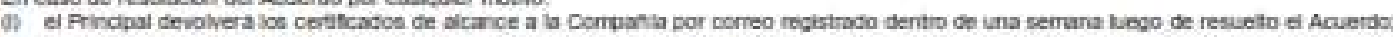

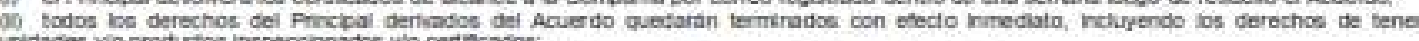
ridaces yia productoa inspecosonader wo certincados;

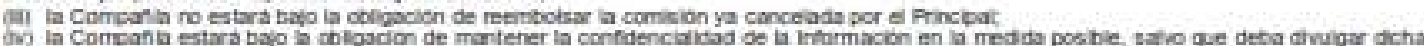

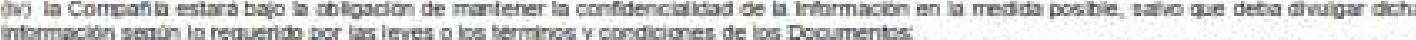

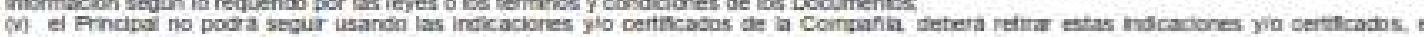
M. el Rncipa no poda stgur isancta

\section{Apelactones}

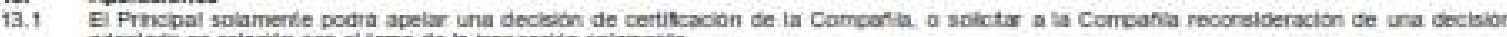

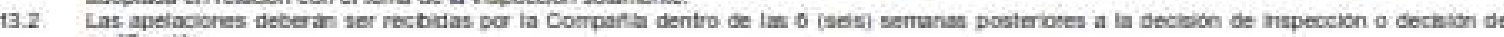
certecadion.

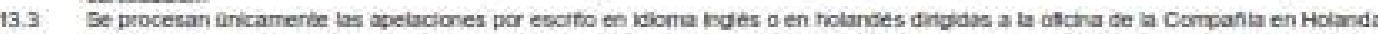

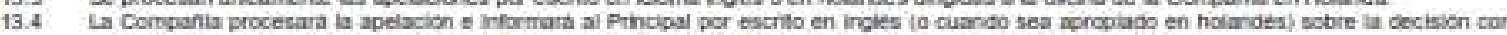

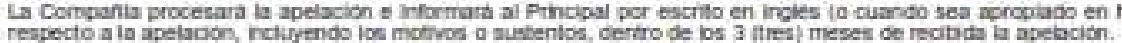

14. Disputa, iey aplicatile y costos (extra) Justiciales

14.1 Toda daputa que surja ertre las partes sera decidda exclushamerte por una Corte bompeterite en Holanda, a menos que la Concranta prefler

14.2 Todoo los acuerdos celebrados entre ia Conponia y el Princpal estan sudelos a ias leyes holandesas.

Ref. no:

ORGOFFERLIOUITO T2 SPA 


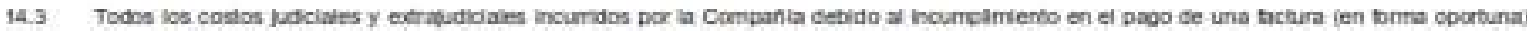

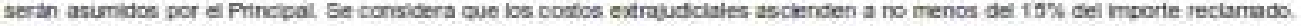

\section{TÉAMNOS Y CONDICIONES DE NEGOCIOS (1999)}

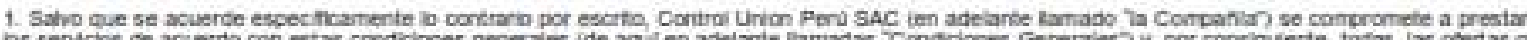

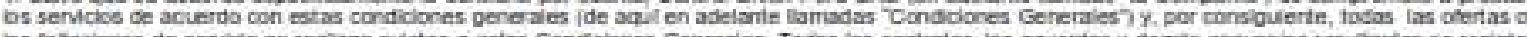
bs ictaciores de seviblo se realzan sujetas a estas Condciones Generales. Todos ins contratos, los acuerdos y demus convenios resultartes se reginan

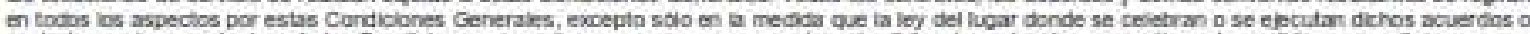

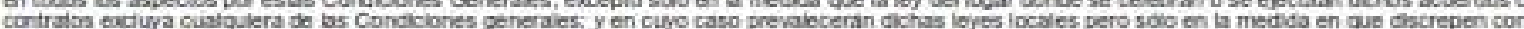
as Condiches peneroles

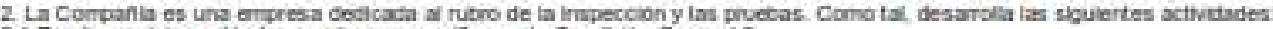
2. Fresta servicos estandar, sepons se eapecisca de ta Condelon General o

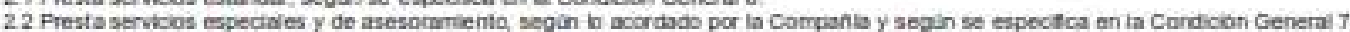

2.3 Emile intormes yio certincsobs segun se especifica en a Condcien Generd o.

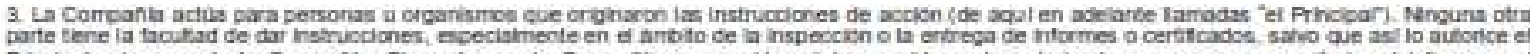

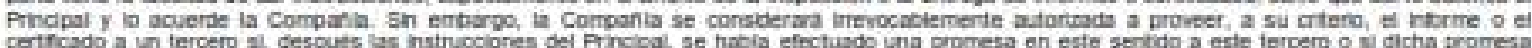

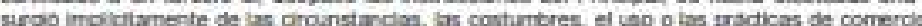

4. La Combenie prestard servios de acuenda cort

4. Las nstrucciones espocheas del Prhcipai, segun la contrmacion de la Conparla

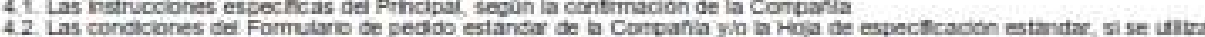

4.3. Cuaviuer costumbie, usp o pracoca de porrerdio relevarte

4.4. Los metodos que is Companita considere apreplados por rame locricas, cocensivas yo trancieras.

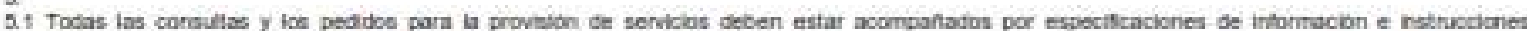
suficiente para permitr que ta Cornpania evalie y'o preste los semicios requerisos.

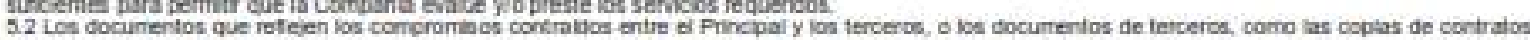

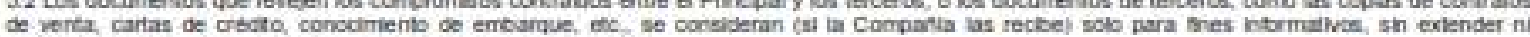
destingir b mision a las ocigaciones aceptadian por la Compafia

6. Los servicios estandar de ia Comporia pueden inclur todoe o alounos de los siguentes:

5.1 trspección ouartiativa yo cualtativa

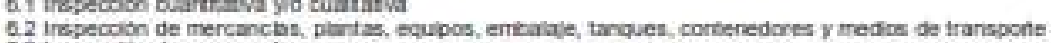

6.2 irspecoion de mercancbs, partas.

6.4 Muestreo

6.5 Muestreo

6.6 inspecrimes y audtorias

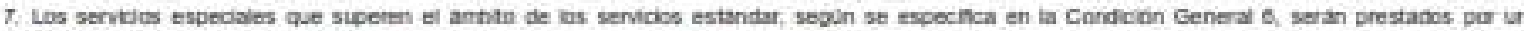

soverdo particusar de is Compalia.

$7-1$ Garatias cuahtohvas yo cuantialivas

7.2 Caltracion ce tanques, castracion de meddares y conprobacien de meddores

7.3 Provision de tecricos y utro tpo ce personal

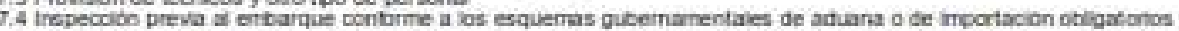

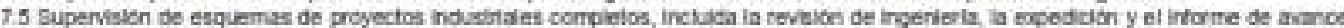

7.6 Servicles de mescrarritenta

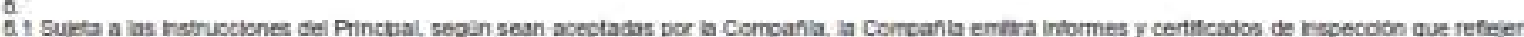

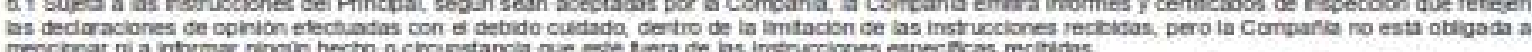

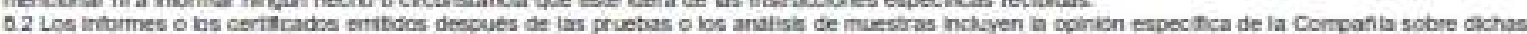

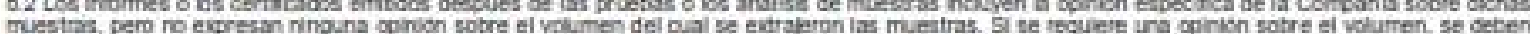

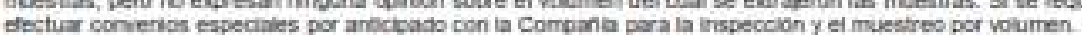

a E Propopar debera

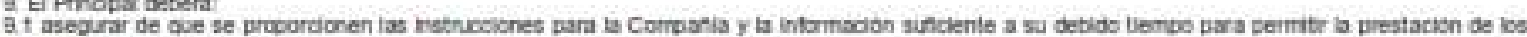
servicios en loima electiva?

92 oblendra todo el acceso necesario para ave los representartes de in Concania puedan prestar las servejos requendos en for ma efoctiva:

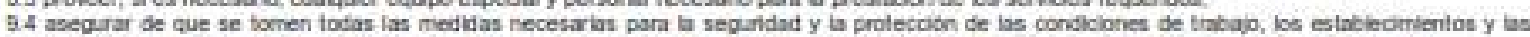

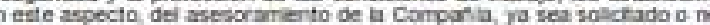

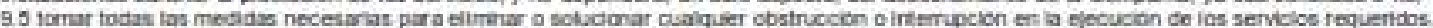

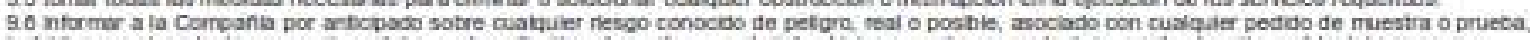

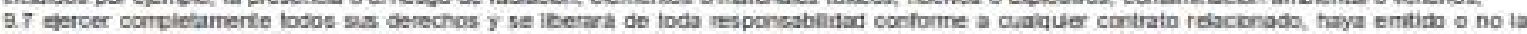

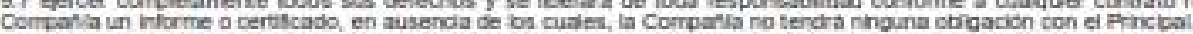

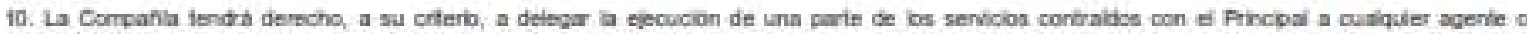
stecontransta

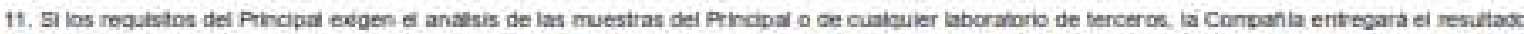

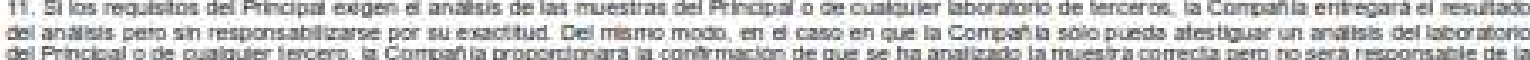

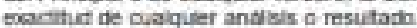

12.

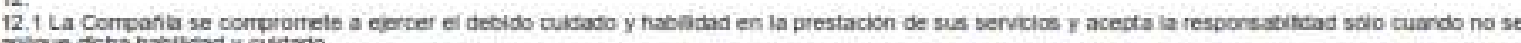
plique dcha habiledad y culdado

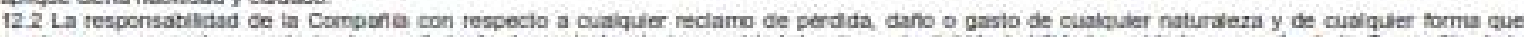
arpese con respecto a caraile incumpamients de conirato yla incapacidad de ejerver a cebida habidiod y cudado por parie de la Camparia, belo

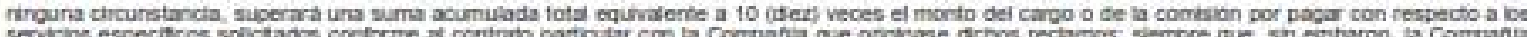

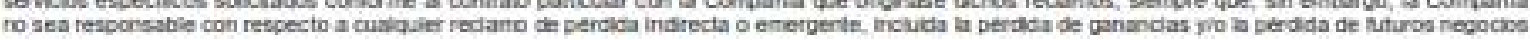

Ref. no: 


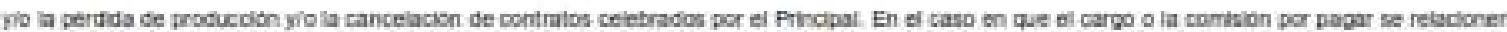

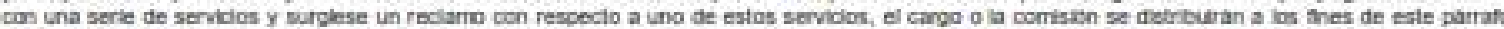

cor relerencla ai tierrpo estumado que levo la prestacion de cada servicio.

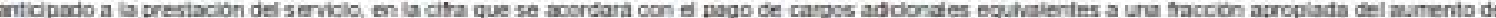
dicha compersacion o como se cnmengn.

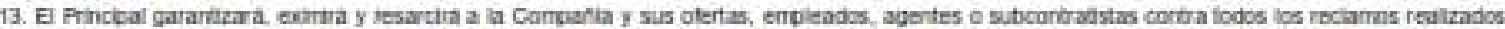

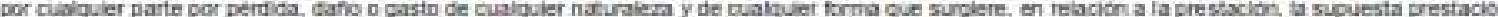

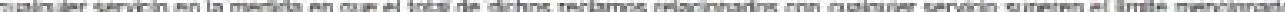
en is Condation 12

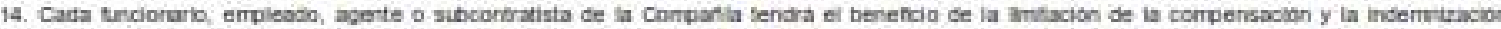

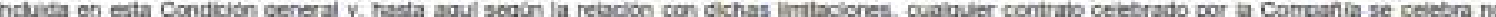

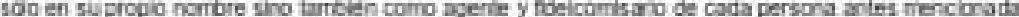

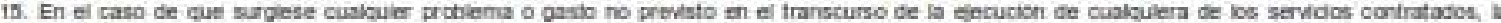

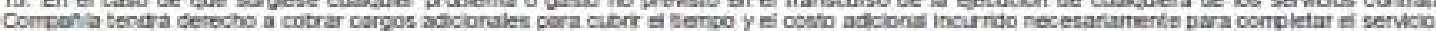

10.

16.1 E Princbal pagara purtualmerte antes de ics 30 dias de in fecha de is factura retevante o contro del periodo que se haya accritado por eacrillo con la

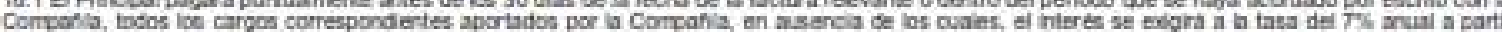
de ia tecta de la tactira hasta st pago

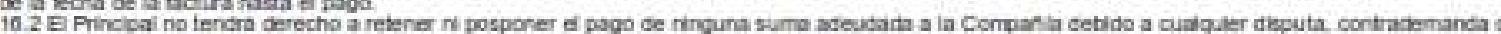
compersacion de deudas que bueda abegar contra la Corrvafila.

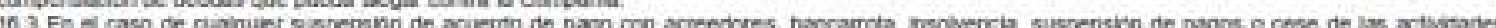

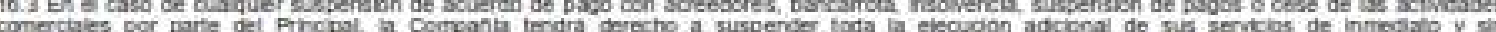
nesponsablidades

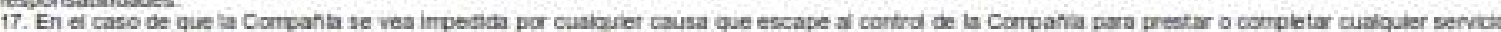

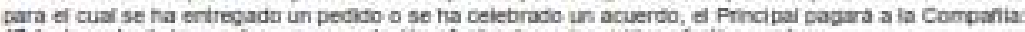

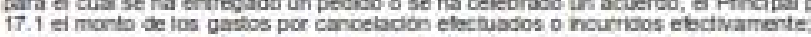

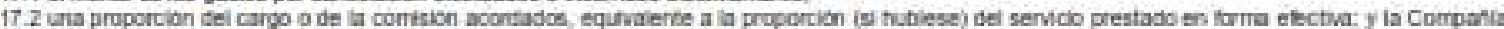

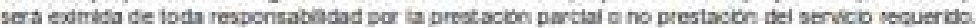

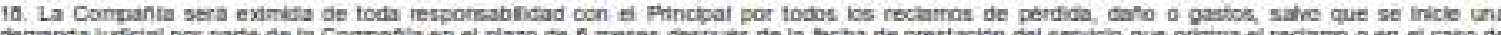

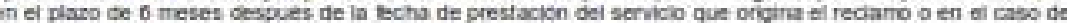

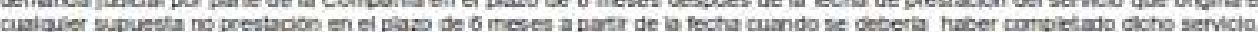

19. La Compana no es ura asegutadora ní un garante y niega boda resporsabildas en dicha cal dad. El Pincipal que jrocure una garartib contra perdida o dafo debe chbener in soguib adecuade

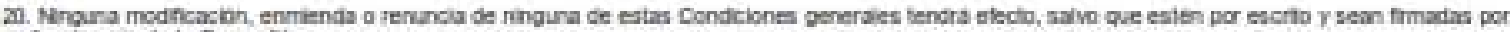
in tuncionorn de is Compahts

Ref. no: 


\section{Certificación Global Gap}

Nombre: COOPERATIVA AGRARIA ALTO GRANDE SANTA SOFIA - COOPAG

Attn:: $\quad$ JHON CARLOS JUÁREZ CORREA

Dirección AV. MIGUEL GRAU NRO. 21 INT. A VILLA SANTA SOFIA (PREG X RICHARD REYES X LA ENTRADA)PIURA - SULLANA - IGNACIO ESCUDERO

Ciudad PIURA

Pals PERU

Lima, 17 DE NOVIEMBRE DE 2016

Asunto: Oferta para servicios de inspección y certificación bajo el programa de certificación GLOBALG.A.P. de Control Union Certifications (en adelante: "CUC")

Estimado Sr. Jhon Juárez:

Gracias por mostrar interés en las actividades de CU. Basado en la información presentada en el Formato de Aplicación se ha calculado la siguiente oferta para ("COOPERATIVA AGRARIA ALTO GRANDE SANTA SOFIA - COOPAG") (en adelante "El Cliente")

La certificación aplica para:

GLOBALG.A.P. IFA V5

\begin{tabular}{|c|c|c|c|}
\hline \multicolumn{2}{|c|}{ Producción Agrícola } & Producción de ganado & Producción de acuicultura \\
\hline $\mathrm{x}$ & Frutas \& Vegetales & $\begin{array}{l}\text { Ganado vacuno y } \\
\text { ovino }\end{array}$ & Peces \\
\hline & Flores \& Ornamentales & Ganado lechero & Moluscos \\
\hline & Cultivos a Granel & $\begin{array}{l}\text { Terneros / Ganado } \\
\text { vacuno joven }\end{array}$ & Crustáceos \\
\hline & $\begin{array}{l}\text { Material de Reproducción } \\
\text { Vegetal }\end{array}$ & Ganado porcino & \\
\hline & $\mathrm{Te}$ & Aves de corral & \\
\hline & & Pavos & \\
\hline
\end{tabular}

GLOBALG.A.P. Estándar transporte de ganado

$\square$ Estándar transporte de ganado

GLOBALG.A.P. Fabricación de piensos compuestos

$\square$ Fabricación de piensos compuestos

GLOBALG.A.P. Cadena de Custodia

Cadena de Custodia

Protocolo Albert Heijn para Control de Residuos (AH)

Protocolo Albert Heijn para Control de Residuos

GLOBALG.A.P. Evaluación de riesgos en la práctica social (GRASP)

GRASP

Ref.No. $x x$ 
Opciones de certificación

Opción 1 (sitio único)
Opción 1 Multi-sitios sin SGC

\section{Inspección anual/Plan de auditoría}

Basándonos en la información proporcionada en el Formato de aplicación de CUC, se planificarán 2 visitas(s) de inspección de $6 \mathrm{dia}(\mathrm{s})$ (incluyendo dias de viaje y trabajo administrativo) para los servicios de inspección y administración por año calendario. Por favor tome en cuenta que el número de dias establecidos anteriormente es una estimación. Después de la primera inspección llevada a cabo por CUC, se determinará el número real de dias de inspección, en función de si, según la opinión de CUC, son necesarias más o menos dias de inspección. Por favor note que CUC se reserva expresamente el derecho a realizar inspecciones anunciadas asi como inspecciones no anunciadas.

\section{Tarifa de Licencia Anual}

Basándose en el plan de inspección establecido anteriormente, la tarifa anual para la inspección y certificación dada por el cliente será: S/. 13,500.00 (en adelante: la "La Tarifa anual").

La Tarifa Anual Comprende: visita(s) de inspección, actividades de inspección y reporte(s) de certificación; si la decisión de certificación CUC es "positiva" la Tarifa Anual incluye: un certificado de alcance; la inclusión del proyecto en el sitio web de CUC, nombramiento como titular del certificado.

\begin{tabular}{|l|l|l|l|}
\hline Descripción & & Tarifa en US\$ & Tarifa en S/.* \\
\hline $\begin{array}{l}\text { Tarifa de auditoria/ ins- } \\
\text { pección y Certificación }\end{array}$ & $\begin{array}{l}\text { Productores } \\
\text { Producto: Banano } \\
\text { Visitas: 2 }\end{array}$ & & \\
\hline $\begin{array}{l}\text { Tarifa de registro de pro- } \\
\text { ductor } \\
\text { FoodPLUS/GLOBALGAP } \\
\text { Tarifa de GLOBALGAP }\end{array}$ & $\begin{array}{l}\text { (ac) Tabla de } \\
\text { Tarifa de licencia de cer- acuerdo con la última Tabla de } \\
\text { tificado } \\
\text { FoodPLUS/GLOBALGAP }\end{array}$ & & \\
\hline Servicio adicional: & & & \\
\hline Tarifa TOTAL anual & & & $13,500.00$ \\
\hline $\begin{array}{l}\text { Tarifa TOTAL anual } \\
\text { (INC. IGV) }\end{array}$ & & & \\
\hline
\end{tabular}

CONSIDERAR TIPO DE CAMBIO EQUIVALENTE A 3.37 SOLES (SUJETO A CAMBIO)

Ref.No. $x x$ 
DATOS DE CONTROL UNIÓN PERÚ SAC:

RUC: 20504194796

Dirección: AV. PETIT THOUARS NRO. 4653 (PISO 6 - OFIC. 603) LIMA - LIMA - MIRAFLORES

NÚMEROS DE CUENTA:

BCP SOL $193-1704576-0-38$

BIF SOL 7000095059

CÓDIGO DE CUENTA INTERBANCARIA DEL BCP:

002-193-001704576038-10 (SOLES)

CÓDIGO DE CUENTA INTERBANCARIA DEL BIF:

03810210700009505904 (SOLES)

CUENTA PARA DETRACCION

Cuenta corriente: $00-000-816523$

Los elementos mencionados a continuación no están incluidos en la tarifa de licencia anual:

(i) Tarifa de FoodPLUS/GLOBALGAP (basado en la información proporcionada en el Formato de Aplicación, la tarifa de FoodPLUS/GLOBALGAP es calculada según la tabla de la última tarifa GLOBALGAP)

(ii) Gastos por análisis(si es necesario);

(iii) gastos de viaje y gastos de estancia de los inspectores (incluyendo, pero no limitado a el alojamiento;

(iv) Gastos de envio de los certificados y muestras por correo registrado, el cual será cargado a la cuenta del cliente basado en gastos reales de CUC;

(v) servicios adicionales conforme a lo solicitado en el Formato de Aplicación para servicios adicionales

CUC tiene como objetivo mantener los costos de los dias de viaje y los costos adicionales (incluyendo, pero no limitado a, los costos de subsistencia) al mínimo.

\section{Documentos y regulaciones aplicables}

Los siguientes documentos (en adelante: los "Documentos") se aplicarán a la presente carta oferta, y por firmar y devolver esta carta oferta, El cliente entrará en un acuerdo con CUC para unirse al programa de certificación CUC, por lo que el cliente acepta expresamente todos los tërminos y condiciones establecidos en los Documentos: 


\begin{tabular}{|c|c|}
\hline Programa Aplicable & Documento \\
\hline Para todos los programas & $\begin{array}{l}\text { - Los Términos Generales de Contratación de CU (Anexo) } \\
\text { - La Regulación de Inspección CU }\end{array}$ \\
\hline \multicolumn{2}{|l|}{$\begin{array}{l}\text { Documentos adicionales GLOBALG.A.P. } \\
\text { cuando sea aplicable }\end{array}$} \\
\hline & $\begin{array}{l}\text { - Regulación General GLOBALG.A.P., } \\
\text { BALG.A.P. } \\
\text { - } \quad \text { Sublicencia y Acuerdo de Certificaciōn GLOBALG.A.P. } \\
\text { - Tabla de tarifas GLOBALG.A.P., Reglas de acceso de datos } \\
\text { - } \quad \text { Guias de Interpretación Nacional GLOBALGA.P. } \\
\end{array}$ \\
\hline $\begin{array}{l}\text { Documentos de Protocolo GLOBALG.A.P. } \\
\text { Albert Heijn }\end{array}$ & $\begin{array}{l}\text { - Todos los documentos identificados en el Anexo GLO- } \\
\text { BALG.A.P. Directriz/ Regulaciones Generales del Protocolo } \\
\text { AH incluido el anexo para Regulaciones Generales de Subli- } \\
\text { cencia y el Acuerdo de Certificación de GLOBALG.A.P.- } \\
\text { Complemento del Protocolo Albert Heijn }\end{array}$ \\
\hline Documentos GLOBALG.A.P. GRASP & $\begin{array}{l}\text { - Reglamento General GRASP, } \\
\text { to). } \\
\text { - Lódulo GRASP (puntos de control y criterios de cumplimien- } \\
\text { - } \quad \text { Orientación aplicación GRASP y directrices nacionales de in- } \\
\text { terpretación GRASP. }\end{array}$ \\
\hline
\end{tabular}

Los documentos pueden ser encontrados en certification.controlunion.com y en www.GLOBALG.A.P.org. Una versión impresa de estos documentos se enviará a usted a su solicitud.

\section{Condiciones especiales de pago}

Antes de que CUC lleve a cabo la primera inspección, el cliente deberá pagar a CUC la tarifa anual total establecida anteriormente. Al final del año, la tarifa real incurrida por el Cliente será calculado y el saldo restante será cargado o reembolsado al Cliente, dependiendo de si dicho saldo restante es positivo o negativo.

La factura se enviará normalmente por CUC cada año, en o alrededor de la misma fecha todos los años. La falta de pago por parte del Cliente dará lugar a un retraso de la auditoria, totalmente atribuible al cliente, y la revocación del certificado antes de la conclusión del proceso de auditoria de CUC. El pago fuera de tiempo también puede llevar a la suspensión del certificado del cliente con efecto inmediato; dicho periodo de suspensión puede permanecer en su lugar hasta e incluyendo la fecha de caducidad del certificado.

CUC podrá modificar de manera unilateral la tarifa anual debida por el Cliente, en caso de que el alcance o la ubicación de las actividades cambien durante el año calendario, dicha 
tarifa modificada será aplicable en el siguiente año calendario. Los clientes registrados, como el Cliente, están obligados a comunicar oportunamente las actualizaciones de datos.

\section{Acuerdo}

Por favor firme esta carta de oferta y devuelva una copia si está de acuerdo con su contenido. Después de recibir la cuota anual, CUC planificará la fecha definitiva para la primera visita de inspección e informará al Cliente de las mismas. Cualquier acuerdo entre CUC y el cliente se renovará tácitamente cada año para otro periodo de un (1) año calendario, salvo rescisión por parte del cliente.

\section{Validez}

Esta oferta es válida solo cuando ha sido firmada por una persona autorizada del cliente, dicha autorización se evidencia por un trato válido del registro mercantil o una copia de los articulos actuales de la asociación del Cliente.

Esta oferta mantendrá su validez hasta (2) meses después de la fecha indicada en esta carta oferta.

Esta oferta deberá reemplazar y sustituir todas las ofertas anteriores emitidas por CUC.

Confiamos en que esta oferta satisface las necesidades y deseos del Cliente. Por favor, no dude en ponerse en contacto con el abajo firmante si tiene alguna pregunta o comentarios adicionales, o en caso de alguna duda.

Esperamos recibir su respuesta positiva.

Atentamente,

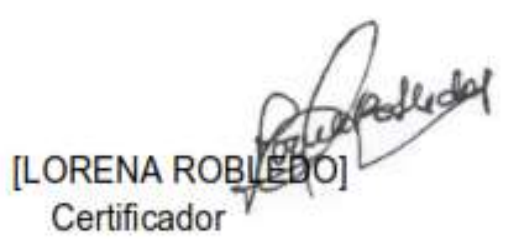

Anexol

Términos Generales de Contrato CU

Ref.No. $x x$ 


\section{POR FAVOR DEVUELVA UNA COPIA FIRMADA DE ESTA OFERTA}

\section{Declaración de aceptación de parte del aplicante}

El que suscribe la presente acepta esta Carta Oferta y se compromete a cumplir con las obligaciones establecidas en los siguientes documentos (incluyendo pero no limitado al pago de la cantidad de la tarifa total a pagar):

(i) Los términos y condiciones de esta carta oferta; $y$

(ii) Los términos y condiciones de los documentos mencionados bajo el item número tres (3) de su carta oferta, que se han considerado aplicable al acuerdo entre el cliente y el CUC.

Además, el cliente confirma que el Formato de Aplicación de fecha: (fecha: 27-09-16) ha sido llenado con veracidad, y que dicho Formato de Aplicación será parte integral del acuerdo entre CUC y el Cliente.

NOMBRE DE LA COMPAÑIA: COOPERATIVA AGRARIA ALTO GRANDE SANTA SOFIA - COOPAG

REPRESENTANTE LEGAL: JHON CARLOS JUÁREZ CORREA

CARGO EN LA COMPAÑIA:

FIRMA:

FECHA: 17 DE NOVIEMBRE DE 2016 
Anexo 1

Términos de Contrato aplicables a las actividades de inspección y certificación de Control Union Certifications BV, en adelante denominada "la Compañia"

Condiclones Generales

1.1 Con respecto a los hems no comprendidos en estos Teminos de Contrato (TOC) se deberan aplacar los TERMINOS Y CONDICIONES DE NEGOCIO (1999) en la forma y contenido que se adjunta ien pdelante: las "Condiciones Generales"? con ta excepcion de los artioulos 7.6 y 10 de la misma.

12 Los semicios estandar de la Compania podran inciür todos o cualquera de ios siguientes servicioa: inspecolones y Certiscaciones de productos, procesos, activededes o sistemas de gestion. Adernas, se considera que tas inspecciones inciuyen evaluationes, auditorlas, invertarlos y vigitancia.

2. Carta Oterta

2. Al firmar y devolver una aterta realizada por la Combanta, el Principal entra en un acuerdo brmal con ia Companta (en adelante "Acuerdo" en los terminos y condiciones especincados en la mencionada carti oferta, asi camo en bodos los demas documentos jinckuyenda estos Teminos de Contrata) que son y han sido declarados explicitamente aplicables al Acuerdo (en adelante denominados los "Documentos?

3. Oblloactones y llmitactones del Princtpal

3.1 El Principal debe notificar imediatamente a la Coempania cualquier cambio o descontinuacion de las actiudades comprendidas en ef ambito del contrato que intertieran a potenciaimente puedan interterir con ef cumplimiento de los requistos mencionados en los "Documentos", o lo que polenclalmente podrian cambiar ef ambito del contrato de inmediato a la Companla.

3.2 El Principat no podra ceder niaguno de sus derechas u obligacibnes en vitud del Acuerdo y los Documientos a terceros

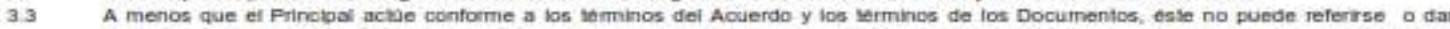
alguna indicacion respecto a cuaiquer Decumento, de manera tal que de ta impresion que ibs productos olas unidades del Princtipas fueran ableridos o se mantenen de acuerdo a los terminos de bs Documentas.

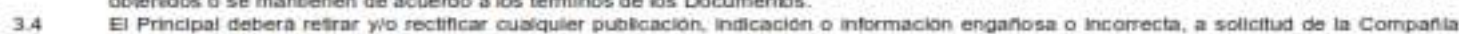
con respecto a sus actividades inspeccionadas ylo certificadas a sasataccion de la Comipanta.

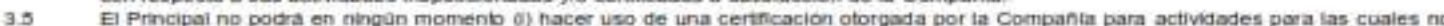
productos que na han saido agrobados por esta de acuerdo con dos procedemientos de certiticacion, y ail) st el Principal proporctona coplas de los documentos de certificacion a otras partes, los documeritos deberan ser reproducidos en su fotalidad o como se espectica en el espuema de certitcacion.

3.6 El Prncipal debera abstenerse de uthizar una certifoacion de sistemas (calidad) oforgada por in Campanla de manera que de a entender que ef producto o servicio ha sido aprobado por la Compania sisternas (calidad) otorgada por il Carraanla de manera que de a entender

3.7 Eu Principol debera abstenerse de actuar de tai manera que pudiera posenctaimente, afectar una indicacion yo certincado de la cornpanta de manera negatva

3.0. El Principal debera informar de inmedato a ta Compania en cuanto conazca el uso incomecto yio no auborizado de una indicacian de ta Compartia yio una pubicacion enganosa o incorrecta que se refiera a la Compania.

4. Inspeccion

4.1. La Companta llevara a cabo las inspecolones o dispondra que un tercero las leve en su regrosertacion, de acuerdo a los vermhos de los Documentos con ei tn de determinar si as condiciones convenidas, como se menciona en los Documenitos, estar siendo cumpidas por ei Principal.

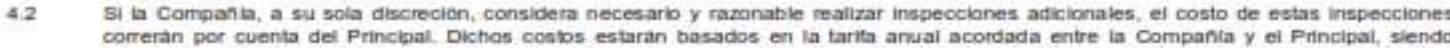
cargados sobre ta base de los costos reajes realizados

4.3 El Principat debera realizar todas las coordinaciones que sean necesartas para levar a cabo las activdadea de inspeccian, incluyendo pero sn limitarse a las desposicianes necesarias para examinar la documentacian por parte de la Compania. Adtickanaimente, el Prinoloal debera

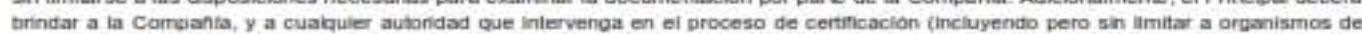

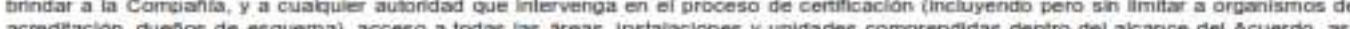

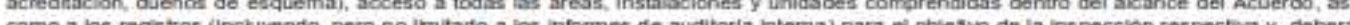

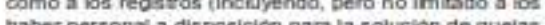

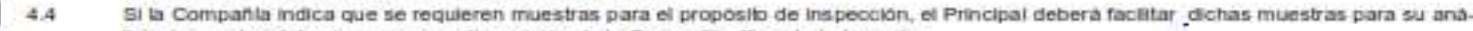
isis, las cuaies deberan ponerse a disposicion de la Compania. ibre de todo cosio.

5. Certincado

5.1 S1 se otorga un cersficado de aicance al Principal, dicho certificado tendra valder hasta la focha de vencimiento mencionada en a certificaido slompre y

(1) No se haya producido ningina variacion, alleracion ynu otro cambio en ei metodo y unidades de produccion desde la focha en que fueron inspectionados los mismos que fueron certilcados en base a dicha inspeccionc $y$ (i) El Acuerdio no se haya ierminado por cualquier razon.

5.2 Los compromisos o acuerdoa verbales efectuadoe con respecto a la certincacion por o con el personal de la Compania o la parke encargada de las inspecciones en representacion de ta Compania, no vincufan a esta en brma aiguna. Scto despues de ta toma de una decision de certincacion formal por escrito par ia Campania, la certificacion sern otor gada por ente oisma al Pnincipal.

5.3 Electuncaso de alcance de la Companta se otorga at Principal sobre una bnse no exclustug.

6. Confldenclaildad inspeciones reallzadas (en adelante, ta "Intormacion" se tratara de manera confidencial y no revelard la infomacion a ringan tervero sin ef consentmiento previo de! Princtiol, excepto en la medida que ta iey y io los Documentos la requieran.

6.2 Para ganax o martener ta confianza en is certincacion, la Companta proporcionara acoeso adecuado a a divubacion de intormacion no corifidencial scerca de las conckasiones de auditorias especitcas (por ejemplo, auditorlas en respuesta a quejas) para las partes conildencial

0.3 El Principal adoptara ias medidas necesarins para garanttzar que toda informecion en reiacion con el metodo de inspecocion empleado por El Principal adoptara las medidas necesarias para garanitzar que tada informacion en reiacion con ei metodo de inspeccián emsicada por la Combania sea tratida de manera confdencial. Asimismo, no se divilgard ninguna informacion sobre ef meto

7. indicaclones

71 Si ef Principal actia de contormidad y cumble los requisitos que se mencionan en los Documentos pertinehtes (inchuyendo perb no limzlado a los Documentos reiativos a la uthizacion de indicaciones de la Componla), podra hocer usio de la(g) indicación(es) en productoe que han sido certilicados por la Companta y por los cuales el Pinncipal posee un certitcado de alicance de producta valido

72 El Priricipal debe, al recibar la notincacion de la suspension o retirada de la certincacion det sistema de gestion, suspender todo uso de bodo el material publicitario ideciaraciones que contenga una reforencia a la certificacion, segun las instruccicnes de la Compania, y revisar bodo el materisi pubicitario cuando el aicance de la certilcacidon se haya reducido.

7.3 El derecho a usar las indicaciones de la Compania se oborga al Principal sobre una base no exclusiva

7.4 El Principal tiene la lbertad de publicar que tene derecho a hacer uso de las indicaciones de la Compania en productos certincados que cuentan con un cerbteado de alcance.

Ref.No. $x x$ 
7.5 Al hacer referencia a la certincacion de producto oforgado por ta Companta en los medias de comunicacion, tales comoc docimentos. solietos o publicidad, et Principat detbera cumplir en bodo momento con ios requisitos impuestoa por ef orgarismo de certificacien o como se especinca en ef esquema de certificacion.

76 El Principas debera cumpir con los requistos que se pueden prescribir en el esquema de cerincacion de producto en relacion con el uso de marcas de conformidad, y sobre la infoemacion relacionada con el producto

0. Modificacion de los documentos

0.1 La Compania esta facultada para moditcar unilaberaimente ios teminos de los Documenitos.

La Companta intormara al Fancipal, por escrito, mediante ura permera nouncacion, sobre cuarquies modtcacion a los Documentos gye guarde relacion con el Acuerdo y notficara al Principal la fecha en que dichas moditcaciones a los Documentos entraran en voencia.

En caso de modticacion a las terminos de los Dociumentas que se contempia en ef articuio of 1 det prosento documento, es Principal qued

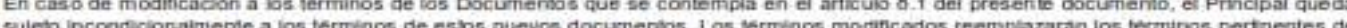
ios Documentos anteriores desde la fecha de entrada en vigencla de tas modincaciones.

9. Responsabilidad e inde mnizacion

9.1 Los articuios 1, 3, 5, 0, 9, 11, 12.1, 12.3, 13, 14, 15, 16, 17, 10, 19 y 20 de las Condiciones Generales se consideran como parte integrai de

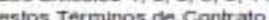

estos Terminos de contro larma en que havan surjido con respecsa a un incumplinierno de contrato ylo el no ejercicia del debido culdado por paris de la Campanta,

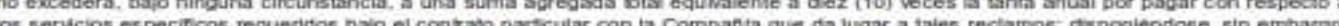
los serucios espe

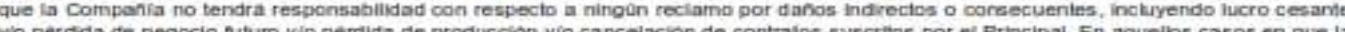

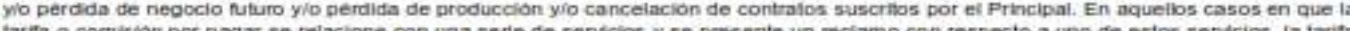

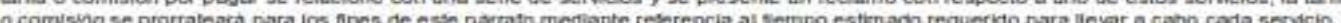

93.3 El Principal savaguartara e indemnizara a ta Compania por los danios que esta pueds gubernamentales internacionales de importacion y exportacion por porte det Principa

10. Comisione:

10.1 Salvo que se indlque o acuerde expresamente la contrario por escrito, los valores cottrados por o acordados con ta Companta serar valores netos $y$, por lo tanto, no velukran et impuesto sobre ei Valor Agregado (iVA.

10.2 El Principar debera pagar una comision sobre ta base del nümero de dias requeridos para a inspeccion (incluyendo los dias de vaje) y bas costos de certicacion (tales como coatos de administracion, certuicados, etc,i Las visitas de inspeccion adicionales que la compania estime ramonables y necessarias se facturaran de acverdo con los terminos de los Documentes pertinentes

10.3 Otras cosilas (tales camo gastos de vale y alojamiento, cos los de analisis y cosios por el envio de certifcados poe coereo registrado) seran tacturados directamente basados en los costos eflectuvamente incurridos.

10.4 La Companta se reserva el derecho de variar la tarfa acordada basada on citras ite indices nacionales (internacionales) o en la poitica de la Compania. La Compania notincara al Principai bodo camtio en la estructura de la tanta par lo menos tres meses antes dei dia que entra en viouncia

10.5 En caso de cancelacion de la vista de inspecoion por parte del Princieal o la Companta (debido at incumplikmiento en el pago de la tactura),

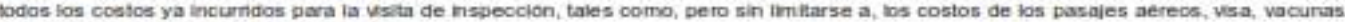
etc se cargaran en todo caso al Principes

10.0 Si ei Principal desea efectuar alguna modificacion o adicion al Acuerdo con respecto a tas unidades yio productos que se deben inspeccionar despues de la suscripcibn del Acuerdo, ia Compania atorpara su consentimiento a estas moditicaciones o adiciones en ia medida que se pueda esperar razonabiemente que ast io hara. si las modncaciones o adicianes que el Principal desea realzar suponen costos adficionales, la Compania cargara el fntegro de tales costos adiclonaies al Principai

11. Pago

11.1. En caso ta Companta no haya recibido ef pago de una tactura remitida para una vista de inspeccion con dos (Z) semanas de anticipacion. la vilita de inspeccion se cancetara

11. El principal renuncia a todo derecho a compensar los importes cargadios por $y$ erte las partes. La compensacion de impories de credita yo reciamos con pagas pendientes a la Compania esta expresamente prohibida.

12. Plazos de vigencla y resolucion

12.1 El Acuerdo entrara en Koencia en la fecha en que ta carta oferta sea firmada y devuelta por parte del Principal y se mantendra imvolaimente

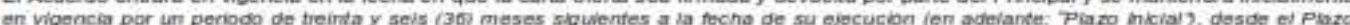
inicial en adetante, el Acuerdo se profongara automaticamente cadta ano cavendario por un plazo adicional de un (1) ano, a menos guse sa Gicial en adetante, ef Acuerdo se proiongara automatic

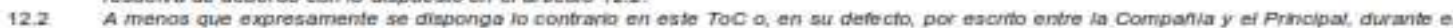

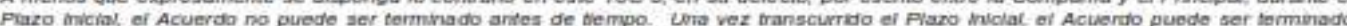

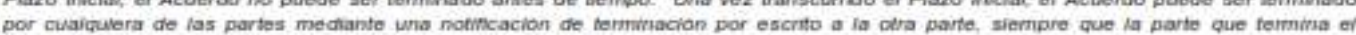
Acuerdo debe tener en clienta un periodo de preaviso de tras (3) meses.

12.3 La Compania podra resolver el Acuerdo con efecto inmediato por razones de incumpiumiento grave mediante nobicacion escrita a

(1) ei Princtbal ha actuado contrartamente a los serminos des Acuerdo ylo de las Documentbs:

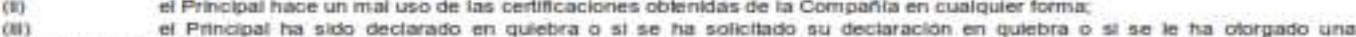
suspension de pagos:

(iv) et Princlgal no cumple con pagar algon importe que adeuda a la Campania dentro de un mes luego del vencimierto dei plazo de pago; 0

iv et Princtpal dana el nombre, reputacion o negocio de ta Companta de cuaiquier forms

12.4 En caso de resolucion del Acuerdo por cualquier mativo:

(1) el Principal devolvera los certincados de aicance a la Compania por correa registrado dentro de una semana kego de resueltb ef Acuerda:

(1) fodos los derechos de! Principal derivados del Acuerdo quedaran teminados con efecto inmediato, incluyendo los derechos de sener unidades y/o productos inapeccionados yio certincados:

(i) la Compania no estara bajo la obilgacion de reembolsar la comision ya cancelada por ef Principal

(iv) la Compania estara tajo la obligacion de mantener la conthdencialidad de la informacion en la medida posibie, satwo que deba divulgat dicha trformación segon la requerido por las leyes o los terminos y candiciones de los Dacurnertas:

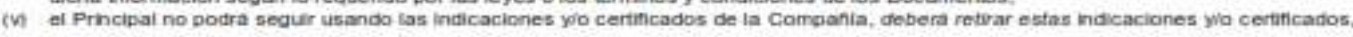
e informara a la Companta sobre esto.

\section{Apetacione:}

13.1. E Principal solamente podra apeiar una decision de pertincacion de la Companfla, a solicitar a la Companta reconsideracion de una decision adogtada en relacion con et tema de ia inspección solamente.

Las apelaciones deberan ser recibidas por la Compania dentro de las 6 (seis) semanas pos beriores a la decision de certitoacion

13.3 Se procesan anicamente las apelaciones por escrto en idioma ingles u holandes dirigidas a la oflicina de le Companta en Holanda

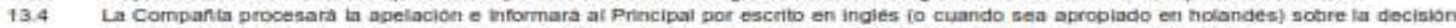
con respecto a la apelacion, incluyendo jos motivos o sustontos, dentro de los 3 (tres) meses de recibida la abetacion.

14. Disputas, ley aplicabie y costos judiciales (y extrajudiclales) 


\section{TERMINOS Y CONDICIONES DE NEGOCIOS (1999)}

1. Saho que se acuerde especificamente lo contrario por escrito, Control Union Perú SAC (en adelante lamado "la Compafỉa") se comr promete a prestar los servicios de acuerdo con estas condiciones generales (de aqui en adelante llamadas "Condiciones Generales") y. pror consiguiente, todas las ofertas o las licitaciones de servicio se realizan sujetas a estas Condiciones Generales. Todos los contratos, por consiguierite, todas las ofertas o las licitacicres de servicio se realizan sujetas a estas Condiciones Generales. Todos los contratos, que la ley del lugar donde se celebran o se ejecutan dichos acuerdos o contratos excluya cualquiera de las Condiciones generales; y en cuyo caso prevalecerản dichas leyes locales pero sólo en la medida en que discrepen con las Condiciones generales.

2. La Companlia es una empresa dedicada al rubro de la inspección y las pruebas. Como tal, desarrolla las siguientes actividades:

2.1 Presta servicios estándar, segün se especifica en la Condición General 6.

2.2 Presta servicios especiales y de asesoramiento, seguin b acordado por la Companía y según se específica en la Condición General 7. 2.3 Emite informes yo certificados según se especifica en la Condición General 8.

3. La Corrpañia actúa para personas u organismos que originaron las instrucciones de acción (de aquí en adelante llamadas "el Princpal"). Ninguna otra parte tiene la facultad de dar instrucciones, especialmente en el ámbito de la inspección o la entrega de informes o certificados, salvo que asi lo autorice el Principal y lo acuerde la Compañia. Sin embargo, la Compańila se considerará irrevocablemente autorizada a proveer, a su criterio, el informe o el certificado a un tercero si, después las instrucciones del Principal, se habia efectuado una promesa en este sentido a este tercero o si dicha promesa surgio implicitamente de las circunstancias, las costurnbres, el uso o las prácticas de comercio.

4. La Compahlia prestará servicios de acuerdo con:

4.1. Las instrucciones especificas del Principal, segùn la confirmación de la Compañia

4.2. Las condiciones del Formulario de pedido estándar de la Compallia y/o la Hoja de especificación eständar, si se utiliza

4.3. Cualquier costumbre, uso o práctica de comercio relevante

4.4. Los métodos que la Compańía considere apropiados por razone técnicas, operativas yío financieras.

5 .

5.1 Todas las consultas y los pedidos para la provisión de servicios deben estar acompañados por especificaciones de información e instruociones suficientes para permitir que la Compafila evalùe yo preste los servicios requeridos.

5.2 Los documentos que refejen los compromisos contraidos entre el Principal y los terceros, o los documentos de terceros, como las copias de contratos de venta, cartas de crédito, conocimiento de embarque, etc., se consideran (si la Companlia las recibe) sólo para fines informativos, sin extender ni restringir la misión o las obligaciones aceptadas por la Compatlia.

6. Los servicios estándar de la Compafila pueden incluir todos o algunos de los siguientes:

6. Los servicios estándar de la Compafilia
6.1 Inspección cuantitativa yjo cualtativa

6.2 inspección de mercancias, plantas, equipos, embalaje, tanques, contenedores y medios de transporte

6.3 Inspección de carga o descarga

6.4 Muestreo

6.5 Análisis de laboratorio y otras pruebas

6.6 Inspecciones y auditorias

7. Los servicios especiales que superen el ämbito de los servicios estándar, segùn se especifica en la Condiciỏn General 6, serán prestados por un acuerdo particular de la Compañia

Estos servicios especiales son los siguientes, a modo lustrativo y no exhaustivo:

7.1 Garantias cualtativas ylo cuantitativas

7.2 Calbración de tanques, calbración de medidores y comprobaciôn de medidores

7.3 Provisión de técricos y otro tipo de personal

7.4 Inspección previa al embarque conforme a los esquemas gubernamentales de aduana o de importación obligatorios

7.5 Supervisión de esquemas de proyectos industriales completos, incluida la revisión de ingenieria, la expedición y el informe de avance 7.6 Servicios de asesoramiento

8.

8.1 Sujeta a las instruociones del Principal, segün sean aceptadas por la Companhia, la Compañia emitira informes y certificados de inspección que reflejen las declaraciones de opinión efectuadas con el debido cuidado, deritro de la limitación de las instrucciones recibidas, pero la Compañ ia no estả obligada a mencionar ni a informar ningún hecho o circunstancia que esté fuera de las instruxciones especificas recibidas.

8.2 Los informes o los certificados emitidos después de las pruebas o los anális is de muestras incluyen la opinión especifica de la Compafila sobre dichas muestras, pero no expresan ninguna opinión sobre el volumen del cual se extrajeron las muestras. Si se requiere una opinión sobre el volumen, se deben efectuar convenios especiales por anticipado con la Compahila para la inspección y el muestreo por

9. El Principal deberả:

9.1 asegurar de que se proporcionen las instrucciones para la Compantia y la información sufciente a su debido tiempo para permití la prestacián de los servicios en forma efectiva;

9.2 obtendrá todo el acceso necesario para que los representantes de la Compantía puedan prestar los servicios requeridos en forma efectiva;

9.3 proveer, si es necesaria. cualquier equipo especial y personal necesario para la prestación de los servicios requeridos;

9.4 asegurar de que se tomen todas las medidas necesarias para la seguridad y la protección de las condiciones de trabajo, los establecmientos y las instalaciones durante la prestación de los servicios, y no dependerá, en este aspecto, del asescramiento de la Compahlia, ya sea solicitado o noc,

9.5 tomar todas las medidas necesarias para eliminar o solucionar cualquier obstruoción o interrupción en la ejecución de los servicios re-

9.6 informar a la Compañia por anticipado sobre cualquier riesgo conocido de peligro, real o posible, asociado con cualquier pedido de muestra o prueba, incluidos por ejemplo, la presencia o el riesgo de radiación, elementos o materiales tóxicos, nocivos o explosivos, contaminación ambiental o venenos;

9.7 ejercer completamente todos sus derechos y se liberara de toda responsabilidad conforme a cualquier contrato relacionado, haya emitido o no la Compañia un informe o certificado, en ausencia de los cuales, la Compañía no tendrá ringuna obligación con el Principal.

10. La Compantia tendrá derecho, a su criterio, a delegar la ejecución de la totalidad o parte de los servicios contraidos con el Principal a cualquier agente o subcontratista.

11. Si los requisitos del Principal exigen el análisis de las muestras del Principal o de cualquier laboratorio de terceros, la Companilia entregará el resultado del análisis pero sin responsabilizarse por su exactitud. Del mismo modo, en el caso en que la Compan̂ia sólo pueda atestiguar un análisis del laboratorio del Principal o de cualquier tercero, la Compaflia proporcionará la confirmación de que se ha analizado la muestra correcta pero no será resporisable de la exactitud de cualquier análisis o resultado.

12.

12.1 La Compahia se compromete a ejercer el debido cuidado y habilided en la prestación de sus servicios y acepta la responsabilidad sólo cuando no se aplique dicha habifidad y cuidado. 
122 La responsabilidad de la Compañia con respecto a cualquier reclamo de pérdida, daño o gasto de cualquier naturaleza y de cualquier forma que surgiese con respecto a cualquier incumplimiento de contrato ylo incapacidad de ejercer la debida hab đidad y cuidado por parte de la Compafía, bajo ninguna circunstancia, superará una suma acumulada total equivalente a 10 (diez) veces el monto del cargo o de la comisión por pagar con respecto a los servicios especficos solicitados conforme al contrato particular con la Compañía que originase dichos reclamos: siempre que, sin embargo. la Companíis no sea responsable con respecto a cualquier reclamo de pérdida indirecta o emergente, incluida la pérdida de ganancias ylo la pérdida de futuros negocios ylo la pérdida de producción ylo la cancelación de contratos celebrados por el Principal. En el caso en que el cargo o la comisión por pagar se relacionen con una serie de servicios y surgiese un reclamo con respecto a uno de estos servicios, el cargo o la comisión se distribuirán a los fínes de este párrafo por referencia al tiempo esticlamo con respecto a uno de estos servicios,

12.3 El limite de responsabilidad de la Compañia conforme a los términos de la Condición 12.2 se podrá aumentar a pedido recibido por la Comparlia, por anticipado a la prestación del servicio, en la cifra que se acordarà con el pago de cargos adicionales equivalentes a una fracción apropiada del aumento de dicha compensación o como se convenga.

13. El Principal garantizará, eximirá y resarcirá a la Comparlía y sus ofertas, empleados, agentes o subcontratistas contra todos los reclamos realizados por cualquier parte por pérdida, daffo o gasto de cualquier naturaleza y de cualquier forma que surgiere, en relación a la prestación, la supuesta prestación o la no prestación de cualquier servicio en la medida en que el total de dichos reclamos relacionados con cualquier servicio superen el limite mencionado en la Condición 12.

14. Cada funcionario, empleado, agente o subcontratista de la Compañia tendra el beneficio de la limitación de la compensación y la in14. Cada uncización incluida en esta Condición general y, hasta aqui según la relación con dichas limitaciones, cualquier contrato celebrado por la Compaflia se celebra no sólo en su propio nombre sino también como agente y fideicomisario de cada persona antes mencionada.

15. En el caso de que surgiese cualquier problema o gasto no previsto en el transcurso de la ejecución de cualquiera de los servicios contratados, la Compañia tendrá derecho a cobrar cargos adicionales para cubri el tiempo y el costo adicional incurrido necesariamente para complatar el servicio.

16.

16.1 El Principal pagaré puntualmente antes de los 30 dias de la fecha de la factura relevante o dentro del periodo que se haya acordado por escrito con la Compantia, todos los cargos correspondientes aportados por la Comparlia, en ausencia de los cuales, el interés se exigirá a la tasa del $7 \%$ anual a partir de la fecha de la factura hasta el pago.

16.2 E Principal no tendrá derecho a retener ni posponer el pago de ninguna suma adeudada a la Compafía debido a cualquier disputa, contrademanda o compensación de deudas que pueda alegar contra la Compafía.

16.3 En el caso de cualquier suspensión de acuerdo de pago con acreedores, bancarrota, insolvencia, suspensión de pagos o cese de las actividades comerciales por parte del Principal, la Compan̂ia tendrà derecho a suspender toda la ejecución adicional de sus servicios de inmediato y sin responsabilidades.

17. En el caso de que la Compañía se vea impedida por cualquier causa que escape al control de la Companila para prestar o completar cualquier servicio para el cual se ha entregado un pedido o se ha celebrado un acuerdo, el Principal pagara a la Compañia.

17.1 el monto de las gastos por cancelación efectuados o incurridos efectivamente;

17.2 una proporción del cargo o de la comisión acordados, equivalente a la proporción (si hubiese) del servicio prestado en forma efectiva; y la Compañla será eximida de toda responsabilidad por la prestación parcial o no prestación del servicio requerido.

18. La Compan̂ia será eximida de toda responsabilidad con el Principal por todos los reclamos de pérdida, daffo o gastos, salvo que se inicie una demanda judicial por parte de la Compañia en el plazo de 6 meses después de la fecha de prestación del servicio que onigina el reclamo o en el caso de cualquier supuesta no prestación en el plazo de 6 meses a partir de la fecha cuando se deberia haber completado dicho servicio.

19. La Compantia no es una aseguradora ni un garante y niega toda responsabilidad en dicha calidad. El Principal que procure una garantia contra perdida o dahto debe obtener un seguro adecuado.

20. Ninguna modificación, enmienda o renuncia de ninguna de estas Condiciones generales tendrá efecto, salvo que estén por escrito y sean firmadas por un funcionario de la Compañia. 


\section{Anexo 3: Ficha Registral de Compra de Derechos y Acciones}

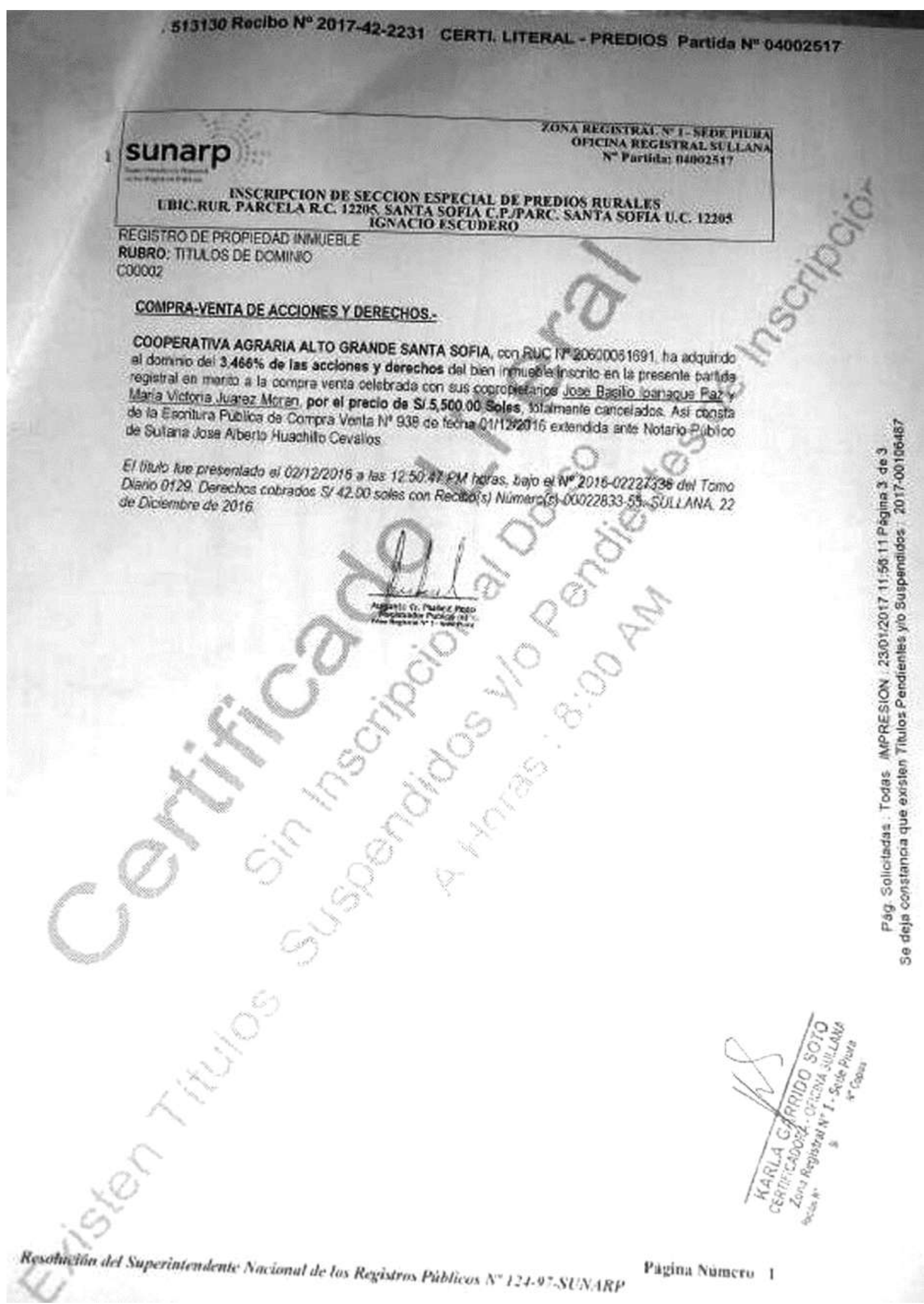


ING. MANUEL RICARDO TORRES PECHE

\title{
MEMORIA DESCRIPTIVA
}

OBRA:

\author{
CONSTRUCCIÓN DE INFRAESTRUCTURA DE UNA TINA \\ FIJA
}

$\begin{array}{lll}\text { UBICACIÓN } & \text { REGION } & \text { : PIURA } \\ & \text { DEPARTAMENTO } & \text { P PIURA } \\ & \text { PROVINCIA } & \text { : SULLANA } \\ & \text { DISTRITO } & \text { : IGNACIO ESCUDERO } \\ & \text { LUGAR } & \text { : SANTA SOFIA }\end{array}$

\subsection{ANTECEDENTES}

La Cooperativa Agraria Alto Grande se encuentra ubicada en La Villa Santa Sofía anexo que pertenece al distrito de Ignacio Escudero

El distrito peruano de Ignacio Escudero es uno de los 8 distritos de la Provincia de Suliana ubicada en el Departamento de Piura. bajo la administración del Gobierno Regional de Piura en la costa norte del Perú. Limita por el norte y este con su similar de Marcavelica: por el sur con el río Chira y; por el oeste con el distrito de Tamarindo de la Provincia de Paita.

El distrito de Ignacio Escudero se encuentra ubicado a la margen derecha del rio Chira y a unos 35 msnm. Su ubicación geográfica. latitud sur $04^{\circ} 50^{\prime} 35^{\prime \prime}$ y longitud oeste $80^{\circ} 52^{\prime} 12^{\prime \prime}$. Dista $25 \mathrm{~km}$ de la ciudad de Sullana, vía Panamericana

La Cooperativa Agraria Alto Grande Santa Sofia - COOPAG, se constituyó con Partida Registral No: 11071682 en Registros Públicos de fecha 09 de enero del 2015. Actualmente contamos con 59 socios activos y con 55.65 ha de banano orgánico en producción. dejando abierta la posibilidad de anexar a más productores por libre adhesion. Los productores activos que participan del PNT 50 socios

Actualmente mantiene relaciones comerciales con la Cooperativa Agraria APBOSMAM como aliado estratégico para la comercialización de nuestro producto aprovechando sus ventajas comerciales haciendo uso de la certificación Orgánica, comercio Justo (Fair Trade). Licencia Global Gap y certificación USDA.

A efecto de mejorar la productividad de su producción de banano organico durante los procesos post cosecha la cooperativa requiere la construccion de un centro de empaque que cuente con una tina fija para el procesamiento de banano orgánico obra que deberá contar con: Empacadora con una tina fija. Instalaciones sanitarias, construcción de comedor

Para ello la COOPAG dispone de un predio: Ubicado en el Distrito Ignacio Escudero. Provincia de Sullana, Departamento de Piura, con un área disponible de $0.0800 \mathrm{Ha}\left(800 \mathrm{~m}^{2}\right)$, como consta en la Partida Registral Nº4002517.

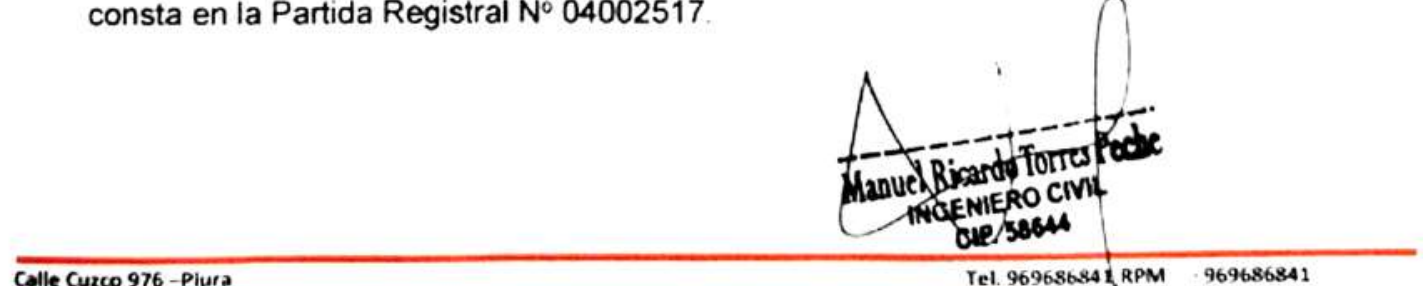




\section{ING. MANUEL RICARDO TORRES PECHE}

\subsection{OBJETIVOS}

La Cooperativa Agraria Alto Grande - COOPAG, tiene programado dentro de su plan de negocios los siguientes objetivos

- Mejorar la Infraestructura Productiva

- Garantizar el adecuado manejo de la fruta para su embalaje

- Lograr estándares de calidad.

\subsection{METAS DEL PROYECTO:}

Las metas son las siguientes:

- Construcción de $130.56 \mathrm{~m} 2$ de cobertura de calamina con tijerales de tubo de $2^{\prime \prime}$ y 11/2" y viguetas de caña Guayaquil.

- Construcción de parantes de 3" para soporte de tijerales y cobertura

- Construcción de Tina de lavado de $5.86 \mathrm{~m} \times 2.75 \mathrm{~m}$., de concreto armado revestidos con cerámico.

- Colocación de material de Over de e = 4" en $97.50 \mathrm{~m} 2$

- Instalaciones Sanitarias para tina de lavado.

\subsection{METAS FISICAS DEL PROYECTO}

\begin{tabular}{|c|c|c|}
\hline \multicolumn{3}{|l|}{ ARQUITECTURA } \\
\hline $\begin{array}{l}\text { Descripción } \\
\text { NLBANILERIA }\end{array}$ & Unidad & Metrado \\
\hline MURO DE SOGA LADRRLLO KING KONG CARAVISTA 1 & $M 2$ & 46.43 \\
\hline \multicolumn{3}{|l|}{ REVOQUES Y EMLUCIDOS } \\
\hline TARRAJEO PFIMARIO RAYADO CMEZZCLA I:5E $=2 \mathrm{CM}$ & 102 & 4564 \\
\hline TARRAJEO DE MUROS INTERIORES C.A $1.5 \mathrm{E}=2 \mathrm{~cm}$ & ME & 5469 \\
\hline TARRRAJEO CON IMPERMEABILIZANTE 1 CAPAE $=2$ CM & M2 & 14,63 \\
\hline ENLUCIDO DE CELLORASO CON MORTERO $1.4 \mathrm{E}=1.5 \mathrm{cM}$ & MR & 25.30 \\
\hline \multicolumn{3}{|l|}{ PISOS Y PAVIEENTOS } \\
\hline CONTRAPISO MORTERO $1: 3 \mathrm{E}=5 \mathrm{CM}$ & MQ & 15.92 \\
\hline ENCHAPE DE CERAMICO DE $20 \times 30$ & M2 & 2503 \\
\hline ENCHAPE DE PORCELANATO EN MESA DE CONCRETO & M2 & 1197 \\
\hline \multicolumn{3}{|l|}{ ZOCALO Y CONTRAZOCALO } \\
\hline ZOCALODE CERAMICA DE $20 \times 30 \mathrm{~cm}$ & 102 & 45.64 \\
\hline \multicolumn{3}{|l|}{ CARPINTERIA DE MADERA } \\
\hline PUERTA CONTRAPLACADA E $=35$ MU CITIPLAY LUPUNA 4 MM & M2 & 5.20 \\
\hline \multicolumn{3}{|l|}{ CARPINTERIA METALUCA } \\
\hline PUERTA METALICA SEGUN DISENO & UND & 2.00 \\
\hline VENTANA DE FIERRI CPERFIL SEGUN DISENO & UND & 2.00 \\
\hline \multicolumn{3}{|l|}{ APARATOS Y ACCESORIOS SANITARIOS } \\
\hline INODORO DE LOSA BLANCA BAJO GJACCES. & PZA & 5.00 \\
\hline LAVATOFIO DE LOSA Q ANCA INCLYYYYE GRFFERIAA & UNO & 400 \\
\hline SUHANISTROE INSTAL. TANOUE ELEVADO PVC DE $1,100 \mathrm{LT}$ C/ACCES & UND & 100 \\
\hline
\end{tabular}

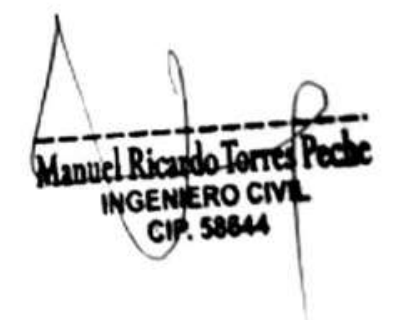




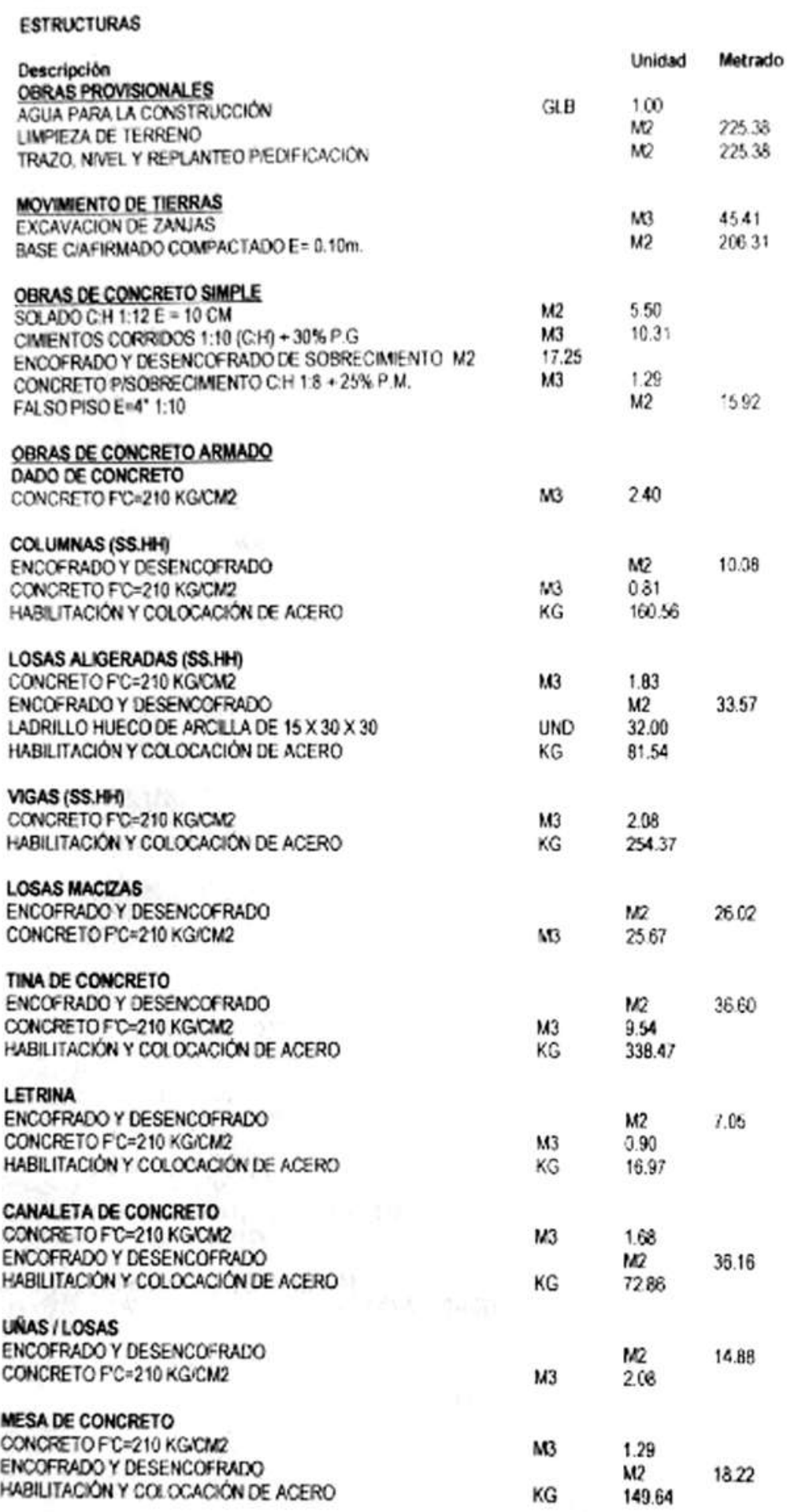

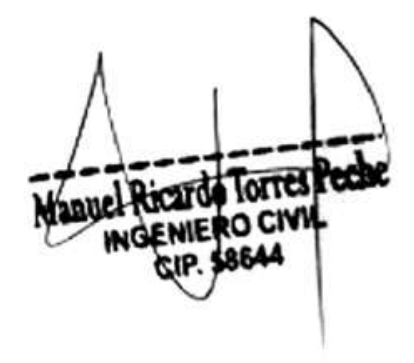

ESTRUCTURAS WEIALCAS Y COBERTURAS 


\section{ING. MANUEL RICARDO TORRES PECHE}

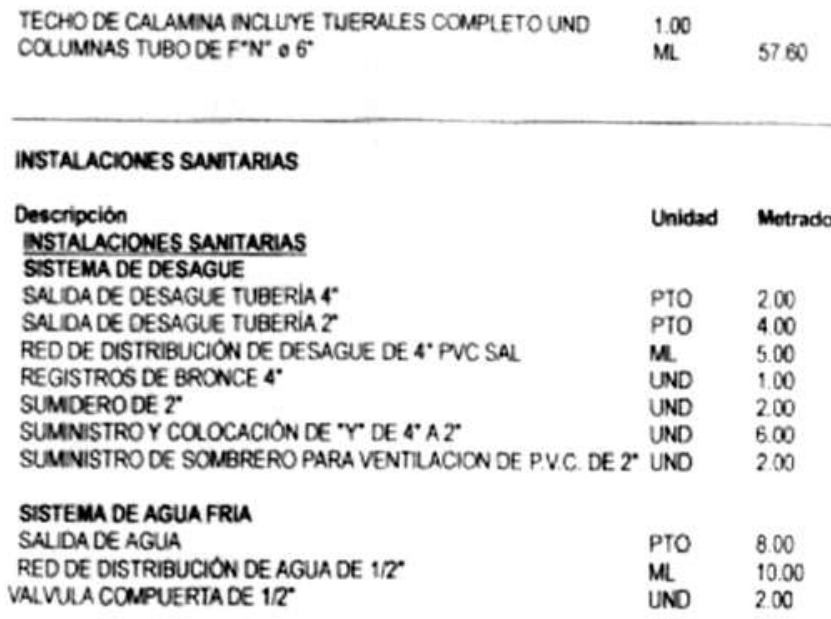

\section{CONSTRUCCION DE COMEDOR \\ Descripción}

Unidad Metrado

CONSTRUCCION DE COMEDOR

\section{Descripción}

\section{TRABANOS PRELIMNURES}

TRAZO, NIVEL Y REPLANTEO PEDIFICACION

UIMPIEZA DE TERREND

\section{MOVIMIENTO DE TIERRAS}

EXCAVACION DE ZANJAS

BASE CIAFIRMADO COMPACTADOE $=0.10 \mathrm{~m}$

\section{QBRAS DE CONCRETO ARUUADO}

DADO DE CONCRETO

CONCRETO FC $=210 \mathrm{KG} / \mathrm{CM}$

\section{LOSAS MACEAS}

CONCRETO FC $=175 \mathrm{KGCM} 2$

ENCOFRADO Y DESENCOFRADO DE LOSA MACIZA

UNASILOSAS

CONCRETO FC $=175 \mathrm{KG} / \mathrm{CN} 2$

ENCOFRADO Y DESENCOFRADO NORMA

BANCAS Y MESA DE CONCRETO

CONCRETO FC $=175 \mathrm{KGICM} 2$

ENCOFRADO Y DESENCOFRADO DE LOSA MACZZA

HABILITACION Y COLOCACION DE ACERO

\section{ESTRUCTURAS METALICAS Y COBERTURAS}

TECHO DE CALAMNA INCLUYE TUERALES COMPLETOEN COMEDOR

$\begin{array}{ll}\text { Unidsd } & \text { Metrado } \\ \text { M2 } & 13.96 \\ \text { M2 } & 13.96 \\ \text { M3 } & 1.40 \\ \text { M2 } & 13.96 \\ & \\ \text { M3 } & 0.39 \\ \text { M3 } & 1.40 \\ \text { M2 } & 1396 \\ & \\ \text { M3 } & 1.28 \\ \text { M2 } & 5.29 \\ & \\ \text { M3 } & 0.78 \\ \text { M2 } & 9.98 \\ \text { KG } & 29.95 \\ & \\ \text { UND } & 1.00 \\ & \end{array}$


5.0 VALOR REFERENCIAL:

El Valor Referencial para la Construcción de la Infraestructura de una Tina Fija, asciende a S/ 105,000.00; CIENTO CINCO MIL Y 00/100 NUEVOS SOLES, con precios vigentes al Mes de Abril del año 2015 , incluye $10 \%$ de Gastos Generales, $10 \%$ de Utilidad y $18 \%$ de I.G.V

5.0 MODALIDAD DE EJECUCIÓN

Se desarrollará bajo el Sistema de Contratación. A SUMA ALZADA

6.0 FUENTE DE FINANCIAMIENTO

Recursos Propios

7.0 PLAZO DE EJECUCION

Sesenta (60) Dias calendario. 


\title{
Anexo 5: Cotización del Camión
}

\author{
INTERAMERICANA NORTE S.A.C. \\ Prridipat \\ ane rasoss

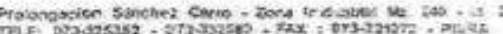

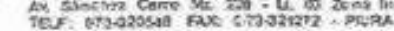

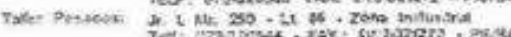

Piura, miércoles, 25 de enero de 2017

CLIENTE

COOPERATIVA AGRARIA ALTO GRANDE SANTA SOFIA

RUC

20600061691

Presente-

Como distribuidores exclusivos de camiones MITSUBISHI para todo el pais, nos es grato difiginos a usted para cotizarles y detallar las caracteristicas técnicas del siguiente vehiculo, importado directamente de fabrica, con especificaciones para ol mercado peruano.

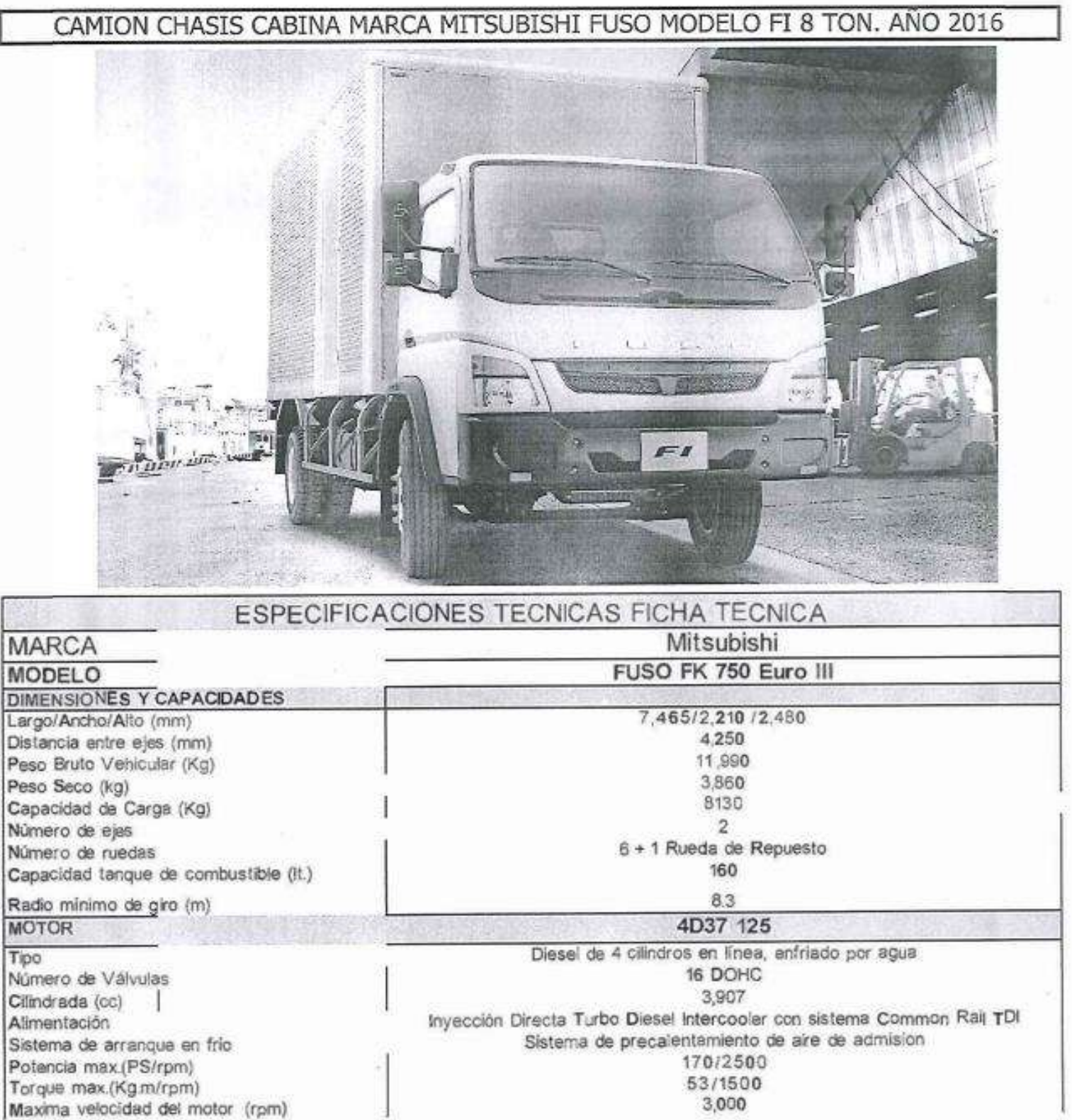


INTERAMERICANA NORTE S.A.C.

Su satisfacelon, neestra mijor manco.
Pereigal:

Dow. parods:

Filde: Peavess:

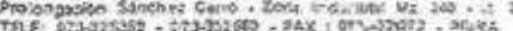
TaS 67म

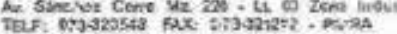

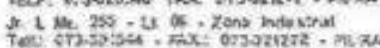

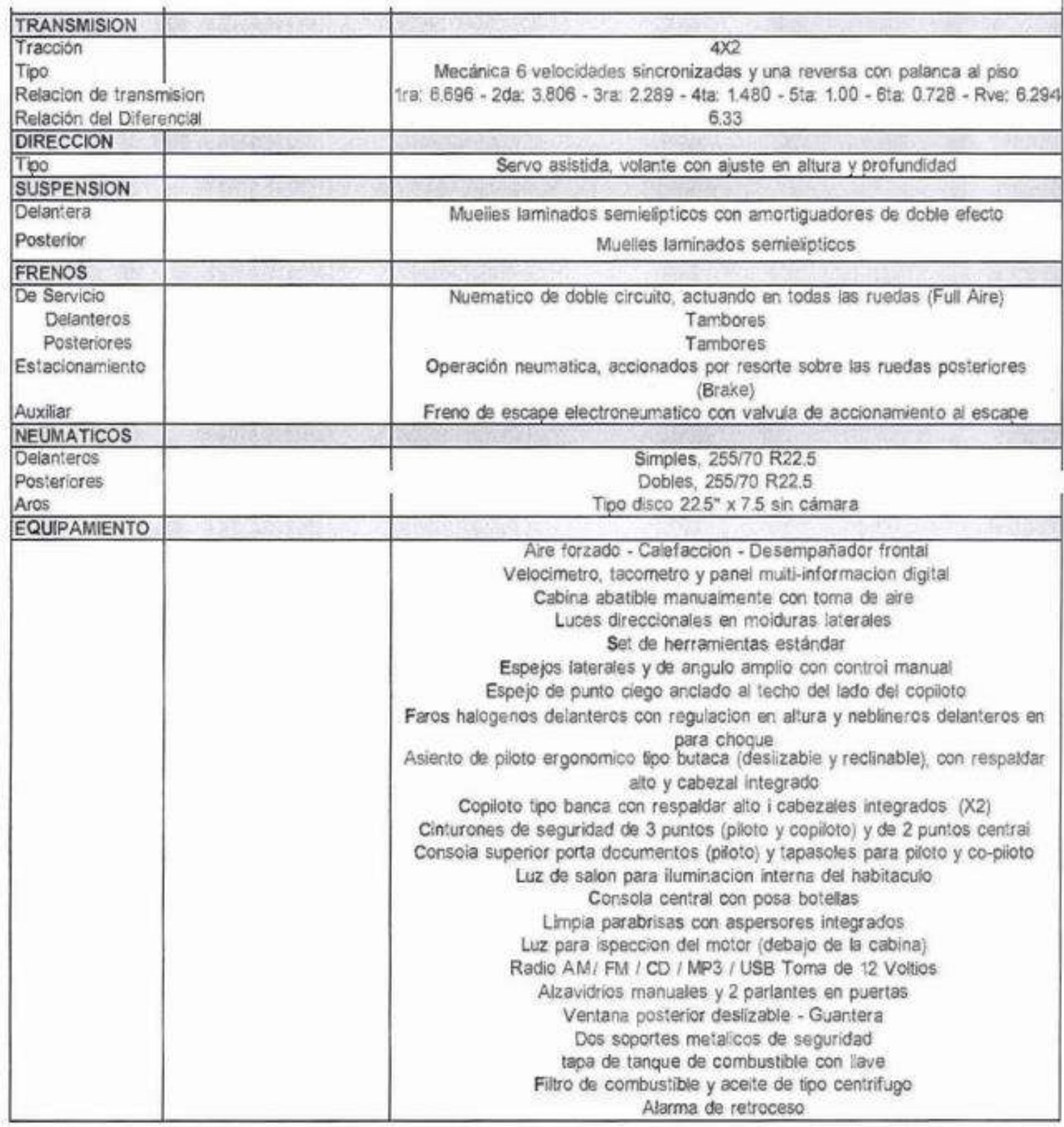

CAMION CHASIS CABINA MARCA FUSO MODELO FI 8 TON. AÑO 2015

\begin{tabular}{|l|r|r|r|r|r|}
\cline { 3 - 6 } \multicolumn{1}{c|}{} & & & \multicolumn{1}{c|}{ DOLARES } & & \multicolumn{1}{c|}{ SOLES } \\
\hline PRECIO CHASIS CABINA & & US\$. & $37,288.14$ & S/. & $124,169.49$ \\
\hline IGV $18 \%$ & & US\$. & $6,711.86$ & S/. & $22,350.51$ \\
\hline PRECIO TOTAL & & US\$. & $44,000.00$ & S/. & $146,520.00$ \\
\hline
\end{tabular}

Tipo de cambro S. 3.33 Caja Interamericana Norte S.A.C 


\section{INTERAMERICANA NORTE S.A.C.}

Si satisfacción. nuestra mojor marcs.
Pricaspat:

On pessoss.

Tolan: Petutos:

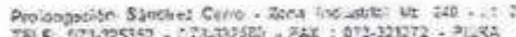

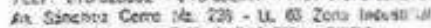

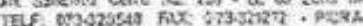

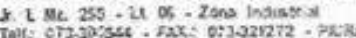

Garantía :

Año de Fabricación:

Disponibilidad

Validez de la oferta:
- 03 Años ó 100000 km

$-2016$

- Según disponibiridad de Stock

-20 dias utiles

Sin otro sobre el particular y agradeciendo la atencion brindada a la presente se despide de usted

Atentamente,

INTERAMERICANA NORTE S.A.C

RUC: 20483998270

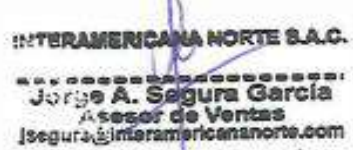

JORGE ANTONIO SEGURA GARCIA ASESOR DE VENTAS PIURA

RPM. \#959952685 CEL. 959952695

EMAl isegura@interamericananorte.com 


\section{Anexo 6: Cotización de la Carrocería Tipo Furgón}

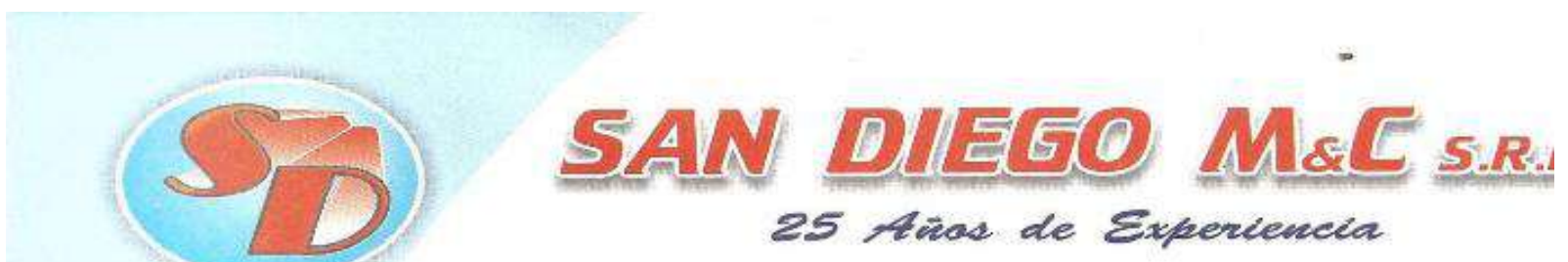

RUC: 20525791557

PIURA, 17 de noviembre de 2016

"Año de la Consolidación del Mar de Grau"

SRES: COOPERATIVA AGRARIA ALTO GRANDE SANTA SOFIA

Nos es grato alcanzarle nuestra cotización, por la fabricación y montaje de carrocería tipo furgón para carga seca para chasis cabinado de 8 toneladas.

\section{Caracteristicas técnicas}

Unidad: Furgón Comercial

Largo : $7.00 \mathrm{mts}$.

Alto : $2.20 \mathrm{mts}$

Ancho : $2.40 \mathrm{mts}$

Nota: dichas medidas pueden ser modificadas de acuerdo al largo del chasis. Materiales a utilizar

- Viga C de $5^{n}$ de altura $\times 3^{n}$ de ala para sobre chasis (muertos) fabricados con plancha de $3 / 16$.

- Vigas C de 4" de altura x 2" de ala (para travesaños) en plancha de $3 / 16^{\prime \prime}$.

- Plataforma con plancha lisa de $1 / 8^{\prime \prime}$

- Dicho furgón será revestido en su totalidad con plancha de 1/20".

- En la parte posterior (01) puerta de dos hojas batientes.

- 01 puerta corrediza lateral.

- Madera tipo tornillo para recubrimiento en las paredes interiores.

\section{Accesorios}

- barandas laterales antiempotre reglamentarias

- Luces de ruta perimetrales (24).

- Luces de salón en el interior del cajón (02)

- Porta extintor.

- Parachoque posterior.

- Corta viento

Terminación

- Pintado con base zincromato y terminado con esmalte acrílico del color que el cliente desee.

Garantía: 02 año en condiciones normales de trabajo.

Se entregara certificado de montaje y garantía para tramitación de tarjeta de propiedad y placas.

PRECIO A TODO COSTO EN SOLES:

INCLUIDO IGV.
Precio
Fecha de entreqa
: Contado
: 20 dias útiles.

$S / 24,800.00$

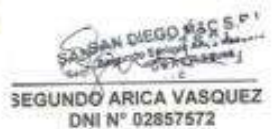




\section{Anexo 7: Betas Publicados por Aswath Damodaran a Febrero 2017}

\begin{tabular}{|c|c|c|c|c|c|c|c|}
\hline Industry Name & $\begin{array}{c}\text { Number of } \\
\text { firms }\end{array}$ & Beta & D/E Ratio & Tax rate & $\begin{array}{c}\text { Unlevered } \\
\text { beta }\end{array}$ & $\begin{array}{c}\text { Cash/Firm } \\
\text { value }\end{array}$ & \begin{tabular}{|c|} 
Unlevered \\
beta corrected \\
for cash
\end{tabular} \\
\hline Advertising & 41 & 1.36 & $62.98 \%$ & $5.10 \%$ & 0.85 & $6.27 \%$ & 0.91 \\
\hline Aerospace/Defense & 96 & 1.07 & $23.53 \%$ & $10.86 \%$ & 0.89 & $5.21 \%$ & 0.94 \\
\hline Air Transport & 18 & 1.12 & $70.12 \%$ & $22.99 \%$ & 0.73 & $4.23 \%$ & 0.76 \\
\hline Apparel & 58 & 0.88 & $34.21 \%$ & $10.95 \%$ & 0.67 & $4.30 \%$ & 0.71 \\
\hline Auto \& Truck & 15 & 0.85 & $150.42 \%$ & $8.14 \%$ & 0.35 & $6.46 \%$ & 0.38 \\
\hline Auto Parts & 63 & 1.12 & $35.22 \%$ & $10.40 \%$ & 0.85 & $8.90 \%$ & 0.94 \\
\hline Bank (Money Center) & 10 & 0.86 & $188.03 \%$ & $27.90 \%$ & 0.37 & $9.89 \%$ & 0.41 \\
\hline Banks (Regional) & 645 & 0.47 & $60.51 \%$ & $25.43 \%$ & 0.33 & $10.76 \%$ & 0.36 \\
\hline Beverage (Alcoholic) & 25 & 0.79 & $29.02 \%$ & $10.86 \%$ & 0.63 & $11.30 \%$ & 0.71 \\
\hline Beverage (Soft) & 36 & 0.91 & $24.51 \%$ & $5.87 \%$ & 0.74 & $4.84 \%$ & 0.78 \\
\hline Broadcasting & 30 & 1.22 & $95.92 \%$ & $18.54 \%$ & 0.68 & $2.17 \%$ & 0.7 \\
\hline Brokerage \& Investment Bank & 45 & 1.08 & $232.21 \%$ & $13.59 \%$ & 0.36 & $14.97 \%$ & 0.42 \\
\hline Building Materials & 41 & 1.01 & $26.98 \%$ & $23.39 \%$ & 0.83 & $4.05 \%$ & 0.87 \\
\hline Business \& Consumer Services & 165 & 1.07 & $35.10 \%$ & $12.61 \%$ & 0.82 & $3.52 \%$ & 0.85 \\
\hline Cable TV & 14 & 1.12 & $49.24 \%$ & $20.28 \%$ & 0.8 & $2.32 \%$ & 0.82 \\
\hline Chemical (Basic) & 45 & 1 & $58.62 \%$ & $7.71 \%$ & 0.65 & $4.00 \%$ & 0.68 \\
\hline Chemical (Diversified) & 8 & 1.52 & $35.52 \%$ & $6.59 \%$ & 1.14 & $6.50 \%$ & 1.22 \\
\hline Chemical (Specialty) & 100 & 1.2 & $29.98 \%$ & $9.58 \%$ & 0.94 & $3.97 \%$ & 0.98 \\
\hline Coal \& Related Energy & 38 & 1.36 & $138.55 \%$ & $0.48 \%$ & 0.57 & $5.34 \%$ & 0.61 \\
\hline Computer Services & 117 & 0.99 & $28.33 \%$ & $11.18 \%$ & 0.79 & $5.24 \%$ & 0.83 \\
\hline Computers/Peripherals & 55 & 1.06 & $19.60 \%$ & $5.68 \%$ & 0.89 & $5.61 \%$ & 0.94 \\
\hline Construction Supplies & 51 & 1.31 & $42.57 \%$ & $18.44 \%$ & 0.98 & $4.68 \%$ & 1.02 \\
\hline Diversified & 24 & 0.76 & $35.98 \%$ & $11.55 \%$ & 0.58 & $7.84 \%$ & 0.63 \\
\hline Drugs (Biotechnology) & 426 & 1.4 & $19.45 \%$ & $1.44 \%$ & 1.18 & $5.54 \%$ & 1.25 \\
\hline Drugs (Pharmaceutical) & 164 & 1.02 & $14.58 \%$ & $2.54 \%$ & 0.89 & $3.98 \%$ & 0.93 \\
\hline Education & 36 & 1.23 & $33.38 \%$ & $9.29 \%$ & 0.94 & $10.16 \%$ & 1.05 \\
\hline Electrical Equipment & 119 & 1.14 & $19.15 \%$ & $5.87 \%$ & 0.97 & $6.42 \%$ & 1.04 \\
\hline Electronics (Consumer \& Offic & 24 & 1.08 & $19.39 \%$ & $3.81 \%$ & 0.91 & $5.99 \%$ & 0.97 \\
\hline Electronics (General) & 164 & 0.86 & $17.87 \%$ & $8.85 \%$ & 0.74 & $10.02 \%$ & 0.83 \\
\hline Engineering/Construction & 48 & 1.18 & $32.45 \%$ & $15.15 \%$ & 0.93 & $8.26 \%$ & 1.01 \\
\hline Entertainment & 79 & 1.2 & $30.83 \%$ & $5.50 \%$ & 0.93 & $3.59 \%$ & 0.97 \\
\hline Environmental \& Waste Servic & 89 & 0.85 & $38.98 \%$ & $5.07 \%$ & 0.62 & $0.95 \%$ & 0.63 \\
\hline Farming/Agriculture & 37 & 0.92 & $60.04 \%$ & $7.89 \%$ & 0.59 & $3.88 \%$ & 0.62 \\
\hline Financial Svcs. (Non-bank \& In & 258 & 0.65 & $1124.41 \%$ & $20.80 \%$ & 0.07 & $2.29 \%$ & 0.07 \\
\hline Food Processing & 87 & 0.75 & $26.84 \%$ & $14.66 \%$ & 0.61 & $2.57 \%$ & 0.63 \\
\hline Food Wholesalers & 16 & 1.2 & $36.34 \%$ & $11.77 \%$ & 0.91 & $1.76 \%$ & 0.93 \\
\hline
\end{tabular}

Fuente: “Aswath Damodaran; http://pages.stern.nyu.edu/ adamodar/;2017”.

Elaboración Propia 
Anexo 8: Riesgo País Perú

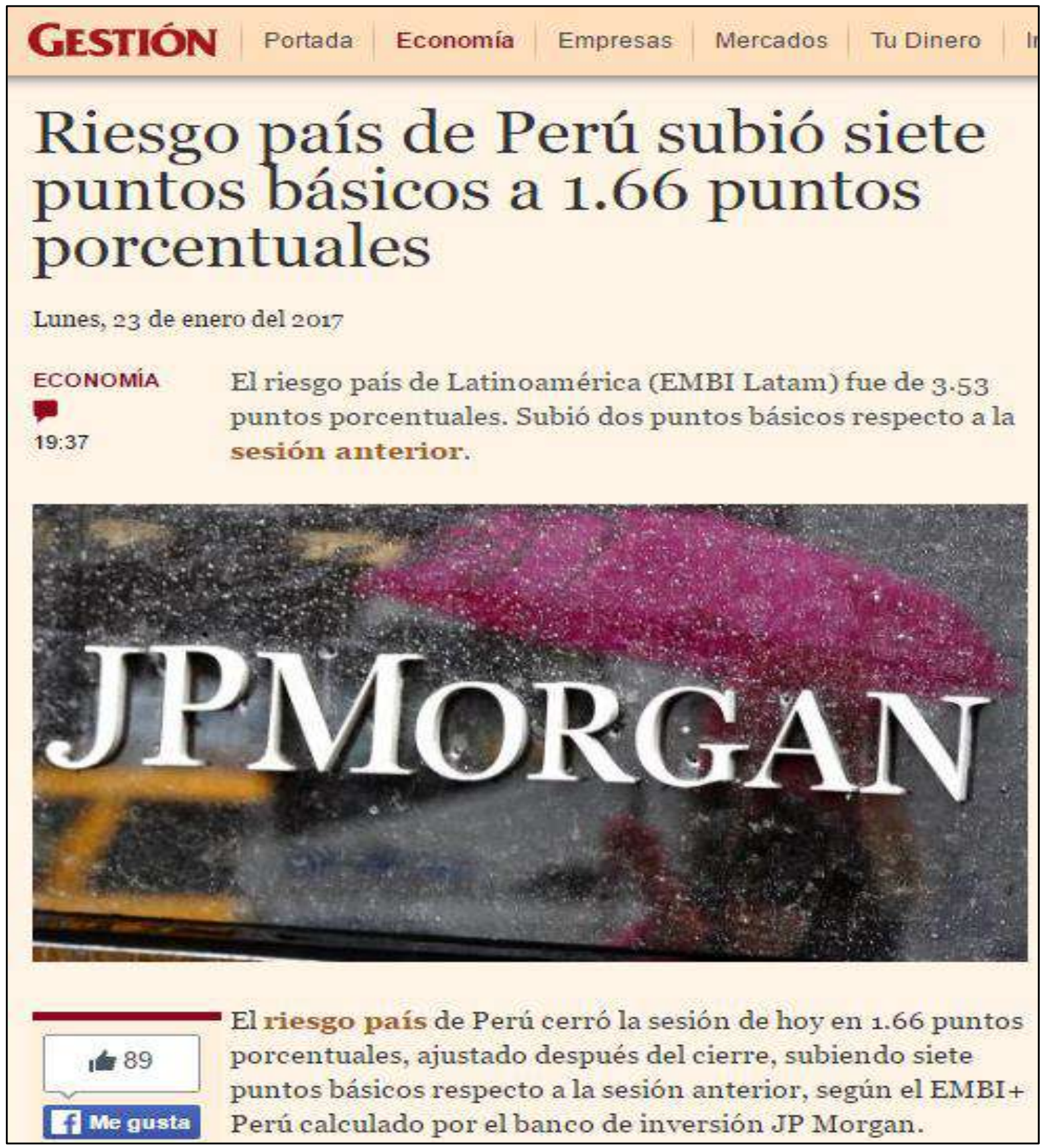

Fuente: JP Morgan - Diario Gestión 


\section{BIBLIOGRAFIA}

Agencia francesa para el desarrollo y fomento de la agricultura ecológica (2015). Mercado global del banano orgánico. Recuperado de file:///C:/Users/Use/Downloads/MERCADO_GLOBAL_DEL_BANANO_ -_24_JUL_2014.pdf

Agrodataperu (2016). Exportaciones peruanas de banano orgánico. Recuperado de www.agrodataperu.com

Agroideas (2017). Programa de compensaciones para la competitividad. Recuperado de www.agroideas.gob.pe

American Marketing Asociation (2012). Definición de Mercado. Recuperado de www.ama.org

Asbama (2015), Acompañamiento técnico de asbama para el mejoramiento de la productividad. Recuperado de www.asbama.com

Asociación de Comercio Orgánico (2016). Análisis del mercado orgánico. Recuperado de https://ota.com/resources/market-analysis

Chávez, J. (2012). Entorno externo de las empresas. México. Recuperado de http://entornoexterno.blogspot.pe/

Chiavenato, I. (2000). Administración de recursos humanos. España: McGrawHill 
Choquehuanca, W. (2008). Monografía: cooperativismo, economía social y políticas públicas en el Perú. Perú.

Chou, J. (2006). Nota técnica: formulación y evaluación de proyectos. Perú: Universidad San Ignacio de Loyola

Control Union (2017), Portal de la página. Recuperado de www.cuperu.com

David, F. (2013). Conceptos de administración estratégica. México: Pearson Educación.

Damodaran, A. (1995). Investment Valuation. Estados Unidos: John Wiley \& Sons.

Downes, L. \& Mui, C. (2014). Estrategias digitales para dominar el mercado. España: Editorial Gránica.

Esteban, A. (2008). Principios de marketing. Madrid: ESIC Editorial.

Everett A. (1991). Administración de la producción y las operaciones. México: Universidad Nacional Autónoma de México.

FAO (2012). Agricultura orgánica, ambiente y seguridad alimentaria. Recuperado de http://www.fao.org/docrep/005/y4137s/y4137s03.htm

FAO (2012). Crecimiento de la población a nivel mundial. Recuperado de www.fao.org/docrep/031/w2561f.htm 
Ferrell, O., Hirt, G., Adriaenséns, M., Flores, M. y Ramos, L. (2004). Introducción a los negocios en un mundo cambiante. México: McGrawHill

Fintrac (2016), La traducción de políticas en resultados para los agronegocios. Recuperado de www.fintrac.com

Franklin, E. (2004). Organización de empresas. México: McGraw-Hill

Fruitrop (2012). El mercado del banano orgánico. Recuperado de http://www.fruitrop.com

Garralda, J. (2014). Nota técnica: la cadena de valor. Madrid: Instituto de Empresa.

Hax, A. \& Majluf N. (2004). Estrategias para el liderazgo competitivo. España: Editorial Gránica.

Hitt, M., Black, S. y Porter, L. (2011). Administración. México: Pearson Prentice Hall.

Hopeman, R. (1986). Administración de producción y operaciones. México: Editorial CECSA

Kakfa, F. (2004). Evaluación estratégica de proyectos de inversión. Perú: Universidad del Pacífico.

Kerin, R., Berkowitz, E., Hartley, S. y Rudelius, W. (2013). Marketing. Ney York: McGraw-Hill 
Kotler, P. (1992). Dirección de marketing: análisis, planificación, gestión y control. México: McGraw-Hill.

Kotler, P. y Armstrong G. (2012). Fundamentos de marketing. México: McGraw-Hill.

Lamb, C., Hair J. y McDaniel C. (2011). Marketing. México: Cengage Learning Editores, $S A$

Larrea, H. (2013). Perfil de mercado y competitividad exportadora del banana orgánico. Recuperado de https://es.slideshare.net/hlarrea/mincetur-bananoorganico

Lira, P. (2013). Evaluación de proyectos de inversión. Perú: Universidad Peruana de Ciencias

Maroto, J. (2007). Estrategia: de la visión a la acción. Madrid: Esic Editorial.

McCarthy, J. y Perreault W. (2005). Basic marketing. Madrid: McGraw-Hill

Micklethwaite , K. (2017). Perspectivas de crecimiento de la economía peruana en el 2017. Recuperado de http://gestion.pe/economia/forbes-cuantocrecera-economia-peruana-2017-2186186

Ministerio de agricultura y riego (2015). Nota de prensa. Recuperado de http://www.minagri.gob.pe/portal/notas-de-prensa/notas-de-prensa2015/12218-minagri-exportacion-de-banano-organico-peruano-crecio-94en-ultimos-5-anos 
Ministerio de agricultura y riego (2016). Tendencias de la producción y el comercio/boletinminagri2016. Recuperado de www.minagri.gob.pe

Ministerio de agricultura y riego (2017). Nota de prensa. Recuperado de www.minagri.gob.pe

Ocex Los Angeles (2016). Oficina comercial del Perú en Los Ángeles. Recuperado de http://www.promperu.gob.pe/OCEX/SedeOCEXUSA.html?keepThis=true $\& T B \_$iframe $=$true $\&$ height $=550 \&$ width $=300$

Pelaez, J. (2016). Marketing aplicado para emprendedores. Perú: Universidad Nacional Mayor de San Marcos.

Perú Orgánico (2011), La ventada de los alimentos orgánicos. Recuperado de www.peruorganico.com.

Porter, M. (1996). Estrategia competitiva: técnicas para el análisis de los sectores industriales y de la competencia. México: Compañía Editorial Continental, S.A. de México.

Salinas, J. (1998). Análisis estadísticos para la toma de decisiones en administración y economía. Perú: Universidad del Pacífico.

Sapag, N. (2000). Preparación y evaluación de proyectos. Chile: McGraw-Hill

Siicex (2016). Requisitos para exportar banano orgánico a Estados Unidos. Rescatado de http://www.siicex.gob.pe 
Sistema nacional de información de recursos hídricos (2017). Módulo para el monitoreo del fenómeno el niño. Rescatado de http://snirh.ana.gob.pelfen/EFEN_Compara.aspx

Stanton, W., Etzel M y Walker B. (2007). Fundamentos de marketing. México: McGraw-Hill

Sunat (2017), Portal de la SUNAT. Recuperado de www.suunat.gob.pe

Thomson, A. \& Strickland, A.J. (2003). Administración estratégica. México: McGraw-Hill.

Trademap (2016). Importaciones mundiales de bananos y plátanos. Recuperado de http://www.trademap.org

Tresierra, A. (2016). Nota técnica: El flujo de caja para la evaluación de proyectos. Perú: Universidad de Piura. 